\title{
Improving meat colour and oxidative stability by antioxidant supplementation of light weight lamb diets
}
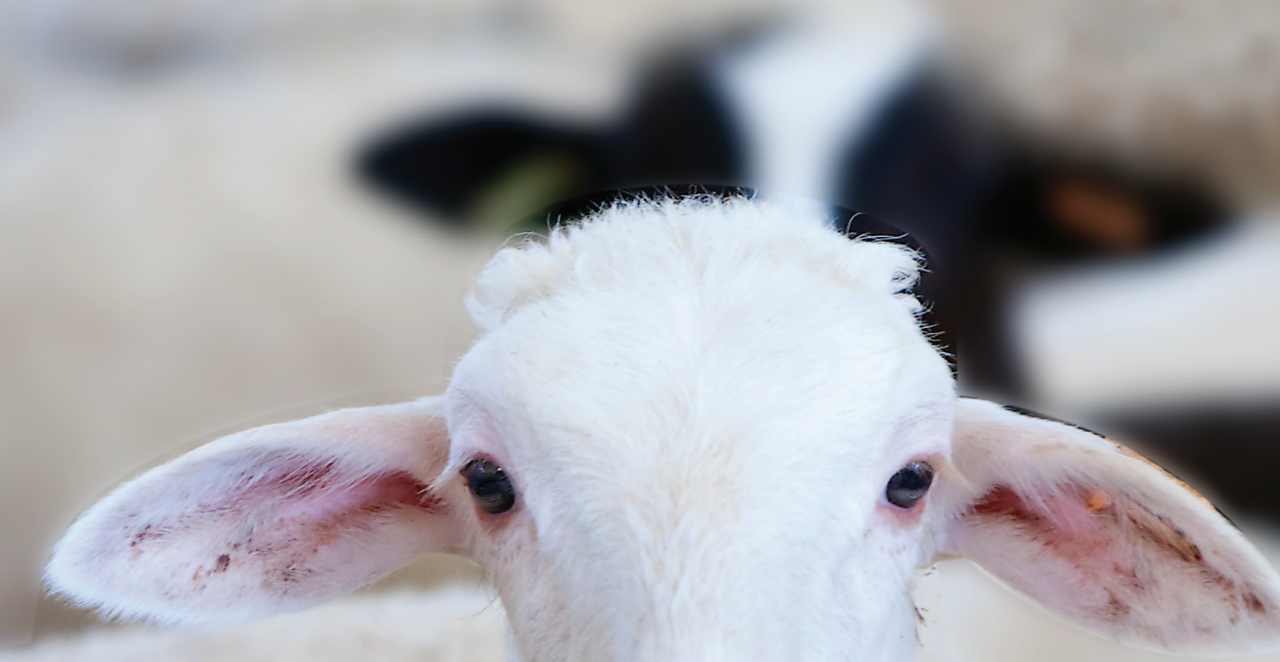

Leonel N. Leal 



\section{Propositions}

1. The difference in the biological activity between natural and synthetic vitamin $E$ cannot be represented by the use of a single ratio.

(this thesis)

2. Dietary supplementation strategies with plant extracts are far from becoming a "gold standard" at preventing oxidation and colour deterioration of lamb meat.

(this thesis)

3. In experiments, the absence of well-chosen "controls" produces meaningless results and incorrect conclusions unwittingly leading to poorly formulated subsequent hypotheses and illdesigned studies.

4. With the dawn of the information era, there is an urgent need for content curation.

5. The best approach to solve a problem is to start anew instead of using someone else's draft.

6. Like with many other aspects of life, in research, knowing where we come from and why we do what we do, unveils the direction that should be followed.

7. Writing a $\mathrm{PhD}$ thesis confronts oneself with their past naivety and brilliance.

Propositions belonging to the thesis, entitled Improving meat colour and oxidative stability by antioxidant supplementation of light weight lamb diets

Leonel N. Leal

Wageningen, 18 October 2019 



\section{Improving meat colour and oxidative stability by}

antioxidant supplementation of light weight lamb diets 


\section{Promotors}

Prof. Dr W.H. Hendriks

Professor Animal Nutrition

Wageningen University \& Research

Prof. Dr L.A. den Hartog

Special professor Animal Nutrition in a Circular Economy

Wageningen University \& Research

$\mathrm{R} \& \mathrm{D}$ director Nutreco

Nutreco, Amersfoort

\section{Co-promotor}

Dr J. Martín-Tereso

Ruminant Research Manager

Trouw Nutrition R\&D

Trouw Nutrition, Amersfoort

\section{Other members}

Prof. Dr G.P.J. Janssens, Ghent University, Belgium

Prof. Dr J.J.M. Vervoort, Wageningen University \& Research

Prof. Dr S. Barbut, University of Guelph, Canada

Prof. Dr S. De Smet, Ghent University, Belgium

This research was conducted under the auspices of the Graduate School WIAS (Wageningen Institute of Animal Sciences). 


\section{Improving meat colour and oxidative stability by antioxidant supplementation of light weight lamb diets}

\section{Leonel N. Leal}

Thesis

submitted in fulfilment of the requirements for the degree of doctor at Wageningen University

by the authority of the Rector Magnificus

Prof. Dr A.P.J. Mol, in the presence of the

Thesis Committee appointed by the Academic Board

to be defended in public

on Friday I8 October 2019

at I.30 p.m. in the Aula 
Leonel N. Leal

Improving meat colour and oxidative stability

by antioxidant supplementation of light weight lamb diets,

I90 pages.

$\mathrm{PhD}$ thesis, Wageningen University, Wageningen, the Netherlands (2019)

With references, with summary in English.

ISBN 978-94-6395-046-6

DOI https://doi.org/IO.I8I74/496702

Copyright (C) Leonel N. Leal 2019

ALL RIGHTS RESERVED. Any unauthorized reprint or use of this material is prohibited. No part of this thesis may be reproduced, stored or transmitted in any form or by any means, without written permission of the author or, when appropriate, of the publishers of the publications. 


\section{Table of Contents}

Chapter I General introduction 9

Chapter 2 Bioavailability of $\alpha$-tocopherol stereoisomers in lambs depends $\quad 27$ on dietary doses of all-rac- or RRR- $\alpha$-tocopheryl acetate

Chapter 3 Dietary vitamin E dosage and source affects meat quality parameters in light weight lambs

Chapter 4 Effect of dietary vitamin E on physicochemical and fatty acid stability 73 of fresh and thawed lamb

Chapter 5 Dietary supplementation of II different plant extracts on the 97 antioxidant capacity of blood and selected tissues in light weight lambs

Chapter 6 Supplementation of lamb diets with vitamin E and rosemary I2I extracts on meat quality parameters

Chapter 7 General discussion

Summary I77

Peer-Reviewed Scientific Publications I80

Contributions to Conferences, Symposia, and Other Scientific Output I8I

Curriculum Vitae 183

Training \& Supervision plan I84

Acknowledgements I85 


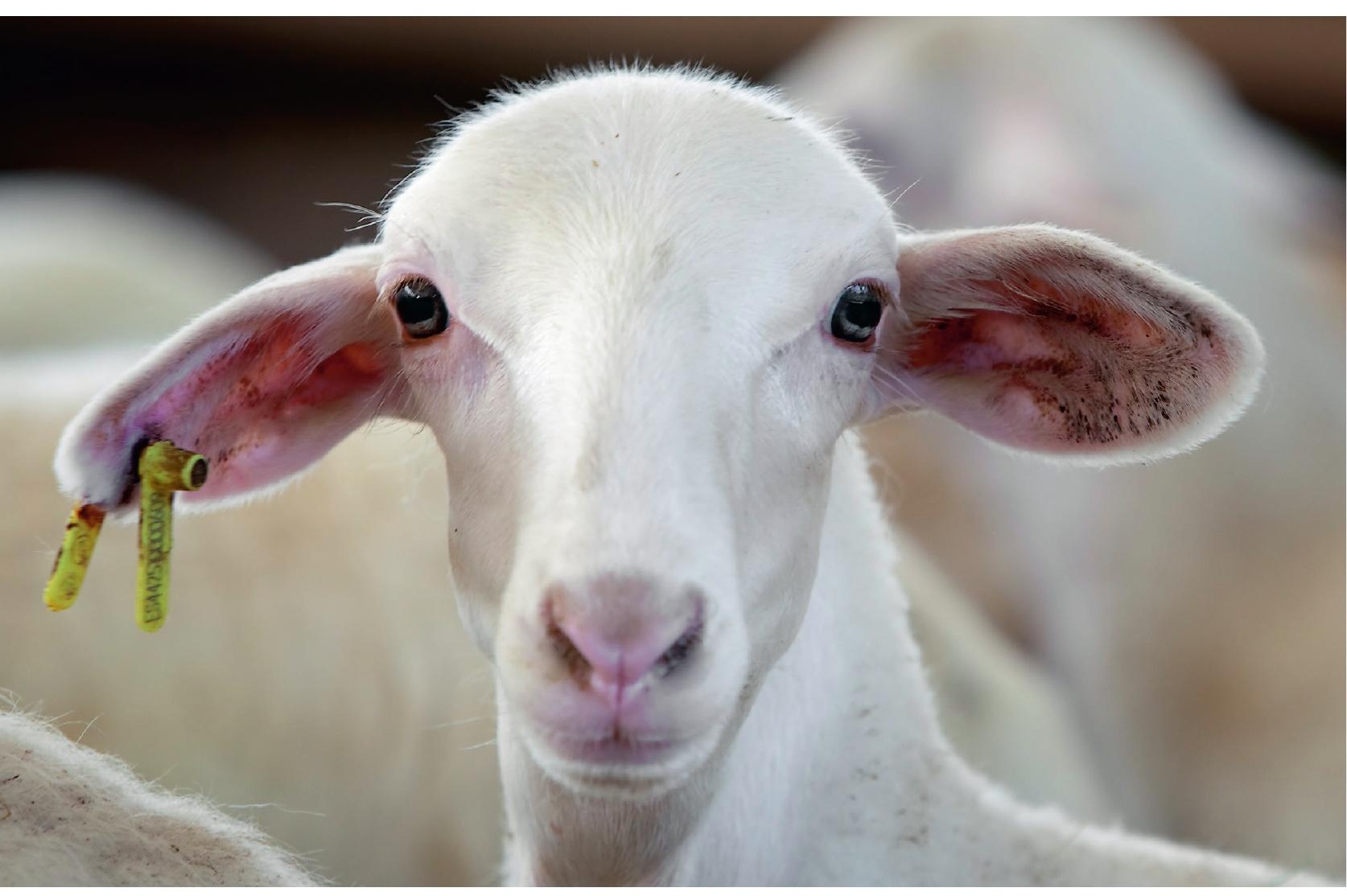


Chapter I

General Introduction 
Each year, one third of all global food products for human consumption are "lost" or "wasted" along the food supply chain (Food and Agriculture Organization, 20II). Apart from its economic impact, food loss and wastage represents a misuse of resources including land, water and energy. In Europe, food waste per capita at the consumer level is approximately $95-\mathrm{II} 5 \mathrm{~kg}_{\text {year }}{ }^{-1}$, which represents more than $35 \%$ of the total food wasted along the entire food chain (production, post-harvest handling, processing, distribution and consumption). For the 6I million tons of meat and meat products produced in Europe, approximately $25 \%$ is lost or wasted (Figure I.I). These losses occur mainly at the end of the food chain (processing, distribution and consumer), with losses occurring by the consumer representing half of the total meat and meat products wasted (Food and Agriculture Organization, 20II).

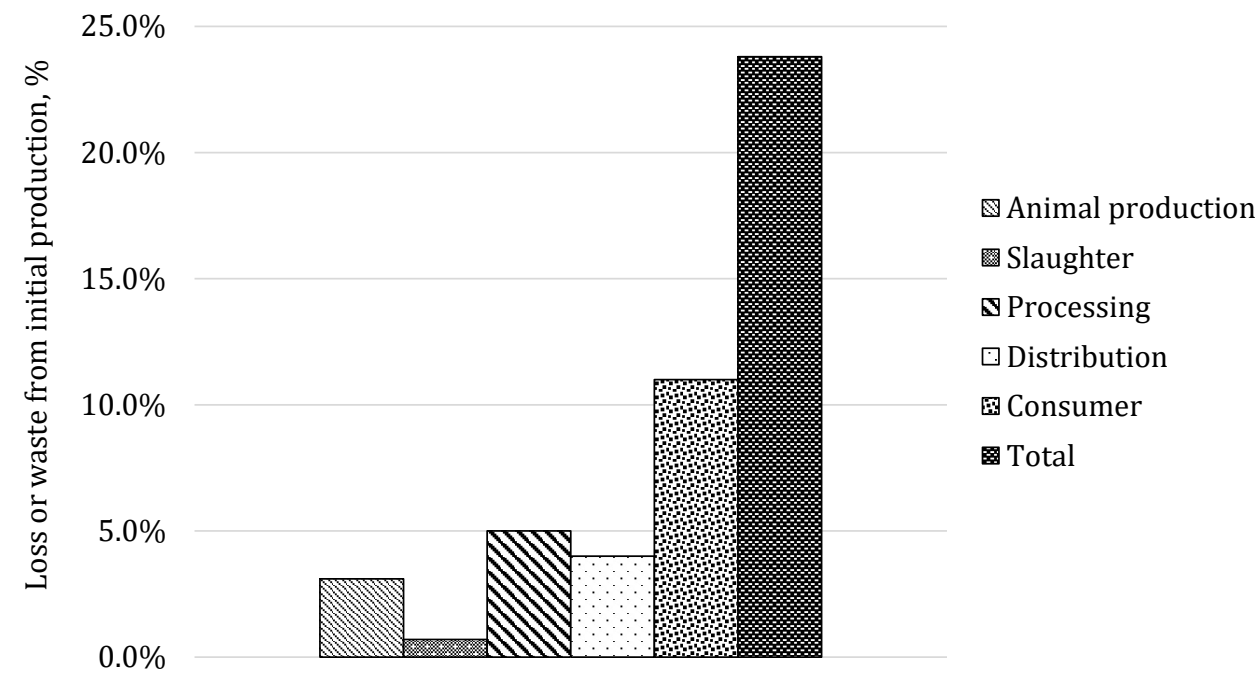

Figure I.I Part of the initial production of meat and meat products wasted at different stages of the food chain in Europe. Source: Food and Agriculture Organization, 20II.

It is widely recognized that the willingness of consumer to eat or purchase fresh meat or meat products is strongly associated by product appearance including its colour (Faustman and Cassens, 1990). In lamb and other ruminant derived meats, consumers perceive a "bright", "cherry-red" colour as an indicator of freshness and wholesomeness of the product, while they discriminate against meat that has turned brown (O'Grady et al., 2000; Djenane et al., 2003). 


\section{Meat Colour and Oxidative Stability}

Meat colour is highly affected by the heme protein myoglobin (Faustman et al., 20Io). The concentration of this protein and its oxidation state determines meat colour via the occurrence of four chemical forms of myoglobin (Figure I.2). Deoxymyoglobin (DeoxyMb) is the purple pigment observed in freshly cut meat. Following its exposure to air, DeoxyMb becomes oxygenated to oxymyoglobin $(\mathrm{OxyMb})$, which presents the desirable bright, cherry red colour appreciated by the consumer. After further exposure to air (hours or days), $\mathrm{OxyMb}$ is further oxidized to metmyoglobin (MetMb) in which a molecule of water is substituted for a molecule of oxygen resulting in brown pigmentation. Discoloration results from conversion of the ferrous iron $\left(\mathrm{Fe}^{2+}\right)$ form present in DeoxyMb and OxyMb to the ferric form $\left(\mathrm{Fe}^{3+}\right)$ present in MetMb. Carboxymyoglobin (CarboxyMb), is formed when carbon monoxide attaches to DeoxyMb, producing a stable bright-red colour in the absence of environmental oxygen. Atmospheres containing oxygen will result in the conversion of CarboxyMb to either OxyMb or MetMb (Mancini and Hunt, 2005).

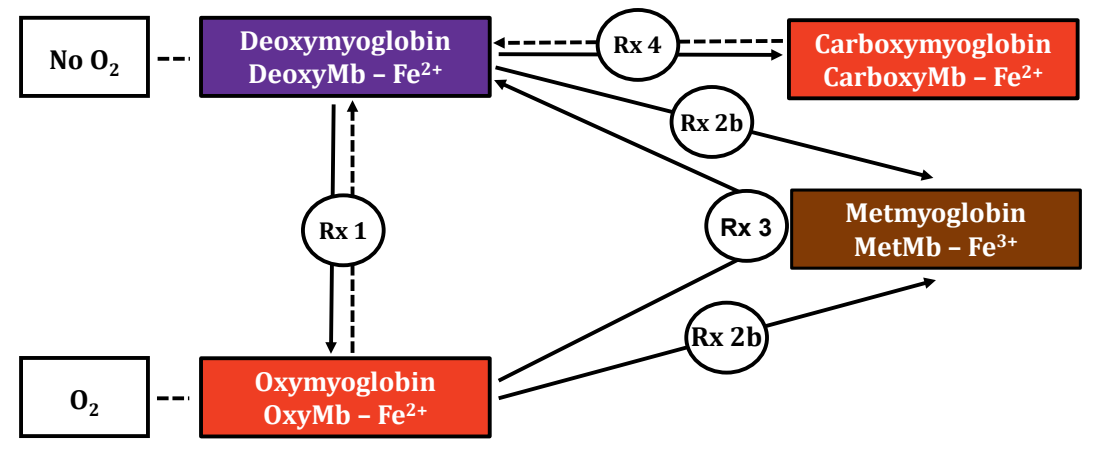

Rx 1 (oxygenation) :

DeoxyMb $+\mathrm{O}_{2} \longrightarrow$ OxyMb

Rx 2a (oxidation):

$\mathrm{OxyMb}+$ [oxygen consumption or low $\mathrm{O}_{2}$ partial pressure] $-\mathrm{e}^{-} \longrightarrow$ MetMb

Rx 2b (oxidation):

$\mathrm{Rx} 3$ (reduction):

[DeoxyMb - hydroxyl ion - hydrogen ion complex] $+\mathrm{O}_{2} \longrightarrow$ MetMb $+\mathrm{O}_{2}^{-}$

Rx 4 (carboxymyoglobin): DeoxyMb + carbon monoxide $\longrightarrow$ CarboxyMb

Figure I.2 Visible myoglobin redox interconversions on the surface of meat. Adapted from: Mancini and Hunt, 2005.

Further enhancements of the red colouring of meat can be achieved with modified atmosphere packaging (MAP) technologies, which can be a highly oxidizing packaging method (70\%-80\% of oxygen and 30\%-20\% carbon dioxide) (Álvarez et al., 2008). As previously described, the high concentrations of oxygen environment increase the oxygenation of myoglobin and lead to the development of the bright red $\mathrm{OxyMb}$ (Gatellier et al., 2005). However, over time these high concentrations of oxygen in the MAP also 
accelerate lipid oxidation and MetMb formation which, in turn, contribute to the deterioration of flavour, texture and colour of the meat or meat products (Jakobsen and Bertelsen, 2000).

Lipid oxidation is commonly described as an oxygen dependent chain reaction that is comprised of three major steps: initiation, propagation and termination (Eitenmiller and Lee, 2004).

Initiation is the first step in lipid oxidation and occurs when a hydrogen is abstracted from a methylene carbon in a fatty acid (RH) by exposure to a catalyst such as light, heat, metal ions or through the action of lipoxygenase to form a lipid (alkyl) radical (R*) (Eq. I) (Halliwell and Chirico, 1993).

$$
\text { (Eq. I) } \mathrm{RH} \longrightarrow \mathrm{R}^{\cdot}+\mathrm{H}^{\cdot}
$$

Propagation is used to describe the high reactivity of lipid radicals with triplet oxygen which leads to the rapid formation of a peroxy radical (ROO•) (Eq. 2).

$$
\text { (Eq. 2) } \mathrm{R}^{\cdot}+\mathrm{O}_{2} \longrightarrow \mathrm{ROO}^{*}+\mathrm{H}^{*}
$$

Peroxy radicals will preferentially oxidize other unsaturated fatty acids to form a hydroperoxide and a new unstable lipid (Eq.3). This lipid radical then reacts with oxygen to produce another peroxy radical, which represents a significant self-propagating reactant for the autocatalytic chain reaction (Eq. 4).

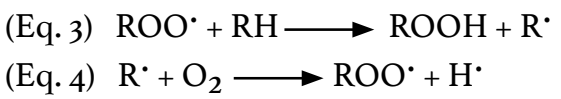

Hydroperoxides $(\mathrm{ROOH})$ are unstable in most chemical and environmental conditions and their radicals can further accelerate propagation reactions. These branching steps or secondary reactions (Eqs. 5 and 6) are often homolytic in their progression and occur rapidly at elevated temperatures.

$$
\begin{array}{ll}
\text { (Eq. 5) } & \mathrm{ROOH} \longrightarrow \mathrm{RO}^{*}+\mathrm{OH} \\
(\text { Eq. 6) } & \mathrm{RO} \cdot+\mathrm{RH} \longrightarrow \mathrm{ROH}+\mathrm{R}^{\cdot}
\end{array}
$$

Secondary decomposition products such as pentanal, hexanal, 4-hydroxynoneal and malondialdehyde (MDA) which are responsible for causing off-flavours and reduced shelflife (Pearson et al., 1983; Raharjo and Sofos, 1993) may then be formed.

Termination, in the last step of the lipid peroxidation reaction and occurs when two radicals react and produce a non-radical product (Eqs. 7, 8 and 9). 


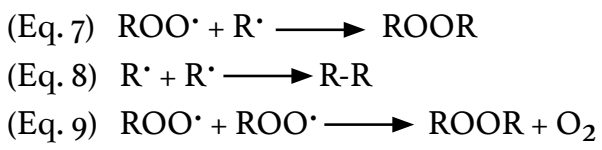

Lipid oxidation is, therefore, another major determinant of quality and acceptability of meats and meat products. The chemistry associated with oxidation of lipids and myoglobin seems to indicate that these reactions may exacerbate one another and that they cannot be easily dissociated. As meat ages, lipid peroxidation increases the rate of MetMb formation and conversely MetMb can act as a catalyst for lipid peroxidation (Faustman et al., 20IO).

\section{Antioxidant Use in Lamb Diets}

In order to delay lipid oxidation and colour deterioration, both retailers and meat producers adopted the incorporation of antioxidants into animal diets or directly added to the meat during processing (Nerín et al., 2006). Nutritional interventions are generally preferred over direct addition of the antioxidant to the muscle, since it is a convenient strategy to uniformly incorporate the antioxidant into the subcellular membranes (Govaris et al., 2004; Descalzo and Sancho, 2008). More importantly, these cell-integrated antioxidants are more effective at preventing oxidative damage than those added directly to the meat (Kerry et al., 1998).

In vivo, antioxidant molecules (such as vitamin E) and enzymes found in skeletal muscle (catalase, superoxide dismutase and glutathione peroxidase) constitute the main line of defence against free radicals (Descalzo and Sancho, 2008). Following exsanguination, cellular antioxidant enzymes maintain only a remnant activity until the onset of cell death (Renerre et al., 1996; Descalzo and Sancho, 2008). Since the enzymatic antioxidant mechanism is compromised after slaughter, a considerable amount of antioxidant molecules must be incorporated into the tissues before slaughter to effectively reduce meat oxidation and colour deterioration.

Among potential antioxidant molecules, vitamin $\mathrm{E}$ is the most commonly used because of its known effects on raising $\alpha$-tocopherol concentrations in tissues (Ochoa et al., 1992), delaying lipid oxidation and improving the colour stability of lamb meat (López-Bote et al., 200I; Lauzurica et al., 2005).

\section{Vitamin E}

After its discovery by Evans and Bishop nearly Ioo years ago, the role of vitamin E as a major chain-breaking antioxidant in biological systems has become largely undisputed. Naturally occurring vitamin E, encompasses a group of eight compounds, including $\alpha$-, $\beta-, \gamma^{-}$, and $\delta$-tocopherols and four corresponding unsaturated analogues $\left(\alpha-, \beta-, \gamma^{-}\right.$, and $\delta$-tocotrienol). As presented in Table I.I, all feature a chromanic nucleus (6-chromanol) with a hydroxyl group that can donate a hydrogen atom to reduce free radicals and an 
aliphatic I6-carbon side chain (unsaturated side chain in case of tocotrienols) that allows its incorporation into biological membranes (Schneider, 2005).

Table I.I Structural terminologies of tocopherol and tocotrienol isoforms. Adapted from Ghosh et al. (2008).

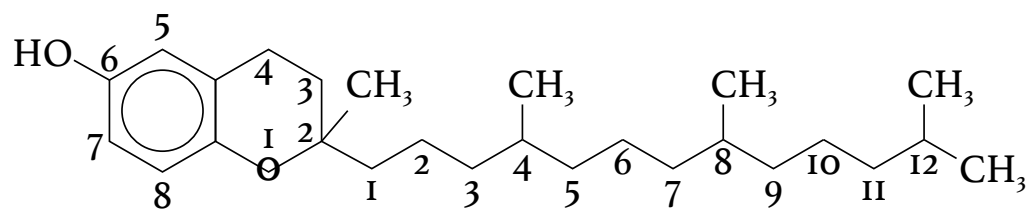

Common

Name

$\alpha$-tocopherol

$\beta$-tocopherol

$\gamma$-tocopherol

$\delta$-tocopherol

$\alpha$-tocotrienol

$\beta$-tocotrienol

$\gamma$-tocotrienol

$\delta$-tocotrienol

\section{Structural}

Terminology

2,5,7,8-tetramethyl-2-(4,8,12-trimethyltridecyl)chroman-6-ol

2,5,8-trimethyl-2-(4,8,I2-trimethyltridecyl)chroman-6-ol

2,7,8-trimethyl-2-(4,8,I2-trimethyltridecyl)chroman-6-ol

2,8-dimethyl-2-(4,8,12-trimethyltridecyl)chroman-6-ol

2,5,7,8-tetramethyl-2-(4,8,I2-trimethyltrideca-3,7,II-trienyl)chroman-6-ol 2,5,8-trimethyl-2-(4,8,I2-trimethyltrideca-3,7,II-trienyl)chroman-6-ol 2,7,8-trimethyl-2-(4,8,12-trimethyltrideca-3,7,II-trienyl)chroman-6-ol 2,8-dimethyl-2-(4,8,I2-trimethyltrideca-3,7,II-trienyl)chroman-6-ol

Alpha and $\gamma$-tocopherols are the predominant forms of vitamin $E$ found in nature, of which $\alpha$-tocopherol has the greatest biological activity and is the main form of vitamin $\mathrm{E}$ found in blood and animal tissues (Wolf, 2006). Following intake, dietary and supplemental vitamin $\mathrm{E}$ is absorbed and delivered to the liver, where mainly $\alpha$-tocopherol is recognized by a specific $32-\mathrm{kDa}, \alpha$-tocopherol transfer protein $(\alpha-\mathrm{TTP})$. This selective binding of $\alpha$-tocopherol by $\alpha$-TTP, regulates body's vitamin E levels, metabolism and excretion (Burton and Traber, 1990;Traber and Atkinson, 2007). As demonstrated in vitro by Hosomi et al. (1997), when considering the affinity of $\alpha$-TTP for $\alpha$-tocopherol as I00\%, the affinity for the remaining tocopherol analogues were the following: $\beta$-tocopherol $38 \%, \gamma$-tocopherol $9 \%$ and $\delta$-tocopherol $2 \%$.

Alpha-tocopherol supplements used in animal nutrition are different from the natural occurring forms which consists of a single stereoisomer, 2 'R, 4'R, 8R'- $\alpha$-tocopherol (see Figure I.3). Due to the 3 asymmetric centres in the side chain, synthetic $\alpha$-tocopherol (allrac- $\alpha$-tocopherol) is a racemic mixture (I2.5\% of each) of eight stereoconfigurations of the $\alpha$-tocopherol molecule (RRR-, RRS-, RSR-, RSS-, SRR-, SSR-, SRS-, and SSS-) (Weiser and Vecchi, I98I, I982). 


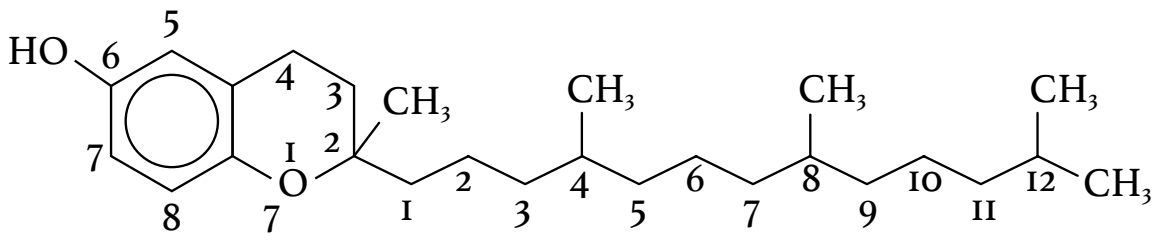

Figure I.3 Struture of RRR- $\alpha$-tocopherol, with R configuration at postion 2', 4', and 8' of the phytil tails. Source: Dersjant-Li and Peisker (20IO).

Discrimination in the liver among these $\alpha$-tocopherol stereoisomers also occurs through the action of $\alpha$-tocopherol transfer protein ( $\alpha$-TTP), which preferentially binds to $2 \mathrm{R}$ stereoisomers, resulting in degradation of the majority of $2 \mathrm{~S}$ stereoisomers in the all-rac- $\alpha$ tocopherol (synthetic $\alpha$-tocopherol) (Kuchan et al., 20I6). Although different $\alpha$-tocopherol stereoisomers may present similar antioxidant activity in vitro (Food and Nutrition Board, 2000), the stereoselectivity of $\alpha$-TTP towards the RRR- $\alpha$-tocopherol stereoisomer seems to be an important factor for the difference in bioactivity between RRR-and all-rac- $\alpha$-tocopherol. In an attempt to standardize vitamin E applications, the United States Pharmacopeia (USP, I979) defined I mg of all-rac- $\alpha$-tocopheryl acetate to equal I international unit (IU) of vitamin E, I mg of all-rac- $\alpha$-tocopherol to I.I IU, I mg of RRR- $\alpha$-tocopheryl acetate to I.36 IU and I mg of RRR- $\alpha$-tocopherol to I.49 IU. These values were mainly derived from a series of rat resorption-gestation tests first published by Harris and Ludwig (1949) and later supported by data using a similar model on the relative biopotency (i.e. capacity of a chemical substance to function in a biological system) of each $\alpha$-tocopherol stereoisomer (Weiser and Vecchi, 198I; 1982). However, some concerns have been identified regarding the use of these conversion factors to discriminate between different forms of vitamin $\mathrm{E}$. When feeding animals diets that are similar in vitamin $\mathrm{E}$ on an IU basis, concentrations of $\alpha$-tocopherol in biological fluids and tissues are almost always higher in RRR- $\alpha$-tocopherol fed animals when compared with all-rac- $\alpha$-tocopherol (Lauridsen et al., 2002; Jensen et al., 2006; Weiss et al., 2009). Moreover, Blatt et al. (2004) added to the overall discussion when proposing that all-rac- and RRR- $\alpha$-tocopherol are not equivalent in any dosage ratio. Based on previous studies, they concluded that a fixed dosage ratio of all-rac- and RRR$\alpha$-tocopherol cannot produce a fixed ratio of effects on all processes in all tissues at all times after all dosages. Therefore, studies focused on quantitative determination of total $\alpha$-tocopherol and its stereoisomer composition in different tissues will allow a better understanding of their relative bioavailability. 


\section{Plant Extracts}

Besides $\alpha$-tocopherol, alternative sources of natural antioxidants have been investigated in several types of plant such as vegetables, fruits, leaves, oilseeds, cereal crops, barks and roots, spices and herbs (Kähkönen et al., 1999). Like in animals, plants are under constant oxidative stress caused by free radicals, reactive oxygen species, and prooxidants generated either exogenously (heat, light and water shortage) or endogenously (hydrogen peroxide). In response, plant cells have developed antioxidant systems to control free radicals, lipid oxidation catalysts, oxidation intermediates and secondary breakdown products (Lacopini et al., 2008). Interestingly, crude extracts from some plant materials rich in phenolics have been reported to have multiple biological effects, including antioxidant activity. The antioxidant activity of plant extracts has been linked to their phenolic compound content, as demonstrated in several in vitro studies (Zheng and Wang, 200I; Shan et al., 2005).

All plant phenolic compounds arise from common precursors (phenylalanine or shikimic acid), so far more than 8000 polyphenolic compounds have been identified in different plants or plant materials (Pandey and Rizvi, 2009). However, based on the number of phenol rings and the structural elements binding those rings to one another, plant phenolics can be broadly classified into 4 groups (Spencer et al., 2008), as shown in Figure I.4.<smiles>[R]c1cc(C(=O)O)cc([R])c1[R]</smiles><smiles>[R]c1ccc(/C=C/C(=O)O)cc1[R]</smiles><smiles></smiles>

Phenolic acids (hydroxy-benzioc \& cinnamic acids)

Flavonoids

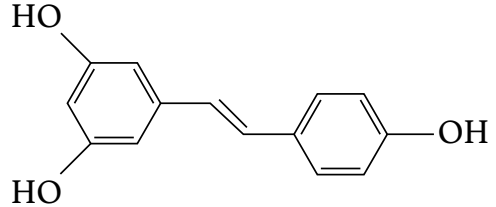

Stilbenes<smiles>COc1cc(C2c3cc(O)c(OC)cc3CC(CO)C2CO)ccc1O</smiles>

Lignans

Figure 1.4 Chemical structures of the different classes of polyphenols. Source: Pandey and Rizvi (2009). 
The chemical structure of phenolic compounds can greatly vary, ranging from simple molecules such as phenolic acids and flavonoids to the highly polymerized tannins (Brewer, 20II). Therefore, molecular complexity of phenolics seems to be a major factor that can limit their bioavailability (Manach et al., 2005). Like for $\alpha$-tocopherol, for these phenolic compounds to exhibit any antioxidant activity post-mortem, they would need to be absorbed along the gastrointestinal tract, transported in the blood and accumulated in the target tissue (such as the skeletal muscle) (Vasta and Luciano, 20II).

The mechanism of action of these phenolic compounds on meat oxidative stability are only partly understood and several hypotheses have been proposed. Some authors suggest an indirect antioxidant effect, where phenolic compounds act in the gut by chelating pro-oxidant metals and reducing the production of lipid peroxides and toxic compounds leading to an overall improvement of the animal's antioxidant status (Halliwell et al., 2005; Kerem et al., 2006). Additionally, the direct antioxidant activity of phenolic compounds in the gut may spare other antioxidants like vitamin E from oxidation (Yamamoto et al., 2006). Based on the reduction of lipid oxidation in plasma from rats and sheep receiving diets supplemented with a polyphenol-rich plant extracts, Gladine et al. (2007a,b) hypothesized that polyphenol rich plant extracts can have a direct effect against oxidation of fatty acids. Moreover, the dietary transfer of polyphenol compounds into skeletal muscle has been demonstrated by Moñino et al. (2008), where lambs receiving milk from sheep fed a distillate of rosemary (Rosmarinus officinalis) leaves had increased muscular contents of rosmarinic acid, carnosol and carnosic acid. This ultimately led to an improved antioxidant capacity of the fresh meat samples when compared with lambs from non-supplemented sheep. In a later study, Nieto et al. (2010) included the distillate of rosemary leaves in sheep diets and improved redness and reduced lipid oxidation in fresh lamb meat packed in MAP and displayed for $2 \mathrm{I} \mathrm{d}$.

The mechanism of action of phenolic compounds in meat and meat products whether direct, indirect, or synergistic, remains unclear. Moreover, there is also limited information on the effect of dietary administration of polyphenols compared with vitamin $\mathrm{E}$ supplementation on lipid oxidation and colour stability in lamb meat. Thus, contrasting both feeding strategies and quantifying their relative value for meat colour and stability, under the same experimental conditions, is a topic of interest for animal nutritionists, as well as for meat scientists.

\section{Lamb Production System in Mediterranean Areas}

Historically, sheep farming have a peculiar importance in Mediterranean areas. The different production systems are adapted to the geographical characteristics of the region, defined by overpopulated coastlines, limited irrigated plain lands, mountainous hinterlands, and dry, warm summers. Moreover, it utilises resources that other farming sectors could not utilize. 
In Spain, unlike northern European countries, consumers value lightweight lamb carcasses $(<\mathrm{I} 3 \mathrm{~kg})$ because of a perceived loss in quality attributes if lambs are slaughter at higher carcass weights (loss of tenderness, flavour and darker meat) (Beriain et al., 2000; Boyazoglu and Morand-Fehr, 200I). Therefore, acknowledging these differences in consumer's perception, the European Union (EU) has established two different scales for carcass classification in sheep based on their carcass weight: heavy ( $>\mathrm{I} 3 \mathrm{~kg})$, and light $(<\mathrm{I} 3$ kg) carcasses (De la Fuente et al., 2007). To ensure carcass homogeneity and to align the product with consumer preference, feedlots and fattening units were developed to act as intermediaries between the reproductive flocks, in which lambs are kept with the sheep, or dairy farms, and the abattoirs where lambs are slaughtered (Miranda-de la Lama et al., 2009). After weaning at I2-I4 $\mathrm{kg}$ body weight (BW), lambs enter the feedlot facilities, are grouped based on body weight and fed a concentrate diet for a period between 2I to $45 \mathrm{~d}$, until a slaughter weight of 22-24 $\mathrm{kg}$ is reached (Lobón et al., 2017).

Unlike fresh forages, that are rich in natural antioxidants (such as RRR- $\alpha$-tocopherol, carotenoids, flavonoids and other phenolic compounds), most concentrate diets, that have not been supplemented with antioxidants (like vitamin E), present low concentrations of antioxidant components (Gatellier et al., 2004). Acknowledging the importance of the nutritional background to prevent fatty acid oxidation and meat discoloration, a large body of literature exits that describes the benefits of vitamin E supplementation of concentrates above the requirements of lambs. From these studies, supplementation levels between $287 \mathrm{mg}$ of all-rac- $\alpha$-tocopheryl acetate per kg diet (Álvarez et al., 2008) and 550$626 \mathrm{mg} \mathrm{kg}^{-1}$ diet (López-Bote et al., 200I) have been proposed. However, when planning a supplementation strategy in lambs, other important aspects that need attention are the antioxidant status of the animal at the beginning of the supplementation period (Descalzo et al., 2005), the length of the supplementation period (Lauzurica et al., 2005), the different slaughter weights (De la Fuente et al., 2007) and the animal breed (López-Bote et al., 200I). Therefore, the value of the available recommendations for antioxidant supplementation found in literature, require adaptation to individual meat production systems and should consider the conditions in which those recommendations were generated.

\section{Research Objectives and Outline}

Based on the knowledge gaps identified above, the objective of this thesis was to investigate the effect of supplementation level with natural (RRR-) and synthetic vitamin E (all-rac-) on stereoisomer deposition, meat colour and oxidative stability in light weight lambs. In Chapter 2, an experiment comparing RRR- and all-rac- $\alpha$-tocopheryl acetate supplementation on $\alpha$-tocopherol stereoisomer distribution in lamb tissues is described. In Chapter 3, the effect of $\alpha$-tocopherol source and dosage on quality attributes of meat stored under retail conditions for $\mathrm{I} 4 \mathrm{~d}$ are evaluated. Then, in Chapter 4 , the results from all-rac- $\alpha$-tocopheryl acetate supplementation on physicochemical and fatty acid stability of thawed lamb meat frozen for 9 months are presented. Secondly, different polyphenol 
rich plant extracts were screened for their potential to alter the antioxidant potential in selected lamb tissues. In Chapter 5, the antioxidant potential of II different plant extracts in selected lamb tissues were evaluated using four different methodologies. Finally, in Chapter 6 a standardized plant extract was compared with all-rac- $\alpha$-tocopheryl acetate in its ability to reduce meat oxidation and improve colour stability in lamb meat stored for I4 $\mathrm{d}$ under retail conditions. Chapter 7 includes an integrative discussion of the results presented in this thesis and general conclusions are drawn. 


\section{REFERENCES}

Álvarez, I., J. De la Fuente, M. T. Díaz, S. Lauzurica, C. Pérez, and V. Cañeque. 2008. Estimation of alpha-tocopherol concentration necessary to optimise lamb meat quality stability during storage in high-oxygen modified atmosphere using brokenline regression analysis. Animal 2(9):I4O5-I4II.

Beriain, M. J., A. Horcada, A. Purroy, G. Lizaso, J. Chasco, and J. A. Mendizabal. 2000. Characteristics of Lacha and Rasa Aragonesa lambs slaughtered at three live weights. Journal of Animal Science 78(I2):3070-3077.

Blatt, D. H., W. A. Pryor, J. E. Mata, and R. Rodriguez-Proteau. 2004. Re-evaluation of the relative potency of synthetic and natural alpha-tocopherol: experimental and clinical observations. The Journal of Nutritional Biochemistry I5(7):380-395.

Boyazoglu, J. and P. Morand-Fehr. 200I. Mediterranean dairy sheep and goat products and their quality. A critical review. Small Ruminant Research 4O(I):I-II.

Brewer, M. S. 20II. Natural Antioxidants: Sources, Compounds, Mechanisms of Action, and Potential Applications. Comprehensive Reviews in Food Science and Food Safety IO(4):22I-247.

Burton, G. W. and M. G. Traber. 1990. Vitamin E: antioxidant activity, biokinetics, and bioavailability. Annual Review of Nutrition Io:357-382.

De la Fuente, J., M. T. Díaz, I. Álvarez, S. Lauzurica, V. Cañeque, and C. Pérez. 2007. Effect of dietary supplementation with vitamin $\mathrm{E}$ on characteristics of vacuum-packed lamb. Journal of the Science of Food and Agriculture 87(4):65I-659.

Dersjant-Li, Y. and M. Peisker. 20IO. Utilization of stereoisomers from alpha-tocopherol in livestock animals. Journal of Animal Physiology and Animal Nutrition 94(4):413-42I.

Descalzo, A. M., E. M. Insani, A. Biolatto, A. M. Sancho, P. T. Garcia, N. A. Pensel, and J. A. Josifovich. 2005. Influence of pasture or grain-based diets supplemented with vitamin E on antioxidant/oxidative balance of Argentine beef. Meat Science 7O(I):35-44.

Descalzo, A. M. and A. M. Sancho. 2008. A review of natural antioxidants and their effects on oxidative status, odor and quality of fresh beef produced in Argentina. Meat Science 79(3):423-436.

Djenane, D., A. Sánchez-Escalante, J. A. Beltrán, and P. Roncalés. 2003. Extension of the shelf life of beef steaks packaged in a modified atmosphere by treatment with rosemary and displayed under UV-free lighting. Meat Science 64(4):4I7-426.

Eitenmiller, R. R. and J. Lee. 2004. Vitamin E: Food Chemistry, Composition, and Analysis. $\mathrm{I}^{\text {st }}$ edition, CRC Press, Boca Raton, Florida, USA.

Food and Agriculture Organization (20II). Global Food Losses and Food Waste-Extent, Causes and Prevention. Rome: FAO.

Faustman, C. and R. G. Cassens. 1990. The biochemical basis for discoloration in fresh meat: a review. Journal of Muscle Foods I(3):217-243.

Faustman, C., Q. Sun, R. Mancini, and S. P. Suman. 20IO. Myoglobin and lipid oxidation interactions: mechanistic bases and control. Meat Science 86(I):86-94. 
Food and Nutrition Board, Institute of Medicine. 2000. Dietary Reference Intakes for Vitamin C, Vitamin E, Selenium, and Carotenoids. The National Academies Press, Washington DC, USA.

Gatellier, P., Y. Mercier, H. Juin, and M. Renerre. 2005. Effect of finishing mode (pasture- or mixed-diet) on lipid composition, colour stability and lipid oxidation in meat from Charolais cattle. Meat Science 69(I):I75-I86.

Gatellier, P., Y. Mercier, and M. Renerre. 2004. Effect of diet finishing mode (pasture or mixed diet) on antioxidant status of Charolais bovine meat. Meat Science 67(3):385-394.

Gladine, C., C. Morand, E. Rock, D. Bauchart, and D. Durand. 2007a. Plant extracts rich in polyphenols (PERP) are efficient antioxidants to prevent lipoperoxidation in plasma lipids from animals fed n-3 PUFA supplemented diets. Animal Feed Science and Technology I36(3):28I-296.

Gladine, C., E. Rock, C. Morand, D. Bauchart, and D. Durand. 2007b. Bioavailability and antioxidant capacity of plant extracts rich in polyphenols, given as a single acute dose, in sheep made highly susceptible to lipoperoxidation. British Journal of Nutrition 98(4):69I-70I.

Ghosh S. P., Hauer-Jensen M. and K. S. Kumar. 2008. Chemistry of Tocotrienols. Pages 8596 in Tocotrienols: Vitamin E Beyond Tocopherols. Watson, R. R. and V. R. Preedy. I ${ }^{\text {st }}$ edition, CRC Press, Boca Raton, Florida, USA.

Govaris, A., N. Botsoglou, G. Papageorgiou, E. Botsoglou, and I. Ambrosiadis. 2004. Dietary versus post-mortem use of oregano oil and/or alpha-tocopherol in turkeys to inhibit development of lipid oxidation in meat during refrigerated storage. International Journal of Food Sciences and Nutrition 55(2):II5-I23.

Halliwell, B. and S. Chirico. 1993. Lipid peroxidation: its mechanism, measurement, and significance. The American Journal of Clinical Nutrition 57(5 Suppl):715S-724S.

Halliwell, B., J. Rafter, and A. Jenner. 2005. Health promotion by flavonoids, tocopherols, tocotrienols, and other phenols: direct or indirect effects? Antioxidant or not? The American Journal of Clinical Nutrition 8I(I Suppl):268s-276s.

Harris, P. L. and M. I. Ludwig. 1949. Relative vitamin E potency of natural and of synthetic alpha-tocopherol. The Journal of Biological Chemistry I79(3):IIII-III5.

Hosomi, A., M. Arita, Y. Sato, C. Kiyose, T. Ueda, O. Igarashi, H. Arai, and K. Inoue. 1997. Affinity for alpha-tocopherol transfer protein as a determinant of the biological activities of vitamin E analogs. FEBS letters 409(I):IO5-IO8.

Jakobsen, M. and G. Bertelsen. 2000. Colour stability and lipid oxidation of fresh beef. Development of a response surface model for predicting the effects of temperature, storage time, and modified atmosphere composition. Meat Science 54(I):49-57.

Jensen, S. K., J. V. Norgaard, and C. Lauridsen. 2006. Bioavailability of alpha-tocopherol stereoisomers in rats depends on dietary doses of all-rac- or RRR-alpha-tocopheryl acetate. The British Journal of Nutrition 95(3):477-487. 
Kähkönen, M. P., A. I. Hopia, H. J. Vuorela, J.-P. Rauha, K. Pihlaja, T. S. Kujala, and M. Heinonen. 1999. Antioxidant Activity of Plant Extracts Containing Phenolic Compounds. Journal of Agricultural and Food Chemistry 47(IO):3954-3962.

Kerem, Z., D. Chetrit, O. Shoseyov, and G. Regev-Shoshani. 2006. Protection of lipids from oxidation by epicatechin, trans-resveratrol, and gallic and caffeic acids in intestinal model systems. Journal of Agricultural and Food Chemistry 54(26):IO288-IO293.

Kerry, J. P., D. J. Buckley, P. A. Morrissey, K. O’Sullivan, and P. B. Lynch. 1998. Endogenous and exogenous $\alpha$-tocopherol supplementation: effects on lipid stability (TBARS) and warmed-over flavour (WOF) in porcine M. longissimus dorsi roasts held in aerobic and vacuum packs. Food Research International 3I(3):2II-2I6.

Kuchan, M. J., S. K. Jensen, E. J. Johnson, and J. C. Lieblein-Boff. 20I6. The naturally occurring alpha-tocopherol stereoisomer RRR-alpha-tocopherol is predominant in the human infant brain. The British Journal of Nutrition II6(I):I26-I3I.

Lacopini, P., M. Baldi, P. Storchi, and L. Sebastiani. 2008. Catechin, epicatechin, quercetin, rutin and resveratrol in red grape: Content, in vitro antioxidant activity and interactions. Journal of Food Composition and Analysis 2I(8):589-598.

Lauridsen, C., H. Engel, A. M. Craig, and M. G. Traber. 2002. Relative bioactivity of dietary RRR- and all-rac-alpha-tocopheryl acetates in swine assessed with deuterium-labeled vitamin E. Journal of Animal Science 80(3):702-707.

Lauzurica, S., J. De la Fuente, M. T. Díaz, I. Álvarez, C. Pérez, and V. Cañeque. 2005. Effect of dietary supplementation of vitamin E on characteristics of lamb meat packed under modified atmosphere. Meat Science 70(4):639-646.

Lobón, S., M. Blanco, A. Sanz, G. Ripoll, J. R. Bertolín, and M. Joy. 20I7. Meat quality of light lambs is more affected by the dam's feeding system during lactation than by the inclusion of quebracho in the fattening concentrate. Journal of Animal Science 95(II):4998-50II.

López-Bote, C. J., A. Daza, M. Soares, and E. Berges. 200I. Dose-response effect of dietary vitamin E concentration on meat quality characteristics in light-weight lambs. Animal Science 73(3):45I-457.

Manach, C., G. Williamson, C. Morand, A. Scalbert, and C. Rémésy. 2005. Bioavailability and bioefficacy of polyphenols in humans. I. Review of 97 bioavailability studies. The American Journal of Clinical Nutrition 8I(I):230S-242S.

Mancini, R. A. and M. C. Hunt. 2005. Current research in meat color. Meat science 7I(I):IOOI2I.

Miranda-de la Lama, G. C., M. Villarroel, J. L. Olleta, S. Alierta, C. Sañudo, and G. A. Maria. 2009. Effect of the pre-slaughter logistic chain on meat quality of lambs. Meat Science 83(4):604-609.

Moñino, I., C. Martínez, J. A. Sotomayor, A. Lafuente, and M. J. Jordán. 20o8. Polyphenolic Transmission to Segureño Lamb Meat from Ewes' Diet Supplemented with the 
Distillate from Rosemary (Rosmarinus officinalis) Leaves. Journal of Agricultural and Food Chemistry 56(9):3363-3367.

Nerín, C., L. Tovar, D. Djenane, J. Camo, J. Salafranca, J. A. Beltrán, and P. Roncalés. 2006. Stabilization of beef meat by a new active packaging containing natural antioxidants. Journal of Agricultural and Food Chemistry 54(20):7840-7846.

Nieto, G., P. Díaz, S. Bañón, and M. D. Garrido. 20Io. Dietary administration of ewe diets with a distillate from rosemary leaves (Rosmarinus officinalis L.): influence on lamb meat quality. Meat Science 84(I):23-29.

O'Grady, M. N., F. J. Monahan, R. M. Burke, and P. Allen. 20oo. The effect of oxygen level and exogenous alpha-tocopherol on the oxidative stability of minced beef in modified atmosphere packs. Meat Science 55(I):39-45.

Ochoa, L., L. R. McDowell, S. N. Williams, N. Wilkinson, J. Boucher, and E. L. Lentz. 1992. alpha-Tocopherol concentrations in serum and tissues of sheep fed different sources of vitamin E. Journal of Animal Science 7o(8):2568-2573.

Pandey, K. B. and S. I. Rizvi. 2009. Plant polyphenols as dietary antioxidants in human health and disease. Oxidative Medicine and Cellular Longevity 2(5): 270-279.

Pearson, A. M., J. I. Gray, A. M. Wolzak, and N. A. Horenstein. 1983. Safety implications of oxidized lipids in muscle foods. Food Technology 37(7):I2I-I29.

Raharjo, S. and J. N. Sofos. 1993. Methodology for measuring malonaldehyde as a product of lipid peroxidation in muscle tissues: A review. Meat Science 35(2):I45-I69.

Renerre, M., F. Dumont, and P. Gatellier. 1996. Antioxidant enzyme activities in beef in relation to oxidation of lipid and myoglobin. Meat Science 43(2):III-I2I.

Schneider, C. 2005. Chemistry and biology of vitamin E. Molecular Nutrition \& Food Research 49(I):7-30.

Shan, B., Y. Z. Cai, M. Sun, and H. Corke. 2005. Antioxidant capacity of 26 spice extracts and characterization of their phenolic constituents. Journal of Agricultural and Food Chemistry 53(20):7749-7759.

Spencer, J. P. E., M. M. Abd El Mohsen, A. M. Minihane, and J. C. Mathers. 2008. Biomarkers of the intake of dietary polyphenols: strengths, limitations and application in nutrition research. British Journal of Nutrition 99(I):I2-22.

Traber, M. G. and J. Atkinson. 2007. Vitamin E, antioxidant and nothing more. Free Radical Biology \& Medicine 43(I):4-I5.

USP. 1979. The United States Pharmacopeia. National Formulary. United States Pharmacopeial Convention, Rockville, Maryland, USA.

Vasta, V. and G. Luciano. 20II. The effects of dietary consumption of plants secondary compounds on small ruminants' products quality. Small Ruminant Research IOI(I):I50I59.

Weiser H and Vecchi M 198I. Stereoisomers of alpha-tocopheryl acetate. Characterization of the samples by physico-chemical methods and determination of biological activities in the rat resorption-gestation test. International Journal for Vitamin and Nutrition 
Research. Internationale Zeitschrift für Vitamin- und Ernáhrungsforschung. Journal International de Vitaminologie et de Nutrition 5I, IOO-II3.

Weiser $\mathrm{H}$ and Vecchi M 1982. Stereoisomers of alpha-tocopheryl acetate. II. Biopotencies of all eight stereoisomers, individually or in mixtures, as determined by rat resorption-gestation tests. International Journal for Vitamin and Nutrition Research. Internationale Zeitschrift für Vitamin- und Ernáhrungsforschung. Journal International de Vitaminologie et de Nutrition 52, 35I-370.

Weiss, W. P., J. S. Hogan, and D. J. Wyatt. 2009. Relative bioavailability of all-rac and RRR vitamin $\mathrm{E}$ based on neutrophil function and total alpha-tocopherol and isomer concentrations in periparturient dairy cows and their calves. Journal of Dairy Science 92(2):720-73I.

Wolf, G. 2006. How an increased intake of alpha-tocopherol can suppress the bioavailability of gamma-tocopherol. Nutrition Reviews 64(6):295-299.

Yamamoto, M., S. Miyamoto, J. H. Moon, K. Murota, Y. Hara, and J. Terao. 2006. Effect of dietary green tea catechin preparation on oxidative stress parameters in large intestinal mucosa of rats. Bioscience, Biotechnology, and Biochemistry 70(I):286-289.

Zheng, W. and S. Y. Wang. 20oI. Antioxidant activity and phenolic compounds in selected herbs. Journal of Agricultural and Food Chemistry 49(II):5I65-5I70. 



\title{
Chapter 2
}

\section{Bioavailability of $\alpha$-tocopherol stereoisomers in lambs depends on dietary doses of all-rac- or RRR- $\alpha$-tocopheryl acetate}

\author{
L. N. Leal ${ }^{\mathrm{a}, \mathrm{b}}$, S. K. Jensen ${ }^{\mathrm{c}}$, J. M. Bello ${ }^{\mathrm{d}}$, L. A. den Hartog ${ }^{\mathrm{a}, \mathrm{b}}$, \\ W. H. Hendriks ${ }^{\mathrm{b}}$ and J. Martín-Tereso ${ }^{\mathrm{a}}$
}

${ }^{a}$ Trouw Nutrition Research and Development, P.O. Box 299, 3800 AG, Amersfoort, the Netherlands.

${ }^{\mathrm{b}}$ Animal Nutrition group, Department of Animal Sciences,

Wageningen University \& Research, De Elst 1 , 6708 WD Wageningen, the Netherlands.

c Aarhus University, Department of Animal Science, Box 50, DK-8830 Tjele, Denmark. ${ }^{d}$ Nanta S.A., Ronda de Poniente 9, 28460 Tres Cantos, Madrid, Spain. 


\begin{abstract}
When supplementing lamb diets with vitamin E, an equivalence factor of 1.36 is used to discriminate between RRR- $\alpha$-tocopheryl acetate and all-rac- $\alpha$-tocopheryl acetate. However, more recent studies suggest a need for new equivalence factors for livestock animals. The current study aimed to determine the effect of RRR- and all-rac- $\alpha$-tocopheryl acetate supplementation on $\alpha$-tocopherol deposition in lamb tissues. One hundred and eight Rasa Aragonesa breed lambs were fed increasing amounts of all-rac- $\alpha$-tocopheryl acetate $(0.25,0.5$, I.o and $2.0 \mathrm{~g} \mathrm{~kg}^{-1}$ compound feed) or RRR- $\alpha$-tocopheryl acetate (0.125, 0.25, 0.5 and I.o $\mathrm{g} \mathrm{kg}^{-1}$ compound feed) added to a basal diet which contained $0.025 \mathrm{~g} \mathrm{~kg}^{-1}$ feed of all-rac- $\alpha$ tocopheryl acetate as part of the standard vitamin and mineral mixture. The diets were fed for the last $\mathrm{I} 4 \mathrm{~d}$ prior to slaughtering at $25.8 \pm \mathrm{I} .67 \mathrm{~kg}$ BW. Within $20 \mathrm{~min}$ after slaughter samples of muscle, heart, liver, brain and spleen were frozen at $-20^{\circ} \mathrm{C}$ until $\alpha$-tocopherol analysis. Increased supplementation of either vitamin E sources led to a significant increase $(\mathrm{P}<\mathrm{O} .00 \mathrm{I})$ in $\alpha$-tocopherol concentration in all tissues studied. The tissue with the highest $\alpha$-tocopherol concentration was the liver followed by spleen, heart and muscle. At similar supplementation levels (0.25, 0.50 and $1.0 \mathrm{~g} \mathrm{~kg}^{-1}$ compound feed), $\alpha$-tocopherol content in the selected tissues was not affected by $\alpha$-tocopherol source. However, the ratios between RRR- and all-rac- $\alpha$-tocopheryl acetate increased with the increasing $\alpha$-tocopherol supplementation (at 0.25 and I.O $\mathrm{g} \mathrm{kg}^{-1}$ compound feed), from I.06 to I.I6 in muscle, I.07 to I.I5 in heart, 0.9I to 0.94 in liver and 0.98 to I.IO in spleen. The highest relative proportion of 2 S (sum of SSS-, SSR-, SRS- and SRR- $\alpha$-tocopherol) configured stereoisomers was found in the liver of lambs supplemented with all-rac- $\alpha$-tocopheryl acetate accounting with up to $35-39 \%$ of the total $\alpha$-tocopherol retained, whereas the proportion of $2 S$ configured stereoisomers in the other tissues accounted for less than $14 \%$. Increasing all-rac- $\alpha$-tocopheryl acetate supplementation was also found to affect the $2 \mathrm{R}$ configured stereoisomer profile in muscle, heart and spleen increasing the proportions of RRS-, RSR- and RSS- at the cost of RRR- $\alpha$-tocopherol. In all tissues, the relative proportion of all non-RRR-stereoisomers in lambs receiving RRR- $\alpha$-tocopheryl acetate was lower than RRR- $\alpha$-tocopherol. These results confirm that the relative bioavailability of RRR- and allrac- $\alpha$-tocopheryl acetate is dose and tissue dependent and that a single ratio to discriminate the two sources cannot be used.
\end{abstract}




\section{INTRODUCTION}

After its discovery nearly Ioo years ago, the role of vitamin $\mathrm{E}$ as a major chain-breaking antioxidant present in membranes and lipoproteins has become largely undisputed. However, vitamin $\mathrm{E}$ is not a single molecule but instead consists of a family of compounds including $\alpha-, \beta-, \gamma^{-}$, and $\delta$-tocopherol and four corresponding unsaturated analogs ( $\alpha-, \beta-$, $\gamma$-, and $\delta$-tocotrienol) (Brigelius-Flohé and Traber, 1999). Alpha- and $\gamma$-tocopherol are the predominant forms of vitamin $\mathrm{E}$ found in nature, of which $\alpha$-tocopherol has the greatest biological activity and is the main form of vitamin $\mathrm{E}$ found in blood and tissues of animals (Wolf, 2006). Unlike the other vitamins, chemically synthesized $\alpha$-tocopherol (all-rac- $\alpha$ tocopherol) is not biochemically equivalent to the natural form (RRR- $\alpha$-tocopherol) due to the presence of eight different stereoisomers (RRR-, RRS-, RSR-, RSS-, SRR-, SRS-, SSRSSS-) with RRR- accounting for I2.5\% of the total mixture (Weiser and Vecchi, I98I).

Interestingly, no consensus has been reached on determining an equivalence ratio between the two vitamin E sources (RRR- vs all-rac- $\alpha$-tocopherol). The United States Pharmacopeia (USP, I979) adopted the official biopotency factors of I.oo for all-rac- $\alpha$-tocopheryl acetate and I.36 for RRR- $\alpha$-tocopheryl acetate. These values were based on results from a rat resorption-gestation test which were first published by Harris and Ludwig (I949) and were later supported by data using a similar model on the relative biopotency (i.e. capacity of a chemical substance to function in a biological system) of each $\alpha$-tocopherol stereoisomer (Weiser and Vecchi, 1982). However, controversy arose after human and animal studies in which deuterium-labeled forms of RRR- and all-rac- $\alpha$-tocopheryl acetate were used, found that a ratio 2.00:I.oo (RRR-:all-rac- $\alpha$-tocopheryl acetate) would better explain the biopotency differences between the two sources (Jensen and Lauridsen, 2007).

In many ruminant production systems, animals are kept indoors and fed ensiled forages and concentrates as an alternative to grazing. However, there is compelling evidence that animals allowed to graze present higher levels of $\alpha$-tocopherol in the tissues (more specifically in muscle) than those fed preserved forages and concentrates (Lanari et al., 2002; Realini et al., 2004; Ripoll et al., 2013; Turner et al., 2002). One could argue that the lower vitamin $\mathrm{E}$ status found in animals kept indoors can be tackled with vitamin $\mathrm{E}$ supplementation. However, the most commonly used source of $\alpha$-tocopherol in animal diets is all-rac- $\alpha$-tocopheryl acetate, which is different from the RRR- $\alpha$-tocopherol found in pasture and may explain to some extent the lower $\alpha$-tocopherol levels in tissues of animals kept indoors.

\section{MATERIALS AND METHODS}

\section{Animals and Diets}

The animal management, care, feeding and performance have been previously reported in a study that discussed the effect of vitamin E dosage and source on meat quality parameters in lambs (Leal et al., 20I8). Briefly, three hundred and sixty weaned Rasa Aragonesa breed lambs (males and females) with an average body weight of $22.3 \pm$ I.I8 kg purchased from 
local dealers were housed at a commercial farm (Franco and Navarro, Zaragoza, Spain). Two batches of 180 animals were used for the experiment. At arrival, lambs were weighed and brought into $20 \mathrm{~m} 2$ straw pens, blocked according to sex and batch of arrival following a randomized complete block design, with four blocks of nine pens each (with Io lambs per pen). Within each block, pens were randomly assigned to one of nine experimental diets. All experimental diets were formulated to be adequate in protein, energy, vitamins, and minerals for this type of animal. Despite the native $\alpha$-tocopherol present in the basal diet, an extra $0.025 \mathrm{~g} \mathrm{~kg}^{-1}$ feed of all-rac- $\alpha$-tocopheryl acetate was included in all experimental diets as part of the mixture of vitamins and minerals. In addition, increasing amounts of $\alpha$-tocopherol were added to the diets; $0.25,0.5$, I.o and $2.0 \mathrm{~g} \mathrm{~kg}^{-1}$ feed added as all-rac- $\alpha$ tocopheryl acetate or $0.125,0.25,0.5$ and I.O $\mathrm{g} \mathrm{kg}^{-1}$ feed added as RRR- $\alpha$-tocopheryl acetate. Diets were pelleted at $2.5 \mathrm{~mm}$ diameter. Supplemental Vitamin E (all-rac- and RRR- $\alpha$ tocopheryl acetate) sourced from Trouw Nutrition Netherlands (Putten, The Netherlands). Ingredients and chemical composition of the experimental diets are shown in Table 2.I. For a period of $\mathrm{I} 4 \mathrm{~d}$ after arrival, the lambs had free access to the experimental diets, wheat straw and water via separated troughs available in each pen. Lambs were weighted individually at the beginning of the experiment and before slaughter ( $\mathrm{I} 4 \mathrm{~d}$ after) to determine body weight and average daily gain. Intakes of the experimental diets were recorded weekly per

Table 2.I Composition of the basal diet and analysed $\alpha$-tocopherol content in the experimental lamb diets.

\begin{tabular}{|c|c|c|c|}
\hline \multicolumn{2}{|l|}{ Ingredients, $\mathrm{g} \mathrm{kg}^{-1}$} & \multicolumn{2}{|l|}{$\alpha$-Tocopherol content, $\mathrm{g} \mathrm{kg}^{-1}$} \\
\hline Wheat & 300 & Basal diet & 0.040 \\
\hline Barley & 260 & All-rac- $\alpha$-tocopheryl acetate & \\
\hline $\begin{array}{l}\text { Soya bean meal ( } 480 \mathrm{~g} \mathrm{~kg}^{-1} \text { of crude } \\
\text { protein) }\end{array}$ & 220 & 0.25 & 0.287 \\
\hline Maize & I50 & 0.50 & 0.549 \\
\hline Soya oil & 20 & I.O & I.083 \\
\hline Limestone & 27 & 2.0 & 2.343 \\
\hline Sodium bicarbonate & 6 & RRR- $\alpha$-tocopheryl acetate & \\
\hline Sodium chloride & 4 & 0.125 & 0.148 \\
\hline $\begin{array}{l}\text { Standard mineral and vitamin } \\
\text { premix* }^{*}\end{array}$ & 3 & 0.25 & 0.353 \\
\hline \multirow[t]{2}{*}{ Vitamin E premix } & IO & 0.50 & 0.584 \\
\hline & & I.O & I.I76 \\
\hline
\end{tabular}

* Mineral and vitamins provided: Ca 0.24 g, Na o.47 g, S o.34 g, Mn 62 mg, Zn IIo mg, Cu 5 $\mathrm{mg}$, I $0.6 \mathrm{mg}$, Co $0.3 \mathrm{mg}$, Se o.I mg, Fe $20 \mathrm{mg}$, vitamin A 8000 IU, vitamin D3 I60o IU, allrac- $\alpha$-tocopheryl acetate $25 \mathrm{mg}$. all-rac- $\alpha$-tocopheryl acetate $=$ synthetic vitamin E. RRR- $\alpha$ tocopheryl acetate $=$ natural vitamin $\mathrm{E}$. 
pen and orts measured at the end of the experiment. Intake of wheat straw and water were not registered.

\section{Sample Collection}

Animals were slaughtered at a local slaughterhouse (Mercazaragoza S.A., Zaragoza, Spain) within 2 hours after leaving the farm. Dissection took place within $30 \mathrm{~min}$ after slaughter and liver, heart, spleen and muscle (longissimus throracis et lumborum) samples were collected from 3 animals randomly selected from each pen, vacuum packed and frozen at $-20^{\circ} \mathrm{C}$ until analysed for $\alpha$-tocopherol concentration and stereoisomer distribution.

\section{Tocopherol Analysis}

Tocopherols were determined by high-pressure liquid chromatography (HPLC) after saponification and extraction into heptane according to Jensen et al. (1999) as follows. In the clean-up procedure, $2.0 \mathrm{~g}$ dry feed sample was mixed with $70 \mathrm{ml}$ of $96 \% \mathrm{v} / \mathrm{v}$ ethanol, $30 \mathrm{ml}$ methanol (Peter Mark, C 2517), $30 \mathrm{ml}$ ascorbic acid (Merck, 5.00074.1000) and $20 \mathrm{ml}$ $\mathrm{KOH}$-water I:I (w/v) (B\&B, 5268I20). The mixture was saponified for $30 \mathrm{~min}$ at $80^{\circ} \mathrm{C}$ in the dark and cooled in cold water. Exactly $2 \mathrm{ml}$ of the saponified mixture were diluted with I $\mathrm{ml}$ distilled water, after which tocopherols were quantitatively extracted with $2 \times 5 \mathrm{ml}$ heptane (Peter Mark, C 25I4) and centrifuged at $1500 \mathrm{~g}$ for Io min between each extraction (Leal et al., 20I8). From the combined heptane extract, Ioo $\mu \mathrm{l}$ was injected into the HPLC. Tissues were homogenized in twice the amount of ethanol by an Ultra-Turrax homogenizer (IKAWerke GmbH, Staufen, Germany), while being kept on ice. Aliquots of the homogenates were saponified in a mixture of ethanol, methanol, ascorbic acid ( $20 \% \mathrm{w} / \mathrm{v})$ and $\mathrm{KOH}$-water I:I $(w / v)(B \& B, 5268120)$ at $80^{\circ} \mathrm{C}$ for $20 \mathrm{~min}$, after cooling in the dark, the samples were extracted with two portions of $5 \mathrm{ml}$ heptane after which IOo $\mu$ l was injected into the HPLC. The HPLC column for determination of total tocopherols consisted of a IOO $\times 4.6 \mathrm{~mm}$ Brownlee Spheri-5 Silica $5 \mu \mathrm{m}$ column (Perkin-Elmer GmbH, D-7770 Überlingen, Germany). The mobile phase was heptane containing 2-propanol (3.0 $\left.\mathrm{ml} \mathrm{l}^{-1}\right)$ and degassed

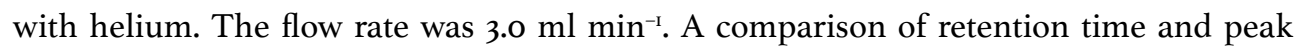
areas with Merck (D-6Ioo Damstadt, Germany) external standards of RRR- $\alpha$-tocopherol and all-rac- $\alpha$-tocopherol were used to obtain the identification and quantification of the tocopherols. Fluorescence detection was performed with an excitation wavelength of 290 $\mathrm{nm}$ and an emission wavelength of $327 \mathrm{~nm}$ (Leal et al., 20I8). The HPLC system was a Perkin Elmer, Series 200.

Stereoisomers of $\alpha$-tocopherol were analysed by HPLC as follows. The remaining heptane extract was evaporated to exact dryness under a stream of nitrogen at $45^{\circ} \mathrm{C}$. Then the $\alpha$-tocopherol was derivatized to its methyl ether based on the method described by Drotleff and Ternes (200I) and described in detail by Jensen and Lauridsen (2007). The methyl ether derivative was extracted with $\mathrm{I} .5 \mathrm{ml}$ heptane, of which Ioo $\mu \mathrm{L}$ was injected into the HPLC. Chromatographic separation was achieved on a Chiralcel OD-H column $(250 \times 4.6$ 
$\mathrm{mm}, 5 \mu \mathrm{m}$ particle size, cellulose tris (3,5-dimethylphenylcarbamate) from Daicel Chemical industries, Ltd. (Tokyo, I0o-6077, Japan) with heptane as eluent.

The method allowed the quantification of total tocopherol content and composition by normal phase HPLC after saponification and extraction into heptane with subsequent separation of the stereoisomers of $\alpha$-tocopherol as methyl ethers by chiral HPLC. By this method, the $\alpha$-tocopherol stereoisomers were separated into five peaks. The first peak consists of the sum of four $\Sigma_{2}$ S configured isomers (SSS-, SSR-, SRR-, SRS-), the second peak consisted of RSS-, the third peak consisted of RRS-, the fourth peak consisted of RRRand the fifth peak consisted of RSR- $\alpha$-tocopherol.

\section{Statistical and Mathematical Calculations}

All statistical analyses were performed using SAS, version 9.3 (SAS Institute, Inc., Cary, NC, USA). Pen was the experimental unit, and individual measurements were averaged per pen.

Total tocopherol content in the tissues and stereoisomer distribution were subjected to ANOVA analysis (PROC MIXED procedure, SAS Inst. Inc., Cary, NC, USA). The model included the fixed effects of the block, vitamin E source, dose and interaction of vitamin E source and dose. Orthogonal-polynomial contrasts were used to determine linear and quadratic effects of increasing vitamin $\mathrm{E}$ dosages on $\alpha$-tocopherol deposition in tissues. The statistical significance level was claimed at $\mathrm{P}<0.05$ and all the values are reported as least square means.

In addition, a non-linear regression procedure (PROC NLIN procedure, SAS Inst. Inc., Cary, NC, USA) was also used to describe the effect of the dietary vitamin E supplementation on $\alpha$-tocopherol concentrations in the selected tissues. An exponential response was calculated using the equation proposed by López-Bote et al. (200I): $y=a+b\left(I-e^{-c x}\right)$, where $\mathrm{y}=$ dependent variable; $\mathrm{a}=$ intercept $\mathrm{a}+\mathrm{b}=$ asymptote; $\mathrm{c}=$ curvature steepness and $\mathrm{x}=$ independent variable.

For the non-linear regression procedure, the supplemental $\alpha$-tocopherol was calculated based on the analytical values (Table 2.I) to represent the level of $\alpha$-tocopherol supplemented above the content in the basal diet. This was achieved by subtracting the basal dietary levels found in the different treatments from the total analysed $\alpha$-tocopherol. Therefore, the $\alpha$-tocopherol contents used for the statistical analysis were $0.108,0.313,0.544$ and $1.136 \mathrm{~g} \mathrm{~kg}^{-1}$ of compound feed for the RRR- $\alpha$ - tocopheryl acetate groups and 0.247, 0.509, I.043 and 2.303 $\mathrm{g} \mathrm{kg}^{-1}$ compound feed for the all-rac- $\alpha$-tocopheryl acetate (Leal et al., 20I8).

\section{RESULTS}

\section{Animal Performance}

Overall least square means and standard error of the means for body weight, average daily weight gain, feed intake and feed efficiency are presented by Leal et al. (2018). Neither 
dietary $\alpha$-tocopherol supplementation level, nor source had an effect $(\mathrm{P}>0.05)$ on the aforementioned parameters.

\section{$\alpha$-Tocopherol Concentration in Tissues}

The highest $\alpha$-tocopherol concentration per unit wet tissue, after the I $4 \mathrm{~d}$ supplementation period, was found in liver followed by spleen, heart and muscle (Figure 2.I). Alphatocopherol concentration in all tissues increased with the increasing dietary level of both $\alpha$-tocopherol sources $(\mathrm{P}<\mathrm{O}$.ooI).
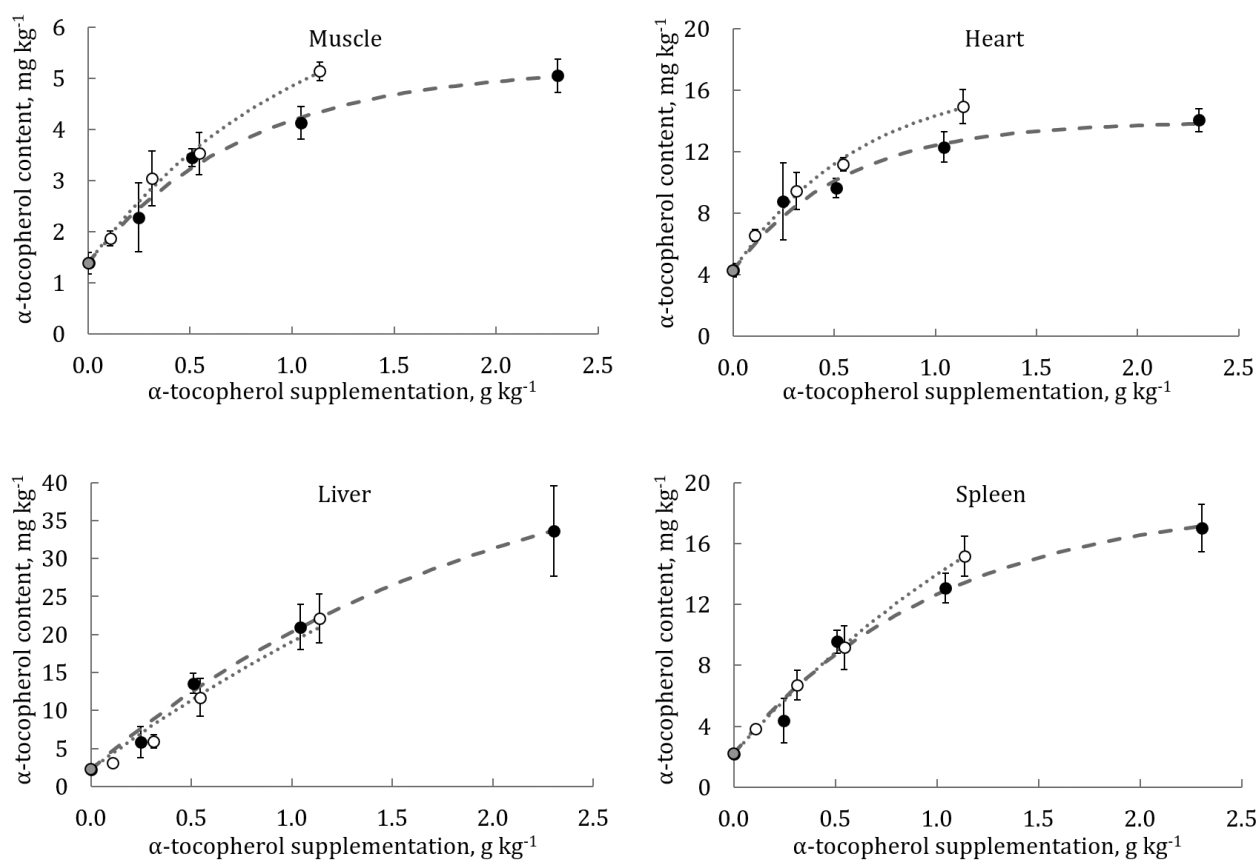

- All-rac- least square means

O RRR- least square means

- - All-rac- regression RRR- regression

Figure 2.I Effect of dietary all-rac- $\alpha$-tocopheryl acetate (synthetic vitamin E) or RRR- $\alpha$ tocopheryl acetate (natural vitamin E) supplementation on $\alpha$-tocopherol concentrations in lamb tissues. The data, per tissue and vitamin E source, were fitted to the following exponential equation: tissue $\alpha$-tocopherol concentration $\left(\mathrm{mg} \mathrm{kg}^{-1}\right.$ of tissue $)=a+b\left(\mathrm{I}-\mathrm{e}^{\mathrm{cX}}\right)$, where $\mathrm{a}=$ common intercept for both vitamin $\mathrm{E}$ sources; $\mathrm{b}$ and $\mathrm{c}=$ regression coefficients; $\mathrm{x}=$ dietary vitamin $\mathrm{E}$ concentration $\left(\mathrm{g} \mathrm{kg}^{-1}\right.$ of feed). The regression coefficients for the nonlinear model are given in Supplementary materials (Table S2.I). 
In muscle, RRR- $\alpha$-tocopheryl acetate supplementation led to a linear increase in $\alpha$-tocopherol (linear effect, $\mathrm{P}<\mathrm{O} .00 \mathrm{I}$; quadratic effect, $\mathrm{P}=0 . \mathrm{I} 83$ ), whereas the effect of allrac- $\alpha$-tocopheryl acetate supplementation on $\alpha$-tocopherol content in muscle was found to be quadratic (linear effect, $\mathrm{P}<\mathrm{O}$. ooI; quadratic effect, $\mathrm{P}=\mathrm{O}$.oII). In the heart, however, increasing dietary inclusion of both $\alpha$-tocopherol sources led to a quadratic increase in $\alpha$-tocopherol content in the tissue (linear effect, $\mathrm{P}<0.00$; quadratic effect, $\mathrm{P}<0.05$ ). At similar supplementation levels $\left(0.25,0.50\right.$ and $\left.1.0 \mathrm{~g} \mathrm{~kg}^{-1}\right), \alpha$-tocopherol content in muscle and heart was not affected by $\alpha$-tocopherol source $(\mathrm{P}>0.05)$. However, the ratio between RRR- and allrac- $\alpha$-tocopherol increased in muscle from I.06 at $0.25 \mathrm{~g} \mathrm{~kg}^{-1}$ feed to I.IO and I.I6 at 0.50 and I.O $\mathrm{g} \mathrm{kg}^{-1}$ feed. Similarly, in the heart, the ratio between the two sources increased from I.07 at $0.25 \mathrm{~g} \mathrm{~kg}^{-1}$ feed to I.II at $0.50 \mathrm{~g} \mathrm{~kg}^{-1}$ feed and to I.I5 at I.0 $\mathrm{g} \mathrm{kg}^{-1}$ feed. Supplementation of I.O $\mathrm{g} \mathrm{kg}^{-1}$ of RRR- $\alpha$-tocopheryl acetate or $2.0 \mathrm{~g} \mathrm{~kg}^{-1}$ of all-rac- $\alpha$-tocopheryl acetate was found to yield the highest $\alpha$-tocopherol concentrations in both tissues $(\mathrm{P}<0.05)$ (Figure 2.I).

In liver, supplementation of both sources (RRR- or all-rac- $\alpha$-tocopheryl acetate) induced a linear increase in $\alpha$-tocopherol content (linear effect, $\mathrm{P}<0.00 I$; quadratic effect, $\mathrm{P}>0.05$ ). Similar to muscle and heart, at similar dosages $\left(0.25,0.50\right.$ and I.0 $\left.\mathrm{g} \mathrm{kg}^{-1}\right)$, no differences were found between the two $\alpha$-tocopherol sources $(\mathrm{P}>0.05)$. Despite that, the ratio between the two forms of $\alpha$-tocopherol increased from 0.91 at $0.25 \mathrm{~g} \mathrm{~kg}^{-1}$ feed to 0.94 at $1.0 \mathrm{~g} \mathrm{~kg}^{-1}$ feed. Moreover, supplementation of $2.0 \mathrm{~g} \mathrm{~kg}^{-1}$ of all-rac- $\alpha$-tocopheryl acetate led to a 1.52 fold increase in total $\alpha$-tocopherol concentration in liver $(\mathrm{P}<0.05)$, when compared with I.o $\mathrm{g}$ $\mathrm{kg}^{-1}$ of RRR- $\alpha$-tocopheryl acetate (33.6 $\mathrm{mg} \mathrm{kg}^{-1}$ and $22.1 \mathrm{mg} \mathrm{kg}^{-1}$, respectively) (Figure 2.I). Spleen tissue showed a similar pattern to that observed for muscle, in that the lambs fed $R R R$ - $\alpha$-tocopheryl acetate showed a linear increase in $\alpha$-tocopherol content (linear effect, $\mathrm{P}<\mathrm{O}$.ooI; quadratic effect, $\mathrm{P}=\mathrm{O} .4 \mathrm{O}$ ), whereas, increasing supplementation levels with all-rac$\alpha$-tocopheryl acetate led to a quadratic increase of total $\alpha$-tocopherol content in this organ (linear effect, $\mathrm{P}<\mathrm{O} . \mathrm{ooI}$; quadratic effect, $\mathrm{P}=\mathrm{O} .003$ ). At similar levels of supplementation $\left(0.25,0.50\right.$ and I.o $\left.\mathrm{g} \mathrm{kg}^{-1}\right)$, no differences were found between the two $\alpha$-tocopherol sources. Notwithstanding, the ratio between RRR- and all-rac- $\alpha$-tocopherol increased in spleen from 0.98 at $0.25 \mathrm{~g} \mathrm{~kg}^{-1}$ feed to 1.02 at $0.5 \mathrm{~g} \mathrm{~kg}^{-1}$ feed and to I.IO at I.O $\mathrm{g} \mathrm{kg}^{-1}$ feed.

\section{Distributions of $\alpha$-Tocopherol Stereoisomers in Tissues}

The relative and absolute distributions of $\alpha$-tocopherol stereoisomers in muscle, heart, liver and spleen from lambs fed either RRR- or all-rac- $\alpha$-tocopheryl acetate are described in Figure 2.2 to 2.5 . 

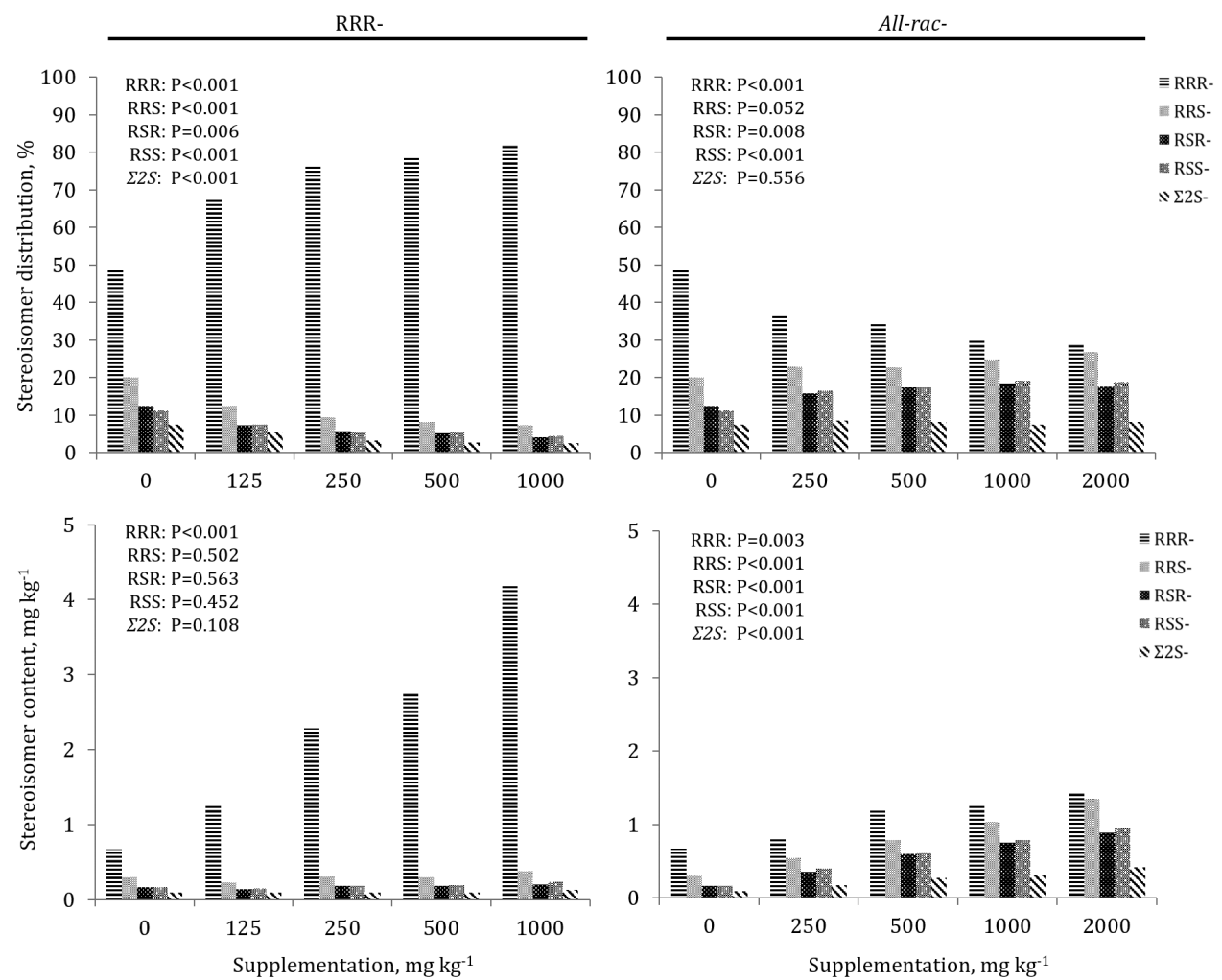

Figure 2.2 Relative and absolute proportion of $\alpha$-tocopherol stereoisomers (RRR, RRS, RSR, RSS and $\sum 2 S=$ SSS + SSR + SRS + SRR) in muscle of lambs supplemented with $\mathrm{RRR}-\alpha$-tocopheryl acetate (natural vitamin $\mathrm{E}$ ) or all-rac- $\alpha$-tocopheryl acetate (synthetic vitamin E). 

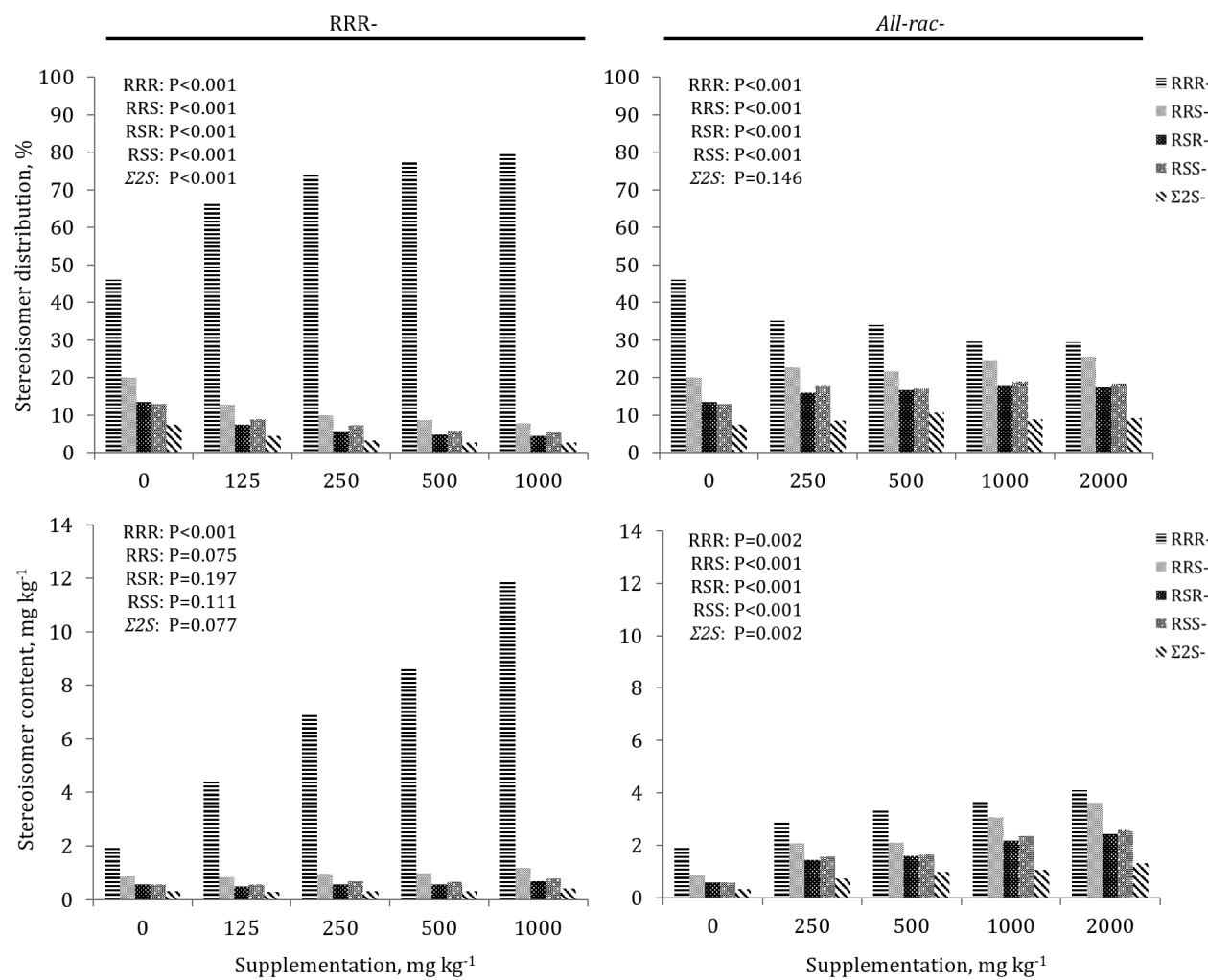

Figure 2.3 Relative and absolute proportion of $\alpha$-tocopherol stereoisomers (RRR, RRS, RSR, RSS and $\sum 2 S=$ SSS + SSR + SRS + SRR) in heart of lambs supplemented with RRR- $\alpha$-tocopheryl acetate (natural vitamin E) or all-rac- $\alpha$-tocopheryl acetate (synthetic vitamin E). 

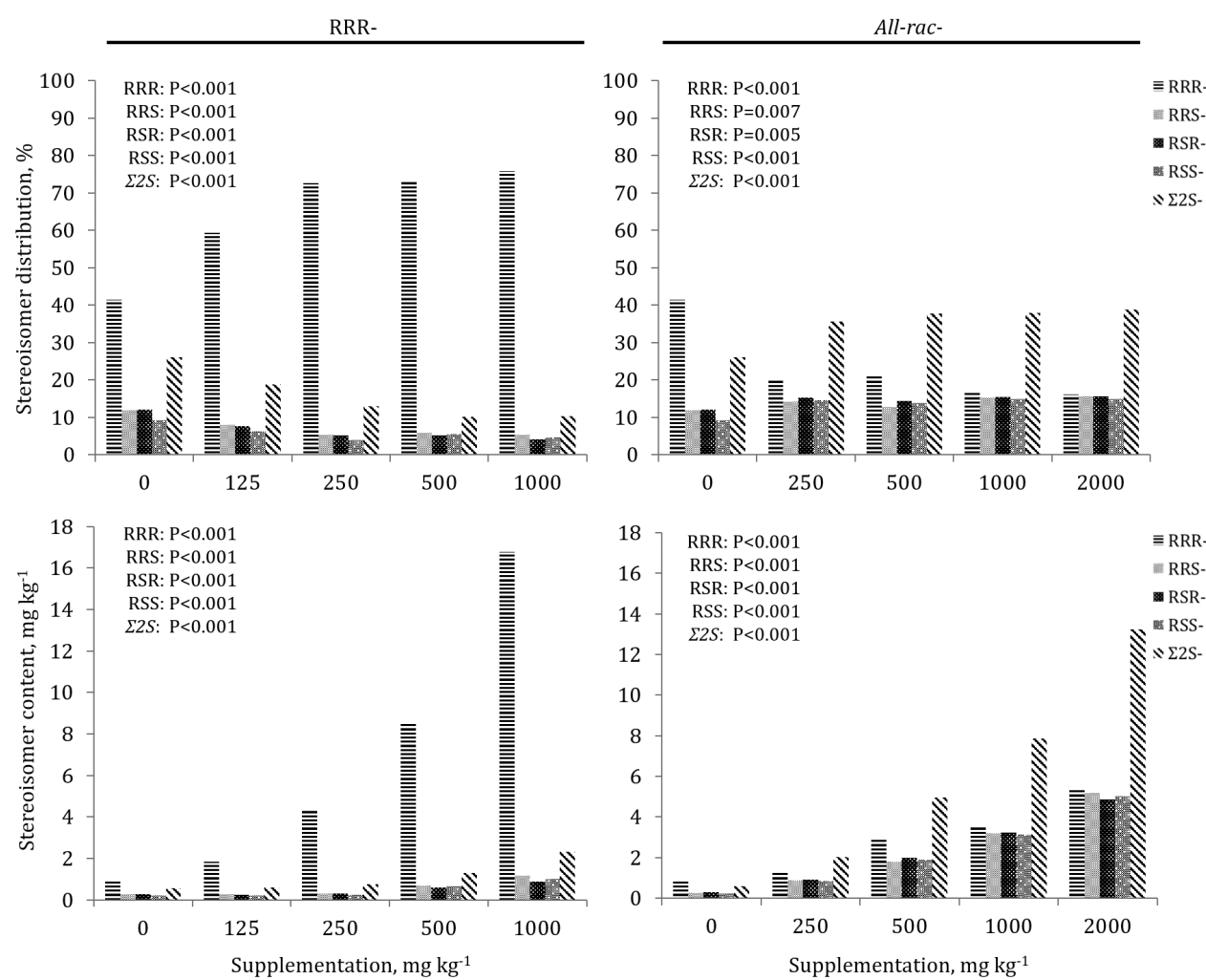

Figure 2.4 Relative and absolute proportion of $\alpha$-tocopherol stereoisomers (RRR, RRS, RSR, RSS and $\sum 2 S$ = SSS + SSR + SRS + SRR) in liver of lambs supplemented with $\mathrm{RRR}-\alpha$-tocopheryl acetate (natural vitamin $\mathrm{E}$ ) or all-rac- $\alpha$-tocopheryl acetate (synthetic vitamin E). 

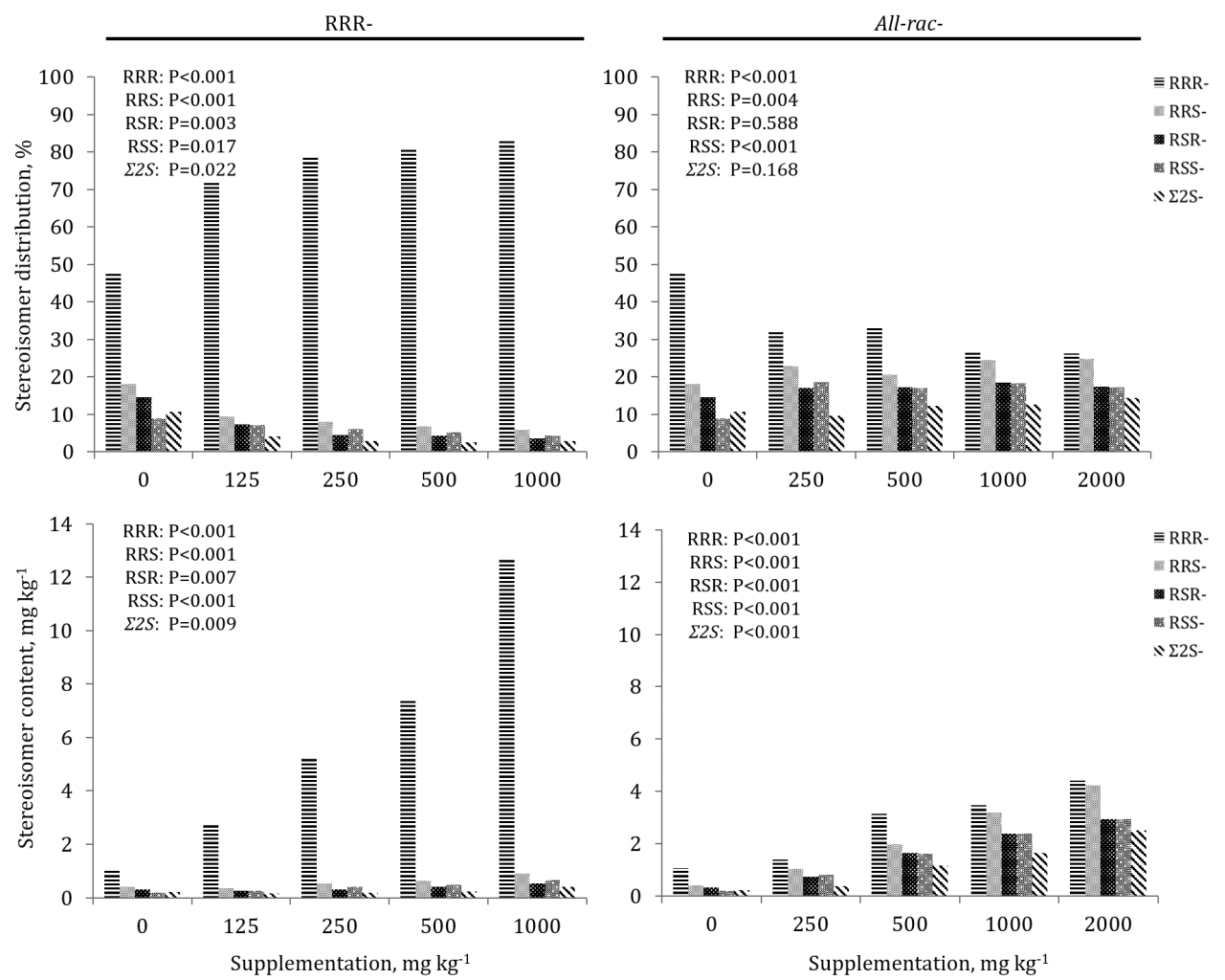

Figure 2.5 Relative and absolute proportion of $\alpha$-tocopherol stereoisomers (RRR, RRS, RSR, RSS and $\sum 2 S=$ SSS + SSR + SRS + SRR) in spleen of lambs supplemented with $\mathrm{RRR}-\alpha$-tocopheryl acetate (natural vitamin $\mathrm{E}$ ) or all-rac- $\alpha$-tocopheryl acetate (synthetic vitamin E).

With increasing dietary content of dietay RRR- $\alpha$-tocopheryl acetate, the relative proportion of RRR- $\alpha$-tocopherol increased in all tissues $(\mathrm{P}<\mathrm{O} .00 \mathrm{I})$. The increase in the relative proportion of RRR- $\alpha$-tocopherol stereoisomer led to a reduction in the proportion of the remaining stereoisomers ( $\mathrm{P}<\mathrm{O}$.OI). However, the relative reduction in the RRS-, RSR-, RSS-, and $\sum 2$ S- (sum of SSS-, SSR-, SRS- and SRR- $\alpha$-tocopherol) stereoisomers had no effect on their absolute concentration in muscle (Figure 2.2) and heart (Figure 2.3) $(\mathrm{P}>0.05)$. In liver (Figure 2.4) and spleen (Figure 2.5), however, it was found when RRR- $\alpha$-tocopheryl acetate concentration increased in the diets, the absolute concentration of all stereoisomers also increased $(\mathrm{P}<\mathrm{O} . \mathrm{OI})$.

When lambs were fed increasing levels of all-rac- $\alpha$-tocopheryl acetate, the relative distribution of RRR- $\alpha$-tocopherol was reduced in all tissues $(\mathrm{P}<\mathrm{O}$.oI). In muscle and heart, the reduction in the relative proportion of $R R R-\alpha$-tocopherol was followed by a significant increase in the relative proportions of RRS-, RSR-, and RSS-stereoisomers $(\mathrm{P}<\mathrm{O} . \mathrm{OI})$. 
Whereas, the relative proportion of $\sum 2 \mathrm{~S}$ stereoisomers was unaffected $(\mathrm{P}>0.05)$ (Figure 2.22.3). Despite all the changes in the relative stereoisomer distribution in muscle and heart, RRR- $\alpha$-tocopherol was the most abundant stereoisomer ( $\mathrm{mg} \mathrm{kg}^{-1}$ tissue) followed by RRS-, RSS-, RSR- and $\sum 2 \mathrm{~S}-\alpha$-tocopherol $(\mathrm{P}<\mathrm{O}$.oI).

In liver, with the increase in all-rac- $\alpha$-tocopheryl acetate supplementation, the relative proportion of $\sum 2 \mathrm{~S}$-stereoisomers increased from $26.0 \%$ in the non-supplemented lambs to $38.8 \%$ in the group supplemented with $2.0 \mathrm{~g} \mathrm{~kg}^{-1}$ feed ( $\left.\mathrm{P}<\mathrm{O} .00 \mathrm{I}\right)$ (Figure 2.4). The increase in the relative proportion of $\sum 2 \mathrm{~S}$-stereoisomers was associated with a concomitant reduction in the relative proportion of the RRR-stereoisomer $(\mathrm{P}<\mathrm{O} .00 \mathrm{I})$, from $4 \mathrm{I} .5 \%$ in the nonsupplemented lambs to I6.I\% in lambs supplemented with $2.0 \mathrm{~g} \mathrm{~kg}^{-1}$ feed. Although the absolute concentration ( $\mathrm{mg} \mathrm{kg}^{-1}$ tissue) of all stereoisomers in liver increased with all-rac$\alpha$-tocopheryl acetate supplementation $\left(\mathrm{P}<\mathrm{O}\right.$.ooI), the $\sum 2 \mathrm{~S}$-stereoisomers were the most abundant followed by RRR-, RRS-, RSS- and RSR- $\alpha$-tocopherol.

The relative and absolute contents of each stereoisomer in spleen are presented in Figure 2.5. Similar to the other tissues, feeding all-rac- $\alpha$-tocopheryl acetate to the lambs caused a decrease in the relative proportion of $\mathrm{RRR}-\alpha$-tocopherol in spleen tissue $(\mathrm{P}<\mathrm{O} . \mathrm{ooI})$. The decrease in the proportion of RRR- $\alpha$-tocopherol was accompanied by an increase in the proportion of RRS- $(\mathrm{P}=0.004)$ and RSS- $(\mathrm{P}<\mathrm{O} .00 \mathrm{I})$ stereoisomers, while no change in relative distribution was found for RSR- $(\mathrm{P}=0.588)$ and $\sum 2 \mathrm{~S}-(\mathrm{P}=0.168)$ stereoisomers. Despite all the changes in the relative stereoisomer distribution in spleen, RRR- $\alpha$-tocopherol was the most abundant stereoisomer (mg kg-1 tissue) followed by RRS-, RSS-, RSR- and $\sum 2 \mathrm{~S}-\alpha-$ tocopherol $(\mathrm{P}<\mathrm{O} . \mathrm{OI})$.

\section{DISCUSSION}

As previously reported by Leal et al. (2018), neither dietary vitamin E supplementation level, nor source had an effect on average daily weight gain, feed intake and feed efficiency in light weight lambs. This is in agreement with early findings in lambs (De la Fuente et al., 2007; López-Bote et al., 200I; Turner et al., 2002) and beef (Arnold et al., 1992; Lee et al., 2008; Nassu et al., 2OII), in which vitamin E supplementation had no effect on growth, feed intake nor efficiency.

Four different doses of RRR- $\alpha$-tocopheryl acetate and all-rac- $\alpha$-tocopheryl acetate were compared in this study, and as seen from Figure 2.I, tissue $\alpha$-tocopherol concentration responded in a curvilinear increase with the increasing dietary level of either $\alpha$-tocopherol source. Moreover, present data demonstrates that various tissues respond differently to increases of dietary supplementation of RRR- and all-rac- $\alpha$-tocopheryl acetate. The tissue with the highest $\alpha$-tocopherol concentration was the liver followed by spleen, heart and muscle. In line with our findings, Hidiroglou (1987) reported in sheep that after a single oral dose of o.I $\mathrm{g} \mathrm{kg}^{-1}$ of body weight with RRR- $\alpha$-tocopherol acetate, the highest $\alpha$-tocopherol concentration in tissue followed the order liver, spleen, heart and muscle. Moreover, when feeding IOoo IU $\mathrm{d}^{-1}$ of different $\alpha$-tocopherol preparations to sheep for $56 \mathrm{~d}$, Ochoa et al. 
(I992) reported consistently higher $\alpha$-tocopherol concentrations in liver when compared with heart and muscle tissues. Conversely, Jensen et al. (2006) when studying the effect of different dietary doses of RRR- and all-rac- $\alpha$-tocopheryl acetate in rats found higher $\alpha$-tocopherol content in the spleen than in the liver. As indicated by the lack of response to incremental doses of RRR- $\alpha$-tocopheryl acetate in that study, the authors argued that $\alpha$-tocopherol content in spleen at the start of the study could be already close to a "plateau" or tissue saturation.

As initially postulated by Blatt et al. (2004) and later supported by the findings of Jensen et al. (2006), the relative bioavailability of RRR- and all-rac- $\alpha$ tocopherols varies between tissues, time after dosing, duration of dosing and the amount of each dose. All these factors combined led both authors to conclude that RRR- and all-rac- $\alpha$-tocopherols are not equivalent in any dose ratio. Accordingly, at similar levels of supplementation (0.25, 0.50 and $\mathrm{I} .0 \mathrm{~g} \mathrm{~kg}^{-1}$ ), the ratio between $\alpha$-tocopherol measured in the selected tissues of lambs fed RRR- and all-rac- $\alpha$-tocopheryl acetate increased with increasing dietary vitamin E supplementation. Moreover, in the current study dietary RRR- $\alpha$-tocopheryl acetate led to a linear increase in $\alpha$-tocopherol concentration in liver, spleen and muscle. Whereas, increasing supplementation levels with all-rac- $\alpha$-tocopheryl acetate led to a linear increase of $\alpha$-tocopherol content only in liver. A linear $(\mathrm{P}<0.05)$ and quadratic $(\mathrm{P}<0.05)$ effect of dietary $\alpha$-tocopherol supplementation was observed in heart from RRR- fed lambs and in muscle, heart and spleen from all-rac- $\alpha$-tocopheryl acetate supplemented lambs. The linear plus quadratic response pattern suggested an exponential response, which was fitted as indicated in Figure 2.I. In an exponential response curve, the asymptote $(a+b)$ indicates the upper limit or "plateau" in tissue $\alpha$-tocopherol concentration that can be reached. Therefore, lambs fed increasing amounts of all-rac- $\alpha$-tocopheryl acetate reached a "plateau" for $\alpha$-tocopherol deposition in muscle and spleen. Whereas, no "plateau" was reached in muscle and spleen from lambs fed increasing amounts of RRR- $\alpha$-tocopheryl acetate (linear effect). The non-parallel dose-concentration curves in the aforementioned tissues indicates that the relative bioavailability of RRR- and all-rac- $\alpha$-tcopheryl acetate is not constant (dose and tissue dependent) (Blatt et al., 2004). As tissue $\alpha$-tocopherol concentrations approach the "plateau", only a marginal increase in $\alpha$-tocopherol deposition will be attained at higher supplementation levels. Thus, explaining the different ratios found in literature to discriminate between these two $\alpha$-tocopherol sources.

The biological value of different $\alpha$-tocopherol sources is influenced by a multitude of factors, such as absorption, transport, distribution, and metabolism (Bramley et al., 200o). All forms of $\alpha$-tocopherol are taken up to a similar extent, in an unspecific process that includes emulsification by biliary and pancreatic secretions together with other lipids in the diet (Clifford et al., 2006; Traber, 1996). From the intestine, $\alpha$-tocopherol stereoisomers are transported in chylomicrons and subsequently in remnants to the liver (BrigeliusFlohé et al., 2002). Once in the liver, the cytosolic $\alpha$-tocopherol transfer protein ( $\alpha$-TTP) 
selectively sorts out the $\alpha$-tocopherol stereoisomers before their incorporation into very low-density lipoproteins, which are then released into the circulation (Traber et al., 1990). From the eight stereoisomers (RRR-, RRS-, RSR-, RSS-, SRR-, SRS-, SSR-, and SSS-) found in all-rac- $\alpha$-tocopherol, the $2 \mathrm{R}$ configured stereoisomers (RRR-, RRS-, RSR-, and RSS-) when compared with the 2 S configured stereoisomers (SRR-, SRS-, SSR-, and SSS-) are preferentially retained in all tissues except in the liver (Burton et al., I998; Ingold et al., 1987). Accordingly, the highest relative proportion and tissue concentration of $2 \mathrm{~S}$ configured stereoisomers was found in the liver of lambs supplemented with all-rac$\alpha$-tocopheryl acetate; accounting with up to $35-39 \%$ of the total $\alpha$-tocopherol retained; whereas the proportion of $2 \mathrm{~S}$ configured stereoisomers in the other tissues accounted for less than $14 \%$ of the total (Figure 2.2-2.5). The fate of the $2 \mathrm{~S}$ configured stereoisomers retained in the liver is still unclear. However, it seems that $2 \mathrm{~S}$ configured stereoisomers are recognized as xenobiotic molecules and are, therefore, predominantly catabolized (Lauridsen et al., 2002; Traber et al., 20I7). On the other hand, the $2 \mathrm{R}$ configured isomers, and to a greater extent the RRR-stereoisomer, are recognized by $\alpha$-TTP and re-secreted from the liver back into the plasma (Brigelius-Flohé et al., 2002). Increasing all-rac- $\alpha$ tocopheryl acetate supplementation level in lamb diets, was also found to affect the $2 \mathrm{R}$ configured stereoisomer profile in muscle, heart and spleen; increasing the proportions of RRS-, RSR- and RSS- at the cost of RRR- $\alpha$-tocopherol. These findings indicates that at higher supplementation levels with all-rac- $\alpha$-tocopheryl acetate, the stereospecificity of $\alpha$-TTP favours $2 \mathrm{R}$ configurations other than only RRR- $\alpha$-tocopherol.

As expected, when lambs were supplemented with RRR- $\alpha$-tocopheryl acetate, the relative proportion of all stereoisomers other than RRR- $\alpha$-tocopherol, were reduced in all tissues analysed. It is noteworthy that, although the proportion of $2 \mathrm{~S}$ configured stereoisomers was reduced with the increase of dietary dose of RRR- $\alpha$-tocopheryl acetate in all tissues, the absolute content of $2 \mathrm{~S}$ configured stereoisomers were maintained in muscle and heart; and increased in liver and spleen. According to Jensen et al. (2006), this could mean that $2 \mathrm{~S}$ configured stereoisomers remained in the tissues for a longer period than the $2 \mathrm{R}$ configured stereoisomers, and only a small exchange in stereoisomers took place during the $\mathrm{I} 4 \mathrm{~d}$ of supplementation.

\section{CONCLUSIONS}

We found that the different tissues responded differently to the increased supplementations of dietary RRR- and all-rac- $\alpha$-tocopheryl acetate. Bioavailability of the $\alpha$-tocopherol stereoisomers in all tissues was affected by vitamin E source and dose. The non-parallel dose-concentration curves found in all tissues indicates that the relative bioavailability of RRR- and all-rac- $\alpha$-tocopheryl acetate is not constant and that a single ratio cannot accurately describe the nutritional difference between the two sources. Therefore, this study illustrates that the generally accepted equivalence value of I.36 is inadequate to describe $\alpha$-tocopherol deposition in ruminant tissues, at least specifically in intensively 
fed growing lambs. The biological implications of the very distinct tissue distribution of these vitamin $\mathrm{E}$ sources deserves further research.

\section{AKNOWLEDGEMENTS}

Preliminary results from the current study have been presented at the 20I7 EAAP meeting (Leal et al., 20I7). The authors would like to thank Franco \& Navarro S.A. (Zaragoza, Spain), Mercazaragoza S.A. (Zaragoza, Spain) and Alejandro Casanova Higes for their support in this study. 


\section{REFERENCES}

Arnold, R. N., K. K. Scheller, S. C. Arp, S. N. Williams, D. R. Buege, and D. M. Schaefer. 1992. Effect of long- or short-term feeding of alpha-tocopheryl acetate to Holstein and crossbred beef steers on performance, carcass characteristics, and beef color stability. Journal of Animal Science 70(IO):3055-3065.

Blatt, D. H., W. A. Pryor, J. E. Mata, and R. Rodriguez-Proteau. 2004. Re-evaluation of the relative potency of synthetic and natural alpha-tocopherol: experimental and clinical observations. The Journal of Nutritional Biochemistry I5(7):380-395.

Bramley, P. M., I. Elmadfa, A. Kafatos, F. J. Kelly, Y. Manios, H. E. Roxborough, W. Schuch, P. J. A. Sheehy, and K. H. Wagner. 200o. Vitamin E. Journal of the Science of Food and Agriculture 80(7):913-938.

Brigelius-Flohé, R., F. J. Kelly, J. T. Salonen, J. Neuzil, J. M. Zingg, and A. Azzi. 2002. The European perspective on vitamin E: current knowledge and future research. The American Journal of Clinical Nutrition 76(4):703-716.

Brigelius-Flohé, R., and M. G. Traber. 1999. Vitamin E: function and metabolism. FASEB Journal: Official Publication of the Federation of American Societies for Experimental Biology I3(IO):II45-II55.

Burton, G. W., M. G. Trabet, R. V. Acuff, D. N. Walters, H. Kayden, L. Hughes, and K. U. Ingold. 1998. Human plasma and tissue $\alpha$-tocopherol concentrations in response to supplementation with deuterated natural and synthetic vitamin E. American Journal of Clinical Nutrition 67(4):669-684.

Clifford, A. J., F. F. De Moura, C. C. Ho, J. C. Chuang, J. Follett, J. G. Fadel, and J. A. Novotny. 2006. A feasibility study quantifying in vivo human $\alpha$-tocopherol metabolism. American Journal of Clinical Nutrition 84(6):I430-I44I.

De la Fuente, J., M. T. Díaz, I. Álvarez, S. Lauzurica, V. Cañeque, and C. Pérez. 2007. Effect of dietary supplementation with vitamin $\mathrm{E}$ on characteristics of vacuum-packed lamb. Journal of the Science of Food and Agriculture 87(4):65I-659.

Drotleff, A. M., and W. Ternes. 200I. Determination of RS,E/Z-tocotrienols by HPLC. Journal of Chromatography. A 909(2):215-223.

Harris, P. L., and M. I. Ludwig. 1949. Relative vitamin E potency of natural and of synthetic alpha-tocopherol. The Journal of Biological Chemistry I79(3):IIII-III5.

Hidiroglou, M. 1987. Vitamin E levels in sheep tissues at various times after a single oral administration of d-alpha-tocopherol acetate. International Journal for Vitamin and Nutrition Research. Internationale Zeitschrift für Vitamin- und Ernahrungsforschung. Journal International de Vitaminologie et de Nutrition 57(4):38I-384.

Ingold, K. U., G. W. Burton, D. O. Foster, L. Hughes, D. A. Lindsay, and A. Webb. 1987. Biokinetics of and discrimination between dietary RRR- and SRR- $\alpha$-tocopherols in the male rat. Lipids 22(3):I63-I72. 
Jensen, S. K., R. M. Engberg, and M. S. Hedemann. 1999. All-rac-alpha-tocopherol acetate is a better vitamin E source than all-rac-alpha-tocopherol succinate for broilers. The Journal of Nutrition I29(7):1355-1360.

Jensen, S. K., and C. Lauridsen. 2007. Alpha-tocopherol stereoisomers. Vitamins and Hormones 76:28I-308.

Jensen, S. K., J. V. Norgaard, and C. Lauridsen. 2006. Bioavailability of alpha-tocopherol stereoisomers in rats depends on dietary doses of all-rac- or RRR-alpha-tocopheryl acetate. The British Journal of Nutrition 95(3):477-487.

Lanari, M. C., M. Brewster, A. Yang, and R. K. Tume. 2002. Pasture and grain finishing affect the color stability of beef. Journal of Food Science 67(7):2467-2473.

Lauridsen, C., H. Engel, A. M. Craig, and M. G. Traber. 2002. Relative bioactivity of dietary RRR- and all-rac-alpha-tocopheryl acetates in swine assessed with deuterium-labeled vitamin E. Journal of Animal Science 8o(3):702-707.

Leal, L. N., J. A. Beltrán, V. Alonso, J. M. Bello, L. A. den Hartog, W.H.Hendriks, and J. MartínTereso. 20I8. Dietary vitamin E dosage and source affects meat quality parameters in light weight lambs. Journal of the Science of Food and Agriculture 98(4):I606-I6I4.

Lee, S. K., Panjono, S. M. Kang, T. S. Kim, and Y. S. Park. 2008. The effects of dietary sulfur and Vitamin E supplementation on the quality of beef from the longissimus muscle of Hanwoo bulls. Asian-Australasian Journal of Animal Sciences 2I(7):I059-I066.

López-Bote, C. J., A. Daza, M. Soares, and E. Berges. 200I. Dose-response effect of dietary vitamin E concentration on meat quality characteristics in light-weight lambs. Animal Science 73(3):45I-457.

Nassu, R. T., M. E. Dugan, M. Juárez, J. A. Basarab, V. S. Baron, and J. L. Aalhus. 20II. Effect of alpha-tocopherol tissue levels on beef quality. Animal 5(I2):2010-20I8.

Ochoa, L., L. R. McDowell, S. N. Williams, N. Wilkinson, J. Boucher, and E. L. Lentz. 1992. Alpha-Tocopherol concentrations in serum and tissues of sheep fed different sources of vitamin E. Journal of Animal Science 70(8):2568-2573.

Realini, C. E., S. K. Duckett, G. W. Brito, M. Dalla Rizza, and D. De Mattos. 2004. Effect of pasture vs. concentrate feeding with or without antioxidants on carcass characteristics, fatty acid composition, and quality of Uruguayan beef. Meat Science 66(3):567-577.

Ripoll, G., L. González-Calvo, F. Molino, J. H. Calvo, and M. Joy. 20I3. Effects of finishing period length with vitamin E supplementation and alfalfa grazing on carcass color and the evolution of meat color and the lipid oxidation of light lambs. Meat Science 93(4):906-913.

Traber, M. G. 1996. Regulation of Human Plasma Vitamin E. Advances in Pharmacology 38:49-63.

Traber, M. G., E. Mah, S. W. Leonard, G. Bobe, and R. S. Bruno. 20I7. Metabolic syndrome increases dietary alpha-tocopherol requirements as assessed using urinary and plasma vitamin E catabolites: a double-blind, crossover clinical trial. The American journal of clinical nutrition I05:57I-579. 
Traber, M. G., R. J. Sokol, G. W. Burton, K. U. Ingold, A. M. Papas, J. E. Huffaker, and H. J. Kayden. 1990. Impaired ability of patients with familial isolated vitamin E deficiency to incorporate $\alpha$-tocopherol into lipoproteins secreted by the liver. Journal of Clinical Investigation 85(2):397-407.

Turner, K. E., K. E. McClure, W. P. Weiss, R. J. Borton, and J. G. Foster. 2002. Alphatocopherol concentrations and case life of lamb muscle as influenced by concentrate or pasture finishing. Journal of Animal Science 80(IO):2513-252I.

USP. 1979. The United States Pharmacopeia. National Formulary. United States Pharmacopeial Convention, Rockville, Maryland, USA.

Weiser, H., and M. Vecchi. 198I. Stereoisomers of alpha-tocopheryl acetate. Characterization of the samples by physico-chemical methods and determination of biological activities in the rat resorption-gestation test. International Journal for Vitamin and Nutrition Research. Internationale Zeitschrift für Vitamin- und Ernahrungsforschung. Journal International de Vitaminologie et de Nutrition 5I(2):IOO-II3.

Weiser, H., and M. Vecchi. 1982. Stereoisomers of alpha-tocopheryl acetate. II. Biopotencies of all eight stereoisomers, individually or in mixtures, as determined by rat resorption-gestation tests. International Journal for Vitamin and Nutrition Research. Internationale Zeitschrift für Vitamin- und Ernahrungsforschung. Journal International de Vitaminologie et de Nutrition 52(3):35I-370.

Wolf, G. 2006. How an increased intake of alpha-tocopherol can suppress the bioavailability of gamma-tocopherol. Nutrition Reviews 64(6):295-299. 


\section{SUPPLEMENTARY MATERIALS}

Table S2.I Regression coefficients (means \pm standard error) of the effect vitamin E supplementation (RRR- $\alpha$-tocopheryl acetate and all-rac- $\alpha$-tocopheryl acetate) on $\alpha$-tocopherol content in lamb tissues.

\begin{tabular}{|c|c|c|c|c|}
\hline & \multicolumn{2}{|c|}{ RRR- } & \multicolumn{2}{|c|}{ all-rac } \\
\hline Muscle & Mean \pm SE & Pvalue & Mean \pm SE & Pvalue \\
\hline a & I. $39 \pm 0.178$ & $<0.00 I$ & $\mathrm{I} .39 \pm 0.178$ & $<0.001$ \\
\hline b & $6.20 \pm 2.585$ & 0.032 & $3.78 \pm 0.477$ & $<0.00 I$ \\
\hline c & $-0.83 \pm 0.510$ & 0.127 & $-\mathrm{I} .32 \pm 0.393$ & 0.006 \\
\hline \multicolumn{5}{|l|}{ Liver } \\
\hline a & $2.29 \pm 0.258$ & $<0.00 I$ & $2.29 \pm 0.258$ & $<0.00 I$ \\
\hline b & $60.3 \pm 32.94$ & 0.090 & $46.4 \pm \mathrm{I} 4.97$ & 0.009 \\
\hline c & $-0.33 \pm 0.208$ & 0.140 & $-0.48 \pm 0.252$ & 0.080 \\
\hline \multicolumn{5}{|l|}{ Heart } \\
\hline a & $4.29 \pm 0.369$ & $<0.00 I$ & $4.29 \pm 0.369$ & $<0.00 I$ \\
\hline b & $13.0 \pm 2.46$ & $<0.00 I$ & $9.0 \pm 0.98$ & $<0.001$ \\
\hline c & $-I .50 \pm 0.539$ & 0.016 & $-2.24 \pm 0.7 \mathrm{I} 2$ & 0.009 \\
\hline \multicolumn{5}{|l|}{ Spleen } \\
\hline $\mathrm{a}$ & $2.2 \mathrm{I} \pm 0.164$ & $<0.00 I$ & $2.2 \mathrm{I} \pm 0.164$ & $<0.00 I$ \\
\hline $\mathrm{b}$ & $36.9 \pm 32.2 \mathrm{I}$ & 0.273 & $\mathrm{I} 6.4 \pm \mathrm{I} .66$ & $<0.001$ \\
\hline c & $-0.39 \pm 0.406$ & 0.360 & $-0.98 \pm 0.223$ & $<0.001$ \\
\hline
\end{tabular}

$\mathrm{a}=$ intercept. $\mathrm{a}+\mathrm{b}=$ asymptote. $\mathrm{c}=$ curvature steepness. $\mathrm{RRR}-\alpha$-tocopheryl acetate $=$ natural vitamin $\mathrm{E}$. all-rac- $\alpha$-tocopheryl acetate $=$ synthetic vitamin $\mathrm{E}$. 
Bioavailability of $\alpha$-tocopherol stereoisomers in lambs depends on dietary doses of all-rac-or RRR- $\alpha$-tocopheryl acetate 


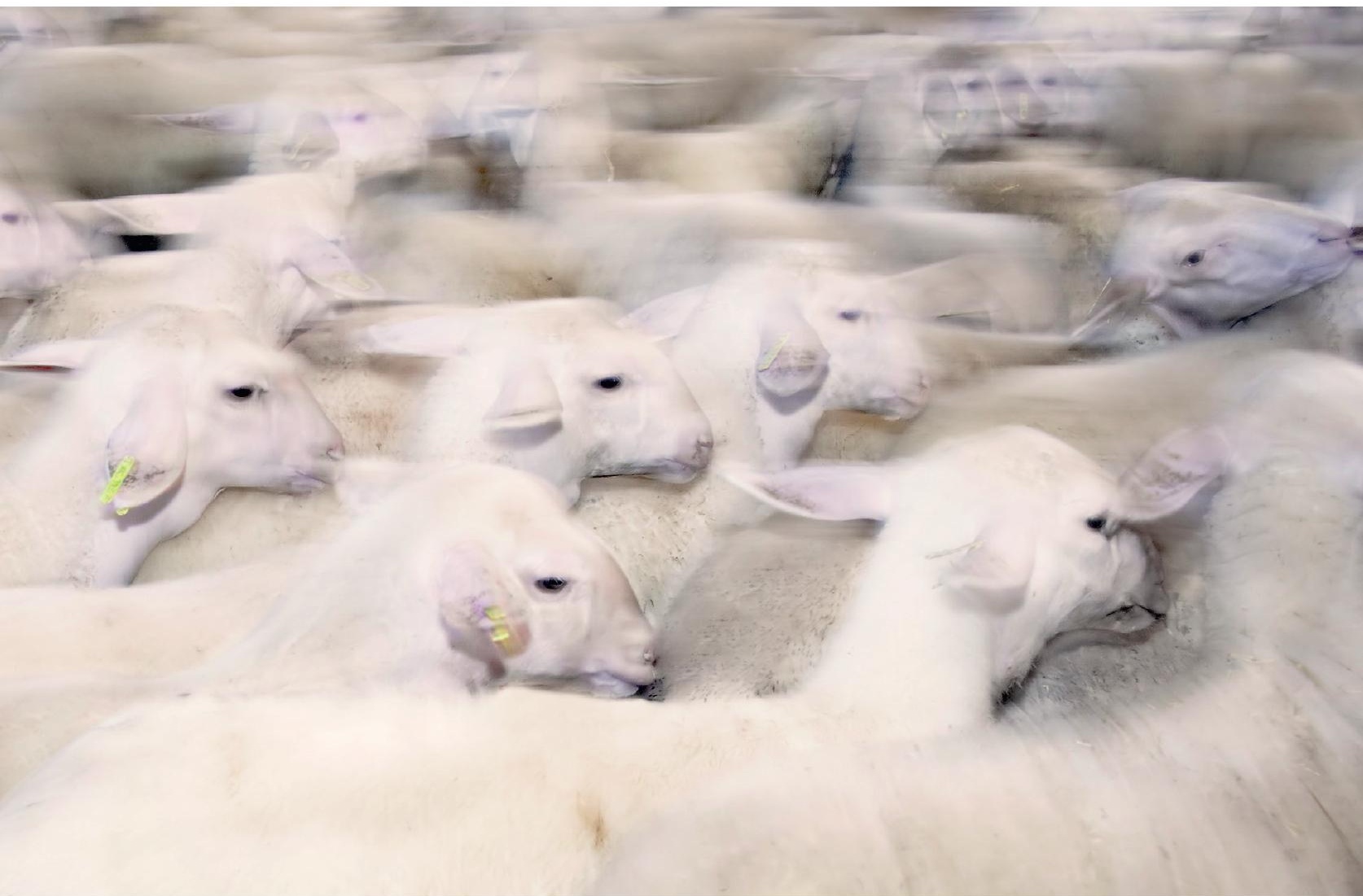




\title{
Chapter 3
}

\section{Dietary vitamin E dosage and source affects meat quality parameters in light weight lambs}

\author{
L. N. Leal ${ }^{\mathrm{a}, \mathrm{b}}$, J. A. Beltrán ${ }^{\mathrm{c}}$, V. Alonso ${ }^{\mathrm{c}}$, J. M. Bello ${ }^{\mathrm{d}}$, L. A. den Hartog ${ }^{\mathrm{a}, \mathrm{b}}$, \\ W. H. Hendriks ${ }^{b}$ and J. Martín-Tereso ${ }^{a}$
}

${ }^{a}$ Trouw Nutrition Research and Development, P.O. Box 299, 3800 AG, Amersfoort, the Netherlands.

${ }^{\mathrm{b}}$ Animal Nutrition group, Department of Animal Sciences, Wageningen University \& Research, De Elst 1, 6708 WD Wageningen, the Netherlands.

c Departamento Tecnología de los Alimentos, Facultad de Veterinaria, Miguel Servet 177-50013 Zaragoza, Spain. ${ }^{d}$ Nanta S.A., Ronda de Poniente 9, 28460 Tres Cantos, Madrid, Spain. 


\begin{abstract}
Supra-nutritional vitamin E supplementation is a commonly used approach to delay lipid oxidation and colour deterioration in lamb and beef meat marketed under modified atmosphere packaging. However, these applications lack a precise calibration of dose for the desired effect and limited information is available regarding the use of natural vitamin E for this purpose. Three hundred and sixty Rasa Aragonesa lambs were fed diets supplemented with all-rac- $\alpha$-tocopheryl acetate $\left(250,500\right.$, 1000 and $2000 \mathrm{mg} \mathrm{kg}^{-1}$ compound feed), RRR- $\alpha$-tocopheryl acetate (I25, 250, 500 and I000 $\mathrm{mg} \mathrm{kg}^{-1}$ compound feed) and a basal diet without vitamin E supplementation, for I4 $\mathrm{d}$ before slaughter at 25.8 \pm I.67 kg BW. Vitamin E supplementation had no effect $(\mathrm{P}>0.05)$ on average daily weight gain, feed intake and feed efficiency. Display time had larger effects on lipid oxidation, colour stability, myoglobin forms and meat discolouration parameters than did vitamin E supplementation. However, vitamin E source and dosage significantly extended meat shelf-life as indicated by lipid oxidation, redness, hue angle, metmyoglobin formation, deoxymyoglobin formation, $\mathrm{A}_{580-630}$ and $\mathrm{I}_{\mathrm{SO}_{2}}$. Quantification of these effects demonstrated that the biological activity value of $\mathrm{I} .36$ used to distinguish both vitamin E sources is not appropriate for meat quality enhancing properties.
\end{abstract}




\section{INTRODUCTION}

Meat quality in lambs, as defined by its colour and stability properties (i.e. shelf-life) is an important factor driving consumer preference and purchase decision (Lanari et al., I994). The "bright red" colour in meat, perceived by consumers as an indicator of freshness and wholesomeness of the meat product (Faustman et al., 1989; Djenane et al., 2003), can be further enhanced by modified atmosphere packaging (MAP) technology. This technology utilises oxidizing gas compositions (70\%-80\% of oxygen and 30\%-20\% carbon dioxide) (Álvarez et al., 2008) which, over time, leads to an increase in lipid oxidation and colour deterioration of the meat (Jakobsen et al., 2000; Baron et al., 2002). To decelerate lipid oxidation and colour deterioration, producers and retailers have adopted the use of antioxidants in meat products during processing (Nerín et al., 2006) or into lamb diets (López-Bote et al., 200I). Dietary application of antioxidants is preferred, due to uniform incorporation of the antioxidants into the subcellular membranes and local inhibition of the oxidative reactions (Govaris et al., 2004).

It is well accepted that vitamin E supplementation to lamb diets can be used as a mean to delay lipid oxidation and prolong colour stability of the meat (López-Bote et al., 200I; Lauzurica et al., 2005). Of the four tocopherol isomers found in nature $(\alpha, \beta, \delta$ and $\gamma), \alpha$-tocopherol is recognized to be the most effective antioxidant in delaying meat discolouration and lipid oxidation (Kamal-Eldin et al., 1996). Commonly, $\alpha$-tocopherol supplements used in lamb diets to delay meat oxidation and colour deterioration differ from the naturally occurring $\alpha$-tocopherol. Commercially available all-rac- $\alpha$-tocopheryl acetate (synthetic vitamin $\mathrm{E}$ ) is a racemic mixture of eight stereoisomers where only one isomer (RRR-), accounting for $\mathbf{1 2 . 5 \%}$ of the total mixture, is found in nature (Weiser and Vecchi, 1982). The official biopotency factors, being the amount of a nutrient associated with some measured physiological endpoint, of I.oo for all-rac- $\alpha$-tocopheryl acetate and I.36 for RRR- $\alpha$-tocopheryl acetate (USP, 1979) are used to discriminate between the two sources. However, based on the relative bioactivity of the eight different stereoisomers, it has been reported that all-rac- $\alpha$-tocopheryl acetate should only exhibit, on average, $58 \%$ of the biological activity of RRR- $\alpha$-tocopheryl acetate (Brand et al., 2006). More recently, Dersjant$\mathrm{Li}$ and Peisker (2010) compiled evidence that new biopotency factors for livestock animals need to be developed, different from the conversion factors used in the International Unit System for vitamin E. As highlighted by Liu et al. (1995) any supplementation strategy with vitamin E should target the optimal concentration of $\alpha$-tocopherol in tissue that provides maximal suppression of lipid and protein oxidation.

The aim of this study was to determine the efficacy of two vitamin E supplementation strategies (RRR- and all-rac- $\alpha$-tocopheryl acetate) on meat colour and lipid stability of lamb meat, stored for $\mathrm{I} 4 \mathrm{~d}$ under retail conditions. 


\section{MATERIALS AND METHODS}

\section{Animals and Diets}

Three hundred and sixty (equal number of males and females) Rasa Aragonesa lambs with an average body weight of $22.3 \pm 1.18 \mathrm{~kg}$ were purchased from local dealers. Animals arrived at the commercial farm Franco and Navarro (Zaragoza, Spain) in two batches of I8o animals. Shortly after arrival, lambs were weighed and housed in straw pens according to sex and batch of arrival following a randomized complete block design, with four blocks of nine pens $\left(20 \mathrm{~m}^{2}\right)$ each (with Io lambs per pen). Within each block, pens were randomly allocated to one of nine treatments consisting of four supplementation levels of all-rac- $\alpha$ tocopheryl acetate $\left(250,500,1000\right.$ and $2000 \mathrm{mg} \mathrm{kg}^{-1}$ compound feed), four supplementation levels of RRR- $\alpha$-tocopheryl acetate (125, 250, 500 and $1000 \mathrm{mg} \mathrm{kg}^{-1}$ compound feed) and a control group (basal diet without supplementation). The vitamin E supplements were included in the basal diet which contained $25 \mathrm{mg}$ all-rac- $\alpha$-tocopheryl acetate per $\mathrm{kg}$ compound feed. The experimental diets were presented as $2.5 \mathrm{~mm}$ diameter granules; the nutritional composition of the basal diet is shown in Table 3.I. For I4 $\mathrm{d}$ before slaughter, the lambs had free access to the experimental diets, wheat straw and water via separated troughs. After $\mathrm{I} 4 \mathrm{~d}$, the lambs were transported to and slaughtered at a local abattoir (Mercazaragoza S.A., Zaragoza, Spain). The experimental and slaughter procedures used met the guidelines of Council Directive 86/609/EEC (European Communities, 1986) on the protection of animals used for experimental and other scientific purposes.

\section{Meat Processing and Packaging}

Within 2 hours after slaughter, carcasses were hung under refrigerated conditions $\left(2^{\circ} \mathrm{C}\right)$. After $24 \mathrm{~h}$, the longissimus thoracis et lumborum (LTL) muscle from 3 animals randomly selected from each pen were dissected, placed in bags (I muscle per bag) and transported in sealed plastic containers in darkness at $4 \pm \mathrm{I}^{\circ} \mathrm{C}$ to the Meat Quality Laboratory of the Veterinary Faculty of Zaragoza (Zaragoza, Spain). Within 2 hours after arrival, the muscles were sectioned into approximately $2 \mathrm{~cm}$ thick steaks and 2 steaks per tray (alongside each other) were packed under modified atmosphere packaging with $70 \% \mathrm{O}_{2}+30 \% \mathrm{CO}_{2}$ (Ulma Smart 500, Ulma Packaging, Guipúzcoa, Spain). Polystyrene trays were used and sealing was done with a polyethylene and polyamide laminate film $(30 \mu \mathrm{m}$ of thickness, water vapour transmission rate at $23^{\circ} \mathrm{C}$ of $<7 \mathrm{~g} / \mathrm{m}^{2} / 24 \mathrm{~h} / 85 \%$ relative humidity, an $\mathrm{O}_{2}$ transmission rate at $23^{\circ} \mathrm{C}$ of $<15 \mathrm{~cm}^{3} / \mathrm{m}^{2} / 0 \%$ R.H. and a $\mathrm{CO}_{2}$ transmission rate at $23^{\circ} \mathrm{C}$ of $<75 \mathrm{~cm}^{3} / \mathrm{m}^{2} / 24 \mathrm{~h} /$ o\% R.H.; Linpac Packaging S.L., Spain). All trays were displayed in the same cabinet simulating retail conditions $\left(4 \pm \mathrm{I}^{\circ} \mathrm{C}\right.$, with a daily exposure to I4 hours of light at I200 $\mathrm{lx}$ ) for I $4 \mathrm{~d}$. All analyses (instrumental meat colour, myoglobin forms, meat discolouration and lipid oxidation) were performed on $\mathrm{d}$ I, 7, 9, I2 and I4 of display. 


\begin{tabular}{|c|c|}
\hline \multicolumn{2}{|l|}{ Ingredients, $\mathrm{g} \mathrm{kg}^{-1}$} \\
\hline Wheat & 300 \\
\hline Barley & 260 \\
\hline Soya bean meal ( $480 \mathrm{~g} \mathrm{~kg}^{-1}$ of crude protein) & 220 \\
\hline Maize & I50 \\
\hline Soya oil & 20 \\
\hline Limestone & 27 \\
\hline Sodium bicarbonate & 6 \\
\hline Sodium chloride & 4 \\
\hline Mineral and vitamin premix* & 3 \\
\hline Vitamin E premix & IO \\
\hline \multicolumn{2}{|l|}{ Composition, $\mathrm{g} \mathrm{kg}^{-\mathrm{I}}$} \\
\hline Dry matter & 879 \\
\hline Crude protein & I7I \\
\hline Starch & 398 \\
\hline Ether extract & 40 \\
\hline Ash & 58 \\
\hline
\end{tabular}

* Minerals and vitamins provided: Ca 0.24 g, Na 0.47 g, S o.34 g, Mn 62 mg, Zn IIo mg, Cu 5 $\mathrm{mg}$, I o.6 mg, Co $0.3 \mathrm{mg}$, Se 0.I mg, Fe $20 \mathrm{mg}$, Vitamin A 8000 IU, Vitamin D3 I60o IU, allrac- $\alpha$ tocopheryl acetate $25 \mathrm{mg}$.

\section{Instrumental Measurement of Colour}

At each time point, a reflectance spectrophotometer (Minolta CM-2002, Osaka, Japan) with an illuminat D65 and $10^{\circ}$ standard observer was used to determine colour of the steaks, after $2 \mathrm{~h}$ exposure to air. Each value was the mean of Io determinations per sample, always on the top side of the steak and avoiding areas with excess fat. The parameters recorded according to the CIE $L^{*} a^{*} b^{*}$ system (CIE, 1976), were lightness $\left(L^{*}\right)$, redness $\left(a^{*}\right)$ and yellowness $\left(b^{*}\right)$. Values of chroma $\left(C^{*}\right)$ and hue angle $(h)$ indexes were calculated as: $\mathrm{C}^{*}=\sqrt{ }\left(\mathrm{a}^{* 2}+\mathrm{b}^{* 2}\right)$, and $h=\tan ^{-1}\left(\mathrm{~b}^{*} / \mathrm{a}^{*}\right) ;$ and expressed in degrees.

\section{Myoglobin Forms and Meat Discolouration}

The relative content of myoglobin forms (metmyoglobin (MetMb), oxymyoglobin $(\mathrm{OxyMb})$ and deoxymyoglobin (DeoxyMb) were calculated from the reflectance curve as described by Krzywicki (1979) using a wavelength of $690 \mathrm{~nm}$. Since the reflectance spectrophotometer only measures the reflectance between $400 \mathrm{~nm}$ and $740 \mathrm{~nm}$ at Io 
$\mathrm{nm}$ intervals, reflectance values not given by the instrument (473, 525 and $572 \mathrm{~nm}$ ) were obtained by linear interpolation. The rate of meat discolouration was measured as $\mathrm{A}_{580}-\mathrm{A}_{630}$ (van den Oord and Wesdorp, 197I) and to access the oxygen saturation of myoglobin on the meat surface, the parameter Iso $_{2}$ was measured following the technique described by Tsuruga et al. (I994).

\section{Lipid Oxidation}

Lipid oxidation, expressed as thiobarbituric acid reactive substances (TBARS) using the 2-thiobarbituric acid method (TBA), was determined according to the method of Pfalzgraf et al. (1995). Briefly, a Io g meat sample was taken and homogenised with I0\% trichloroacetic acid using an Ultra-Turrax T25 (Janke \& Kunkel, Staufen, Germany). Samples were centrifuged at $4000 \mathrm{rpm}$ for $30 \mathrm{~min}$ at $10^{\circ} \mathrm{C}$ and the supernatants were filtered through a paper (Filterlab, Barcelona, Spain). Two $\mathrm{ml}$ of the filtrate were taken and mixed with 2 $\mathrm{ml}$ of TBA $(20 \mathrm{mM})$, homogenized and incubated for $20 \mathrm{~min}$ in boiling water. Absorbance was measured at $532 \mathrm{~nm}$ and TBARS values were calculated from a standard curve of malonaldehyde (MDA). All samples were analysed in duplicate and the results expressed as mg of MDA per $\mathrm{kg}$ muscle.

\section{$\alpha$-Tocopherol Analysis in Feed}

$\alpha$-Tocopherol content in the experimental diets was determined by high-pressure liquid chromatography (HPLC) after saponification and extraction into heptane as described by Jensen et al. (1999). Briefly, $2 \mathrm{~g}$ of dry feed was mixed with $70 \mathrm{ml}$ of $96 \% \mathrm{v} / \mathrm{v}$ ethanol, $30 \mathrm{ml}$ methanol, $30 \mathrm{ml}$ ascorbic acid and $20 \mathrm{ml} \mathrm{KOH}$-water I:I (w/v). The mixture was saponified for $30 \mathrm{~min}$ at $80^{\circ} \mathrm{C}$ in the dark and cooled in cold water. Exactly $2 \mathrm{ml}$ of the saponified mixture were diluted with $\mathrm{I} \mathrm{ml}$ distilled water, after which tocopherols were quantitatively extracted with $2 \times 5 \mathrm{ml}$ heptane (Peter Mark, C 25I4) and centrifuged at $1500 \mathrm{~g}$ for Io min between each extraction. From the combined heptane extracts, Ioo $\mu \mathrm{l}$ was injected into the HPLC (Perkin Elmer, Series 200) which contained a 100 x $4.6 \mathrm{~mm}$ Brownlee Spheri-5 Silica $5 \mu \mathrm{m}$ column (Perkin-Elmer GmbH, D-7770 Überlingen, Germany). The mobile phase was heptane containing 2-propanol (3.0 $\left.\mathrm{ml} \mathrm{l}^{-1}\right)$ and degassed with helium. The flow rate was 3.0 $\mathrm{ml} \mathrm{min}{ }^{-1}$. A comparison of retention time and peak areas with Merck (D-6Ioo Damstadt, Germany) external standards was used to obtain the identification and quantification of the tocopherol isomers. Fluorescence detection was performed with an excitation wavelength of $290 \mathrm{~nm}$ and an emission wavelength of $327 \mathrm{~nm}$.

\section{Mathematical and Statistical Analysis}

All statistical analyses were performed using the SAS statistical software (SAS 9.3, SAS Inst., Inc., Cary, NC). Individual lamb data were summarized per pen which was considered the experimental unit for all the parameters studied. For all statistical models, dose of supplemental $\alpha$-tocopherol was calculated based on the analytical values (Table 3.2), to 
represent the level of $\alpha$-tocopherol supplementation above the content in the basal diet. This was achieved by subtracting the basal dietary levels found in the different treatments from the total dietary $\alpha$-tocopherol. Therefore, the $\alpha$-tocopherol content used for the statistical analysis were $0.108,0.353,0.584$ and $1.176 \mathrm{~g} \mathrm{~kg}^{-1}$ of compound feed for the RRR$\alpha$-tocopheryl acetate groups and $0.247,0.509,1.049$ and $2.303 \mathrm{~g} \mathrm{~kg}^{-1}$ compound feed for the all-rac- $\alpha$-tocopheryl acetate.

Feed intake, average daily gains (ADG) and feed efficiency data were analysed using the PROC MIXED procedure. The model included the fixed effects of treatment, initial body weight, and block. A Tukey test was performed to correct for multiple comparisons and all the values are reported as least square means.

A non-linear regression procedure, PROC NLIN and one of two models were used to fit the data on lipid oxidation (TBARS) (I), instrumental colour $\left(a^{*}, b^{*}, L^{*}, C^{*}\right.$ and $\left.h\right)(2)$, myoglobin forms (MetMb, OxyMb and DeoxyMb) (2) and meat discolouration (A58o-630 and Iso ${ }_{2}$ (2):

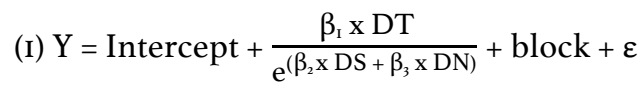

(2) $\mathrm{Y}=$ Intercept $+\beta_{1} \times \mathrm{DT}+\beta_{2} \times \mathrm{DT}^{2}+\left(\beta_{3} \times \mathrm{DS}+\beta_{4} \times \mathrm{DN}\right)+\mathrm{DT} \times\left(\beta_{5} \times \mathrm{DS}+\beta_{6} \times \mathrm{DN}\right)+\left(\beta_{7} \times \mathrm{DS}^{2}+\right.$

$$
\left.\beta_{8} \times \mathrm{DN}^{2}\right)+\mathrm{DT}^{2} \times\left(\beta_{9} \times \mathrm{DS}+\beta_{\mathrm{Ir}} \times \mathrm{DN}\right)+\mathrm{DT}^{2} \times\left(\beta_{\mathrm{II}} \times \mathrm{DS}^{2}+\beta_{\mathrm{I} 2} \times \mathrm{DN}^{2}\right)+\text { block }+\varepsilon
$$

where $\mathrm{Y}$ is the predicted response variable, DT the display time in days (I, 7, 9, I2 or I4), DN the dosage of RRR- $\alpha$-tocopheryl acetate in $\mathrm{g} \mathrm{kg}^{-1}$, DS the dosage of all-rac-tocopheryl acetate in $\mathrm{g} \mathrm{kg}^{-1}, \beta$ s are regression coefficients, the effect of block (block) and $\varepsilon$ is the random error. Akaike's information criterion (AIC) and Bayesian information criterion (BIC) were used to select the best model, with higher degree terms being progressively added to the model. Briefly, for a new term to be added to the model, a reduction in AIC $>3$ and BIC $>0$ was required. As demonstrated previously (Schwarz et al., I978; Burnham et al., 2002), a model with lower AIC and BIC is significantly better than models with larger AIC and BIC. To access the validity of the models, an ANOVA was performed, enabling a check on the significance of all the effects. Response surface plots displaying the levels of a response as affected by the three continuous variables of interest (DT, DN and DS), were used for the final interpretation of the response.

In the exponential equation used to fit the data on TBARS (equation I), regression coefficients $\beta_{2}$ and $\beta_{3}$ represent the slopes at dose zero (maximum response) for all-rac- $\alpha$ tocopheryl acetate and RRR- $\alpha$-tocopheryl acetate respectively. These coefficients reflect the effect of an infinitesimal increment in dose above the basal level of $\alpha$-tocopherol on the development of TBARS. Consequently, the ratio between $\beta_{3}$ and $\beta_{2}$ was calculated to determine the relative efficacy between the two vitamin E sources on TBARS (Table 3.3). For the remaining parameters fitted with equation 2, there was not a single coefficient 
indicating this maximum response to an incremental dose independently from DT. Therefore, relative efficacies for the remaining parameters were not calculated.

\section{RESULTS AND DISCUSSION}

\section{Animal Performance}

All animals remained healthy during the study and there were no missing values for any of the measurements. Neither dietary vitamin E supplementation level nor source had an effect $(\mathrm{P}>0.05)$ on the ADG, feed intake and feed efficiency (Table 3.2). This is in contrast to results of Wulf et al. (1995) who found differences in daily weight gain between lambs supplemented with I0oo $\mathrm{mg}$ to those supplemented with $500 \mathrm{mg} \alpha$-tocopheryl acetate or non-supplemented lambs over $56 \mathrm{~d}$ of fattening. Later reports (Lauzurica et al., 2005; Ripoll et al., 20II), found no relationship between vitamin E supplementation and the productive performance in finishing lambs.

Table 3.2 Productive performance of the lambs and $\alpha$-tocopherol content in feed for the control and vitamin E supplemented groups.

\begin{tabular}{|c|c|c|c|c|c|c|c|c|c|c|c|}
\hline \multirow[t]{2}{*}{ Item } & \multirow{2}{*}{$\begin{array}{l}\text { Control } \\
\text { o }\end{array}$} & \multicolumn{4}{|c|}{ Natural ( $\mathrm{g} \mathrm{kg}^{-1}$ feed) } & \multicolumn{4}{|c|}{ Synthetic ( $\mathrm{g} \mathrm{kg}^{-1}$ feed) } & \multirow[t]{2}{*}{ SEM } & \multirow[t]{2}{*}{ P value } \\
\hline & & 0.125 & 0.250 & 0.50 & I.O & 0.250 & 0.50 & I.O & 2.0 & & \\
\hline $\begin{array}{l}\text { Feed intake, } \\
\mathrm{kg} \mathrm{d}^{-\mathrm{I}}\end{array}$ & 0.99 & 0.99 & 0.93 & 0.97 & 0.95 & 0.93 & I.O2 & I.OO & 0.97 & 0.039 & $0.26 \mathrm{I}$ \\
\hline $\begin{array}{l}\text { Average daily } \\
\text { gain, } \mathrm{kg} \mathrm{d}^{-1}\end{array}$ & 0.268 & 0.269 & 0.265 & 0.270 & 0.255 & 0.267 & $0.27 \mathrm{I}$ & 0.263 & 0.260 & 0.0112 & 0.474 \\
\hline $\begin{array}{l}\text { Feed efficiency, } \\
\mathrm{kg} \mathrm{kg}^{-1}\end{array}$ & 3.80 & $3.9 \mathrm{I}$ & 4.29 & 3.89 & 4.25 & 3.86 & 3.95 & 3.82 & 3.90 & 0.244 & 0.337 \\
\hline $\begin{array}{l}\alpha \text {-Tocopherol, } \\
\mathrm{g} \mathrm{kg}^{-1} \text { feed }\end{array}$ & 0.040 & 0.148 & 0.353 & 0.584 & I.I76 & 0.287 & 0.549 & I.083 & 2.343 & - & - \\
\hline
\end{tabular}

Table 3.3 Mean \pm standard error regression coefficients of a model describing the effect of all-rac- $\alpha$-tocopheryl acetate (DS) and RRR- $\alpha$-tocopheryl acetate (DN) supplementation to lambs before slaughter on subsequent TBARS values of longissimus thoracis et lumborum steaks during I $4 \mathrm{~d}$ of display (DT) under retail conditions (modified atmosphere packing).

\begin{tabular}{|lll|}
\hline Parameter & Estimate & P value \\
\hline Intercept & $0.10 \pm 0.026$ & $<$ O.OOI \\
$\beta$ I & $0.09 \pm 0.005$ & $<$ O.OOI \\
$\beta 2$ & $2.29 \pm 0.307$ & $<$ O.OOI \\
$\beta 3$ & $4.1 \mathrm{II} \pm 0.555$ & $<$ O.OOI \\
$\beta 3: \beta 2$ & $\mathrm{I} .80 \pm 0.268$ & $<$ O.OOI \\
\hline \multicolumn{3}{c}{ TBARS $=$ Intercept $+\frac{\beta 1 \times \mathrm{DT}}{\mathrm{e}^{\wedge}(\beta 2 \times \mathrm{DS}+\beta 3 \times \mathrm{DN})}$} \\
\hline
\end{tabular}




\section{Meat Oxidation}

The effect of vitamin E dose and source on TBARS values of the LTL steaks are presented in Table 3.3. In lambs, when studying the effect of dietary $\alpha$-tocopheryl acetate inclusion level for TBARS values at different storage times, López-Bote et al. (200I) found that an exponential model was the most appropriate to fit TBARS data.

As shown in Table 3.3, there was a significant effect of DT, DS and DN on TBARS values $(\mathrm{P}<\mathrm{O} . \mathrm{OOI})$. In Figure 3.I, a response surface plot on TBARS values when varying supplementation level (DS and DN) and DT is presented.
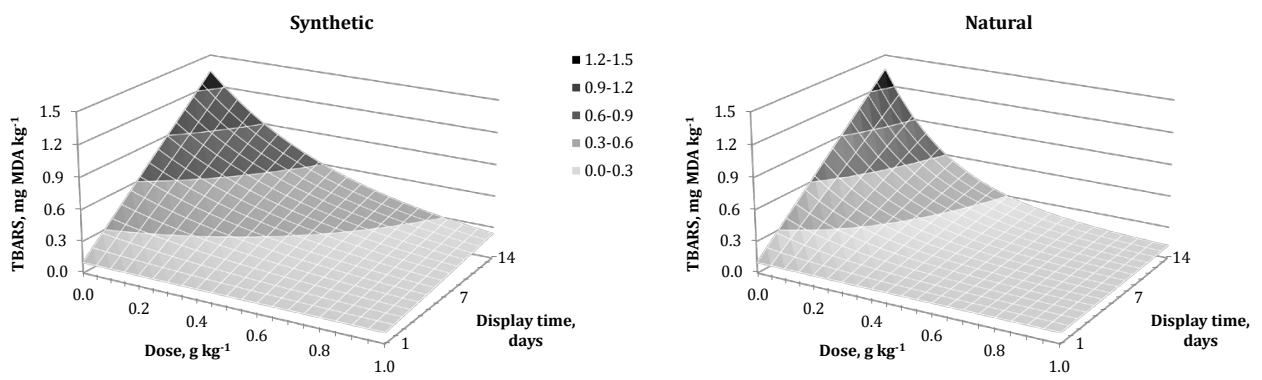

Figure 3.I Response surface plot of predicted TBARS values of longissimus thoracis et lumborum steaks of lambs fed different doses of synthetic (all-rac- $\alpha$-tocopheryl acetate) and natural (RRR- $\alpha$-tocopheryl acetate) vitamin E daily for $\mathrm{I} 4 \mathrm{~d}$ before slaughter and displayed for $\mathrm{I} 4 \mathrm{~d}$ under retail conditions (modified atmosphere packing).

At $\mathrm{d} o$, there were no differences in TBARS values between the different vitamin $\mathrm{E}$ supplementation levels or sources. However, with increasing DT, the differences between treatments become apparent. Thresholds for oxidized meat acceptability have been proposed by different authors: 0.6-2.0 mg MDA kg-1 for beef (Greene and Cumuze, 1982; Campo et al., 2006), 0.5-1.0 mg MDA kg-1 for pork (Tarladgis et al., 1960; Dunshea et al., 2005), and I.O mg MDA kg-1 for lambs (Ripoll et al., 20II). In our study, in most of the supplementation levels and DT studied meat samples remained far below the threshold of I.o mg MDA kg-1 of meat. TBARS values of I.o mg MDA kg-1 in meat of non-supplemented animals were reached at $9 \mathrm{~d}$ of DT. Whereas, supplementation of synthetic vitamin E above $0 . I 6 \mathrm{~g} \mathrm{~kg}^{-1}$ of feed or natural vitamin $\mathrm{E}$ above $0.09 \mathrm{~g} \mathrm{~kg}^{-1}$ of feed, would be sufficient to keep TBARS values below the threshold of I.O mg MDA kg-1 meat for as long as I4 d DT. When supplementing lamb diets with vitamin E, Ripoll et al. (2OII) found that $0.5 \mathrm{~g}$ of synthetic vitamin E per $\mathrm{kg}$ of feed was sufficient to ensure a value of TBARS lower than $0.23 \mathrm{mg}$ MDA $\mathrm{kg}^{-1}$ lamb meat at $\mathrm{I} 4 \mathrm{~d}$ of DT. Such levels were achieved in our experiment at $0.56 \mathrm{~g} \mathrm{~kg}^{-1}$ of feed for DN and I.oI $\mathrm{g} \mathrm{kg}^{-1}$ of feed for DS. Interestingly, Ripoll et al. (2OII) supplemented lambs for a period of $33 \mathrm{~d}$ while in the current study the supplementation period lasted for $\mathrm{I} 4 \mathrm{~d}$ pre-slaughter. These findings are in line with previous work in lambs (Ripoll et al., 
2013), which demonstrate that for a shorter supplementation period an increased level of vitamin E supplementation is required to achieve a target value of TBARS.

The effectiveness of synthetic vitamin $\mathrm{E}$ to reduce lipid oxidation in lamb meat has been extensively described (López-Bote et al., 200I; Lauzurica et al., 2005; Muela et al., 20I4). However, it is important to quantify the relative effectiveness of natural vitamin E compared to synthetic vitamin E to delay meat oxidation in lamb meat. According to the international unit system RRR- $\alpha$-tocopheryl acetate (natural vitamin E) is I.36 times more biopotent than all-rac- $\alpha$-tocopheryl acetate (synthetic vitamin E) (Dersjant-Li et al., 20I0). However, in the present study, natural vitamin E was I.80 times more effective in slowing meat oxidation (TBARS) than synthetic vitamin E (Table 3.3). The conversion factor currently used by the international unit system to benchmark natural and synthetic vitamin E was determined using a rat foetal gestation-resorption model (Weiser et al., 1982) and its validity is applicable to the nutritional value of these vitamin E sources to prevent nutritional deficiency of vitamin E, which substantially differs from supra-nutritional applications of vitamin $\mathrm{E}$ to enhance meat quality.

\section{Colour Stability}

Changes in redness due to vitamin E supplementation are shown in Table 3.4. The main factor affecting the development of the $a^{*}$ values in the current study was DT (quadratic effect) $(\mathrm{P}<\mathrm{O}$.ooI). However, significant interactions between $\mathrm{DT}$ and vitamin $\mathrm{E}$ supplementation (DS and DN) were found. 


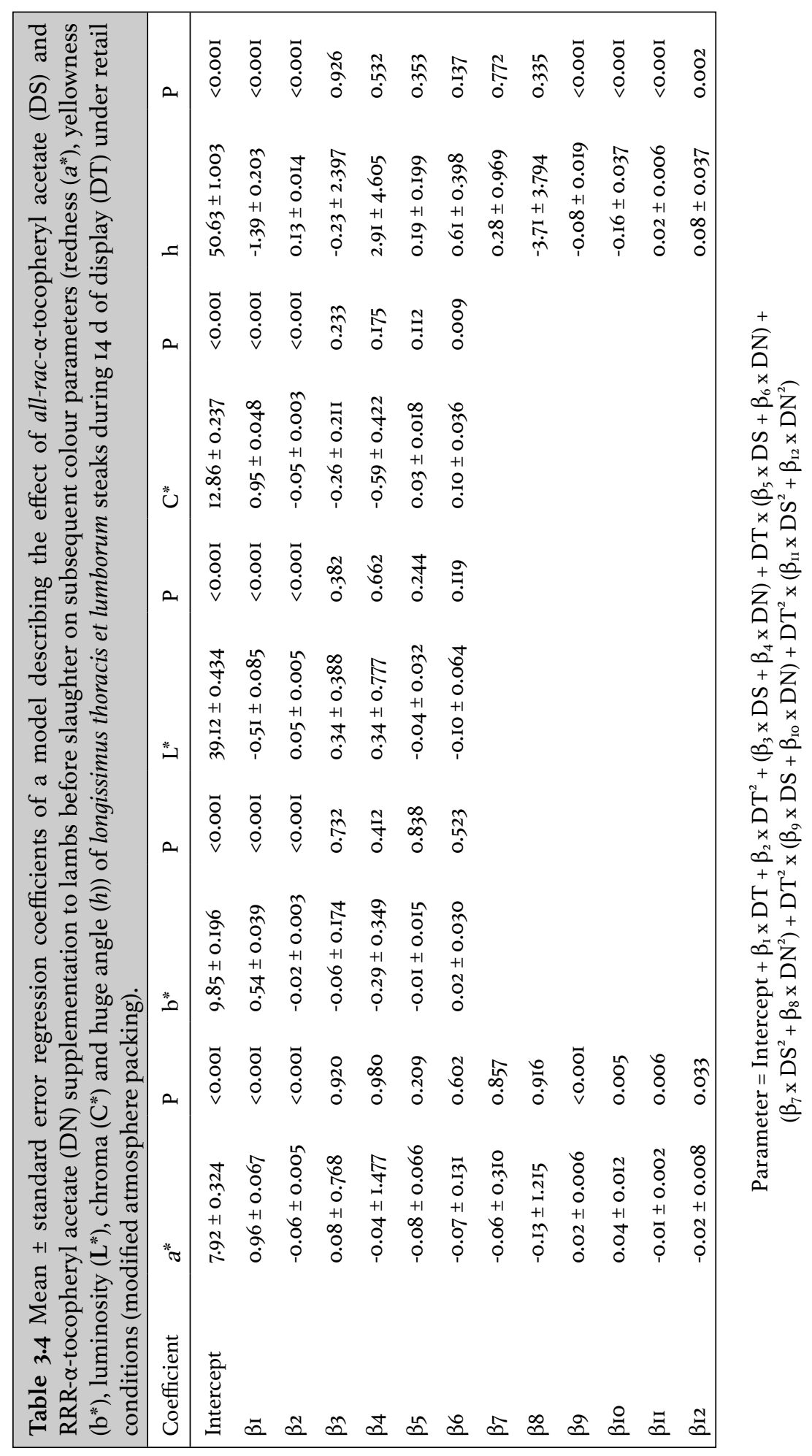


In Figure 3.2, a response surface plot is presented to better illustrate the shape of the response and the differences between the two vitamin E sources studied. Dietary vitamin E supplementation not only increased the maximum value of $a^{*}$ in the meat (II.57, I2.I2 and $\mathbf{1 2 . 3 5}$ for non-supplemented, DS and DN, respectively), but it also increased the DT that takes to reach that maximum value of redness. The highest $a^{*}$ value in the nonsupplemented group was achieved after $8 \mathrm{~d}$ of DT, whereas, a DS supplementation of 0.45 $\mathrm{g} \mathrm{kg}^{-1}$ or a DN supplementation of $0.25 \mathrm{~g} \mathrm{~kg}^{-1}$ delayed the peak of redness by $\mathrm{I} \mathrm{d}$. Moreover, if vitamin E supplementation is higher than $1.00 \mathrm{~g} \mathrm{~kg}^{-1}$ or $0.55 \mathrm{~g} \mathrm{~kg}^{-1}$ (for DS and DN, respectively), the peak of redness can be delayed to Io $d$ of DT. In the last day of DT (d I4), non-supplemented lambs had a redness value of 9.02, while DS supplementation above $0.85 \mathrm{~g} \mathrm{~kg}^{-1}$ and DN supplementation above $0.45 \mathrm{~g} \mathrm{~kg}^{-1}$ ensured $a^{*}$ values higher than II.O.
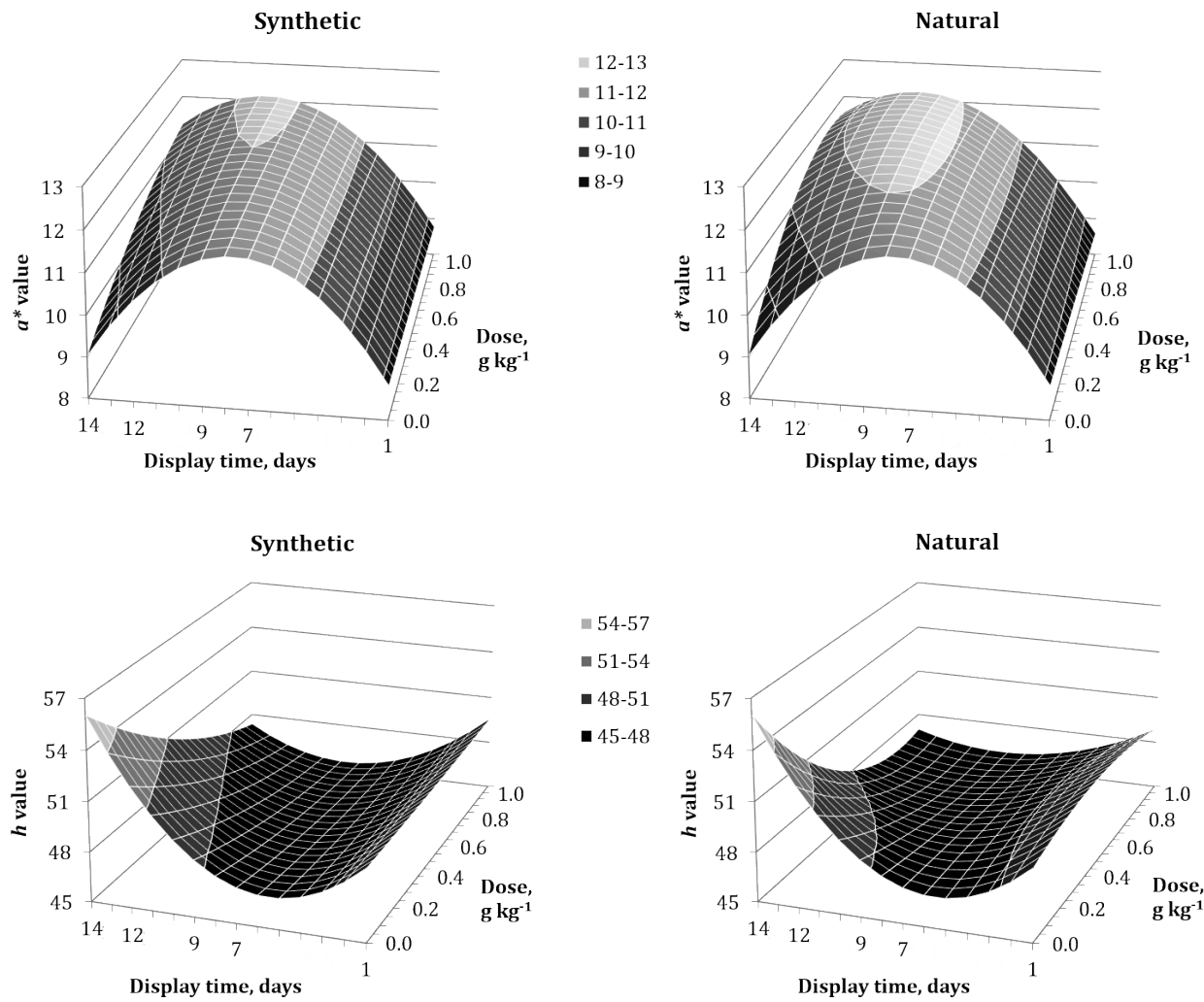

Figure 3.2 Response surface plot of predicted redness $\left(a^{*}\right)$ and huge angle $(h)$ values of longissimus thoracis et lumborum steaks of lambs fed different doses of synthetic (all-rac- $\alpha$-tocopheryl acetate) and natural (RRR- $\alpha$-tocopheryl acetate) vitamin E daily for I $4 \mathrm{~d}$ before slaughter and displayed for $\mathrm{I} 4 \mathrm{~d}$ under retail conditions (modified atmosphere packing). 
The effect of synthetic vitamin E supplementation on meat redness values has been described in beef (Liu et al., I995; Mitsumoto et al., 1998) and lambs (Guidera et al., I997; Macit et al., 2003). However, to our knowledge, our study is the first to demonstrate the effect of vitamin $\mathrm{E}$ dose and source on $\mathrm{a}^{*}$ values in light weight lambs.

Dietary vitamin E supplementation did not affected $b^{*}, L^{*}$ and $C^{*}$ values in the meat (Table 3.4). In the current study, these parameters were only affected by DT (both linear and quadratic, $\mathrm{P}<\mathrm{O} . \mathrm{OOI})$ with no effect $(\mathrm{P}>0.05)$ of dose or an interaction of dose with DT observed.

Assessment of the colours represented by $b^{*}$ (blue and yellow) are difficult to panellists (O'Sullivan et al., 2003) and are not intuitively related with meat colour (Mancini and Hunt, 2005). $b^{*}$ values increased consistently with display time, from values around io at $d$ I of DT to values close to I3 at d I4 of DT. According to Wyszecki and Styles (I982) however, it is advisable to define colour in terms of lightness, chroma and hue to avoid possible errors in colour interpretation.

Lightness $\left(L^{*}\right)$ values are related to muscle and protein structures which seem to play a role in water holding capacity of the meat (Macdougall et al., 1982; Huff-Lonergan and Lonergan, 2005). Lipid peroxidation is known to cause damage to membrane proteins leading to a loss of muscle cell membrane integrity and it can affect water holding capacity (Gray and Buckley, 1996). Although TBARS values were clearly affected by vitamin E supplementation, no differences were found in $L^{*}$ values. Similarly to our study, Muela et al. (20I4) found no effect of dietary vitamin E supplementation on lamb meat lightness during storage under MAP.

Chroma $\left(C^{*}\right)$ values increase with DT until they peak and progressively decrease from that point as DT increases (Bañón et al., 20I2). In line with that, we found that all treatments reached their peak of $\mathrm{C}^{*}$ at d Io of DT and decreased from that point on until d I4 of DT. Synthetic vitamin E supplementation was found to have no effect on $C^{*}$ values (Muela et al., 20I4), despite the significant differences found in $a^{*}$ values (Andrés et al., 2013), which together with $b^{*}$ values (not significant for both sources in the current study) are the two factors that determine $\mathrm{C}^{*}$ values. However, a significant interaction $(\mathrm{P}=0.009)$ between DT and DN was found. Which indicates different behaviour in the development of $C^{*}$ values between the two sources.

Just like for $a^{*}, h$ values were affected by DT (linear and quadratic, $\mathrm{P}<\mathrm{O}$.ooI) but also by an interaction between DT and vitamin E supplementation (both DS and DN) (Table 3.4). Although the initial values for $\mathrm{h}$ were similar across treatment groups, meat samples from the non-supplemented lambs showed a marked increase in $h$ values with DT (Figure 3.2). At I4 d of DT, samples from non-supplemented lambs presented an h value of 56.o. Vitamin E supplementation levels above $0.6 \mathrm{~g} \mathrm{~kg}^{-1}$ or $0.4 \mathrm{~g} \mathrm{~kg}^{-1}$ of DS and DN, respectively were able to ensure $h$ values in the samples below 50. It is generally accepted that $h$ is an important indicator of meat discolouration (Ripoll et al., 2008). Previous work with lambs (Ripoll et al., 20II) and beef (Albertí et al., 2005) indicated that dietary vitamin E supplementation can 
delay meat discolouration, maintaining meat with a better appearance during extended periods of display. However, the present study is the first to stress the fact that different dietary vitamin E sources will yield different efficacies in delaying $h$ development during DT.

\section{Myoglobin Forms}

Meat colour in lambs is primarily determined by the constant conversion between the heme-containing proteins: deoxymyoglobin (DeoxyMb), oxymyoglobin (OxyMb) and metmyoglobin (MetMb) (Minotti et al., 1992). As presented in Table 3.5, MetMb formation increased with DT (linearly, P>0.0oI) but supplementation of lamb diets with DS or DN slowed MetMb formation during DT. The surface plot for the relative percentage of MetMb during DT is shown in Figure 3.3. On d I of DT, all treatments had similar values of MetMb (between 24-25\%). Similar, Guidera et al. (1997) found no effect of dietary vitamin E supplementation on MetMb formation in lamb meat at $\mathrm{d}$ o of display time. However, with an increase in DT, they found that supplementation (I.0 $\mathrm{g} \mathrm{kg}^{-1}$ ) resulted in lower MetMb values. This is in line with the present study, in which DS supplementation above $1.0 \mathrm{~g} \mathrm{~kg}^{-1}$ of feed or DN supplementation above $0.55 \mathrm{~g} \mathrm{~kg}^{-1}$ resulted in MetMb levels below $35 \%$ at $\mathrm{d}$ I4 of DT compared with the level of $43.5 \%$ of MetMb reached by the non-supplemented group. In the studies of Lauzurica et al. (2005) comparing lamb meat packed under MAP and displayed for $\mathrm{I} 4 \mathrm{~d}$, supplementation of $\mathrm{I.O} \mathrm{g} \mathrm{kg}^{-1}$ of synthetic vitamin $\mathrm{E}$ for a period of $34 \mathrm{~d}$ yielded a MetMb level of $29.2 \%$ compared with $50.6 \%$ of MetMb for the nonsupplemented group. The lower MetMb levels found by these authors for the $1.0 \mathrm{~g} \mathrm{~kg}^{-1} \mathrm{of}^{-}$ synthetic vitamin E compared with the current study may be explained by the differences in the vitamin E supplementation period between the two studies ( $34 \mathrm{~d}$ vs. I4 d).

High oxygen content in MAP improves meat colour due to OxyMb formation, which is associated with the bright-red colour of meat (Mancini and Hunt, 2005). In the present study, OxyMb formation was found to be mainly driven by DT (both linear and quadratic, $\mathrm{P}<\mathrm{O}$.ooI) (Table 3.5). Vitamin E source and dose had no effect on OxyMb formation, neither in its development over DT $(\mathrm{P}>0.05)$. 


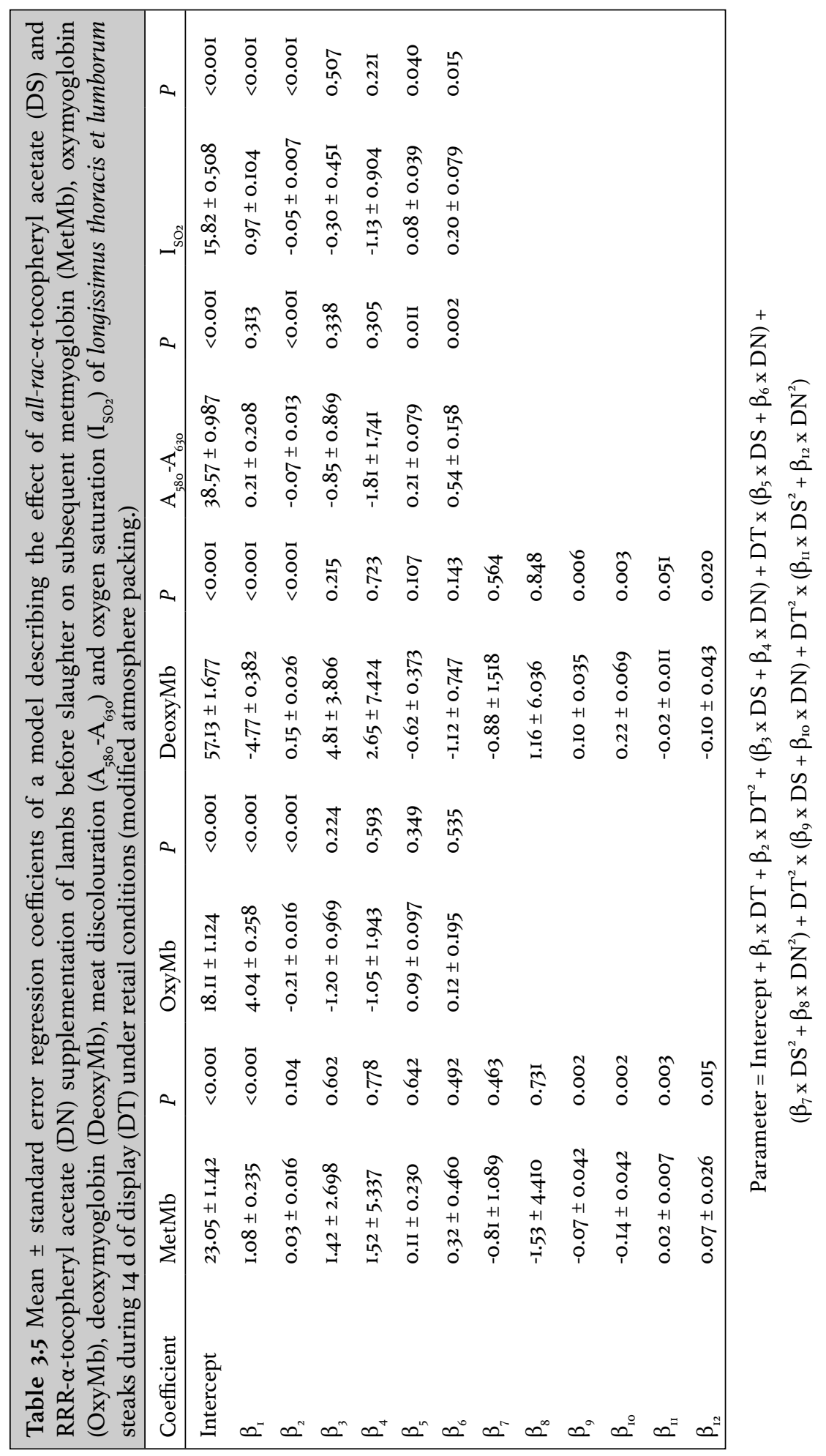


At I d of DT, similar OxyMb levels (2I-22\%) were found across all vitamin E sources and supplementation levels. Oxymyoglobin levels increased with DT until they reach a predicted maximum (at approximately $38 \%$ ) on $\mathrm{d}$ Io, and progressively decrease from that point as DT increased to final values between $34-35 \%$ at $\mathrm{I} 4 \mathrm{~d}$ of display. These findings are in line with previous work, which found the peak of OxyMb to be reached between 7 (Muela et al., 20I4) and I4 d (Lauzurica et al., 2005) of display.
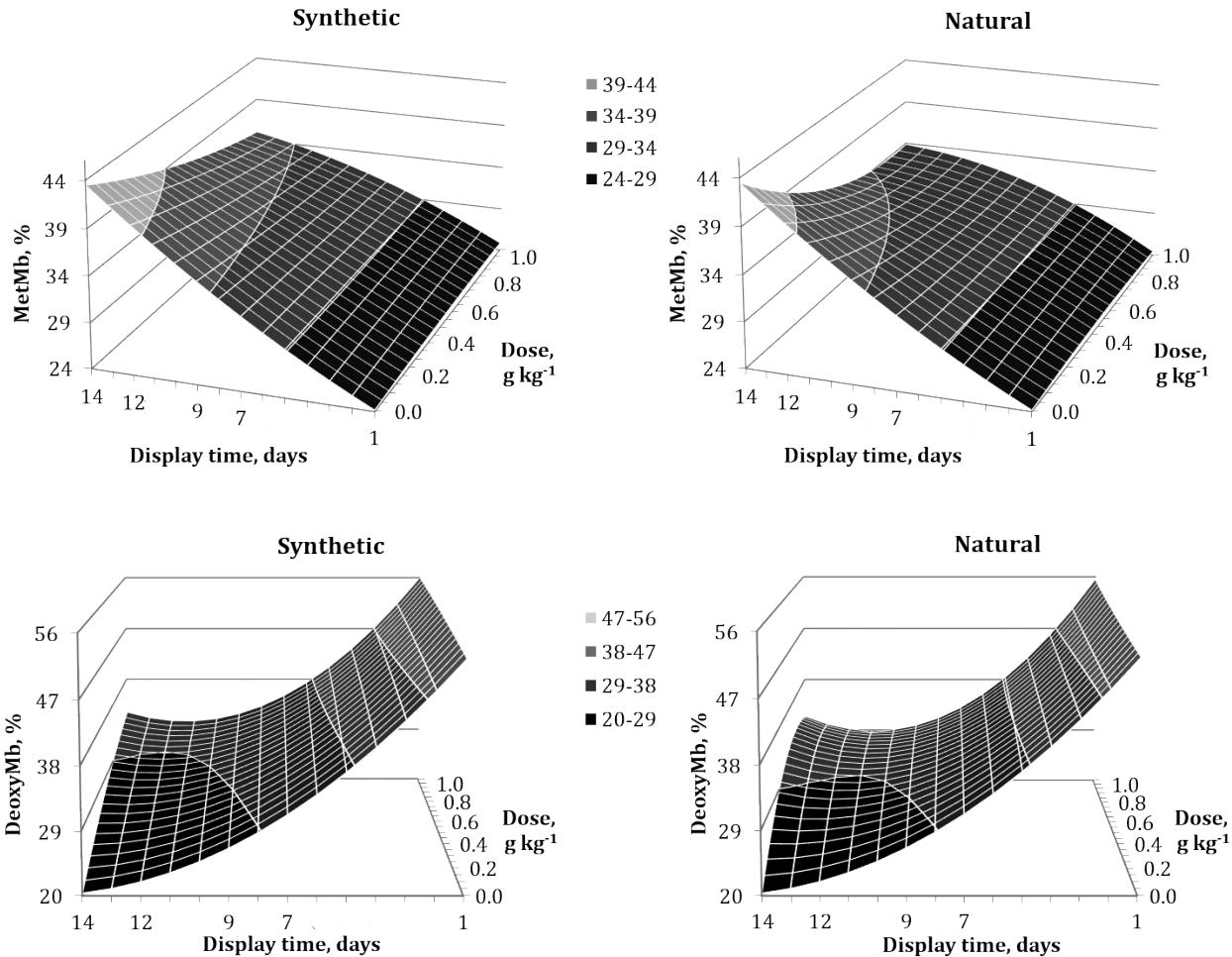

Figure 3.3 Response surface plot of predicted metmyoglobin (MetMb) and deoxymyoglobin (DeoxyMb) content of longissimus thoracis et lumborum steaks of lambs fed different doses of synthetic (all-rac- $\alpha$-tocopheryl acetate) and natural (RRR- $\alpha$-tocopheryl acetate) vitamin $\mathrm{E}$ daily for $\mathrm{I} 4 \mathrm{~d}$ before slaughter and displayed for $\mathrm{I} 4 \mathrm{~d}$ under retail conditions (modified atmosphere packing). 
Deoxymyoglobin is characterized as the purple colour observed in freshly cut meat or vacuum packed product (Mancini and Hunt, 2005). Changes of this parameter during storage are presented also in Table 3.5. Display time was found to be the main factor driving DeoxyMb (Linear and Quadratic, $\mathrm{P}<0.00 \mathrm{O})$, however, significant $(\mathrm{P}<0.05)$ interactions between DT and vitamin E supplementation (DS and DN) were found. As presented in Figure 3.3, DeoxyMb levels were the highest for all treatments on the first day of DT (between 52.5\% and 56\%). Afterwards, DeoxyMb progressively decreased at a different rate depending on vitamin E source and supplementation level. On d I4 of DT, non-supplemented lambs presented $20.3 \%$ of DeoxyMb, whereas, DS supplementation above $0.75 \mathrm{~g} \mathrm{~kg}^{-1}$ or DN supplementation above $0.40 \mathrm{~g} \mathrm{~kg}^{-1}$ ensured DeoxyMb levels higher than $30 \%$.

Ultimately, a prolonged exposure to a highly oxygenated environment (like MAP) leads $\mathrm{OxyMb}$ and DeoxyMb to convert into MetMb (Mancini and Hunt, 2005). In the current study, we found that vitamin E supplementation affected MetMb and DeoxyMb levels in lamb meat. However, no effect was found in OxyMb formation, which was mainly affected by DT.

\section{Meat Discolouration}

Oxygen saturation on the meat surface, assessed by $\mathrm{I}_{\mathrm{SO}_{2}}$, was affected by DT (linear and quadratic, $\mathrm{P}<\mathrm{O} . \mathrm{OoI})$. Moreover, a linear interaction between $\mathrm{DT}$ and vitamin $\mathrm{E}$ supplementation (DS and DN) was found $(\mathrm{P}<0.05)$ (Table 3.5). As previously reported (Lauzurica et al., 2005; Minotti and Aust, 1992), the development of $\mathrm{I}_{\mathrm{SO}_{2}}$ with DT follows the same pattern of OxyMb. Dietary vitamin E supplementation marginally affected the maximum value of $\mathrm{I}_{\mathrm{SO}_{2}}$ in the meat $(20.6 \%$ and $2 \mathrm{I} .7 \%$ for non-supplemented and vitamin $\mathrm{E}$ supplemented groups, respectively) whilst delaying the DT necessary to reach that value. In the case of non-supplemented lambs, DS supplemented lambs up to $0.75 \mathrm{~g} \mathrm{~kg}^{-1}$ and DN supplemented lambs up to $0.30 \mathrm{~g} \mathrm{~kg}^{-1}$, the maximum value of $\mathrm{ISO}_{2}$ is achieved after $10 \mathrm{~d}$ of DT. However, if a DS supplementation level above $2.0 \mathrm{~g} \mathrm{~kg}^{-1}$ or DN supplementations above $0.85 \mathrm{~g} \mathrm{~kg}^{-1}$ are considered, the time to reach the maximum value of $\mathrm{I}_{\mathrm{SO}_{2}}$ can be delayed an additional $2 \mathrm{~d}$.

Another important parameter associated with meat discolouration is $A_{580}-A_{630}$ (Eikelenboom et al., 200o), presented in Table 3.5. Overall, meat discolouration increased significantly with DT in all groups $(\mathrm{P}<\mathrm{O} .00 \mathrm{I})$, with the dietary supplementation level and DT interaction being statistically significant $(\mathrm{P}<0.05)$. After $\mathrm{I} 4 \mathrm{~d}$ of DT, $\mathrm{A}_{580}-\mathrm{A}_{630}$ values were found to be lower in the non-supplemented group when compared with the supplemented group, which suggests higher meat discolouration at lower supplementation levels. Meat from non-supplemented lambs had an $\mathrm{A}_{580}-\mathrm{A}_{630}$ value of $27 \%$ at $\mathrm{d}$ I4 of DT, whereas, DS supplementation above $\mathrm{I} .4 \mathrm{~g} \mathrm{~kg}^{-1}$ or DN supplementation above $0.5 \mathrm{~g} \mathrm{~kg}^{-1}$ resulted in $\mathrm{A}_{580}-\mathrm{A}_{630}$ values higher than 30\%. Early work from (Renerre and Mazuel, 1985) reported a value of I2.5\% as the lower limit of colour acceptability based on $\mathrm{A}_{580}-\mathrm{A}_{630}$. In the current study, if 
$\mathrm{A}_{580}-\mathrm{A}_{630}$ values were to be considered on their own, all treatment groups showed suitable meat colour at d I4 of DT based on the minimum threshold of $12.5 \%$.

\section{CONCLUSIONS}

Dietary vitamin E supplementation of the finishing diets of lambs for $\mathrm{I} 4 \mathrm{~d}$ pre-slaughter increased the lipid and colour stability of meat stored under modified atmosphere packaging for $\mathrm{I} 4 \mathrm{~d}$ of display. Vitamin E supplementation had a clear effect on lipid oxidation as measured by TBARS), instrumental colour ( $a^{*}$ and $h$ ), myoglobin forms (MetMb and DeoxyMb) and meat discoloration $\left(\mathrm{I}_{\mathrm{SO}_{2}}\right.$ and $\left.\mathrm{A}_{580}-\mathrm{A}_{630}\right)$. The effect of supplementation was clearly different between natural and synthetic vitamin $\mathrm{E}$ sources, being natural vitamin E substantially more efficient in affecting the different meat quality parameters during display time. The nutritionally established equivalence between the sources of 1.36 in the international system is not appropriate to be used in meat quality supra-nutritional applications of vitamin $\mathrm{E}$.

\section{ACKNOWLEDGEMENTS}

The authors would like to thank Franco \& Navarro S.A. (Zaragoza, Spain) and Mercazarogoza S.A. (Zaragoza, Spain) for their support in this study. 


\section{REFERENCES}

Albertí, P., G. Ripoll, F. Goyache, F. Lahoz, J. L. Olleta, B. Panea, and C. Sañudo. 2005. Carcass characterisation of seven Spanish beef breeds slaughtered at two commercial weights. Meat Science 7I(3):5I4-52I.

Álvarez, I., J. De la Fuente, M. T. Díaz, S. Lauzurica, C. Pérez, and V. Cañeque. 2008. Estimation of alpha-tocopherol concentration necessary to optimise lamb meat quality stability during storage in high-oxygen modified atmosphere using brokenline regression analysis. Animal 2(9):I405-I4II.

Andrés, S., M. L. Tejido, R. Bodas, L. Morán, N. Prieto, C. Blanco, and F. J. Giráldez. 2013. Quercetin dietary supplementation of fattening lambs at $0.2 \%$ rate reduces discolouration and microbial growth in meat during refrigerated storage. Meat Science 93(2):207-2I2.

Bañón, S., L. Méndez, and E. Almela. 2012. Effects of dietary rosemary extract on lamb spoilage under retail display conditions. Meat Science 90(3):579-583.

Baron, C. P., and H. J. Andersen. 2002. Myoglobin-induced lipid oxidation. A review. Journal of Agricultural and Food Chemistry 50(I4):3887-3897.

Brand, A., R. J. E. Stewart, and K. A. M. Peeters. 2006. Monitoring vitamin E status in Ruminants. Bergh Books, Giethoorn.

Burnham, K. P., and D. R. Anderson. 2002. Model selection and multimodel inference. 2nd edition, Springer Verlag, New York City, New York, USA.

Campo, M. M., G. R. Nute, S. I. Hughes, M. Enser, J. D. Wood, and R. I. Richardson. 2006. Flavour perception of oxidation in beef. Meat Science 72(2):303-3II.

Dersjant-Li, Y., and M. Peisker. 20IO. Utilization of stereoisomers from alpha-tocopherol in livestock animals. Journal of Animal Physiology and Animal Nutrition 94(4):413-42I.

Djenane, D., A. Sánchez-Escalante, J. A. Beltran, and P. Roncalés. 2003. Extension of the shelf life of beef steaks packaged in a modified atmosphere by treatment with rosemary and displayed under UV-free lighting. Meat Science 64(4):4I7-426.

Dunshea, F. R., D. N. D’Souza, D. W. Pethick, G. S. Harper, and R. D. Warner. 2005. Effects of dietary factors and other metabolic modifiers on quality and nutritional value of meat. Meat Science 7I(I):8-38.

Eikelenboom, G., A. H. Hoving-Bolink, I. Kluitman, J. H. Houben, and R. E. Klont. 2000. Effect of dietary vitamin E supplementation on beef colour stability. Meat Science 54(I):I7-22.

Faustman, C., R. G. Cassens, D. M. Schaefer, D. R. Buege, S. N. Williams, and K. K. Scheller. 1989. Improvement of pigment and lipid stability in Holstein steer beef by dietary supplementation with vitamin E. Journal of Food Science 54(4):858-862.

Govaris, A., N. Botsoglou, G. Papageorgiou, E. Botsoglou, and I. Ambrosiadis. 2004. Dietary versus post-mortem use of oregano oil and/or alpha-tocopherol in turkeys to inhibit development of lipid oxidation in meat during refrigerated storage. International Journal of Food Sciences and Nutrition 55(2):II5-I23. 
Gray, J. I., E. A. Gomaa, and D. J. Buckley. 1996. Oxidative quality and shelf life of meats. Meat Science 43:SIII-Si23.

Greene, B. E., and T. H. Cumuze. 1982. Relationship between TBA numbers and inexperienced panelists' assessments of oxidized flavor in cooked beef. Journal of Food Science 47(I):52-54.

Guidera, J., J. P. Kerry, D. J. Buckley, P. B. Lynch, and P. A. Morrissey. 1997. The effect of dietary vitamin E supplementation on the quality of fresh and frozen lamb meat. Meat Science 45(I):33-43.

Huff-Lonergan, E., and S. M. Lonergan. 2005. Mechanisms of water-holding capacity of meat: The role of postmortem biochemical and structural changes. Meat Science 7I(I):194-204.

Jakobsen, M., and G. Bertelsen. 200o. Colour stability and lipid oxidation of fresh beef. Development of a response surface model for predicting the effects of temperature, storage time, and modified atmosphere composition. Meat Science 54(I):49-57.

Jensen, S. K., R. M. Engberg, and M. S. Hedemann. 1999. all-rac-alpha-tocopherol acetate is a better vitamin E source than all-rac-alpha-tocopherol succinate for broilers. The Journal of Nutrition I29(7):1355-1360.

Kamal-Eldin, A., and L. A. Appelqvist. 1996. The chemistry and antioxidant properties of tocopherols and tocotrienols. Lipids 3I(7):67I-70I.

Kerry, J. P., M. G. O’Sullivan, D. J. Buckley, P. B. Lynch, and P. A. Morrissey. 2000. The effects of dietary alpha-tocopheryl acetate supplementation and modified atmosphere packaging (MAP) on the quality of lamb patties. Meat Science 56(I):6I-66.

Khliji, S., R. van de Ven, T. A. Lamb, M. Lanza, and D. L. Hopkins. 20Io. Relationship between consumer ranking of lamb colour and objective measures of colour. Meat Science 85(2):224-229.

Krzywicki, K. 1979. Assessment of relative content of myoglobin, oxymyoglobin and metmyoglobin at the surface of beef. Meat Science 3(I):I-IO.

Lanari, M. C., R. G. Cassens, D. M. Schaefer, and K. K. Scheller. 1994. Effect of dietary vitamin $\mathrm{E}$ on pigment and lipid stability of frozen beef: A kinetic analysis. Meat Science 38(I):3-I5.

Lauzurica, S., J. De la Fuente, M. T. Díaz, I. Álvarez, C. Pérez, and V. Cañeque. 2005. Effect of dietary supplementation of vitamin $\mathrm{E}$ on characteristics of lamb meat packed under modified atmosphere. Meat Science 70(4):639-646.

Liu, Q., M.C. Lanari, and D. M. Schaefer. 1995. A review of dietary vitamin E supplementation for improvement of beef quality. Journal of Animal Science 73(IO):3I3I-3I40.

López-Bote, C. J., A. Daza, M. Soares, and E. Berges. 200I. Dose-response effect of dietary vitamin $\mathrm{E}$ concentration on meat quality characteristics in light-weight lambs. Animal Science 73(3):45I-457.

MacDougall, D. B. 1982. Changes in the color and opacity of meat. Food Chemistry 9(I2):75-88. 
Macit, M., V. Aksakal, E. Emsen, M. I. Aksu, M. Karaoglu, and N. Esenbuga. 2003. Effects of vitamin E supplementation on performance and meat quality traits of Morkaraman male lambs. Meat Science 63(I):5I-55.

Mancini, R. A., and M. C. Hunt. 2005. Current research in meat color. Meat Science 7I(I):IOOI2I.

Minotti, G., and S. D. Aust. 1992. Redox cycling of iron and lipid-peroxidation. Lipids 27(3):219-226.

Mitsumoto, M., S. Ozawa, T. Mitsuhashi, and K. Koide. 1998. Effect of dietary vitamin E supplementation for one week before slaughter on drip, colour and lipid stability during display in Japanese Black steer beef. Meat Science 49(2):I65-I74.

Muela, E., V. Alonso, M. M. Campo, C. Sañudo, and J. A. Beltrán. 20I4. Antioxidant diet supplementation and lamb quality throughout preservation time. Meat Science 98(2):289-295.

Nerín, C., L. Tovar, D. Djenane, J. Camo, J. Salafranca, J. A. Beltrán, and P. Roncalés. 2006. Stabilization of beef meat by a new active packaging containing natural antioxidants. Journal of Agricultural and Food Chemistry 54(20):7840-7846.

O'Sullivan, M. G., D. V. Byrne, H. Martens, L. H. Gidskehaug, H. J. Andersen, and M. Martens. 2003. Evaluation of pork colour: prediction of visual sensory quality of meat from instrumental and computer vision methods of colour analysis. Meat Science 65(2):909-918.

Pfalzgraf, A., M. Frigg, and H. Steinhart. 1995. Alpha-tocopherol contents and lipid oxidation in pork muscle and adipose tissue during storage. Journal of Agricultural and Food Chemistry 43(5):1339-1342.

Renerre, M., and J. P. Mazuel. 1985. Relations entre méthodes de mesures instrumentales et sensorielles de la couleur de la viande. Science des Aliments (5):54I-557.

Ripoll, G., L. González-Calvo, F. Molino, J. H. Calvo, and M. Joy. 20I3. Effects of finishing period length with vitamin E supplementation and alfalfa grazing on carcass color and the evolution of meat color and the lipid oxidation of light lambs. Meat Science 93(4):906-9I3.

Ripoll, G., M. Joy, and F. Munoz. 20II. Use of dietary vitamin E and selenium (Se) to increase the shelf life of modified atmosphere packaged light lamb meat. Meat Science 87(I):8893.

Ripoll, G., M. Joy, F. Muñoz, and P. Albertí. 2008. Meat and fat colour as a tool to trace grassfeeding systems in light lamb production. Meat Science 8o(2):239-248.

Schwarz, G. 1978. Estimating the Dimension of a Model. The Annals of Statistics 6(2):46I464 .

Tarladgis, B. G., B. M. Watts, M. T. Younathan, and L. Dugan. 1960. A distillation method for the quantitative determination of malonaldehyde in rancid foods. Journal of the American Oil Chemists Society 37(I):44-48. 
Tsuruga, T., T. Ito, M. Kanda, S. Niwa, T. Kitazaki, T. Okugawa, and S. Hatao. 1994. Analysis of meat pigments with tissue spectrophotometer TS-200. Meat Science 36(3):423-434.

USP. 1979. The United States Pharmacopeia. National Formulary. United States Pharmacopeial Convention, Rockville, Maryland, USA.

van den Oord, A. H. A., and J. J. Wesdorp. 197I. Colour rating and pigment composition of beef: Relation between colour measurement by reflectance spectrophotometry, subjective colour evaluation, and the relative concentration of oxymyoglobin and ferric myoglobin in chilled retail-packed beef. International Journal of Food Science \& Technology 6(I):I5-20.

Weiser, H., and M. Vecchi. 1982. Stereoisomers of alpha-tocopheryl acetate. II. Biopotencies of all eight stereoisomers, individually or in mixtures, as determined by rat resorptiongestation tests. Journal for Vitamin and Nutrition Research. Internationale Zeitschrift für Vitamin- und Ernáhrungsforschung. Journal International de Vitaminologie et de Nutrition 52(3):35I-370.

Wulf, D. M., J. B. Morgan, S. K. Sanders, J. D. Tatum, G. C. Smith, and S. Williams. 1995. Effects of dietary supplementation of vitamin $\mathrm{E}$ on storage and caselife properties of lamb retail cuts. Journal of Animal Science 73(2):399-405.

Wyszecki, G., and W. G. Styles. 1982. Color Science: Concepts and methods, Quantitative Data and Formulae. 2nd edition, John Wiley \& Sons, New York City, New York, USA. 


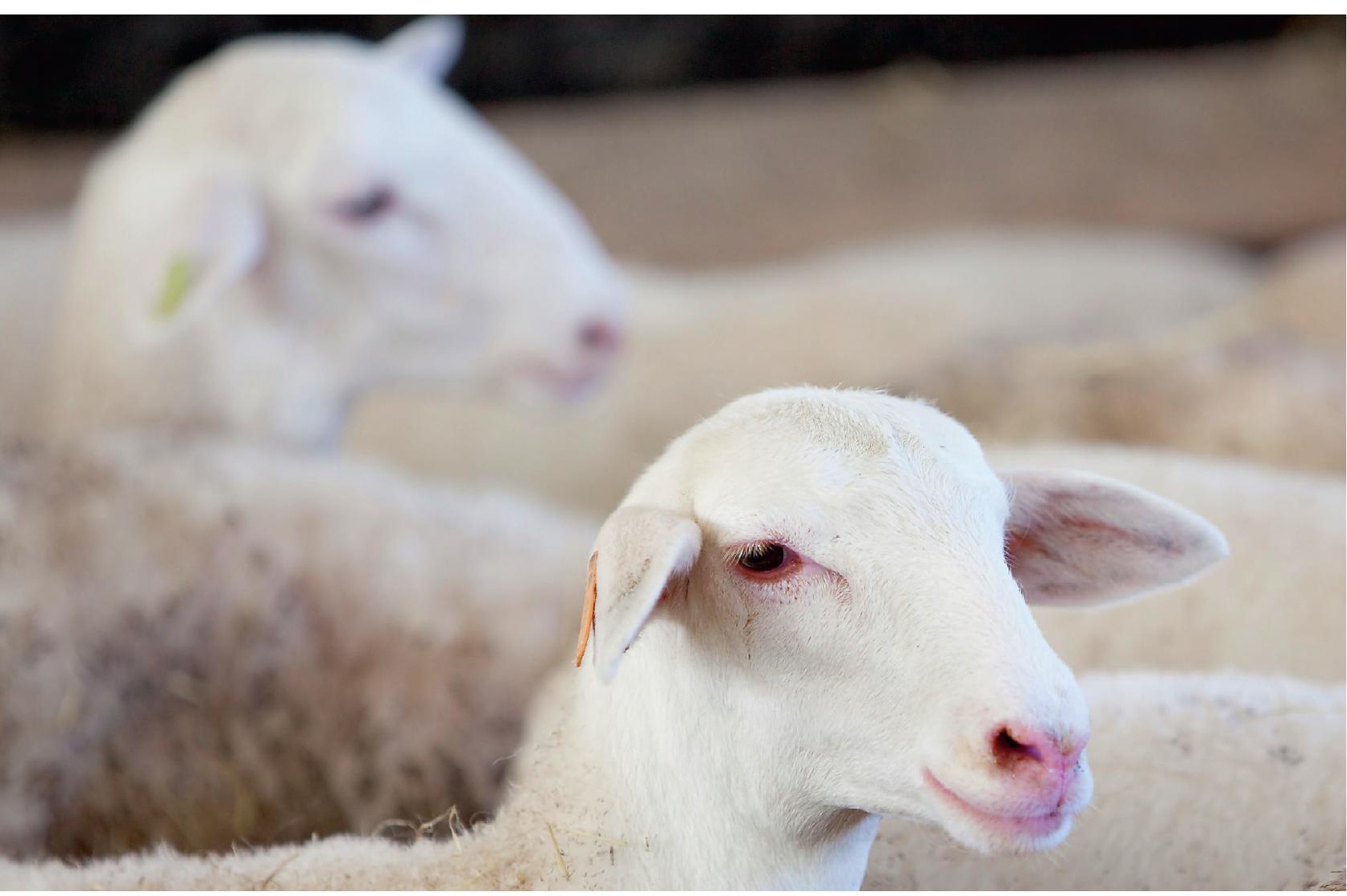




\section{Chapter 4}

\section{Effect of dietary vitamin E on physicochemical and fatty acid stability of fresh and thawed lamb}

M. Bellés ${ }^{a}$, L. N. Leal ${ }^{b}$, V. Díaz ${ }^{a}$, V. Alonso ${ }^{a}$, P. Roncalés ${ }^{a}$ and J. A. Beltrán ${ }^{a}$

a Departamento Tecnología de los Alimentos, Facultad de Veterinaria, Miguel Servet 177-50013 Zaragoza, Spain.

${ }^{\mathrm{b}}$ Trouw Nutrition Research and Development, P.O. Box 299, 3800 AG, Amersfoort, the Netherlands.

Food Chemistry (2018) 239:1-8

https://doi.org/10.1016/j.foodchem.2017.06.076 


\begin{abstract}
This study evaluated the effect of dietary vitamin E supplementation (IOoo mg of DL- $\alpha$ tocopheryl acetate $\mathrm{kg}^{-1}$ of basal diet) on physicochemical and fatty acid stability of fresh and thawed lamb leg chops frozen stored for 3, 6 and 9 months. Legs were chopped, modified atmosphere packaged $\left(70 \% \mathrm{O}_{2} / 30 \% \mathrm{CO}_{2}\right)$ and maintained under retail conditions ( $4 \pm 0.5^{\circ} \mathrm{C}$, with $\mathrm{I} 4 \mathrm{~h}$ fluorescent light) during $9 \mathrm{~d}$. Muscle $\alpha$-tocopherol concentration was over 3.5-fold higher in supplemented than in control lambs. The effect of dietary vitamin E was independent of frozen storage, so these effects were analysed separately. Vitamin E supplementation reduced lipid oxidation $(\mathrm{P}<\mathrm{O} . \mathrm{OoI})$ and decreased metmyoglobin formation, leading to a more attractive colour of meat. Moreover, supplementation led to a higher percentage of polyunsaturated fatty acids. Therefore, vitamin E supplementation could be recommended for preserving either fresh or thawed lamb.
\end{abstract}




\section{INTRODUCTION}

Colour is the main sensory property of lamb used by consumers to select a product at the time of purchase (Jeremiah, 200I). A bright red colour is traditionally considered a positive aspect since it is associated with freshness and superior product quality (Berruga et al., 2005). Fresh lamb for retail sale is therefore commonly packaged in an oxygen enriched atmosphere with the aim of enhancing this colour development (Bellés et al., 20I7). A disadvantage of these packaging conditions is the development of lipid oxidation, which leads to a decrease in meat quality, concerning colour, aroma, flavour, texture and even fatty acid composition (particularly polyunsaturated) (Rodríguez-Carpena et al., 20II).

The inclusion of vitamin $\mathrm{E}$ in the basal compound feed of lambs during the last days before slaughter has been proposed to overcome these problems, obtaining promising results (Lauzurica et al., 2005; Ripoll et al., 20II; Jose et al., 20I6). Vitamin E is not degraded in the rumen (Leedle et al., 1993) and then, it accumulates in cell membranes and lipid depots, where it shows antioxidant activity (Liu et al., 1996). It has been satisfactorily applied to reduce lipid oxidation of fresh meat, showing a better colour stability and reducing off odours and flavours (Kerry et al., 2000; Ripoll et al., 201I). However, the knowledge about the effect of vitamin $\mathrm{E}$ on lamb quality after long-term frozen storage is scarce. Freezing is commonly used for long-term preservation as it results in a greater flexibility for distributors and retailers. Nonetheless, the possible negative effect of freezing and thawing on meat quality is still a point of concern. Primary compounds of lipid oxidation are formed during frozen storage, which lead to lipid oxidation secondary radicals after thawing. This phenomenon produces adverse changes on colour, odour, flavour and nutritional value (Owen and Lawrie, 1975). Thus, dietary vitamin E may be envisaged as a very suitable tool for inhibiting deteriorative oxidation of thawed lamb. The aim of this work was therefore to investigate the effect of dietary vitamin E on colour, lipid oxidation and fatty acid stability of fresh lamb and thawed lamb after frozen storage for three, six or nine months, maintained under retail conditions.

\section{MATERIALS AND METHODS}

The lambs used for this trial were reared in accordance with the guidelines from the Spanish Ministry of Agriculture (Boletín Oficial del Estado (BOE), 2007)

\section{Slaughtering, Storage, Packaging and Refrigerated Storage}

Sampling procedure is shown in Figure 4.I. 


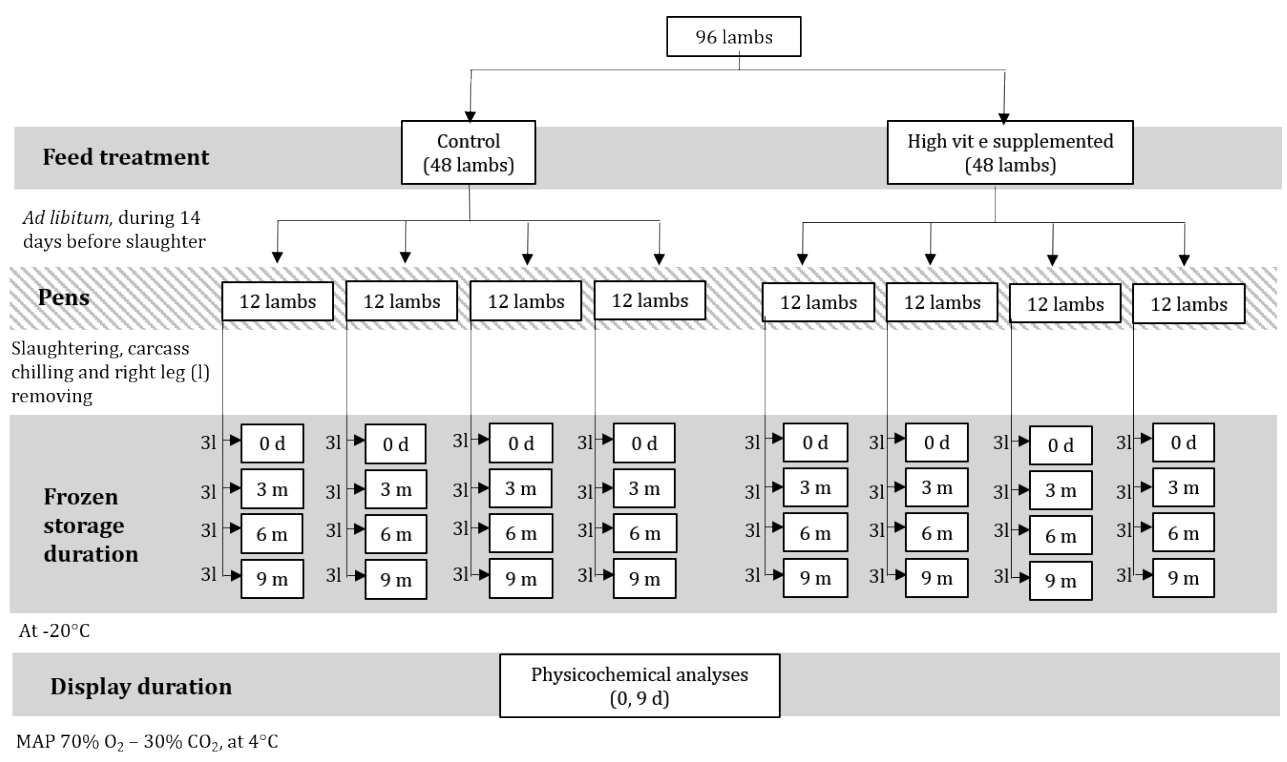

Figure 4.I Sampling procedure.

Ninety six male Rasa Aragonesa lambs, a medium wool breed that is reared for meat purpose in Spain, with an average body weight of $22.3 \pm 0.25 \mathrm{~kg}$ were randomly allocated in 8 different pens (I2 lambs per pen). Four pens were fed with a basal diet containing 30 $\mathrm{mg} \mathrm{kg}^{-1}$ feed of DL- $\alpha$-tocopheryl acetate (control feed, C) while the other four received the basal diet plus Iooo $\mathrm{mg} \mathrm{kg}^{-1}$ feed of DL- $\alpha$-tocopheryl acetate (high supplemented feed, HS). Ingredients and chemical composition of the concentrates are presented in Table 4.I.

Lambs were offered ad libitum access to the experimental compound feed and wheat straw, for $14 \mathrm{~d}$ before slaughter. Thereafter, lambs were slaughtered at a local slaughterhouse with a body weight of $25.8 \pm 0.7 \mathrm{Ig}$ and the carcasses were chilled during $24 \mathrm{~h}$ at $4^{\circ} \mathrm{C}$.

The right leg of each carcass was removed and assigned (I2 carcasses of each feed treatment) to one of the four frozen storage durations: o d (fresh meat), 3, 6 and 9 months. Prior to freezing, lamb legs were vacuum packaged (-900 mbar of pressure) in polyethylenepolyamide bags with ethyl vinyl acetate sealant layer $(30 \times 25 \mathrm{~cm}, 90 \mu \mathrm{m}$ thickness, water vapour transmission rate at $23 \pm \mathrm{I}^{\circ} \mathrm{C}$ of $2.8 \mathrm{~g} / \mathrm{m}^{2} / 24 \mathrm{~h} 85 \pm 2 \% \mathrm{RH}$, an $\mathrm{O}_{2}$ transmission rate at $23 \pm \mathrm{I}^{\circ} \mathrm{C}$ of $50 \mathrm{~cm}^{3} / \mathrm{m}^{2} / 24 \mathrm{~h} / \mathrm{bar} 75 \pm 2 \% \mathrm{RH}$ and $\mathrm{aCO}$ transmission rate at $23 \pm \mathrm{I}^{\circ} \mathrm{C}$ of $\mathrm{I} 5 \mathrm{O}$ $\mathrm{cm}^{3} / \mathrm{m}^{2} / 24 \mathrm{~h} /$ bar; Eurobag \& Film S.L., Spain) using a Tecnotrip EV-I3-L-CD-SC machine (Tecnotrip S.A., Spain) to prevent freezer burn and water losses. Frozen storage conditions $\left(-20^{\circ} \mathrm{C}\right)$ were monitored with a data logger Testo $\mathrm{I} 75-\mathrm{H} 2$ (Testo S.A., Spain). 


\begin{tabular}{|c|c|c|}
\hline Raw material (\%) & Control feed & $\begin{array}{l}\text { High vitE } \\
\text { supplemented feed }\end{array}$ \\
\hline Barley grain & 28.5 & 28.5 \\
\hline Corn grain & 32.0 & 32.0 \\
\hline Wheat grain & 6.0 & 6.0 \\
\hline Toasted soybean meal & 26.0 & 26.0 \\
\hline Beet molasses & 2.0 & 2.0 \\
\hline Powder milk serum & I.O & I.O \\
\hline Animal fats & I.O & I.O \\
\hline Fatty acids calcium salts & I.O & I.O \\
\hline Calcium carbonate & 2.0 & 2.0 \\
\hline Salt & 0.5 & 0.5 \\
\hline \multicolumn{3}{|l|}{ Chemical composition (\%) } \\
\hline Crude protein & I7.0 & I7.0 \\
\hline Crude fibre & 3.9 & 3.9 \\
\hline Crude fat & 4.0 & 4.0 \\
\hline Ash & 6.0 & 6.0 \\
\hline Salt & 0.2 & 0.2 \\
\hline \multicolumn{3}{|l|}{ Additives } \\
\hline Vitamin A & I3000 UI kg-1 & I3000 UI kg-1 \\
\hline Vitamin $\mathrm{D}_{3}$ & 3000 UI kg ${ }^{-1}$ & 3000 UI kg-1 \\
\hline DL- $\alpha$-tocopheryl acetate & $30 \mathrm{mg} \mathrm{kg}^{-1}$ & IOOO $\mathrm{mg} \mathrm{kg-1}$ \\
\hline Total oligoelements & $199.05 \mathrm{mg} \mathrm{kg}^{-1}$ & $199.05 \mathrm{mg} \mathrm{kg}^{-1}$ \\
\hline Butilhidroxitoluene (BHT) & $30 \mathrm{mg} \mathrm{kg}^{-1}$ & $30 \mathrm{mg} \mathrm{kg}^{-1}$ \\
\hline
\end{tabular}

After the corresponding frozen storage duration (o d, 3, 6 or 9 months) legs were sliced in $20 \mathrm{~mm}$ chops in the facilities of Casa Ganaderos (Zaragoza, Spain) and then, chops were transported to the pilot plant of the Faculty of Veterinary (University of Zaragoza), where they were modified atmosphere packaged $\left(70 \% \mathrm{O}_{2}\right.$ and $\left.30 \% \mathrm{CO}_{2}\right)$ with a product to gas ratio of I:3 (ULMA-SMART-500). Polystyrene trays were used and sealing was done with a polyethylene and polyamide laminate film $(30 \mu \mathrm{m}$ of thickness, water vapour transmission rate at $23^{\circ} \mathrm{C}$ of $<7 \mathrm{~g} / \mathrm{m}^{2} / 24 \mathrm{~h} / \mathrm{bar} / 85 \%$ relative humidity $(\mathrm{RH})$, an $\mathrm{O}_{2}$ transmission rate at $23^{\circ} \mathrm{C}$ of $<\mathrm{I} 5 \mathrm{~cm}^{3} / \mathrm{m}^{2} / \mathrm{bar} \mathrm{O} \%$ R.H. and a $\mathrm{CO}_{2}$ transmission rate at $23^{\circ} \mathrm{C}$ of $<75 \mathrm{~cm}^{3} / \mathrm{m}^{2} / 24 \mathrm{~h} / \mathrm{bar}$ o\% R.H.; Linpac Packaging S.L., Spain). Samples were displayed under retail conditions 
( $4 \pm 0.5^{\circ} \mathrm{C}$, with $\mathrm{I} 4 \mathrm{~h}$ fluorescent light) during $9 \mathrm{~d}$ of storage. Chops from frozen legs thawed within the package during the display period at $4^{\circ} \mathrm{C}$.

The content of $\alpha$-tocopherol was measured in the muscle semimembranosus after carcass chilling. Instrumental colour, lipid oxidation and fatty acid profile analyses were performed at $\mathrm{o}$ and $9 \mathrm{~d}$ after packaging using only the muscle semimembranosus.

\section{Content of $\alpha$-Tocopherol in Semimembranosus}

The content of $\alpha$-tocopherol in tissue was determined following the methodology described by Liu et al. (1996) and Kasapidou et al. (2012). Samples were analysed by reverse phase HPLC (LiChrospher RP-I8 column, $4.60 \times \mathrm{I} 50 \mathrm{~mm}, 5 \mu \mathrm{m}$, Ioo $\AA$ ) with a mobile

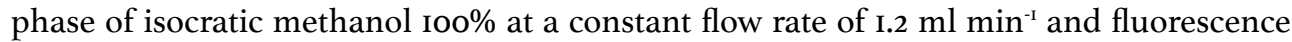
detection ( $\lambda$ excitation $=295 \mathrm{~nm}$ and $\lambda$ emision $=330 \mathrm{~nm}$; Agilent Series IIOO). The injection volume was $20 \mu \mathrm{l}$ and 9 minutes of run time. For peak identification and quantification $( \pm)-\alpha$-tocopherol was used as external standard. Results were expressed as $\mathrm{mg}$ vitamin $\mathrm{E}$ $\mathrm{kg}^{-\mathrm{I}}$ fresh meat.

\section{Instrumental Colour}

A Minolta CM-2002 (Osaka, Japan) spectrophotometer was used for measuring colour at the surface of a $20-\mathrm{mm}$-thick chop just after opening the tray. The parameters registered were $L^{*}$ (lightness), $a^{*}$ (redness) and $b^{*}$ (yellowness) values. A D65 illuminant was used at an observation angle of $10^{\circ}$ and with a cell opening of $30 \mathrm{~mm}$. Equipment was previously calibrated using a white and black standard. Ten measurements were done in each sample. The hue angle $(\mathrm{h})$ and chroma $\left(\mathrm{C}^{*}\right)$ indexes were calculated as: $h=\tan ^{-1}(\mathrm{~b} / \mathrm{a})$ expressed in degrees, and $C^{*}=\sqrt{ }\left(a^{2}+b^{2}\right)$. The ratio 630/580 values were calculated dividing the percentage of light reflectance at wavelength $630 \mathrm{~nm}$ by the percentage of light reflectance at wavelength $580 \mathrm{~nm}$. The relative content of metmyoglobin was calculated from the reflectance curve according to Krzywicky (1979) using 690nm (the highest wavelength of the instrument).

\section{Lipid Oxidation}

Lipid oxidation was determined following the methodology described by Alonso et al. (20I5).

\section{Intramuscular Fat and Fatty Acid Analysis}

The muscle semimembranosus was ground and Io $g$ were used to extract the fat in chloroformmethanol (I:I v/v), with 2, 6-di-tert-butyl-4-methylphenol (BHT) (I g/IO ml methanol) as antioxidant (Bligh and Dyer, 1959). One millilitre of chloroform phase was used to assess the percentage of intramuscular fat (IMF) by drying at $100^{\circ} \mathrm{C}$ for $20 \mathrm{~min}$; the results were expressed as the weight percentage of wet muscle. The rest was evaporated in a sand bath under nitrogen gas at $50^{\circ} \mathrm{C}$. The fatty acid methyl esters (FAMES) were formed using a $\mathrm{KOH}$ 
solution in methanol and collected in hexane for analysis by gas chromatography following the methodology described by Carrilho et al. (2009). The FAMES were analysed in a gas chromatograph HP-6890 II (Hewlett-Packard, Waldbronn, Germany) using a capillary column SP-2380 (IOO $\mathrm{m} \times 0.25 \mathrm{~mm} \times 0.20 \mu \mathrm{m}$ ), and oven temperature programming as follows: column temperature was set at $140^{\circ} \mathrm{C}$, then raised at a rate of $3^{\circ} \mathrm{C} \mathrm{min}^{-1}$ from $\mathrm{I} 30$ to $\mathrm{I}^{\circ} 8^{\circ} \mathrm{C}$, and $\mathrm{I}^{\circ} \mathrm{C}$ min-I to $165^{\circ} \mathrm{C}$, kept for Io min, raised at 5 to $220^{\circ} \mathrm{C}$ and kept constant for 50 min. Nitrogen was used as a gas carrier at a constant flow rate of $0.8 \mathrm{ml} \mathrm{min}{ }^{-1}$ with an injected volume of I $\mu$ l. The methyl esters were identified using retention times of Supelco ${ }^{\circledR} 37$ Component FAME Mix. Data regarding FAMES composition was expressed as area percentage of total identified FAMES. Fatty acid Ci9:0 was used as the internal standard for quantification. All chemicals were supplied by Sigma-Aldrich.

\section{Statistical Analysis}

The effects of feed treatment (FT), frozen storage duration (FSD), display duration (D), and their interactions on meat quality traits, were assessed using the GLM procedure of the SPSS statistical package, version I9.0 (IBM SPSS, 20I0), with pen as random effect. The model is as follows:

$$
Y_{i j k l}=\mu+F T_{i}+F S D_{j}+D_{k}+A_{l}+\left(F T_{i} \times F S D_{j}\right)+\left(F T_{i} \times D_{k}\right)+\left(F S D_{j} \times D_{k}\right)+\left(F T_{i} \times F S D_{j} \times D_{k}\right)+e_{i j k l}
$$

Where Yijkl is the dependent variable; $\mu$ is the population average; $\mathrm{FT}_{\mathrm{i}}$ is the fixed effect of the feeding treatment (C, HS); $\mathrm{FSD}_{j}$ is the fixed effect of frozen storage duration (o d, 3 , 6, 9 months); $D_{k}$ is the fixed effect of display duration (o, $\left.9 \mathrm{~d}\right) ; \mathrm{Al}$ is the random effect of pen; $\left(\mathrm{FT}_{\mathrm{i}} \times \mathrm{FSD}_{\mathrm{j}}\right)$ is the interaction effect of feed treatment and frozen storage duration; $\left(\mathrm{FT}_{\mathrm{i}} \times \mathrm{D}_{\mathrm{k}}\right)$ is the interaction effect of feed treatment and display duration; $\left(\mathrm{FSD}_{\mathrm{j}} \times \mathrm{D}_{\mathrm{k}}\right)$ is the interaction effect of frozen storage duration and display duration; $\left(\mathrm{FT}_{i} \times \mathrm{FSD}_{\mathrm{j}} \times \mathrm{D}_{\mathrm{k}}\right)$ is the interaction effect of feed treatment, frozen storage duration and display duration; and eijkl is the aleatory error. Differences were declared significant when $\mathrm{P}<0.05$. Tukey's post hoc test was used to assess differences between mean values when $\mathrm{P}<0.05$.

There was not any interaction between the effects of frozen storage conditions and feed treatment on the variables measured, so both effects were analysed separately. However, significant interactions $(\mathrm{P}<\mathrm{O} . \mathrm{ooI})$ between each one of them and display time were noted for lipid oxidation and colour, so a second model was designed for these variables where the effect of frozen storage conditions and feed treatment were analysed within the day of display and vice versa. This model determined the quality differences among treatments in each day of study and it also assessed changes of each treatment over the days of study. Fatty acid profile was not affected by the interactions among the fixed effects so the effects of frozen storage conditions, feed treatment and display duration on fatty acid profile were analysed separately. 


\section{RESULTS AND DISCUSSION \\ Content of $\alpha$-Tocopherol in Muscle}

Table 4.2 shows the content of $\alpha$-tocopherol in muscle at slaughter. Following the recommendations of the Agricultural Research Council (ARC, I980), the basal diet contained $30 \mathrm{mg}$ of DL- $\alpha$-tocopherol $\mathrm{kg}^{-1}$ in order to satisfy the minimal nutritional requirements for normal growth and health of sheep.

The content of $\alpha$-tocopherol in semimembranosus at this vitamin E level was $1.057 \mathrm{mg} \mathrm{kg}^{-1}$ meat, which agreed with previously published data. Both Lauzurica et al. (2005) and Álvarez et al. (2009) quantified $0.95 \mathrm{mg}$ of $\alpha$-tocopherol per $\mathrm{kg}$ of muscle in lambs fed with a basal diet. Kasapidou et al. (2012) also registered a similar concentration in muscle at slaughter $\left(0.73 \mathrm{mg} \mathrm{kg}^{-1}\right)$. Compared with the concentration of vitamin $\mathrm{E}$ obtained with the basal diet, the muscle deposition of vitamin E strongly increased with the supplementation of lambs with Iooo $\mathrm{mg} \mathrm{kg}^{-1}$ of $\mathrm{DL}$ - $\alpha$-tocopheryl acetate $(\mathrm{P}<\mathrm{O}$.0oI). As a result, muscle vitamin $\mathrm{E}$ concentration at slaughter was over 3.5-fold higher in supplemented than in control lambs.

Table 4.2 M. semimembranosus $\alpha$-tocopherol concentration after slaughter of high (IOoO $\mathrm{mg}$ of DL- $\alpha$-tocopheryl acetate $\mathrm{kg}^{-1}$ of feed) and low supplemented (30 $\mathrm{mg}$ of DL- $\alpha$-tocopheryl acetate $\mathrm{kg}^{-1}$ of feed) (control) lambs.

\begin{tabular}{|lllll|}
\hline Item & $\mathrm{C}$ & $\mathrm{HS}$ & SEM & P value \\
$\alpha$-tocopherol $\left(\mathrm{mg} \mathrm{kg}^{-1}\right)$ & $\mathrm{I} .057$ & 3.908 & $0.2 \mathrm{OI}$ & $<0.00 \mathrm{I}$ \\
\hline
\end{tabular}

$\mathrm{C}=$ Control feed. $\mathrm{HS}=$ high supplemented feed. SEM = standard error of the mean.

The deposition of vitamin $\mathrm{E}$ in muscle depends on the length and the level of supplementation (González-Calvo et al., 20I5; Jose et al., 2016). Kasapidou et al. (2012) obtained a concentration in muscle $\left(3.73 \mathrm{mg} \alpha\right.$-tocopherol $\mathrm{kg}^{-1}$ muscle) similar to that we found using a lower level of vitamin E (500 $\left.\mathrm{mg} \mathrm{kg}^{-1}\right)$ but extending the period of supplementation to $63 \mathrm{~d}$. In contrast, Lauzurica et al. (2005) and Álvarez et al. (2009) observed a similar deposition with a supplementation length of $37 \mathrm{~d}$ and a level of vitamin E of $1000 \mathrm{mg} \mathrm{kg}^{-1}$.

Jose et al. (20I6) established a concentration of 3.5-4.0 $\mathrm{mg} \alpha$-tocopherol $\mathrm{kg}^{-1}$ tissue as the threshold above which no added benefit of vitamin $\mathrm{E}$ on meat colour can be expected while Álvarez et al. (2008) did not observe any difference in inhibiting lipid oxidation when muscle $\alpha$-tocopherol concentration overpasses 1.87 and $2.37 \mathrm{mg} \mathrm{kg}^{-1}$ meat. Our results showed that these concentrations of vitamin $\mathrm{E}$ in muscle may be reached already after I4 d of high vitamin

E level supplementation, which would represent a significant economical saving. Either natural or artificial vitamin $\mathrm{E}$ has a high cost, so optimizing a rate of supplementation is the key to achieve the maximum improvement in product quality without an unnecessary cost (González-Calvo et al., 20I5). 


\section{Instrumental Colour}

Effect of dietary vitamin $E$

Dietary vitamin E supplementation did not modify Hue, Chroma, metmyoglobin (MetMb) content or the $630 / 580$ index before display but its effect on colour after $9 \mathrm{~d}$ was significant (Table 4.3). Increasing the rate of supplementation resulted in lower values for Hue and higher for the ratio 630/580 than those measured in control samples at $9 \mathrm{~d}$ post-packaging ( $\mathrm{P}<\mathrm{O}$.00I). Similar results were obtained by Ripoll et al. (20II) when they evaluated the effect of vitamin $\mathrm{E}$ on lamb colour. These results could be explained by the different content of metmyoglobin noted in control and vitamin E supplemented samples after display $(\mathrm{P}<\mathrm{O} . \mathrm{OoI})$. In fact, higher contents of metmyoglobin are related to changes in colorimetric parameters such as an increase of Hue or a decrease of the 630/580 ratio (Liu et al., 1996). According to Lawrie (1998), a brownish discolouration can be perceived onto meat surface when $60 \%$ of meat pigment is oxidised to metmyoglobin. This percentage was exceeded in control samples after $9 \mathrm{~d}$ of display while dietary vitamin $\mathrm{E}$ allowed to maintaining a better colour for a longer period of time. However, Ripoll et al. (20II) observed that consumers rejected lamb when the value of the index 630/580 fell below 2.23, which was observed either in control or supplemented lamb. Therefore, despite the great effect of vitamin $\mathrm{E}$ on preventing discolouration, the concentration of $\alpha$-tocopherol reached in muscle was unable to maintain a desirable colour during $9 \mathrm{~d}$ of display. 


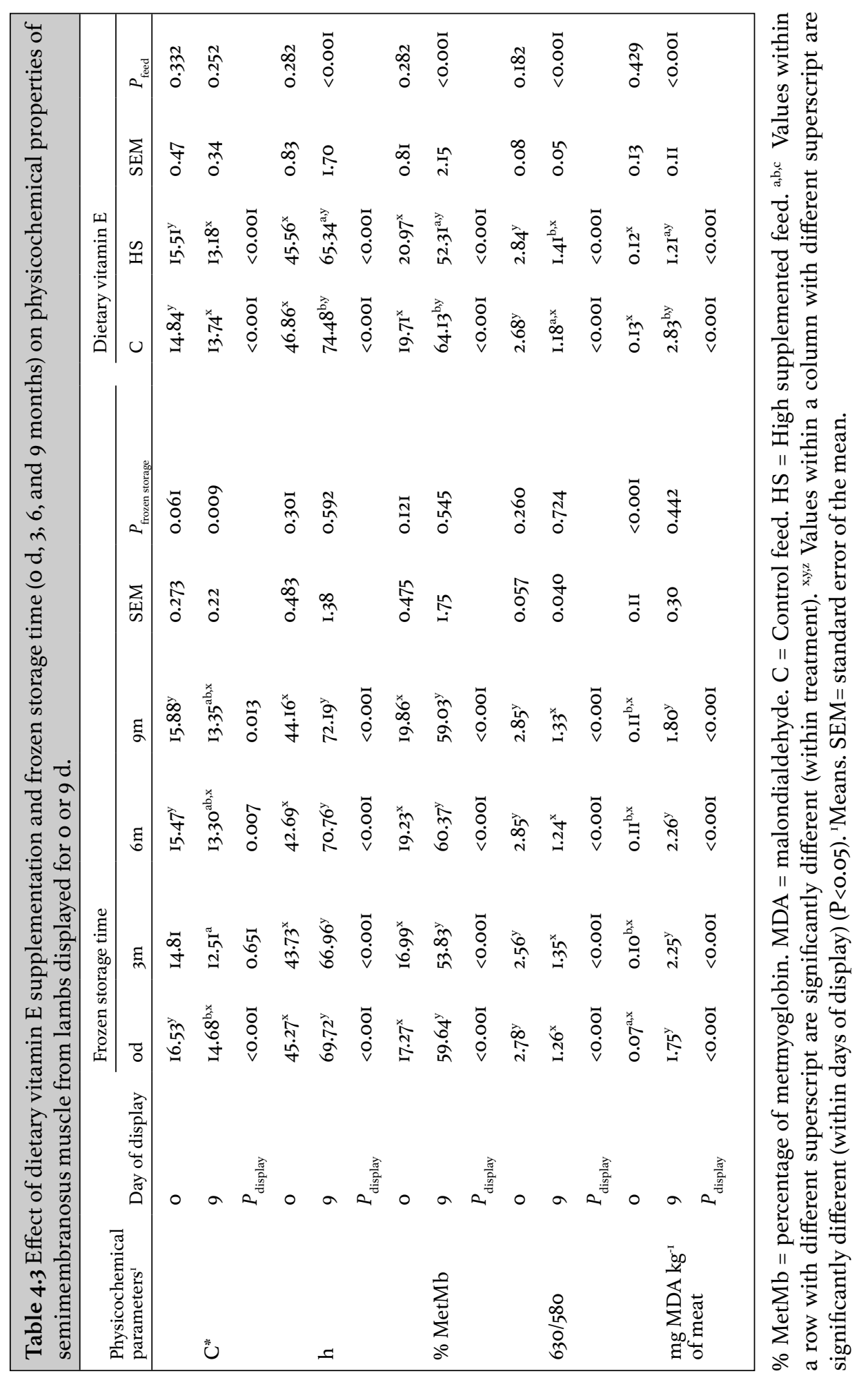




\section{Effect of frozen storage}

As it is shown in Table 4.3, significant differences were not found in $h$ and 630/580 values between fresh and thawed lamb either before or after display. Concerning the content of metmyoglobin found in fresh lamb before display, it was similar to values previously registered in fresh meat (Ripoll et al., 20II, Muela et al., 20I4). These initial values did not differ significantly from those measured in thawed meat. Moreover, frozen storage prior to thawing did not result in an increase of metmyoglobin content after display. At this time, differences were only found in Chroma, showing fresh lamb the highest values $(\mathrm{P}<0.05)$.

\section{Lipid Oxidation}

\section{Effect of dietary vitamin $E$}

The effect of dietary vitamin $\mathrm{E}$ on TBARS index is shown in Table 4.3. There was no difference between both treatments before display, which may be due to a residual activity of muscle enzymes post-mortem (Renerre et al., 1996) and the presence of cell antioxidant compounds. However, control samples showed a higher malondialdehyde content after 9 $\mathrm{d}(\mathrm{P}<\mathrm{O}$.ooI). The large amount of malonaldehyde measured in controls at this time agreed with bibliography (Lauzurica et al., 2005) and it could be related to the high percentage of $\mathrm{O}_{2}$ of the atmosphere used for this trial, which has been described to enhance lipid oxidation ( $\mathrm{O}^{\prime}$ Grady et al. 2000). In contrast, oxidative reactions were significantly inhibited by the inclusion of vitamin $\mathrm{E}$ in the basal feed $(\mathrm{P}<\mathrm{O}$.ooI). Dietary vitamin E supplementation reduced at least half the content of MDA found in control samples after $9 \mathrm{~d}$ of display.

The effectiveness of vitamin $\mathrm{E}$ on reducing lipid oxidation in fresh lamb had been already described. Ripoll et al. (2OII) reported that treatments with vitamin E kept low values of MDA (O.I-0.23 mg MDA $\mathrm{kg}^{-1}$ ) while control treatments reached values greater than I.5 mg kg-1. Lauzurica et al. (2005) and Muela et al. (2014) also found a strong inhibition of lipid oxidation by adding vitamin E in the basal feed. According to Álvarez et al. (2008), a concentration of $\alpha$-tocopherol comprised between $\mathrm{I} .87$ and $2.37 \mathrm{mg} \alpha$-tocopherol $\mathrm{kg}^{-1}$ meat may be enough for optimum improvement against lipid oxidation while González-Calvo et al. (2015) suggested that it could be even lower (0.6I-0.90 $\mathrm{mg} \alpha$-tocopherol kg-1 muscle). Nevertheless, our results showed a development of lipid oxidation reactions with a higher content of $\alpha$-tocopherol in muscle (3.908 mg $\alpha$-tocopherol $\mathrm{kg}^{-1}$ muscle). These differences may have been related to different storage conditions, which pointed out that the minimum concentration of $\alpha$-tocopherol in muscle for completely inhibiting lipid oxidation depends on storage conditions and it may be higher under commonly retail conditions (high oxygen content atmospheres and I $4 \mathrm{~h}$ of fluorescent light). In fact, oxidation affects colour, odour, flavour, texture and nutritional value, and it finally compromises lamb shelf life. Products of lipid oxidation have been associated with off flavours and off odours (Jeremiah, 200I), which decrease meat quality by overpowering its characteristic flavour and odour. TBARS has been described to be a good indicator of the development of rancid offflavours. Several researchers have related TBARS values with human perception of rancid 
compounds. Greene and Cumuze (1982) observed that untrained panellists accepted beef with TBARS values up to $2 \mathrm{mg} \mathrm{kg}^{-1}$. Similarly, Campo et al. (2006) noted that beef flavours were overpowered when TBARS values exceeded a value of $2 \mathrm{mg} \mathrm{kg}^{-1}$, so this point was proposed as the maximum level for positive sensory perception of beef. In our trial, control samples widely exceeded the threshold for the acceptability of oxidized beef of $2 \mathrm{mg}$ MDA $\mathrm{kg}^{-1}$; meanwhile a dietary dosage of IOoo $\mathrm{mg}$ of $\alpha$-tocopherol $\mathrm{kg}^{-1}$ was enough to maintain oxidation levels under the limit of acceptance after display. Therefore, supplemented lamb is expected to keep better characteristics of odour and flavour, obtaining a good acceptance of consumers.

\section{Effect of frozen storage}

Table 4.3 also shows the effect of frozen storage duration before thawing on lipid oxidation of lamb. TBARS values before display were lower in fresh than in thawed lamb $(\mathrm{P}<\mathrm{O} . \mathrm{ooI})$. Initial differences between fresh and thawed lamb had been already described (Muela et al., 20I0) probably because of damage caused to cellular structure during freezing, frozen storage and thawing or as a result of MDA accumulation during frozen storage. Lipid oxidation has widely described to accelerate after thawing as peroxidation (primary lipid oxidation) is not stopped during frozen storage giving rise to rapid and severe secondary lipid oxidation (thiobarbituric acid forming), which results in increased TBARS values (Owen and Lawrie, 1975). In this study, however, there were no significant differences in MDA content among treatments after $9 \mathrm{~d}$ of display. Similar to our results, Leygonie et al. (2012) and Alonso et al. (2016) did not register differences in TBARS values among fresh and thawed meat after frozen storage during different periods of time. Muela et al. (2010) neither registered any significant difference between fresh and 3 months frozen storage meat after Io $d$ of display but differences became significant when thawed meat had been kept frozen up to 6 months. The lack of a higher content of MDA in thawed samples could be explained due to its consumption in other chemical pathways. According to Leygonie et al. (20I2) the interaction between lipid and protein oxidation presumably leads to a lower TBARS value as malondiadehyde (MDA) acts as a substrate in one of the pathways of protein oxidation.

\section{Intramuscular Fatty Acid Profile}

Effect of dietary vitamin $E$

Vitamin E supplementation did not modify the content of intramuscular fat (Table 4.3), which was in agreement with the findings of Kasapidou et al., (2OI2) and Zhao et al. (20I3). Nevertheless, there were some significant effects of the supplementation with vitamin $\mathrm{E}$ on fatty acid composition of intramuscular fat in semimembranosus.

Supplementation with $\alpha$-tocopherol resulted in a higher percentage of PUFA ( $\mathrm{P}<\mathrm{O} . \mathrm{OoI})$ (Table 4.4), which was previously reported by Chen et al. (2008) and Álvarez et al. (2009). The higher percentage of PUFA found in vitamin E added samples may be related to its 
antioxidant activity. A relationship among in vivo low tissue concentrations of vitamin $\mathrm{E}$ and lower amounts of both n-6 and n-3 PUFA has been demonstrated (Kasapidou et al., 200I), which suggests that PUFA decrease appears in vivo when antioxidant concentrations are low. Unsaturated fatty acids are known to be more susceptible to oxidation so the inclusion of dietary vitamin $\mathrm{E}$ in the basal diet may have protected PUFA from these reactions, obtaining a higher PUFA percentage in these samples than in controls. According to Álvarez et al. (2009) the supplementation with $250 \mathrm{mg}$ DL- $\alpha$-tocopheryl acetate $\mathrm{kg}^{-1}$ feed is enough to prevent PUFA from oxidation while Demirel et al. (2004) noted significant differences in intramuscular PUFA proportions when the concentration of $\alpha$-tocopherol in muscle increased from $0.27 \mathrm{mg} \mathrm{g}^{-1}$ to $0.52 \mathrm{mg} \mathrm{g}^{-1}$. Regarding to individual PUFA percentages, supplemented samples presented significant higher proportions of Ci 8:2 n-6, C20:3 n-6 and C2O:4 n-6. In a similar way, Zhao et al. (2013) registered a higher proportion of Ci8:2 and C20:3 in vitamin E supplemented lambs while Álvarez et al. (2009) also found a significant effect of vitamin E on preserving Ci8:2 n-6. This fatty acid is considered essential to humans (Beare-Rogers, 1988) and vitamin E supplementation seems to protect it against degradation.

The oxidation of PUFA in control samples may have led to a relative increase of the percentage of total SFA $(\mathrm{P}<\mathrm{O} . \mathrm{OOI})$ as well as a significant higher percentage of some individual saturated fatty acids (Cı0:0, Ci6:0, Ci8:0). Regarding to the percentage of Ci8:I n-9 fatty acid, as it was previously noted by Zhao et al. (20I3), a lower content was found in vitamin E supplemented than in control samples ( $\mathrm{P}=0.039)$. This result could be explained by the findings of Hou et al. (2013), who reported that vit E supplementation might accelerate the ruminal biohydrogenation of Ci8:I unsaturated fatty acids in vivo. In contrast, no effect on fatty acid profile was reported by Kasapidou et al. (2012) and Berthelot et al. (20I4), which suggests the need of more studies about this topic. 


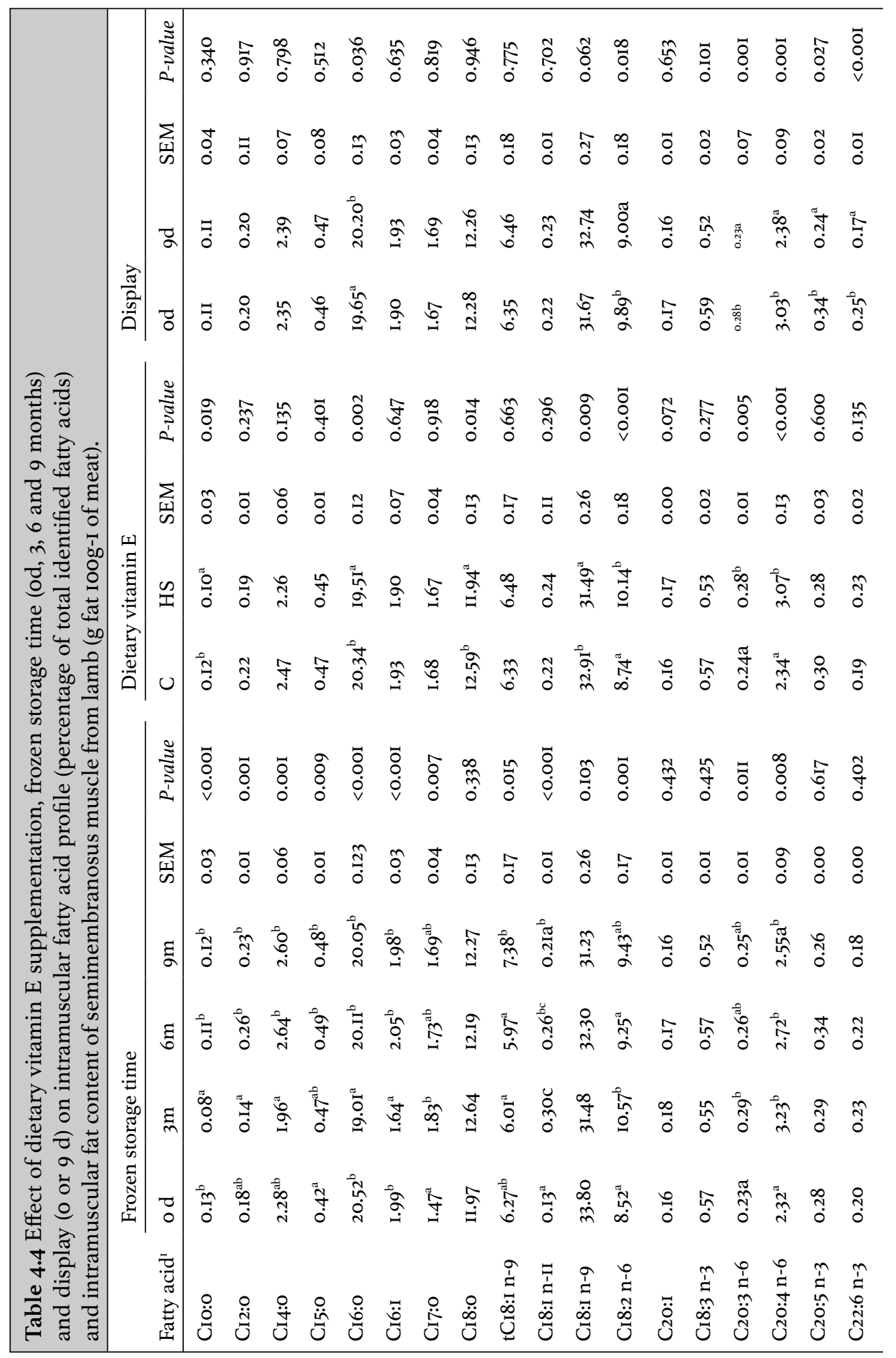




\begin{tabular}{|c|c|c|c|c|c|c|}
\hline $\begin{array}{l}n \\
0 \\
0 \\
0\end{array}$ & $\begin{array}{l}\hat{n} \\
\tilde{0} \\
0\end{array}$ & $\begin{array}{l}0 \\
\circ \\
0\end{array}$ & 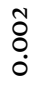 & $\begin{array}{l}\circ \\
\circ \\
0 \\
0\end{array}$ & 茴 & 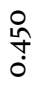 \\
\hline$\stackrel{\sim}{\tilde{O}}$ & $\stackrel{\sim}{0}$ & $\hat{n}$ & ণิ & 'ọ & 'ô. & $\stackrel{\pi}{0}$ \\
\hline 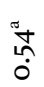 & 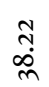 & $\begin{array}{l}\text { in } \\
\text { jo } \\
\text { J }\end{array}$ & $\begin{array}{l}\stackrel{\pi}{\tilde{\sigma}} \\
\stackrel{\sim}{n}\end{array}$ & 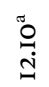 & ஸ̃ & $\begin{array}{l}\tilde{\sigma} \\
\stackrel{i}{*}\end{array}$ \\
\hline $\begin{array}{l}\infty \\
\infty \\
0 \\
0\end{array}$ & $\underset{n}{\stackrel{N}{i}}$ & 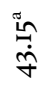 & $\begin{array}{l}\infty \\
\infty \\
\infty \\
\stackrel{\infty}{\infty}\end{array}$ & $\begin{array}{l}\stackrel{\leftrightarrow}{\circ} \\
\dot{n}\end{array}$ & 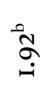 & 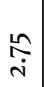 \\
\hline 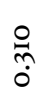 & $\begin{array}{l}\partial \\
\stackrel{0}{0} \\
\dot{0}\end{array}$ & $\begin{array}{l}n \\
\hat{0} \\
0\end{array}$ & $\begin{array}{l}\stackrel{0}{\circ} \\
\dot{0} \\
\dot{0}\end{array}$ & $\begin{array}{l}\stackrel{0}{0} \\
\dot{0} \\
\dot{0}\end{array}$ & $\stackrel{\substack{n \\
0}}{0}$ & $\begin{array}{l}\hat{n} \\
\stackrel{0}{0} \\
0\end{array}$ \\
\hline $\begin{array}{l}\text { Õ } \\
0\end{array}$ & $\stackrel{\Im}{+}$ & กิ & $\hat{0}$ & 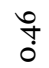 & $\stackrel{\circ}{+}$ & $\stackrel{\circ}{\circ}$ \\
\hline $\begin{array}{l}\text { ț } \\
\stackrel{0}{0}\end{array}$ & $\begin{array}{l}\tilde{\infty} \\
0 \\
0 \\
\dot{n}\end{array}$ & $\overrightarrow{\hat{m}}$ & 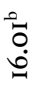 & $\begin{array}{l}\infty \\
\stackrel{N}{ \pm} \\
\dot{\Xi}\end{array}$ & $\underset{\sim}{\stackrel{+}{\sim}}$ & 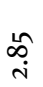 \\
\hline$\stackrel{\infty}{\stackrel{\infty}{\leftrightarrow}}$ & $\begin{array}{l}\stackrel{0}{0} \\
\infty \\
\infty \\
m\end{array}$ & $\overrightarrow{\tilde{y}}$ & 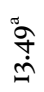 & 沉 & 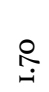 & $\underset{\sim}{\infty}$ \\
\hline $\begin{array}{l}\text { Ln } \\
0 \\
0 \\
0\end{array}$ & $\stackrel{\stackrel{n}{\overparen{N}}}{0}$ & $\begin{array}{l}\Re \\
0 \\
0 \\
0\end{array}$ & 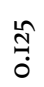 & $\begin{array}{l}\infty \\
0 \\
0 \\
0\end{array}$ & $\stackrel{\text { å }}{+}$ & $\stackrel{\infty}{\underset{+}{*}}$ \\
\hline $\begin{array}{l}\pi \\
0 \\
0\end{array}$ & $\stackrel{7}{0}$ & $\stackrel{\text { n̂. }}{o}$ & ஸे & ọ & $\begin{array}{l}\infty \\
0 \\
0\end{array}$ & ợ \\
\hline$\stackrel{+}{+}$ & 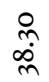 & $\begin{array}{l}\infty \\
\infty \\
\dot{y}\end{array}$ & $\begin{array}{l}\hat{\mathfrak{J}} \\
\text { J }\end{array}$ & 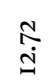 & & 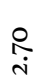 \\
\hline$\stackrel{\text { îे }}{0}$ & $\stackrel{\tilde{n}}{\infty}$ & $\begin{array}{l}\hat{\sigma} \\
\dot{y}\end{array}$ & $\stackrel{\infty}{+} \underset{ \pm}{ \pm}$ & 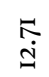 & $\underset{\sim}{\curvearrowright}$ & $\underset{i}{\infty}$ \\
\hline$\underset{0}{\mathbb{N}}$ & 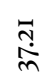 & $\begin{array}{l}\text { ğ } \\
\dot{y}\end{array}$ & 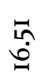 & $\begin{array}{l}\text { đ̛ } \\
\text { đ্র }\end{array}$ & $\stackrel{\infty}{\infty}$ & $\stackrel{\substack{+i}}{ }$ \\
\hline $\begin{array}{l}0 \\
0 \\
0\end{array}$ & $\underset{m}{\stackrel{+}{\infty}}$ & $\begin{array}{l}\text { gे } \\
\dot{y}\end{array}$ & $\stackrel{n}{\stackrel{n}{\sim}}$ & $\begin{array}{l}\text { ô } \\
\text { తి }\end{array}$ & $\underset{\sim}{\infty}$ & 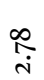 \\
\hline $\begin{array}{l}\hat{n} \\
\stackrel{n}{\mid} \\
\stackrel{\hat{N}}{\tilde{U}}\end{array}$ & $\begin{array}{l}\mathbb{S} \\
\underset{\omega}{W}\end{array}$ & 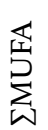 & $\begin{array}{l}\underset{\Phi}{5} \\
\text { 岕 } \\
\text { 出 }\end{array}$ & L & 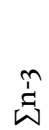 & $\frac{\widehat{e}}{e_{j}^{e}}$ \\
\hline
\end{tabular}

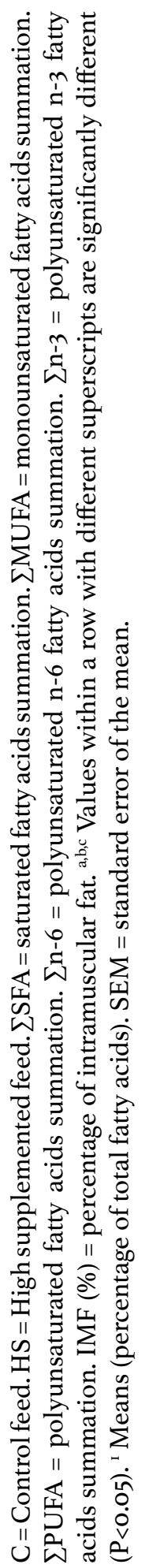




\section{Effect of frozen storage}

As it is widely known, PUFA are particularly susceptible to oxidative processes and enzymatic reactions are not completely inhibited during frozen storage. Therefore, it was expected a decrease in the percentage of PUFA due to lipolysis and oxidative reactions, producing a relative increase in the percentages of MUFA and SFA. In fact, this is what Alonso et al. (2016) found in pork after long-term frozen storage. Hernández et al. (1999), who reported a significant increase in free fatty acids during frozen storage, identified phospholipids hydrolysis as the major cause of this phenomenon. Alonso et al. (2016) also considered oxidative reactions a significant cause of the reduction of PUFA during frozen storage. Contrary to it was expected, frozen storage did not modify the percentage of total SFA, MUFA or PUFA (Table 4.4). Similar to our results Zymon et al. (2007) did not found any effect of frozen storage on meat fatty acid profile. A feasible explanation to our results could be that legs were vacuum packaged prior to be frozen, so it may have inhibited oxidative reactions (Table 4.3).

\section{Effect of display}

Display led to a significant decrease in the percentage of C20:5 n-3, C22:6 n-3, C22:5 n-3, Ci8:2 $n-6, C 20: 3 n-6, C 20: 4 n-6$ as well as in the summary of n-3, n-6 and total polyunsaturated fatty acids (Table 4.4). As it has been previously mentioned, PUFA are more susceptible to degradation, especially long chain fatty acids with a higher degree of unsaturation, so oxidative reactions throughout display may have been responsible of this decrease. In fact, malondialdehyde content was significantly higher after the storage period. Álvarez et al. (2009) studied the changes in fatty acid profile of vitamin E supplemented lamb packaged in modified atmosphere and displayed during $28 \mathrm{~d}$, registering great changes in PUFA percentage. They noted a reduction in the percentage of $n-3$ and $n-6$ fatty acids of nonsupplemented samples throughout display, which was attributed to lipid oxidation. In contrast, no changes were measured in the vitamin E high supplemented samples (IOoo mg DL- $\alpha$-tocopheryl acetate $\mathrm{kg}^{-1}$ feed), which demonstrated the relationship between antioxidant content, oxidative reactions and PUFA content.

\section{Principal Components Analysis}

The first two components of the principal component analysis (PCA) explained 56.98\% of the variability of the results (Figure 4.2). The first component (PCI), which was able to explain $33.65 \%$ of the variation of the whole study, was characterised by the variables metmyoglobin, Hue, and thiobarbituric acid reactive substances (TBARS) in the positive side and $\sum$ PUFA, $\sum \mathrm{n}-6$, and the index 630/580 in the negative side. This component divided the observations in two main groups depending on the day of display. The centroids of the observations at o $\mathrm{d}$ of storage were mainly on the left quadrants of the figure, closely related to $\sum$ PUFA, $\sum \mathrm{n}-6, \sum \mathrm{n}-3$ and the index 630/580; meanwhile, the observations at d 9 were located on the right side, characterized by the $\%$ of metmyoglobin, $\Sigma$ SFA, Hue and 
TBARS. Display significantly affected colour, lipid oxidation (Table 4.3), PUFA, $\sum n-6$ and $\sum \mathrm{n}-3$ (Table 4.4). A significant positive correlation was found between lipid oxidation and the percentage of metmyoglobin (0.393) and significant strong correlations were also registered among the latter and $\mathrm{h}$ (0.94) and the index 630/580 (-0.910).

Enriched oxygen atmospheres have been described to favour lipid oxidation, which increased throughout display in all conditions evaluated in this trial (Table 4.3). Primary and secondary products of lipid oxidation enhance myoglobin oxidation, leading to its conversion into metmyoglobin and resulting in meat discolouration (Faustman et al., 20I0). Polyunsaturated fatty acids are known to be more susceptible to oxidative reactions which could explain its decrease during display (Ródriguez-Cárpena et al., 20II). Similarly, Álvarez et al. (2009) noted a reduction in the percentage of n-3 and n-6 fatty acids throughout display, which was attributed to lipid oxidation. In fact, a significant negative correlation was observed between TBARS and $\sum$ PUFA (-0.326).

Moreover, a discrimination between high and low vitamin E supplemented samples within each day could be noted. The observations of the animals supplemented with Iooo $\mathrm{mg} \alpha$-tocopherol $\mathrm{kg}^{-1}$ were at the left of those which were supplemented with $30 \mathrm{mg}$ at both days. As a result, the centroid of the animals with a high level of supplementation was located in the lower left-hand quadrant, which was related with $\sum$ PUFA, $\sum n-6, \sum n-3$ and the concentration of $\alpha$-tocopherol in muscle. The centroid of the animals supplemented with a dosage of $30 \mathrm{mg} \alpha$-tocopherol $\mathrm{kg}^{-1}$ was on the opposed quadrant, defined by the percentage of intramuscular fat (\%IMF), $\Sigma$ SFA and the TBARS.

Significant negative correlations among the concentration of $\alpha$-tocopherol in muscle TBARS and $\Sigma$ SFA (-0.34I, -0.425) were noted, while the content of tocopherol was positive correlated with SPUFA (0.34I) and En-6. Vitamin E supplementation significantly reduced lipid oxidation during display (Table 4.3), which could have protected PUFA from degradation. Therefore, SFA are expected to increase if the percentage of PUFA decrease. The correlation between tissue antioxidant status and fatty acid stability has been previously reported (Kasapidou et al., 200I). 
Biplot (PC1 and PC2: 56.98\%)

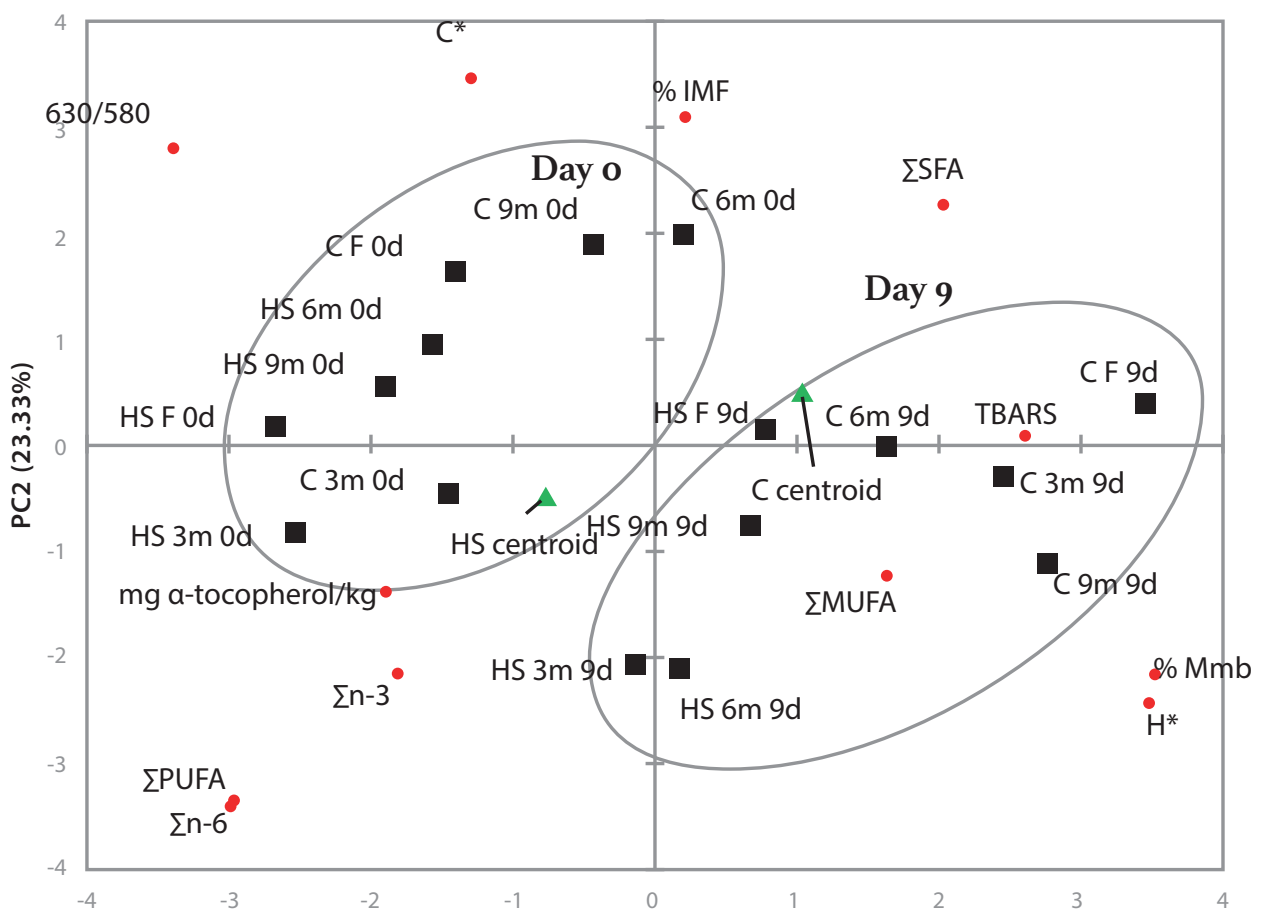

Figure 4.2 Projection in the plane of physicochemical parameters, fatty acid groups and the centroids of the observations defined by two principal components. HS: High rate of vitamin E supplementation (IOoo mg $\alpha$-tocopherol $\mathrm{kg}^{-1}$ ), C: Control feed (30 $\mathrm{mg} \alpha$-tocopherol $\mathrm{kg}^{-1}$ ), Frozen storage duration: F (fresh meat), $3 \mathrm{~m}$ ( 3 months), $6 \mathrm{~m}$ (6 months), $9 \mathrm{~m}$ (9 months), Days of display after frozen storage: od or $9 \mathrm{~d}$. \% MetMb: percentage of metmyoglobin, TBA: Thiobarbituric acid reactive substances, $\sum$ SFA:saturated fatty acids summation; $\sum$ MUFA: monounsaturated fatty acids summation; $\sum$ PUFA: polyunsaturated fatty acids summation; $\sum \mathrm{n}-6$ :polyunsaturated $\mathrm{n}-6$ fatty acids summation; $\sum \mathrm{n}-3$ : polyunsaturated $\mathrm{n}-3$ fatty acids summation; IMF (\%): percentage of intramuscular fat. 


\section{CONCLUSIONS}

The effect of dietary vitamin $\mathrm{E}$ on lamb quality was independent from freezing and frozen storage duration. Muscle $\alpha$-tocopherol concentration was over 3.5 -fold higher in supplemented than in control lambs. At this vitamin E level, lipid oxidation was significantly reduced, leading to a lower metmyoglobin formation and a better colour maintenance (a lower value for Hue and a higher for the 630/580 ratio). However, a higher concentration of $\alpha$-tocopherol in muscle is required to completely inhibit lipid oxidation and discolouration. Vitamin $\mathrm{E}$ addition also had an effect on fatty acid profile. The antioxidant effect of vitamin E protected PUFA from oxidative reactions during display, showing higher values in these samples than in controls. In conclusion, dietary vitamin $\mathrm{E}$ could be recommended either for fresh or frozen thawed meat, resulting in a better colour maintenance, a lower lipid oxidation and a higher nutritional value.

\section{ACKNOWLEDGEMENTS}

This study was financially supported by the Gobierno de Aragón (Grupo Consolidado de Calidad y Tecnología de la Carne, Ref: Ao4), The European Regional Development Fund (ERDF) and the Ministerio Español de Educación, Cultura y Deporte that provided M. Bellés with a grant (FPUor4/or225) to carry on this investigation. The authors would also thank the Animal Production personnel at the Faculty of Veterinary Science, especially Prof. M.M. Campo for her scientific assistance, Franco \& Navarro S.A. and Nanta S.A. (especially J.M. Bello Dronda) for the technical support. 


\section{Chapter 4}




\section{REFERENCES}

Alonso, V., E. Muela, B. Gutiérrez, J. B. Calanche, P. Roncalés and J. A. Beltrán. 2015. The inclusion of Duroc breed in maternal line affects pork quality and fatty acid profile. Meat Science I07:49-56.

Alonso, V., E. Muela, J. Tenas, J. B. Calanche, P. Roncalés and J. A. Beltrán. 2016. Changes in physicochemical properties and fatty acid composition of pork following long-term frozen storage. European Food Research and Technology 242(I2):2II9-2I27.

Álvarez, I., J. De La Fuente, V. Cañeque, S. Lauzurica, C. Pérez and M. T. Díaz. 2009. Changes in the fatty acid composition of M. longissimus dorsi of lamb during storage in a highoxygen modified atmosphere at different levels of dietary vitamin E supplementation. Journal of Agricultural and Food Chemistry 57(I):I40-I46.

Álvarez, I., J. De La Fuente, M. T. Díaz, S. Lauzurica, C. Pérez and V. Cañeque. 2008. Estimation of a-tocopherol concentration necessary to optimise lamb meat quality stability during storage in high-oxygen modified atmosphere using broken-line regression analysis. Animal 2(9): I405-I4II.

ARC (1980). Nutrient requirement of ruminant livestock. CAB, International, p. 35I.

Beare-Rogers, J. I988. Nutritional attributes of seafoods. Food Technology 65(I):I46-I7I.

Bellés, M., V. Alonso, P. Roncalés and J. A. Beltrán. 2017. A review of fresh lamb chilling and preservation. Small Ruminant Research I46:4I-47.

Berruga, M. I., H. Vergara and L. Gallego. 2005. Influence of packaging conditions on microbial and lipid oxidation in lamb meat. Small Ruminant Research 57:257-264.

Berthelot, V., L. Broudiscou and P. Schmidely. 20I4. Effect of vitamin E supplementation on fatty acid composition of muscle and adipose tissues of indoor lambs with special attention on rumen-derived trans monounsaturated fatty acids. Meat Science 96(3):I28I-I288.

Bligh, E. G., and W. J. Dyer. 1959. A rapid method of total lipid extraction and purification. Canadian Journal of Biochemistry and Physiology 37:9II-9I4.

Boletín Oficial del Estado (BOE) (2007) Ley Española 32/2007 sobre el cuidado de los animales, en su explotación, transporte, experimentación y sacrificio. BOE 268:4591445920.

Campo, M. M., G. R. Nute, S. I. Hughes, M. Enser, J. D. Wood and R. I. Richardson. 2006. Flavour perception of oxidation in beef. Meat Science 72(2):303-3II.

Carrilho, M.C., M. López and M. M. Campo. 2009. Effect of the fattening diet on the development of the fatty acid profile in rabbits from weaning. Meat Science 82:37-43.

Chen, X. J., H. L. Mao, J. Lin and J. X. Liu. 2008. Effects of supplemental soybean oil and vitamin $\mathrm{E}$ on carcass quality and fatty acid profiles of meat in Huzhou lamb. Acta Agriculturae Scandinavica, Section A - Animal Science 58(3):I29-I35.

Demirel, G., M. Wachira, L. Sinclair, R. G. Wilkinson, J. D. Wood and M. Enser. 2004. Effects of dietary n-3 polyunsaturated fatty acids, breed and dietary vitamin E on the 
fatty acids of lamb muscle, liver and adipose tissue. The British Journal of Nutrition 9I(4):55I-565.

Faustman, C., Q. Sun, R. Mancini and P. Suman. 20I0. Myoglobin and lipid oxidation interactions: Mechanistic bases and control. Meat Science 86:86-94.

Greene, B. E., and T. H. Cumuze. 198I. Relationship between TBA numbers and inexperienced panellists' assessments of oxidized flavor in cooked beef. Journal of Food Science 47, 52-54, 58.

González-Calvo, L., G. Ripoll, F. Molino, J. H. Calvo and M. Joy. 2015. The relationship between muscle $\alpha$-tocopherol concentration and meat oxidation in light lambs fed vitamin E supplements prior to slaughter. Journal of the Science of Food and Agriculture 95(I):IO3-IIO.

Hernández, P., J. Navarro and F. Toldrá. 1999. Effect of frozen storage on lipids and lipolytic activities in the longissimus dorsi muscle of the pig. European Food Research and Technology 208:IIO-II5.

Hou, J., F. Wang, Y. Wang and F. Liu. 2013. Effects of vitamin E on the concentration of conjugated linoleic acids and accumulation of intermediates of ruminal biohydrogenation in vitro. Small Ruminant Research III(I):63-70.

Jeremiah, L. (200I). Packaging alternatives to deliver fresh meats using short- or long-term distribution. Food Research International 34(9):749-772.

Jose, C. G., R. H. Jacob, D. W. Pethick and G. E. Gardner. 20I6. Short term supplementation rates to optimise vitamin $\mathrm{E}$ concentration for retail colour stability of Australian lamb meat. Meat Science III:IOI-IO9.

Kasapidou, E., J. D. Wood, R. I. Richardson, L. A. Sinclair, R. G. Wilkinson and M. Enser. 2012. Effect of vitamin E supplementation and diet on fatty acid composition and on meat colour and lipid oxidation of lamb leg steaks displayed in modified atmosphere packs. Meat Science 90:908-9I6.

Kasapidou, E., J. D. Wood, L. D. Sinclair, R. G. Wilkinson and M. Enser. 200I. Diet and vitamin E metabolism in lambs: effects of dietary supplementation on meat quality. In Proceedings of the 47th Congress of Meat Science and Technology, 26-3I August 200I, Kraków, Poland, pp 42-43.

Kerry, J., M. O'Sullivan, D. Buckley, P. Lynch and P. Morrissey. 20oo. The effects of dietary $\alpha$-tocopheryl acetate supplementation and modified atmosphere packaging (MAP) on the quality of lamb patties. Meat Science 56(I):6I-66.

Krzywicki, K. (1979). Assessment of relative content of myoglobin, oxymyoglobin and metmyoglobin at the surface of beef. Meat Science 3:I-IO.

Lauzurica, S., J. De la Fuente, M. T. Díaz, I. Álvarez, C. Pérez and V. Cañeque. 2005. Effect of dietary supplementation of vitamin $\mathrm{E}$ on characteristics of lamb meat packed under modified atmosphere. Meat Science 70(4):639-646.

Lawrie, R. A. 1998. The eating quality of meat. In R. A. Lawrie (Ed.), Meat Science (pp. 2I2-254). Oxford: Pergamon Press. 
Leedle, R., J. Leedle, and M. Butine. 1993. Vitamin E is not degraded by ruminal microorganisms - assessment with ruminal contents from a steer fed a high-concentrate diet. Journal of Animal Science 7I(I2):3442-3450.

Leygonie, C., T. J. Britz and L. C. Hoffman. 2012. Meat quality comparison between fresh and frozen/thawed ostrich M. iliofibularis. Meat Science 9I:364-368.

Liu, Q., K. K. Scheller and D. M. Schaefer. 1996. Technical Note: A simplified procedure for Vitamin E determination in beef muscle. Journal of Animal Science 74:2406-24Io.

Muela, E., V. Alonso, M. M. Campo, C. Sañudo, and J. A. Beltrán. 20I4. Antioxidant diet supplementation and lamb quality throughout preservation time. Meat Science 98(2): 289-295.

Muela, E., C. Sañudo, M. M. Campo, I. Medel and J. A. Beltrán. 20ıo. Effect of freezing method and frozen storage duration on instrumental quality of lamb throughout display. Meat Science 84(4):662-669.

O'Grady, M. N., F. J. Monahan, R. M. Burke and P. Allen. 200o. The effect of oxygen level and exogenous $\alpha$-tocopherol on the oxidative stability of minced beef in modified atmosphere packs. Meat Science 55: 9-45

Owen, J. E. and R. A. Lawrie. 1975. The effect of an artificially induced high $\mathrm{pH}$ on the susceptibility of minced porcine muscle to undergo oxidative rancidity under frozen storage. International Journal of Food Science and Technology I0:I69-I80.

Renerre, M., F. Dumont and P. Gatellier. 1996. Antioxidant enzyme activities in beef in relation to oxidation of lipid and myoglobin. Meat Science 43:III-I2I.

Ripoll, G., M. Joy and F. Muñoz. 20II. Use of dietary vitamin E and selenium (Se) to increase the shelf life of modified atmosphere packaged light lamb meat. Meat Science 87:8893.

Rodríguez-Carpena, J. G., D. Morcuende and M. Estévez. 20II. Avocado by-products as inhibitors of color deterioration and lipid and protein oxidation in raw porcine patties subjected to chilled storage. Meat Science 89(2):I66-I73.

Zhao, T., H. Luo, Y. Zhang, K. Liu, H. Jia, Y. Chang and W. Gao. 2013. Effect of vitamin E supplementation on growth performance, carcass characteristics and intramuscular fatty acid composition of longissimus dorsi muscle in Tan' sheep. Chilean Journal of Agricultural Research 73(4):358-365.

Zymon, M., J. Strzetelski, H. Pustkowiak and E. Sosin. 2007. Effect of freezing and frozen storage on fatty acid profile of calves. Polish Journal of Food Nutrition and Science 57:647-650. 


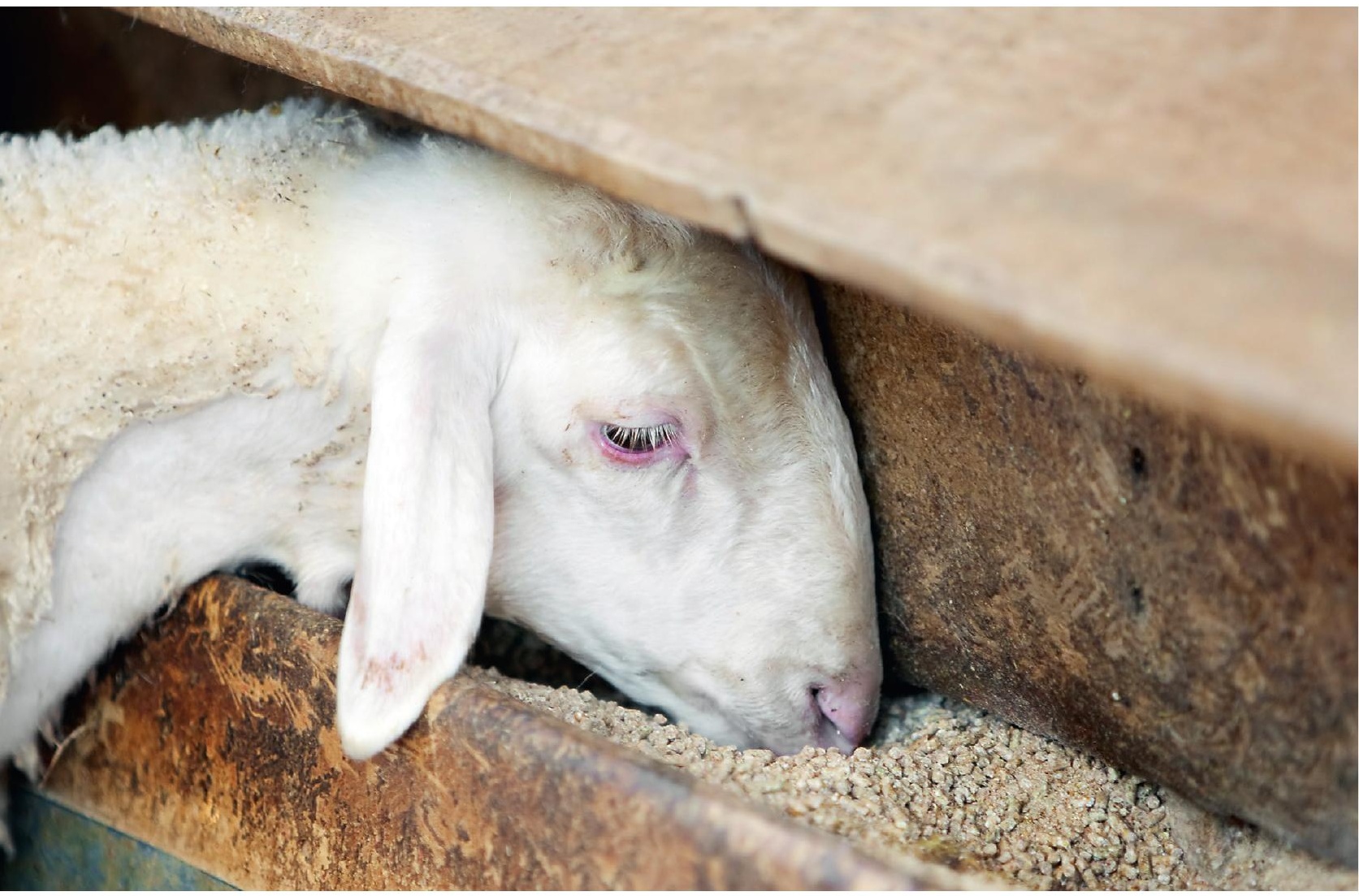




\section{Chapter 5}

\section{Dietary supplementation of II different plant extracts on the antioxidant capacity of blood and selected tissues in light weight lambs}

L. N. Leal ${ }^{\mathrm{a}, \mathrm{b}}$, M. J. Jordánc ${ }^{\mathrm{c}}$ J. M. Bello ${ }^{\mathrm{d}}$, J. Otal ${ }^{\mathrm{e}}$, L. A. den Hartog ${ }^{\mathrm{a}, \mathrm{b}}$, W. H. Hendriks ${ }^{b}$ and J. Martín-Tereso ${ }^{\mathrm{a}}$

${ }^{a}$ Trouw Nutrition Research and Development, P.O. Box 299, 3800 AG Amersfoort, the Netherlands.

${ }^{\mathrm{b}}$ Animal Nutrition group, Department of Animal Sciences, Wageningen University \& Research, De Elst 1, 6708 WD Wageningen, the Netherlands.

${ }^{\mathrm{c}}$ Murcian Institute of Investigation and Agricultural Development, 30150 Murcia, Spain.

d Nanta S.A., Ronda de Poniente 9, 28460 Tres Cantos, Madrid, Spain.

${ }^{\mathrm{e}}$ Department of Animal Production, Faculty of Veterinary Science, University of Murcia, 30100 Murcia, Spain. 


\begin{abstract}
Due to the growing public concern regarding the addition of chemical antioxidants to foods, focus has shifted towards natural alternatives. Because of their antioxidant potential, culinary herbs and spices have long been used to extend the shelf-life of foods. However, a better understanding of the fate of these products following intake, is required to assess their use in lamb diets. Two hundred eighty-eight Rasa Aragonesa male lambs (70 d old) were supplemented (5.0 $\mathrm{g} \mathrm{kg}^{-1}$ compound feed) with bay, marjoram, oregano, rosemary, thyme, turmeric, cumin, caraway, dill, cinnamon and nutmeg extracts for $\mathrm{I} 4 \mathrm{~d}$ before slaughter. Dietary supplementation with plant extracts had no effect on intake, growth performance and antioxidant activity in blood (TEAC values). In muscle, nutmeg supplementation increased $(\mathrm{P}<0.05)$ the radical-scavenging capacity (TEAC). Whereas, a decrease in the radical-scavenging capacity was found for oregano, dill, cinnamon and nutmeg supplemented lambs (ORAC values). In liver, nutmeg supplementation increased $(\mathrm{P}<0.05)$ the antioxidant capacity (TEAC). Whereas, bay (ORAC), turmeric, cinnamon and nutmeg (DPPH • values) decreased $(\mathrm{P}<0.05)$ the radical-scavenging capacity of the tissue. In kidney, a lower $(\mathrm{P}<0.05)$ radical-scavenging capacity (TEAC values) was found in oregano, cumin and caraway supplemented lambs. Whereas, turmeric, cumin, caraway, cinnamon and nutmeg increased $(\mathrm{P}<0.05)$ the antioxidant capacity (ORAC values) in kidney. Supplementation of lamb diets with plant extracts affected the radical scavenging activity in muscle, liver and kidney. However, due to the divergent results of the different assays for the same tissue, it is not advisable to discriminate plant extracts using this approach.
\end{abstract}




\section{INTRODUCTION}

Due to the growing concern among the public opinion (consumers and meat industry) regarding the addition of chemical additives to foods, the use of synthetic antioxidants is diminishing and focus has shifted toward the use of naturally occurring antioxidants. Many natural antioxidants are recognized as promising alternatives to increase the shelf life of meat products (Moñino et al., 2008; Nieto et al., 20IO; Vasta and Luciano, 20II). Supplementation of feed with $\alpha$-tocopherol was found to be a simple and convenient way to introduce a natural antioxidant into cellular matrices (such in muscle) where initiation of lipid oxidation is expected to occur (Nieto et al., 20I0).

In Mediterranean lamb production systems, after weaning at I2-I4 $\mathrm{kg}$ of body weight (BW), lambs are fed ad libitum compound feed plus straw until they reach a slaughter weight of 22$28 \mathrm{~kg}$ of BW (Lobón et al., 20I7; Leal et al., 20I8a). Under these conditions, supplementation of lamb diets with $0.5 \mathrm{~g}$ vitamin $\mathrm{E}$ per $\mathrm{kg}$ diet for 7-I4 $\mathrm{d}$ before slaughter, has been shown to elevate $\alpha$-tocopherol concentrations in tissues (Leal et al., 20I8b) and to delay meat oxidation.(González-Calvo et al., 20I5; Leal et al., 20I8a). However, other phenolics (such as flavonoids and phenolic acids) are also assumed to be able scavenge free radicals before lipid oxidation propagation.

Alternative sources of phenolics in several types of plant rich materials such as vegetables, fruits, leaves, oilseeds, cereal crops, barks and roots, spices and herbs have been investigated (Kähkönen et al., 1999). Apart from improving the flavour and organoleptic properties of different types of foods, culinary herbs and spices such as bay (Laurus nobilis), marjoram (Origanum majorana), oregano (Origanum vulgare), rosemary (Rosmarinus officinalis) thyme (Thymus vulgaris), turmeric (Curcuma longa), cumin (Cuminum cyminum), caraway (Carum carvi), dill (Anethum graveolens), cinnamon (Cinnamomum zeylanicum) and nutmeg (Myristica fragans), have been consistently reported to exhibit antioxidant properties (Wojdyło et al., 2007; Vallverdú-Queralt et al., 20I4; Vallverdú-Queralt et al., 20I5). Some authors have attributed the in vitro antioxidant capacity of these plants to their phenolic compound content, resulting in a positive linear correlation between them (Zheng and Wang, 200I; Shan et al., 2005).

Like $\alpha$-tocopherol, the direct antioxidant capacity of a dietary polyphenol would be affected by its absorption along the gastrointestinal tract and to its deposition in the tissues (Vasta and Luciano, 20II). A better understanding of the fate of polyphenolic compounds present in culinary herbs and spices following intake is needed. Moreover, data on tissue antioxidant potential of polyphenolic compounds present in herbs and spices is scarce, even in experimental animals (Crozier et al., 2009).

The aim of the current study was to investigate whether the supplementation of lamb diets with plant extracts from II culinary herbs and spices affects the antioxidant capacity of different lamb tissues (plasma, muscle, liver, and kidney). 


\section{MATERIALS AND METHODS}

\section{Reagents}

All the chemicals used were of AnalR grade. The 2,2-diphenyl-I-picrylhydrazyl (DPPH•), 2,4,6-tris(2-pyridyl)-s-triazine (TPTZ), $\mathrm{FeSO}_{4} 7 \mathrm{H}_{2} \mathrm{O}, 2,2$-azino-bis-(3-ethylbenzothiazoline6-sulphonicacid) (ABTS), ( \pm )-6-hydroxy-2,5,7,8 tetramethylchroman-2-carboxylic acid (Trolox), Fluorescein and potassium persulphate $\left(\mathrm{K}_{2} \mathrm{~S}_{2} \mathrm{O}_{8}\right)$ were purchased from SigmaAldrich (Madrid, Spain). The $\mathrm{CH}_{3} \mathrm{COOH}, \mathrm{CH}_{3} \mathrm{COONa}, \mathrm{HCl}$, and $\mathrm{FeCl}_{3}-6 \mathrm{H}_{2} \mathrm{O}$ were obtained from Scharlau Chemie S.A. (Barcelona, Spain). Methanol (HPLC grade) was purchased from J.T. Baker (Mallinckrodt Baker B.V., Deventer-Holland). 2,2'-azobis (2-amidinopropane) dihydrochloride (AAPH) was obtained from Wako Chemicals USA, Inc. (Richmond, VA).

\section{Animals and Diets}

All the experimental and slaughter procedures used met the guidelines of Council Directive 86/609/EEC (European Communities, 1986) on the protection of animals used for experimental or other scientific purposes.

Two hundred eighty-eight Rasa Aragonesa male lambs (23.5 \pm I.38 kg) were purchased from local dealers to arrive at the commercial farm Franco and Navarro (Zaragoza, Spain) in three batches of 96 animals. After $7 \mathrm{~d}$ of adaptation to the basal compound feed (control), lambs were randomly allocated (per batch) based on body weight to I2 pens (8 lambs per pen in $20 \mathrm{~m}^{2}$ ) containing straw bedding. For each batch, a pen was randomly assigned to one of 12 diets consisting of a basal compound feed (control) and the basal compound feed supplemented $\left(5.0 \mathrm{~g} \mathrm{~kg}^{-1}\right)$ with II different plant extracts (bay, Laurus nobilis; marjoram, Origanum majorana; oregano, Origanum vulgare; rosemary, Rosmarinus officinalis; thyme,

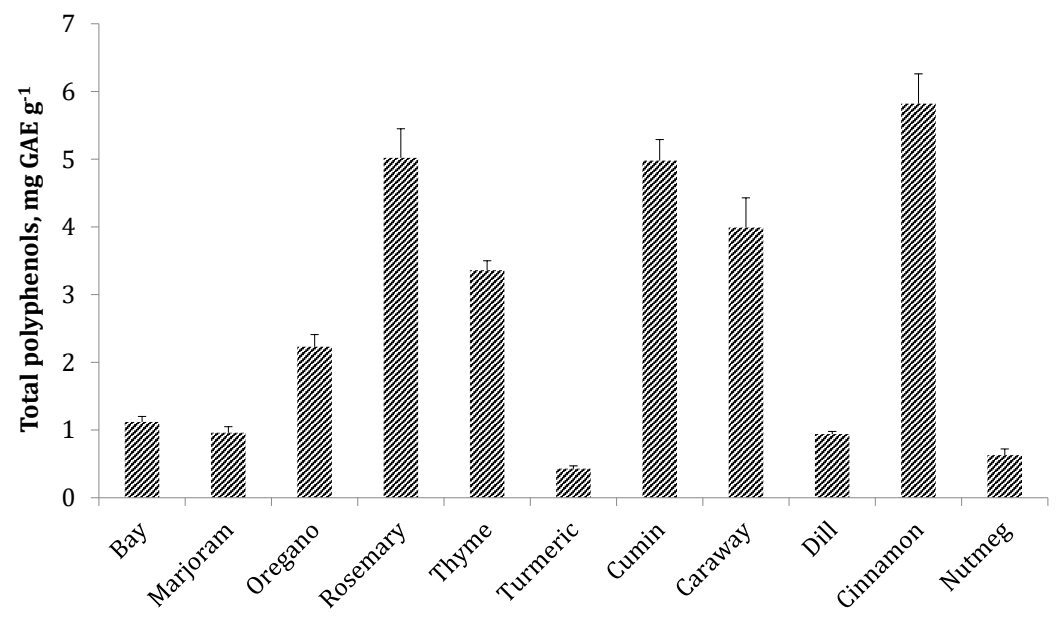

Figure 5.I Total polyphenol content of the selected plant extracts evaluated by the FolinCiocalteau method and expressed per unit Gallic Acid Equivalents (GAE) of dried product. Adapted from: Vallverdú-Queralt et al. (2014) and Vallverdú-Queralt et al. (2015). 
Thymus vulgaris; turmeric, Curcuma longa; cumin, Cuminum cyminum; caraway, Carum carvi; dill, Anethum graveolens; cinnamon, Cinnamomum zeylanicum and nutmeg, Myristica fragans). When lambs were supplemented with standardized rosemary extracts, dosages in the range of 0.2 to $1.2 \mathrm{~g} \mathrm{~kg}^{-1}$ diet have been tested (Moran et al., 20I2; Ortuño et al., 20I4). However, when plant extracts from different plant origins were assessed, dosages ranging from 2.0 to $40.0 \mathrm{~g} \mathrm{~kg}^{-1}$ diet were reported (Andrés et al., 20I3; Valenti et al., 20I8).

In the current study, a dosage of $5.0 \mathrm{~g} \mathrm{~kg}^{-1}$ compound feed was defined based on the diversity of the plant extracts investigated. Vallverdú-Queralt et al.(20I4) and Vallverdú-Queralt et al. (20I5) have previously described plant extract production, composition and phenolic profile. The total polyphenol content per plant extract is provided in Figure 5.I.

The experimental compound feed was pelleted at $62 \pm 2^{\circ} \mathrm{C}$ to a $3.5 \mathrm{~mm}$ pellet. Ingredients of the experimental compound feed is shown in Table 5.I. During a period of $\mathrm{I} 4 \mathrm{~d}$ (experimental period), lambs had free access to the experimental compound feeds, wheat straw and water via separated troughs available in each pen. Intakes of the experimental compound feed were recorded weekly and orts measured at the end of the experiment. Water and wheat straw intakes we not recorded. Lambs were weighed individually at the start and the end of the experimental period ( $14 \mathrm{~d}$ of supplementation). After an overnight period without feed (with free access to water) of approximately to hours, animals were transported and slaughtered at a local abattoir (Mercazaragoza S.A., Zaragoza, Spain) within 2 hours after leaving the farm.

Table 5.I Composition of the basal compound feed.

\begin{tabular}{|rr|}
\hline Ingredient & $\mathbf{g ~ k g}^{-1}$ \\
Barley & 285 \\
Wheat & 260 \\
Maize & 200 \\
Soya bean meal (490 g kg \\
Soya oil & 190 \\
Limestone & 17 \\
Sodium bicarbonate & 25 \\
Sodium chloride & 6 \\
Standard mineral and vitamin premix & 6 \\
Experimental premix & 4 \\
\hline
\end{tabular}

${ }^{\dagger}$ Minerals and vitamins provided: Ca 0.24 g, Na 0.47 g, S 0.23 g, Mn 30 mg, Zn 50 mg, Cu $5 \mathrm{mg}$, I $0.5 \mathrm{mg}$, Co $0.5 \mathrm{mg}$, Se $0.15 \mathrm{mg}$, Fe $50 \mathrm{mg}$, vitamin A 800o IU, vitamin D3 I60o IU, all-rac- $\alpha$-tocopheryl acetate $25 \mathrm{mg}$. ${ }^{\ddagger}$ Experimental premix: wheat bran 5g, plant extract or hydrated silica $(50 \%$ water and $50 \%$ silica) $5 \mathrm{~g}$. 


\section{Blood and Tissue Sampling}

Four lambs per pen (in total I2 lambs per treatment) were randomly selected at the start of the experimental period for blood and tissue sampling. Upon arrival and in the last day of the experimental period ( $\mathrm{d}$ I4), blood samples (IO $\mathrm{mL}$ ) were collected in heparinized evacuated tubes (Belliver Industrial Estate, Plymouth, U.K.). All tubes were immediately placed on ice and, within $2 \mathrm{~h}$ after collection were centrifuged at $2500 \times \mathrm{g}$ for $10 \mathrm{~min}$ at $4^{\circ} \mathrm{C}$. The plasma was collected, acidified (I:II) with acetic acid (IO $\mathrm{mM}$ ) and frozen at $-80^{\circ} \mathrm{C}$ until the extraction of the polyphenolic fraction.

The lambs were slaughtered in the local abattoir according to EC Regulations. Within 30 min after slaughter, liver and kidneys (detoxification organs) were removed, cut into pieces, vacuum-packed in BB4L bags (Cryovac Packaging, Barcelona, Spain) of low gas permeability $\left(8-12 \mathrm{~cm}^{3} \mathrm{~m}^{-2}\right.$ per $\left.24 \mathrm{~h}\right)$ using a discontinuous INELVI VISC 500 packer (Industrial Elétrica Vilar, Barcelona, Spain), and stored at $-80^{\circ} \mathrm{C}$ prior to analysis. The carcasses were chilled $\left(2^{\circ} \mathrm{C}\right)$ for $24 \mathrm{~h}$ before a professional butcher removed the longissimus throracis et lumborum muscle. The muscles were filleted (1.5 $\mathrm{cm}$ thick) and stored under the same conditions as described above for the detoxification organs.

\section{Plasma Polyphenol Extraction}

A modified method described by Faggian et al. (2016) was used to determine the presence of polyphenolic components in lamb plasma. In order to precipitate proteins, $2 \mathrm{~mL}$ of acetonitrile was added to $2 \mathrm{~mL}$ of acidified plasma before samples were vortexed and placed for $45 \mathrm{~min}$ in an ultrasound bath in ice. The sample was then centrifuged (63II x g, $4^{\circ} \mathrm{C}$ for Io min) and the clear supernatant was collected and dried at $40^{\circ} \mathrm{C}$ under vacuum conditions in an evaporator system (Syncore Polyvap R-96) (Buchi). The residue was redissolved in methanol and brought up to I $\mathrm{mL}$. The extracts were kept in vials at $-80^{\circ} \mathrm{C}$ until their corresponding analyses.

\section{DPPH• Radical-Scavenging Capacity}

The antioxidant scavenging activities of the muscle, liver and kidney tissues were determined according to the method described by Brand-Williams et al. (1995). Methanolic extracts (500 $\mu \mathrm{L}$ ) at different concentrations ( 400 to $25 \mu \mathrm{L} \mathrm{mL}^{-1}$ ) were added to I ml of methanolic DPPH solution $(0.1 \mathrm{mM})$. The estimated time of reaction $(2 \mathrm{O} \mathrm{min}$ ) was determined by considering the reduction of the absorbance at $517 \mathrm{~nm}$ (monitored every $5 \mathrm{~min}$ ), until the reaction curve reached a plateau. The absorbance was measured at room temperature, in dark conditions, against a blank ( $500 \mu \mathrm{L}$ of sample plus I $\mathrm{mL}$ of methanol). The absorbance of the control (500 $\mu \mathrm{L}$ of methanol in I $\mathrm{mL}$ of DPPH' solution) was measured daily. All the assays were conducted in triplicate. The percentage capacity for the $\mathrm{DPPH}{ }^{\bullet}$ technique was calculated as:

$$
\% \text { Discolouration }=[\mathrm{I}-(\text { Abs sample } / \mathrm{Abs} \text { control })] \times \mathbf{I O O}
$$


The results were expressed as the inhibitory concentration of the fresh tissue necessary to decrease the $\mathrm{DPPH}^{\cdot}$ absorbance by $50 \%$ (IC50). Concentrations are expressed in $\mathrm{mg} \mathrm{ml}^{-1}$.

\section{Trolox Equivalent Antioxidant Capacity (TEAC)}

The TEAC assay was used for the determination of the plasma, muscle, liver and kidney tissue antioxidant capacity according to the method described by Re et al. (1999). The ABTS radical cation $\left(\mathrm{ABTS}^{*}\right)$ was produced by reacting $\mathrm{I} 4 \mathrm{mM}$ ABTS with an equal volume of 4.9 $\mathrm{mM}$ potassium persulphate (final concentration: $7 \mathrm{mM}$ ABTS in $2.45 \mathrm{mM}$ potassium persulphate). The mixture was incubated in the dark at room temperature, $\mathrm{I} 2-\mathrm{I} 6 \mathrm{~h}$ before use. The $\mathrm{ABTS}^{\cdot+}$ solution was diluted with ethanol to an absorbance of $0.70 \pm 0.02$ at 734 $\mathrm{nm}$ and equilibrated to $30^{\circ} \mathrm{C}$. Polyphenolic extracts ( $\left.\mathrm{I} 5 \mu \mathrm{l}\right)$ or Trolox standard $(25-2000 \mu \mathrm{M}$ in ethanol) were added to $\mathrm{I} .5 \mathrm{~mL}$ of the diluted $\mathrm{ABTS}^{\cdot+}$ solution and the absorbance was read at $30^{\circ} \mathrm{C}, \mathrm{I}-20 \mathrm{~min}$ after the initial mixing. All the absorbance readings were taken against a blank containing $15 \mu \mathrm{L}$ of sample plus $\mathrm{I} .5 \mathrm{~mL}$ of ethanol. Results are expressed as mmol of Trolox equivalent per $\mathrm{g}$ of fresh tissue or $\mathrm{mL}$ of plasma.

\section{Ferric Reducing Antioxidant Power (FRAP)}

The ferric reducing ability of polyphenolic tissue extracts was measured according to a modified method developed by Descalzo et al. (2007). To prepare the FRAP reagent, a mixture of $300 \mathrm{mM}$ acetate buffer ( $\mathrm{pH} 3.6$ ), IO $\mathrm{mM} \mathrm{TPTZ} \mathrm{in} 40 \mathrm{mM} \mathrm{HCl}$, and $20 \mathrm{mM}$ ferric chloride (IO:I:I) was made. To I.2 $\mathrm{mL}$ of reagent, $0.04 \mathrm{ml}$ of methanolic extract and $0.12 \mathrm{~mL}$ of deionised water was added. Readings at the maximum absorption $(593 \mathrm{~nm})$ at $37^{\circ} \mathrm{C}$ were taken every $\mathrm{I} 5 \mathrm{~s}$, and the reaction was monitored up to $30 \mathrm{~min}$. The endogenous $\mathrm{Fe}(\mathrm{II})$ content of muscle and detoxification organs (FRAP) were determined with a TPTZ/ $\mathrm{HCl}$ solution without ferric chloride in the reaction mixture. Ferrous sulphate solutions $\left(\mathrm{FeSO}_{4} \cdot 7 \mathrm{H} 2 \mathrm{O}\right.$ ) of $0.05-3 \mathrm{mM}$ were used to obtain the calibration curve, and results are expressed as mmol Fe (II) equivalent per $\mathrm{g}$ of fresh tissue.

\section{Oxygen Radical Absorbing Capacity (ORAC)}

The automated ORAC assay was carried out with a Fluostar Optima microplate reader (BMG Labtechnologies, Durham, NC) as described by Prior et al. (2003). Methanolic extracts were diluted I:IO; I:IOO and I:500 with phosphate buffer (75 mM, pH 7.0). The diluted extract $(40 \mu \mathrm{L})$ was added to each well in clear 48 -well Falcon plates. Phosphate buffer was used as a blank and Trolox $(40 \mu \mathrm{L})$ was used as the standard $(6.25,12.5,25$, and $50 \mu \mathrm{M})$. The Fluostar Optima instrument, equipped with two automated injectors, was programmed to add $400 \mu \mathrm{L}$ of fluorescein (o.II $\mu \mathrm{M}$ ) followed by I5O $\mu \mathrm{L}$ of AAPH (31.6 mM) to each well. Fluorescence readings (excitation $485 \mathrm{~nm}$, emission $520 \mathrm{~nm}$ ) were recorded immediately after the addition of fluorescein, immediately after the addition of AAPH, and every $192 \mathrm{~s}$ thereafter for $90 \mathrm{~min}$ to reach a $95 \%$ loss of fluorescence. Final fluorescence measurements were expressed relative to the initial reading. Results were calculated on the 
basis of differences in area under the fluorescein decay curve between the blank, samples, and Trolox standards. A standard curve was obtained by plotting the four concentrations of Trolox standards against the net area under the curve of each standard. Finally ORAC values were calculated using the regression equation between Trolox concentration and area under the curve and were expressed as mmol of Trolox equivalent per $g$ of fresh tissue.

\section{Statistical Analysis}

All statistical analyses were performed using SAS, version 9.3 (SAS Institute, Inc., Cary, NC, USA). To assess the effects of dietary plant extract supplementation on average daily weight gain, feed intake, feed efficiency and antioxidant capacity (TEAC, FRAP, ORAC and DPPH•) in the tissues (muscle, liver and kidney), data were analysed with a MIXED procedure where the model accounted for the fixed effect of treatment, with pen and the residuals entered in the model as random effects. For initial body weight, final body weight and TEAC levels in blood, the fixed effects of treatment and time (as repeated measures), and the first-order interactions were considered. Pen and the residuals entered the model as random effects. When a treatment and time interaction was detected, a Tukey post-hoc test was used to correct for multiple comparisons. Significance was declared when P<0.05 and trends were declared when $\mathrm{P}<$ o.IO.

\section{RESULTS}

\section{Animal Performance}

The experimental period lasted I4 d, from an initial body weight of $23.5 \pm \mathrm{I} .38 \mathrm{~kg}$ (mean \pm $\mathrm{SD}$ ) to a final body weight of $27.9 \pm \mathrm{I} .9 \mathrm{I} \mathrm{kg}$. The average daily weight gain, average daily feed intake and feed conversion ratio are presented in Table 5.2. Supplementation of lamb diets with the selected plant extracts had no effect on the aforementioned parameters. 


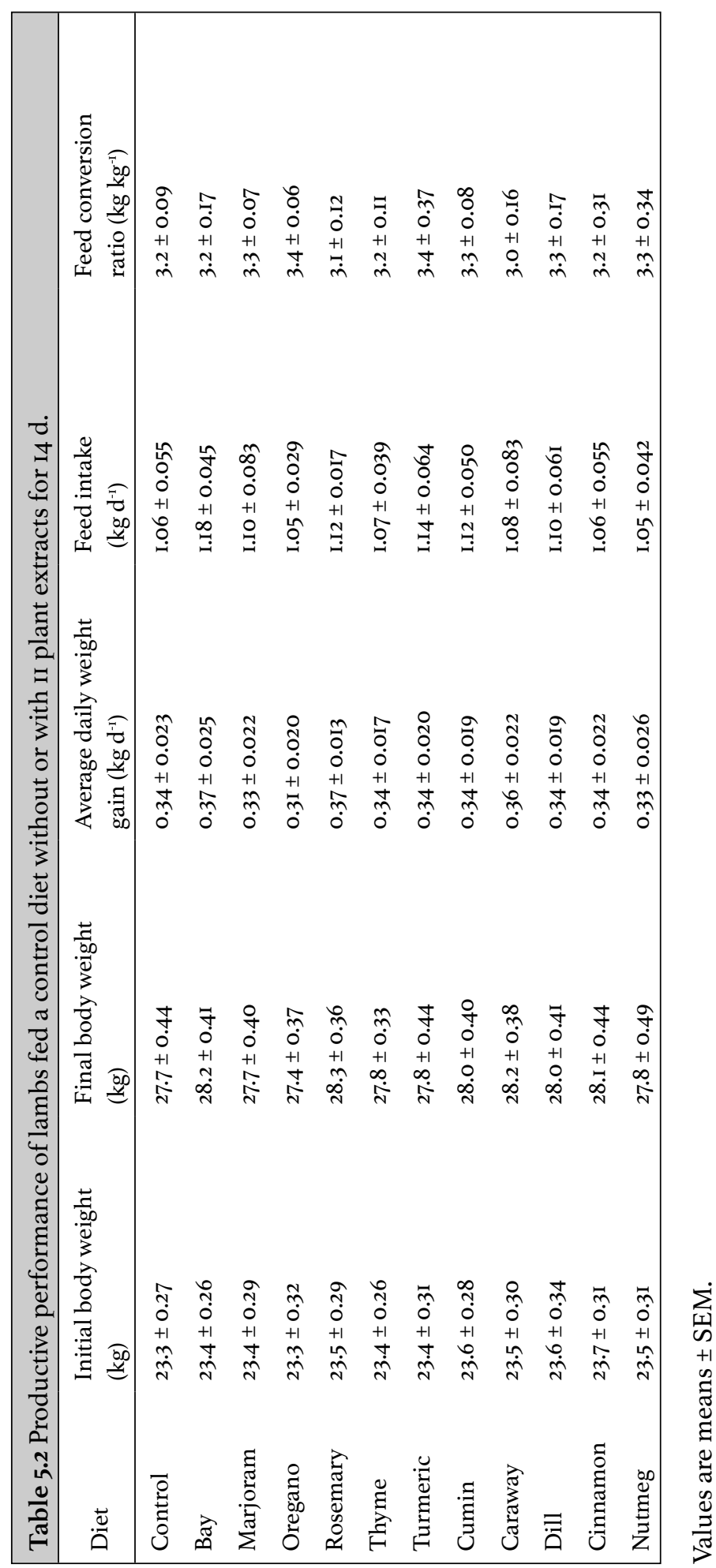




\section{Radical-Scavenging Capacity in Blood}

Dietary supplementation of lamb diets with selected plant extracts had no effect $(\mathrm{P}>0.05)$ on TEAC values in blood (Table 5.3).

Table 5.3 Trolox equivalent antioxidant capacity ( $\left.\mathrm{mM}_{\text {trolox }} \mathrm{g}^{-1}\right)$ of blood of lambs at the start and the end of feeding a control diet without or with II plant extracts for I4 $\mathrm{d}$.

\begin{tabular}{|lll|}
\hline Diet & Initial & Final \\
\hline Control & $4 \mathrm{I} .0 \pm 3.17$ & $47.4 \pm \mathrm{I} .74$ \\
Bay & $5 \mathrm{I} .5 \pm 4.56$ & $40.6 \pm 3.6 \mathrm{O}$ \\
Marjoram & $48 . \mathrm{I} \pm 2.23$ & $42.7 \pm 3.16$ \\
Oregano & $42.9 \pm 3.36$ & $39.2 \pm 3.3 \mathrm{I}$ \\
Rosemary & $43.9 \pm 3.38$ & $44.8 \pm 3.6 \mathrm{I}$ \\
Thyme & $46.6 \pm 4.83$ & $36.4 \pm 2.54$ \\
Turmeric & $50.0 \pm 3.48$ & $40.8 \pm 2.97$ \\
Cumin & $40.6 \pm 3.87$ & $39.5 \pm 4.68$ \\
Caraway & $45.6 \pm 3.63$ & $50.0 \pm \mathrm{I} .89$ \\
Dill & $44.4 \pm 3.19$ & $4 \mathrm{I} .7 \pm 2.67$ \\
Cinnamon & $48.6 \pm 4.24$ & $42.9 \pm 2.74$ \\
Nutmeg & $5 \mathrm{I} .3 \pm 2.3 \mathrm{I}$ & $44.2 \pm 3.77$ \\
\hline
\end{tabular}

Values are means \pm SEM.

\section{dical-Scavenging Capacity in Muscle}

Based on the results from the TEAC assay, supplementation of lamb diets with $5.0 \mathrm{~g} \mathrm{~kg}^{-1}$ of nutmeg extract significantly increased the radical-scavenging capacity in muscle when compared with the Control and marjoram groups (Table 5.4). No differences were found among treatments when muscle radical-scavenging capacity was accessed by FRAP. When considering the results from the ORAC assay, the radical-scavenging capacity of muscle samples from the oregano, dill, cinnamon and nutmeg were significantly lower than the Control and rosemary groups $(\mathrm{P}<0.05)$. Moreover, higher $\mathrm{DPPH}^{\cdot}$ values in the cinnamon group found when compared to bay, thyme and nutmeg supplemented lambs. 


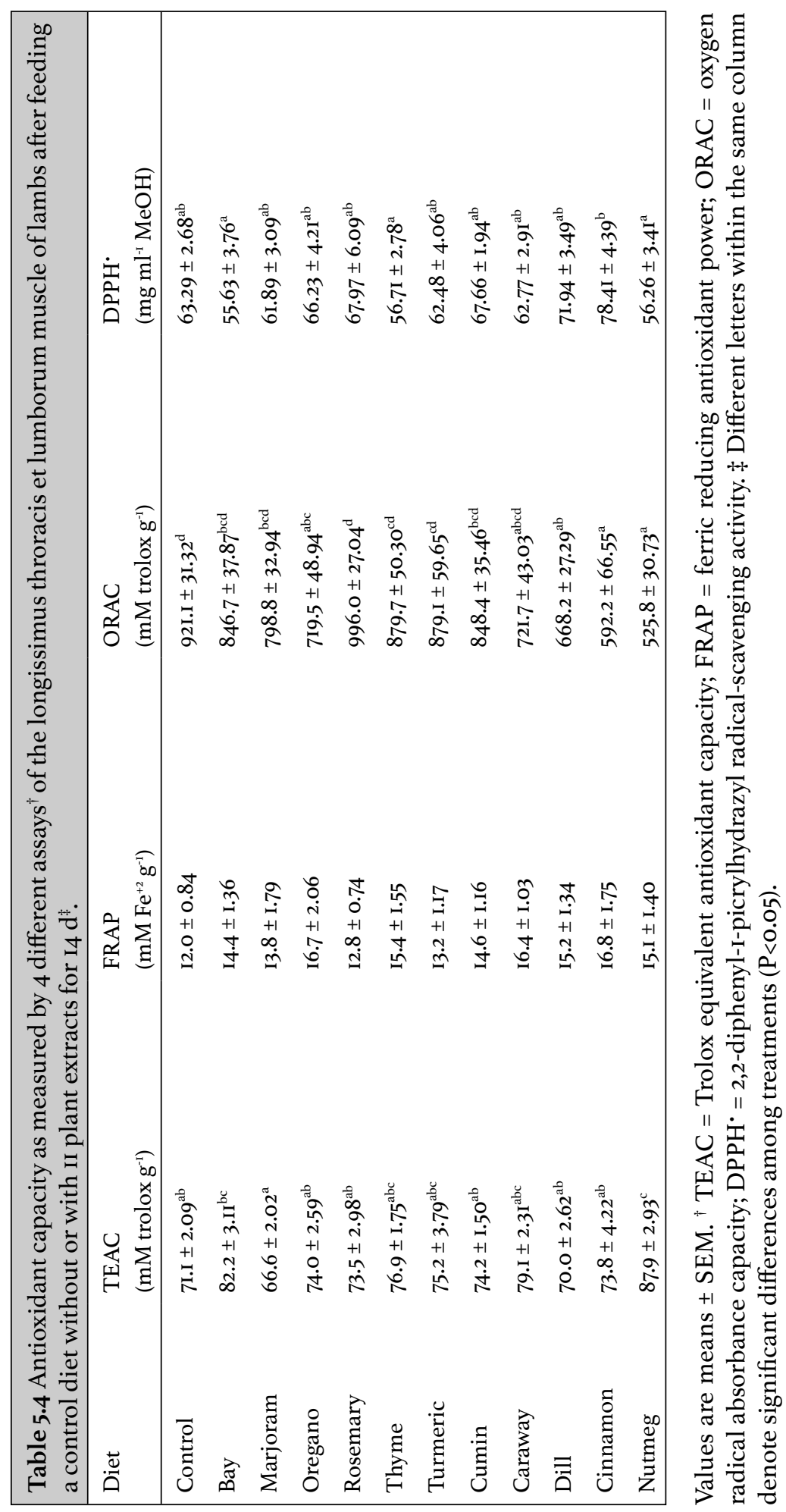




\section{Radical-Scavenging Capacity in Liver}

Data from the assessment of radical-scavenging capacity in liver samples from lambs fed the II different plant extracts are presented in Table 5.5. Nutmeg extract supplementation significant increased TEAC values compared to the Control and marjoram fed groups. Like in muscle, there was no effect of plant extract supplementation on radical-scavenging capacity in the liver, as indicated by the FRAP assay. Lambs supplemented with bay extract presented significantly lower ORAC values in liver than lambs supplemented with marjoram, oregano, rosemary and turmeric. Liver $\mathrm{DPPH}^{\bullet}$ values from nutmeg, cinnamon and turmeric supplemented lambs were significantly lower than the control, marjoram, rosemary and thyme supplemented groups.

\section{Radical-Scavenging Capacity in Kidney}

The effect of plant extract supplementation on radical-scavenging capacity of kidney tissue is presented in Table 5.6. According to the TEAC assay results, supplementation of lamb diets with oregano, cumin and caraway plant extracts significantly lowered the radicalscavenging capacity in kidney tissue compared to the Control, marjoram and rosemary fed lambs. Similarly to muscle and liver, no differences among treatment groups were found for FRAP in kidney tissue. When focusing on the ORAC assay values, turmeric, cumin, caraway, cinnamon and nutmeg presented significantly higher radical-scavenging capacity than the Control, bay, oregano and rosemary fed lambs. Moreover, in kidney tissue, supplementation of lamb diets with oregano extract yielded the lowest radical-scavenging capacity, as accessed by the $\mathrm{DPPH}^{*}$ assay. 


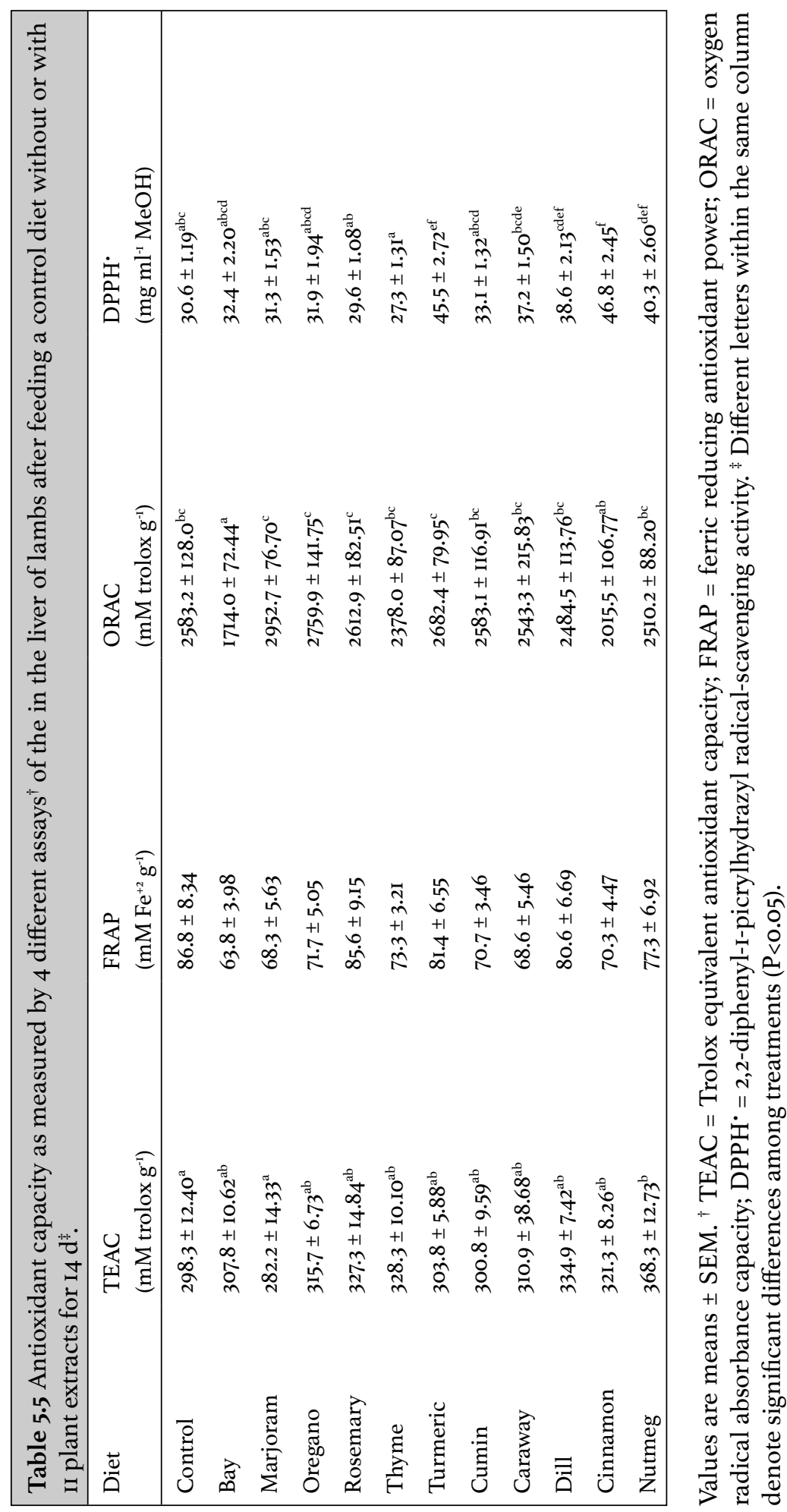




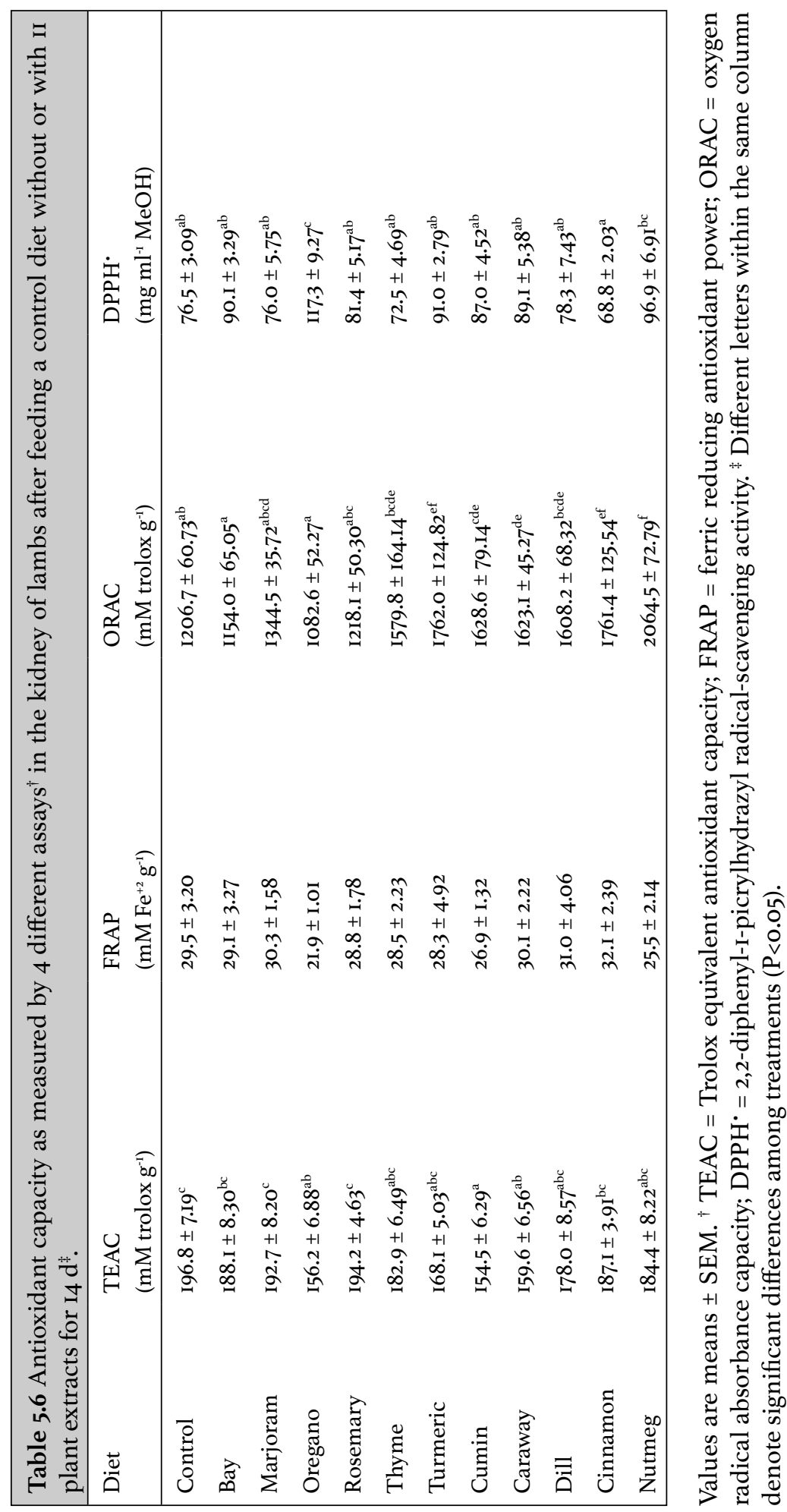




\section{DISCUSSION}

Supplementation of lamb diets with selected plant extracts had no effect on final body weight, average daily weight gain, feed intake and feed efficiency. This is in agreement with previous findings in lambs (Chaves et al., 2008; Smeti et al., 2018) and cattle (Devant et al., 2007; Balcells et al., 2012), in which supplementation of different plant extracts or essential oils had no effect on growth, feed intake nor efficiency.

In the current study, there was no effect of plant extract supplementation on blood radical-scavenging capacity (in $\mathrm{mM}$ Trolox $\mathrm{g}^{-1}$ ), as assessed by the TEAC assay. However, when feeding plant extracts to sheep by direct ruminal infusion, Gladine et al. (2007) was able to detect the presence of epicatechins in blood. Karami et al. (2010) reported a decrease in blood lipid oxidation in goat kids as a result of dietary supplementation with Andrographis paniculata and turmeric, and more recently, Kafantaris et al. (20I7) found that supplementation of lamb diets with grape pomace enhanced the antioxidant mechanisms in blood and tissues, as indicated by an increase in catalase and glutathione capacity. We focused on the radical scavenging ability of the plant extracts in blood by performing the TEAC assay. However, it is advisable to use more than one assay per blood/tissue sample for a better understanding of the effects and mechanisms of action of plant extracts in the target sample (Ghiselli et al., 200o).

In muscle, the radical scavenging and reducing ability of the selected plant extracts were assessed with TEAC, FRAP, ORAC and DPPH ${ }^{\cdot}$ assays. We found that supplementation of lamb diets with nutmeg extract significantly increased TEAC values in muscle when compared with non-supplemented lambs. Phenolic compounds, or their metabolites, can be absorbed along the gastrointestinal tract and may act as direct antioxidants in the animal tissues (Moñino et al., 2008; Jordán et al., 2010). Supplementation of ewe diets during gestation and lactation with distilled rosemary leaves (up to $20 \%$ of the basal diet), increased the phenolic content in the lamb's muscle which was associated with a higher overall antioxidant activity, measured by FRAP and TEAC assays. Moreover, when supplementing lamb diets with $8.98 \%$ (dry matter basis) quebracho extract (Schinopsis lorentzii), Luciano et al. (20II) found an increase in total phenols in muscle (+31.3\%) which resulted in higher antioxidant capacity in the tissue (TEAC and FRAP assays). Based on the ORAC assay, supplementation of lamb diets with oregano, dill, cinnamon and nutmeg significantly reduced the radical scavenging capacity (ORAC assay) in muscle compared with the non-supplemented lambs. It is recognized that phenolics present in plant extracts can act as prooxidants under certain conditions, including high concentrations of transition metal ions, alkaline $\mathrm{pH}$ and the presence of oxygen molecules (Blokhina et al., 2003). Earlier work from Cao et al. (1997), demonstrated that myricetin, quercetin, and kaempferol behaved as prooxidants using the ORAC assay with $\mathrm{Cu}(\mathrm{II})$ as a transition metal oxidant. Moreover, they also found that the same compounds could behave as antioxidants or prooxidants, depending on the concentration in the mixture and the free radical used in the assay. 
Natural antioxidants and phytochemicals are multifunctional and differences among assays can also be attributed to their antioxidant properties (Frankel and Meyer, 200o). An antioxidant may act directly by scavenging reactive species or by inhibiting their generation. For instance, the ORAC assay is based on the inhibition of lipid peroxidation, and it is known to correlate poorly with FRAP, ABTS and DPPH techniques, which measure the capability of an antioxidant to quench free radicals either by $\mathrm{H}$ atom donation or by electron transfer. Therefore, an antioxidant with a high TEAC value may not perform well in preventing/delaying lipid peroxidation (Apak et al., 20I6).

Determination of the radical-scavenging capacity of plant extracts in detoxification organs such as liver and kidney is of great importance to better understand the fate of plant derived polyphenols, following their intake, absorption and tissue deposition. However, data are still very scarce, even in production animals (Crozier et al., 2009). Metabolites of polyphenols are expected to follow two main routes of excretion, i.e., the urinary or biliary route. The large conjugated metabolites are more likely to follow the biliary route, whereas small conjugates are preferentially excreted in urine (Manach et al., 2004).

In liver, we found an increased radical-scavenging capacity with turmeric supplementation (TEAC assay). This could indicate that following absorption, the metabolization of turmeric in the liver could have promoted a higher concentration of this compounds in the organ, where it was potentially conjugated before being excreted in the urine and/or faeces. Interestingly, in the current study turmeric supplementation had no effect on the radical scavenging activity in muscle, but higher ORAC values were found in the kidney. Similarly, Bodas et al. (20II) when supplementing lambs with citrus flavonoids (0.15\% of the diet), found elevated concentrations of naringenin in the liver but not in muscle. Interestingly, when supplementing lambs with quebracho tannins, López-Andrés et al. (2013) found a greater antioxidant capacity in liver and plasma of supplemented lambs compared with the non-supplemented animals. However, the antioxidant effects induced in the animal tissues occurred almost with null intestinal absorption of these compounds (indirect antioxidant effect). Lambs supplemented with bay extract presented significantly lower ORAC values than the non-supplemented lambs. Moreover, incorporation of turmeric, cinnamon and nutmeg plant extracts did not favour the antioxidant stability of the liver, due to the higher $\mathrm{DPPH} \cdot$ values compared with the non-supplemented lambs. As previously highlighted in muscle, phenolic compounds present in plant extracts can act as prooxidants in tissues, particularly in the presence of metals such as $\mathrm{Cu}$ and Fe (Eghbaliferiz and Iranshahi, 20I6). Curcumin, a major phenolic compound present in turmeric extract, has shown prooxidant capacity in the presence of $\mathrm{Cu}(\mathrm{II})$, creating reactive oxygen species through the reduction of $\mathrm{Cu}(\mathrm{II})$ to $\mathrm{Cu}(\mathrm{I})$. This in turn can cause a copper-dependent DNA damage and induce apoptosis (Yoshino et al., 2004).

In kidney, supplementation of the lamb diets with oregano, cumin and caraway lowered the radical scavenging capacity. However, higher ORAC values were found for turmeric, cumin, caraway, cinnamon and nutmeg, which seems to indicate an increased radical 
scavenging capacity or increased polyphenol concentration in the tissue. In a review conducted by Manach et al. (2005), urinary excretion of polyphenols in humans was found to vary from $0.3 \%$ to $43 \%$ of the polyphenol intake, which emphasizes the great variability in the bioavailability (absorption, transport, deposition and elimination) of the different polyphenols from different botanical origins.

\section{CONCLUSIONS}

The antioxidant status of muscle was increased by nutmeg supplementation (TEAC values). In liver, an increase in the radical-scavenging capacity was found in lambs supplemented with turmeric extract (TEAC values). Whereas, supplementation of lamb diets with turmeric, cumin, caraway, cinnamon and nutmeg increased the radicalscavenging capacity in kidney (ORAC values). Unfortunately, it is unclear if the divergent results on the antioxidant status registered in the tissues (as assessed by the different methods) is associated with a prooxidant effect of the plant extracts or with the specificity of the different assays.

\section{ACKNOLEDGEMENTS}

The authors would like to thank Franco \& Navarro S.A. (Zaragoza, Spain), Mercazaragoza S.A. (Zaragoza, Spain), J. A. Beltrán, V. Alonso and S. Garcia for their support in this study. 


\section{REFERENCES}

Andrés, S., M. L. Tejido, R. Bodas, L. Morán, N. Prieto, C. Blanco, and F. J. Giráldez. 2013. Quercetin dietary supplementation of fattening lambs at $0.2 \%$ rate reduces discolouration and microbial growth in meat during refrigerated storage. Meat science 93(2):207-2I2.

Apak, R., M. Özyürek, K. Güçlü, and E. Çapanoğlu. 20I6. Antioxidant activity/capacity measurement. I. Classification, physicochemical principles, mechanisms, and electron transfer (ET)-based Assays. Journal of agricultural and food chemistry 64(5):997-IO27.

Balcells, J., A. Aris, A. Serrano, A. R. Seradj, J. Crespo, and M. Devant. 2012. Effects of an extract of plant flavonoids (Bioflavex) on rumen fermentation and performance in heifers fed high-concentrate diets. Journal of animal science 90(I3):4975-4984.

Blokhina, O., E. Virolainen, and K. V. Fagerstedt. 2003. Antioxidants, oxidative damage and oxygen deprivation stress: a review. Annals of Botany 9I:I79-I94.

Bodas, R., N. Prieto, M. J. Jordán, Ó. López-Campos, F. J. Giráldez, L. Morán, and S. Andrés. 20II. The liver antioxidant status of fattening lambs is improved by naringin dietary supplementation at $0.15 \%$ rates but not meat quality. Animal 6(5):863-870.

Brand-Williams, W., M. E. Cuvelier, and C. Berset. 1995. Use of a free radical method to evaluate antioxidant activity. Food Science and Technology 28(I):25-30.

Cao, G., E. Sofic, and R. L. Prior. 1997. Antioxidant and prooxidant behavior of flavonoids: structure-activity relationships. Free Radical Biology \& Medicine 22(5):749-76o.

Chaves, A. V., K. Stanford, L. L. Gibson, T. A. McAllister, and C. Benchaar. 2008. Effects of carvacrol and cinnamaldehyde on intake, rumen fermentation, growth performance, and carcass characteristics of growing lambs. Animal Feed Science and Technology I45(I):396-408.

Crozier, A., I. B. Jaganath, and M. N. Clifford. 2009. Dietary phenolics: chemistry, bioavailability and effects on health. Natural Product Reports 26(8):IOOI-IO43.

Descalzo, A. M., L. Rossetti, G. Grigioni, M. Irurueta, A. M. Sancho, J. Carrete, and N. A. Pensel. 2007. Antioxidant status and odour profile in fresh beef from pasture or grainfed cattle. Meat Science 75(2):299-307.

Devant, M., A. Anglada, and A. Bach. 2007. Effects of plant extract supplementation on rumen fermentation and metabolism in young Holstein bulls consuming high levels of concentrate. Animal Feed Science and Technology I37(I):46-57.

Eghbaliferiz, S., and M. Iranshahi. 20I6. Prooxidant activity of polyphenols, flavonoids, anthocyanins and carotenoids: Updated review of mechanisms and catalyzing metals. Phytotherapy Research 30(9):I379-I39I.

Faggian, M., S. Sut, B. Perissutti, V. Baldan, I. Grabnar, and S. Dall'Acqua. 2016. Natural deep eutectic solvents (NADES) as a tool for bioavailability improvement: Pharmacokinetics of rutin dissolved in proline/glycine after oral administration in rats: possible application in nutraceuticals. Molecules 2I(II):I53I. 
Frankel, E. N., and A. S. Meyer. 2000. The problems of using one-dimensional methods to evaluate multifunctional food and biological antioxidants. Journal of the Science of Food and Agriculture 80(I3):I925-I94I.

Ghiselli, A., M. Serafini, F. Natella, and C. Scaccini. 200o. Total antioxidant capacity as a tool to assess redox status: critical view and experimental data. Free Radical Biology \& Medicine 29(II):IIO6-III4.

Gladine, C., E. Rock, C. Morand, D. Bauchart, and D. Durand. 2007. Bioavailability and antioxidant capacity of plant extracts rich in polyphenols, given as a single acute dose, in sheep made highly susceptible to lipoperoxidation. British Journal of Nutrition 98(4):69I-70I.

González-Calvo, L., G. Ripoll, F. Molino, J. H. Calvo, and M. Joy. 2015. The relationship between muscle $\alpha$-tocopherol concentration and meat oxidation in light lambs fed vitamin E supplements prior to slaughter. Journal of the Science of Food and Agriculture 95(I):IO3-IIO.

Jordán, M. J., M. I. Moñino, C. Martínez, A. Lafuente, and J. A. Sotomayor. 20Io. Introduction of distillate rosemary leaves into the diet of the Murciano-Granadina goat: transfer of polyphenolic compounds to goats' milk and the plasma of suckling goat kids. Journal of Agricultural and Food Chemistry 58(I4):8265-8270.

Kafantaris, I., B. Kotsampasi, V. Christodoulou, E. Kokka, P. Kouka, Z. Terzopoulou, K. Gerasopoulos, D. Stagos, C. Mitsagga, I. Giavasis, S. Makri, K. Petrotos, and D. Kouretas. 20I7. Grape pomace improves antioxidant capacity and faecal microflora of lambs. Journal of Animal Physiology and Animal Nutrition IoI(5):eIo8-eI2I.

Kähkönen, M. P., A. I. Hopia, H. J. Vuorela, J.-P. Rauha, K. Pihlaja, T. S. Kujala, and M. Heinonen. 1999. Antioxidant activity of plant extracts containing phenolic compounds. Journal of Agricultural and Food Chemistry 47(IO):3954-3962.

Karami, M., A. R. Alimon, A. Q. Sazili, and Y. M. Goh. 20IO. Meat quality and lipid oxidation of Infraspinatus muscle and blood plasma of goats under dietary supplementation of herbal antioxidants. Journal of Animal and Veterinary Advances 9(22):2839-2847.

Leal, L. N., J. A. Beltrán, V. Alonso, J. M. Bello, L. A. den Hartog, W. H. Hendriks, and J. MartínTereso. 20I8a. Dietary vitamin E dosage and source affects meat quality parameters in light weight lambs. Journal of the Science of Food and Agriculture 98(4):I606-I6I4.

Leal, L. N., S. K. Jensen, J. M. Bello, L. A. Den Hartog, W. H. Hendriks, and J. Martin-Tereso. 20I8b. Bioavailability of alpha-tocopherol stereoisomers in lambs depends on dietary doses of all-rac- or RRR-alpha-tocopheryl acetate. Animal 27:I-9.

Lobón, S., M. Blanco, A. Sanz, G. Ripoll, J. R. Bertolín, and M. Joy. 2017. Meat quality of light lambs is more affected by the dam's feeding system during lactation than by the inclusion of quebracho in the fattening concentrate. Journal of Animal Science 95(II):4998-50II. 
López-Andrés, P., G. Luciano, V. Vasta, T. M. Gibson, L. Biondi, A. Priolo, and I. MuellerHarvey. 2013. Dietary quebracho tannins are not absorbed, but increase the antioxidant capacity of liver and plasma in sheep. British Journal of Nutrition IIO(4):632-639.

Luciano, G., V. Vasta, F. J. Monahan, P. López-Andrés, L. Biondi, M. Lanza, and A. Priolo. 20II. Antioxidant status, colour stability and myoglobin resistance to oxidation of longissimus dorsi muscle from lambs fed a tannin-containing diet. Food Chemistry I24(3):I036-IO42.

Manach, C., A. Scalbert, C. Morand, C. Rémésy, and L. Jiménez. 2004. Polyphenols: food sources and bioavailability. The American Journal of Clinical Nutrition 79(5):727-747.

Manach, C., G. Williamson, C. Morand, A. Scalbert, and C. Rémésy. 2005. Bioavailability and bioefficacy of polyphenols in humans. I. Review of 97 bioavailability studies. The American Journal of Clinical Nutrition 8I(I):230S-242S.

Moñino, I., C. Martínez, J. A. Sotomayor, A. Lafuente, and M. J. Jordán. 20o8. Polyphenolic transmission to Segureño lamb meat from ewes' diet supplemented with the distillate from rosemary (Rosmarinus officinalis) leaves. Journal of Agricultural and Food Chemistry 56(9):3363-3367.

Morán, L., S. Andrés, R. Bodas, N. Prieto, and F. J. Giráldez. 20I2. Meat texture and antioxidant status are improved when carnosic acid is included in the diet of fattening lambs. Meat Science 9I(4):430-434.

Nieto, G., P. Díaz, S. Bañón, and M. D. Garrido. 20Io. Effect on lamb meat quality of including thyme (Thymus zygis ssp. gracilis) leaves in ewes' diet. Meat Science 85(I):82-88.

Ortuño, J., R. Serrano, M. J. Jordán, and S. Bañón. 20I4. Shelf life of meat from lambs given essential oil-free rosemary extract containing carnosic acid plus carnosol at 200 or 400 $\mathrm{mg} \mathrm{kg}$.- Meat science 96(4):I452-I459.

Prior, R. L., H. Hoang, L. Gu, X. Wu, M. Bacchiocca, L. Howard, M. Hampsch-Woodill, D. Huang, B. Ou, and R. Jacob. 2003. Assays for hydrophilic and lipophilic antioxidant capacity (oxygen radical absorbance capacity (ORACFL)) of plasma and other biological and food samples. Journal of Agricultural and Food Chemistry 5I(II):3273-3279.

Re, R., N. Pellegrini, A. Proteggente, A. Pannala, M. Yang, and C. Rice-Evans. 1999. Antioxidant activity applying an improved ABTS radical cation decolorization assay. Free Radical Biology and Medicine 26(9):I23I-I237.

Shan, B., Y. Z. Cai, M. Sun, and H. Corke. 2005. Antioxidant capacity of 26 spice extracts and characterization of their phenolic constituents. Journal of Agricultural and Food Chemistry 53(20):7749-7759.

Smeti, S., H. Hajji, I. Mekki, M. Mahouachi, and N. Atti. 20I8. Effects of dose and administration form of rosemary essential oils on meat quality and fatty acid profile of lamb. Small Ruminant Research 158:62-68.

Valenti, B., A. Natalello, V. Vasta, L. Campidonico, V. Roscini, S. Mattioli, M. Pauselli, A. Priolo, M. Lanza, and G. Luciano. 20I8. Effect of different dietary tannin extracts on 
lamb growth performances and meat oxidative stability: comparison between mimosa, chestnut and tara. Animal I3(2):435-443.I-9.

Vallverdú-Queralt, A., J. Regueiro, M. Martínez-Huélamo, J. F. Rinaldi Alvarenga, L. N. Leal, and R. M. Lamuela-Raventos. 20I4. A comprehensive study on the phenolic profile of widely used culinary herbs and spices: Rosemary, thyme, oregano, cinnamon, cumin and bay. Food Chemistry I54:299-307.

Vallverdú-Queralt, A., J. Regueiro, J. F. Rinaldi Alvarenga, M. Martinez-Huelamo, L. N. Leal, and R. M. Lamuela-Raventos. 2015. Characterization of the phenolic and antioxidant profiles of selected culinary herbs and spices: caraway, turmeric, dill, marjoram and nutmeg. Food Science and Technology 35:I89-I95.

Vasta, V., and G. Luciano. 20II. The effects of dietary consumption of plants secondary compounds on small ruminants' products quality. Small Ruminant Research IOI(I):I50-I59.

Wojdyło, A., J. Oszmiański, and R. Czemerys. 2007. Antioxidant activity and phenolic compounds in 32 selected herbs. Food Chemistry I05(3):940-949.

Yoshino, M., M. Haneda, M. Naruse, H. H. Htay, R. Tsubouchi, S. L. Qiao, W. H. Li, K. Murakami, and T. Yokochi. 2004. Prooxidant activity of curcumin: copper-dependent formation of 8-hydroxy-2'-deoxyguanosine in DNA and induction of apoptotic cell death. Toxicology in Vitro I8(6):783-789.

Zheng, W., and S. Y. Wang. 20oI. Antioxidant activity and phenolic compounds in selected herbs. Journal of Agricultural and Food Chemistry 49(II):5I65-5I70. 


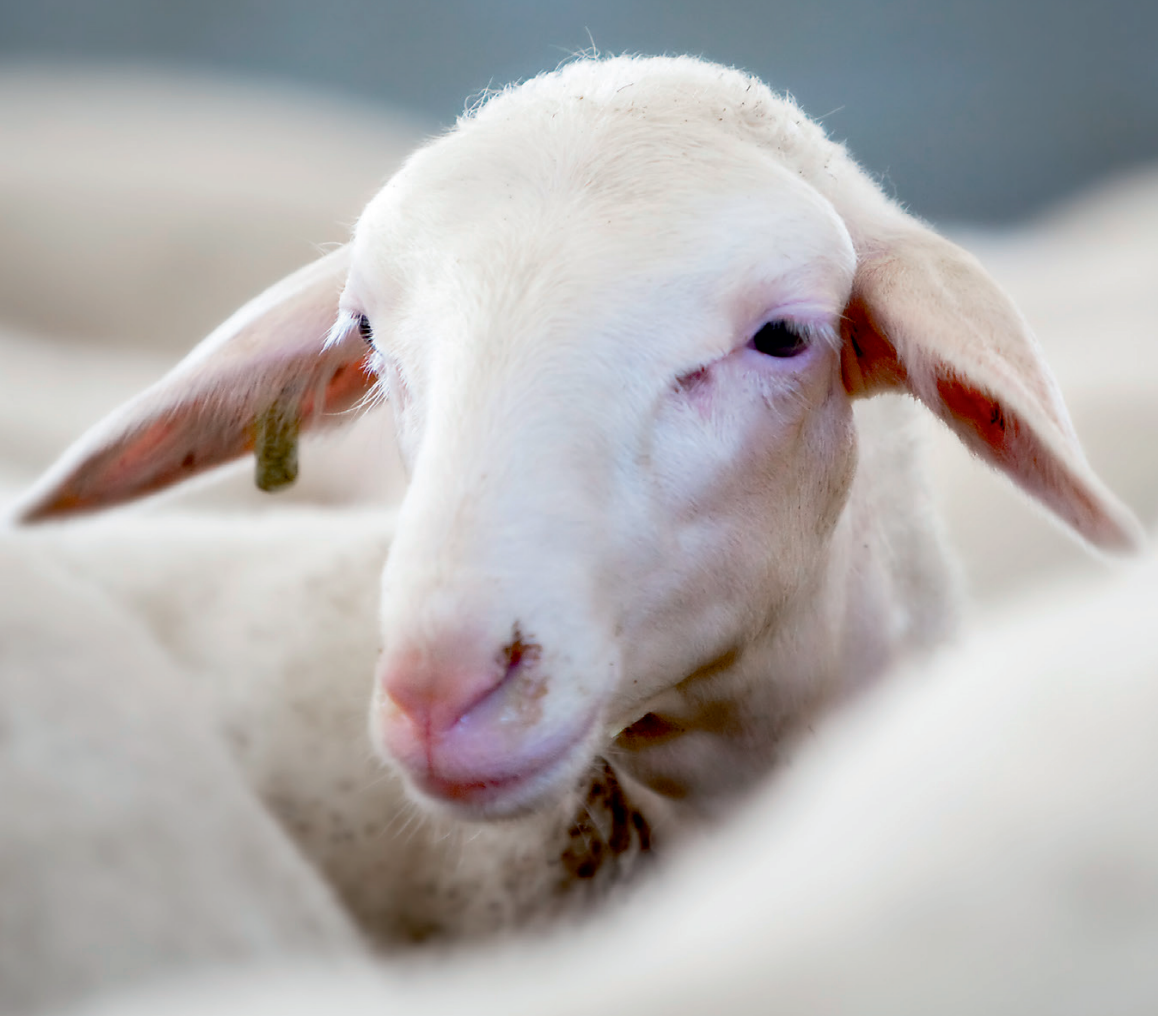




\title{
Chapter 6
}

\section{Supplementation of lamb diets with vitamin $\mathrm{E}$ and rosemary extracts on meat quality parameters}

\author{
L. N. Leala, ${ }^{\mathrm{a} b}$ J. A. Beltrán ${ }^{\mathrm{c}}$, M. Bellés ${ }^{\mathrm{c}}, \mathrm{J}$. M. Bello ${ }^{\mathrm{d}}$, L. A. den Hartog ${ }^{\mathrm{a}, \mathrm{b}}$, \\ W. H. Hendriks ${ }^{b}$ and J. Martín-Tereso ${ }^{a}$
}

\author{
${ }^{a}$ Trouw Nutrition Research and Development, \\ P.O. Box 299, 3800 AG Amersfoort, the Netherlands. \\ ${ }^{\mathrm{b}}$ Animal Nutrition group, Department of Animal Sciences, \\ Wageningen University \& Research, \\ De Elst 1,6708 WD Wageningen, the Netherlands. \\ d Nanta S.A., Ronda de Poniente 9, 28460 Tres Cantos, Madrid, Spain..
}

${ }^{\mathrm{c}}$ Departamento de Producción Animal y Ciencia de los Alimentos, Facultad de Veterinaria, Instituto Agroalimentario de Aragón (IA2) Miguel Servet 177-50013 Zaragoza, Spain.

To Be Submitted to Journal of the Science of Food and Agriculture 


\section{ABSTRACT}

Supra-nutritional supplementation of lamb diets with $\alpha$-tocopherol is an effective method to reduce lipid oxidation and colour deterioration in meat products. Alternative antioxidant sources have been proposed to replace the supra-nutritional vitamin E applications. A standardized rosemary extract (embedded or not in a fat matrix) was compared to vitamin $\mathrm{E}$ in ability to improve meat colour and stability selected parameters in lamb meat stored for $\mathrm{I} 4 \mathrm{~d}$ under retail conditions. Indoor concentrate-fed light weight lambs $(\mathrm{n}=480)$ were supplemented with increasing levels of all-rac- $\alpha$-tocopheryl acetate $\left(0.25,0.5,1.0 \mathrm{~g} \mathrm{~kg}^{-1}\right.$ compound feed), rosemary extract (0.20, 0.40 or $0.80 \mathrm{~g} \mathrm{~kg}^{-1}$ compound feed) or rosemary extract embedded in a fat matrix (0.20, 0.40 or $0.80 \mathrm{~g} \mathrm{~kg}^{-1}$ compound feed), for I4 $\mathrm{d}$ before slaughter at $26.4 \pm 1.29 \mathrm{~kg}$ BW. Supra-nutritional supplementation with antioxidants had no effect $(\mathrm{P}>0.05)$ on average daily weight gain, feed intake and feed efficiency. Independently from treatment, display time significantly affected lipid oxidation (TBARS), colour stability $\left(L^{*}, a^{*}\right.$ and $h$ ), myoglobin forms (DeoxyMb, OxyMb and MetMb) and meat discolouration $\left(\mathrm{A}_{580-630}\right.$ and $\mathrm{I}_{\mathrm{SO}_{2}}$. Rosemary extract supplementation (with or without fat embedment) had no effect on lipid oxidation, myoglobin forms or colour stability parameters, regardless of the dose. All vitamin E supplementation levels significantly affected lipid oxidation, colour stability $\left(L^{*}, a^{*}, C^{*}\right.$ and $h$ ), myoglobin forms and meat discolouration parameters compared to non-supplemented lambs. No effect of vitamin E dosage (0.25, 0.5, $1.0 \mathrm{~g} \mathrm{~kg}^{-1}$ compound feed) in the aforementioned meat oxidation and colour parameters was found. This study demonstrates that unlike vitamin E, neither dose nor protection of the rosemary extract had an effect on lipid oxidation or meat colour stability of lambs, during the I $4 \mathrm{~d}$ of storage under retail conditions. 


\section{INTRODUCTION}

Appearance, texture and flavour are important quality attributes influencing the consumer's choice to purchase meat products (Liu et al., 1995). In lamb meat, post-mortem biochemical changes such as lipid oxidation leads to off-odours and flavour development which have a negative impact on the shelf-life of these products (Morrissey et al., 1998). Therefore, the possibility to extend shelf-life and subsequent display time in lamb meat is a primary objective of the meat industry.

Dietary supplementation of lamb diets with vitamin E, and more specifically $\alpha$-tocopherol, raises the concentrations of $\alpha$-tocopherol in lamb tissues (Ochoa et al., 1992, Leal et al., 2018a), which in turn delays lipid oxidation and improves the colour stability of the meat (López-Bote et al., 200I, Lauzurica et al., 2005, Leal et al., 2018b). The protective role of $\alpha$-tocopherol against lipid oxidation in lamb meat is well established. However, there is still a debate on the minimum dose of vitamin $\mathrm{E}$ in lamb diets that effectively protects the meat from lipid deterioration and values ranging from $287 \mathrm{mg} \mathrm{kg}^{-1}$ and $1000 \mathrm{mg} \mathrm{kg}^{-1}$ feed have been proposed (Wulf et al., I995, López-Bote et al., 200I, Lauzurica et al., 2005, Álvarez et al., 2008, González-Calvo et al., 2015). Any recommendation on vitamin E needs to consider the wide variation of $\alpha$-tocopherol concentration in feedstuffs (Yang et al., 2002), vitamin $\mathrm{E}$ status of the animal at the start of the supplementation period (Descalzo et al., 2005), length of the supplementation period (González-Calvo et al., 20I5), differences in slaughter weight (De la Fuente et al., 2007) and animal breed (López-Bote et al., 200I). In Mediterranean farming systems, lambs are typically weaned around I2-I4 $\mathrm{kg}$ of body weight (BW), and afterwards fed ad libitum concentrates plus straw until they reach 22 to $24 \mathrm{~kg}$ BW (Bernués et al., 20II). Under these conditions, González-Calvo et al. (20I5) found that a concentrate supplemented with $500 \mathrm{mg}$ of vitamin E per kg, fed for a period of 7-I4 d before slaughter, was sufficient to protect lamb meat from lipid oxidation and metmyoglobin formation.

Alternative antioxidant sources to vitamin E from several types of plants and plant materials have been investigated to replace vitamin E. However, to effectively replace supranutritional vitamin E applications, these plant derived antioxidants need to be effectively absorbed, transported and have a considerable deposition into the lamb muscle. In recent years, special attention has been given to rosemary (Rosmarinus officinalis L.) products and by-products such as leaves, essential oils, distilled leaves and extracts from the second distillation of rosemary leaves with different solvents (Nieto et al., 20I0, Bañón et al., 20I2, Smeti et al., 20I3, Ortuño et al., 2015, Smeti et al., 20I8). Early work from Nieto et al. (20I0), found that supplementation of pregnant ewes with roo $\mathrm{g}$ of rosemary leaves $\mathrm{kg}^{-1}$ feed during pregnancy and lactation, improved the shelf-life of lamb meat. Interestingly, two major diterpenes present in rosemary, carnosic acid and carnosol, were later identified in lamb muscle at concentrations that could potentially lead to an antioxidant and antimicrobial effect in the meat (Jordán et al., 20I4). Supplementation of lamb diets with rosemary byproducts has yielded some conflicting results (Aouadi et al., 20I4, Serrano et al., 20I4, 
Smeti et al., 20I8), probably due to a lack of product standardization (Ortuño et al., 20I5) or because of potential rumen degradation (Salem et al., 2006, 20I0).

There are only few studies comparing supra-nutritional doses of vitamin E with rosemary by-products on their capacity to protect lamb meat from oxidative deterioration (Ortuño et al., 20I5, 20I7). Moreover, none of the studies performed a dose titration for both antioxidant sources in order to determine the relative value of each supplementation strategy on meat quality parameters.

The aim of the present study is to compare increasing dosages of a standardized rosemary extract with vitamin $\mathrm{E}$ (all-rac- $\alpha$-tocopheryl acetate) in their ability to improve meat colour and stability parameters in lamb meat stored for $\mathrm{I} 4 \mathrm{~d}$ under common retail conditions. Secondly, the standardized plant extract embedded in rumen inert fat will be also compared, as a mean to potentially mitigate the degradation of the rosemary extract by rumen microorganisms.

\section{MATERIALS AND METHODS}

The animal care and slaughter procedures used met the guidelines of Council Directive 86/609/EEC (European Communities, 1986) on the protection of animals used for experimental and other scientific purposes.

\section{Animals and Diets}

Four hundred and eighty Rasa Aragonesa male lambs were used in this study (BW $=28.8 \pm \mathrm{I} .39$ $\mathrm{kg}$ ). Lambs were purchased from local dealers and were incorporated in the experiment in three separated batches of I6o animals each. Upon arrival at the commercial farm Franco y Navarro (Zaragoza, Spain), lambs were allocated based on body weight to 20 concrete pens $\left(20 \mathrm{~m}^{2}\right)$ bedded with straw. For $\mathrm{I} 4 \mathrm{~d}$ before slaughter, the lambs had free access to the experimental compound feed (presented as $3.5 \mathrm{~mm}$ diameter pellet) (Table 6.I), barley straw and water via separated troughs. Per batch, two pens were randomly assigned to one of Io treatments consisting of a basal compound feed (Control), supplemented with increasing levels of all-rac- $\alpha$-tocopheryl acetate $\left(0.25,0.50\right.$ or $1.0 \mathrm{~g} \mathrm{~kg}^{-1}$ compound feed), rosemary extract (RE) (Nutrafur S.A., Spain) (0.20, 0.40 or $0.80 \mathrm{~g} \mathrm{~kg}^{-1}$ compound feed) or the same rosemary extract embedded in a fat matrix (FRE) $\left(0.20,0.40\right.$ or $0.80 \mathrm{~g} \mathrm{~kg}^{-1}$ compound feed). After $4 \mathrm{~d}$, animals were slaughtered at the local abattoir (Mercazaragoza S.A., Zaragoza, Spain) after an overnight period without feed but with free access to water. Three lambs per pen (in total, I8 lambs per treatment) were randomly selected at the start of the experimental period for meat analysis.

To produce the fat embedded rosemary extract (FRE treatments), hydrogenated palm fatty acids (Norel, Spain) were melted at $70 \pm 2^{\circ} \mathrm{C}$. Afterwards, the rosemary extract (Nutrafur S.A., Spain) was added to the melted hydrogenated palm fatty acids and stirred for Io min at $7 \mathrm{O} \pm 2^{\circ} \mathrm{C}$, until an homogeneous mixture was obtained. The mixture of hydrogenated palm fatty acids and rosemary extract was then added to silica (Trouw Nutrition, the 
Netherlands), stirred for 20 minutes and cooled at room temperature. The final product (free-flowing powder), was composed by $43.75 \%$ hydrogenated palm fatty acids, 3I.25\% silica and $25.0 \%$ rosemary extract.

\section{Meat Processing and Packaging}

The carcasses were chilled for $24 \mathrm{~h}$ at $2^{\circ} \mathrm{C}$, before split longitudinally into two halves. The longissimus thoracis et lumborum (LTL) muscle from the right half was dissected, with subcutaneous fat removed, placed in bags (I muscle per bag) and transported in sealed plastic containers in darkness at $4 \pm \mathrm{I}^{\circ} \mathrm{C}$ to the Meat Quality Laboratory of the Veterinary Faculty of Zaragoza (Zaragoza, Spain).

Within 2 hours after arrival, the LTL muscles were sectioned into approximately $1.5 \mathrm{~cm}$ thick portions, which were placed in polystyrene trays B5-37 (Aerpack), packed under modified atmosphere packaging with $70 \% \mathrm{O}_{2}+30 \% \mathrm{CO}_{2}$ (Ulma Smart 500, Ulma Packaging, Guipúzcoa, Spain) and sealed with a polyethylene and polyamine laminate film $(30 \mu \mathrm{m}$ of thickness, water vapour transmission rate at $23^{\circ} \mathrm{C}$ of $<7 \mathrm{~g} / \mathrm{m}^{2} / 24 \mathrm{~h} / 85 \%$ relative humidity, an $\mathrm{O}_{2}$ transmission rate at $23^{\circ} \mathrm{C}$ of $<15 \mathrm{~cm}^{3} / \mathrm{m}^{2} / 0 \%$ R.H. and a $\mathrm{CO}_{2}$ transmission rate at $23^{\circ} \mathrm{C}$ of $<75 \mathrm{~cm}^{3} / \mathrm{m}^{2} / 24 \mathrm{~h} / \mathrm{o} \%$ R.H.; Linpac Packaging S.L., Spain). The trays were stored at $4 \pm \mathrm{I}^{\circ} \mathrm{C}$ for I, 7, 9, I2 or I4 $\mathrm{d}$ in a Zafrio display cabinet (ZAFRIO, Zaragoza, Spain) simulating retail conditions with a daily exposure to $\mathrm{I} 4 \mathrm{~h}$ of light at I2OO lx. 


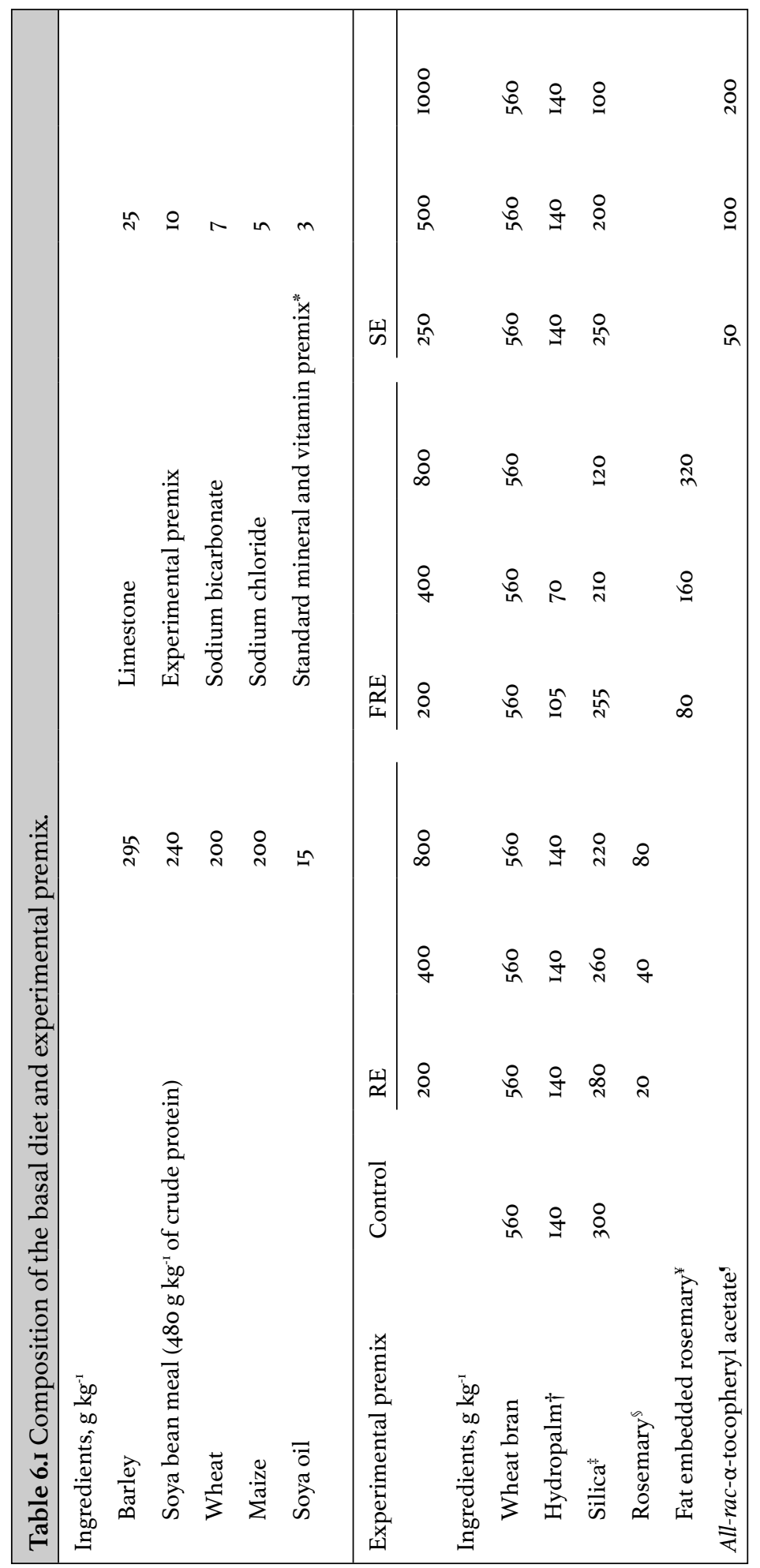

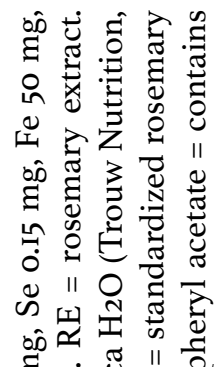

bo 2 का

घ

0 च क

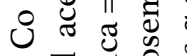

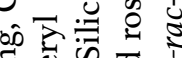

व क

○े वि

की 응 응

है के है थै

in 宅矛苛

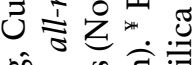

ôी II

되 융

엥 कू क्ष

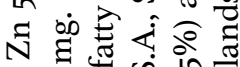

oô un की

घ $\tilde{\Xi}$

웜

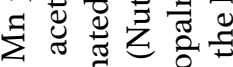

की

กิษ

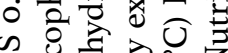

ô 0 11 त्र

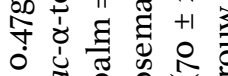

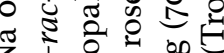

乙

bô.

กิำ

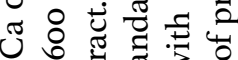

远领

๑ิ

పี ซี สี

흐 है च्च

क.

药

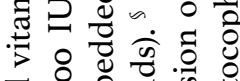

: $:$ :

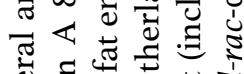

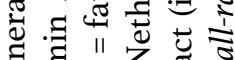

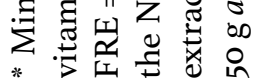




\section{Physical and Chemical Analysis}

Colour was measured using a reflectance spectrophotometer (CM-2002; Minolta, Osaka, Japan) directly on the meat surface, after $2 \mathrm{~h}$ exposure to air. Each value was the mean of Io determinations per sample. The parameters recorded according to the CIELAB system (CIE, I976), were lightness $\left(L^{*}\right)$, redness $\left(a^{*}\right)$ and yellowness $\left(b^{*}\right)$. Values of chroma $\left(C^{*}\right)$ and hue angle $(h)$ were calculated as: $C^{*}=\sqrt{ }\left(a^{* 2}+b^{* 2}\right)$, and $\mathrm{h}=\tan ^{-1}\left(b^{*} / a^{*}\right)$, expressed in degrees. Lipid oxidation was expressed as thiobarbituric acid reactive substances (TBARS) and expressed as mg malondialdehyde (MDA) per kg meat, as described by Pfalzgraf et al. (1995). Briefly, Io g of meat sample was homogenized with IO\% trichloroacetic acid using an Ultra-Turrax T25 (Janke \& Kunkel, Staufen, Germany). After centrifugation at $1500 \times \mathrm{g}$ for $30 \mathrm{~min}\left(\right.$ at $\left.\mathrm{IO}^{\circ} \mathrm{C}\right)$ the supernatant was filtered (Filterlab, Barcelona, Spain), $2 \mathrm{~mL}$ of the filtrate mixed with $2 \mathrm{~mL}$ of TBA $\left(20 \mathrm{~mol} \mathrm{~L}^{-1}\right)$, homogenized and incubated for $20 \mathrm{~min}$ (in boiling water). Absorbance was measured at $532 \mathrm{~nm}$ and TBARS values were calculated from a standard curve of MDA (Sigma-Aldrich, Madrid, Spain). Samples were analysed in duplicate and the results were expressed as mg of MDA kg-1 of meat.

Myoglobin forms [deoxymyoglobin (DeoxyMb), oxymyoglobin (OxyMb) and metmyoglobin (MetMb)] were calculated from the reflectance curve described by Krzywicki (1979) using a wavelength of $690 \mathrm{~nm}$. The reflectance at 473, 525 and $572 \mathrm{~nm}$ was obtained by linear interpolation, since the reflectance spectrophotometer only measures the reflectance between $400-740 \mathrm{~nm}$ at intervals of $\mathrm{IO} \mathrm{nm}$.

The rate of meat discoloration was accessed by the parameter $A_{580}-A_{630}$, according to the method proposed by van den Oord and Wesdorp (197I). Oxygen saturation of myoglobin on meat surface $\left(\mathrm{I}_{\mathrm{SO}_{2}}\right)$ was measured following the technique described by Tsuruga et al. (I994).

\section{Polyphenol Analysis in Feed}

Feed samples were homogenized using a blender and sieved with a mesh $\mathrm{N}^{\circ}$ I8 (corresponding to I $\mathrm{mm}$ ) to remove large particles before extraction. The phenolic compounds were extracted using methanol:water (80:20, v:v), sonicated for $5 \mathrm{~min}$ and centrifuged. This procedure was repeated twice with the feed residue. The supernatants were combined and the methanol evaporated. For better chromatography resolution, the extracts were cleaned using solid phase extraction (SPE) with Oasis MAX 96-well plates (30mg, 30 $\mu \mathrm{m}$ ) from Waters, according to Vallverdú-Queralt et al. (20I4).

The identification and quantification of the major phenolic compounds was performed in a UHPLC (Waters Acquity Ultra Performace LC) coupled to an API 3000 triple quadrupole mass spectrometer (ABSciex) equipped with a Turbo ionspray source operating in negative mode. Separation was carried out using a BEH CI8 (2.I x 50 mm, I.7 $\mu \mathrm{m}$ ) (Acquity UHPLC) maintained at $30^{\circ} \mathrm{C}$. Gradient elution was performed with acetonitrile with $0.1 \%$ of formic acid (v/v) and water with o.I\% of formic acid (v/v) using an increase linear gradient flow of acetonitrile with $0.1 \%$ of formic acid (v/v) under conditions: $\mathrm{O} \min , 20 \%$; 
$0.5 \mathrm{~min}, 20 \%$; I.5 $\mathrm{min}, 30 \%$; $2 \mathrm{~min}, 30 \%$; $2.5 \mathrm{~min}, 50 \%$; $3 \mathrm{~min}, \mathrm{I00} \%$; $3.5 \mathrm{~min}$, $100 \%$; $3.7 \mathrm{~min}$, $20 \%$ and $4.5 \mathrm{~min}, 20 \%$. The flow rate was $0.4 \mathrm{~mL} \mathrm{~min}^{-1}$ and the injection volume was io $\mu \mathrm{L}$. The identification and quantification of each compound was carried out with the mass spectrometer using multiple reaction monitoring (MRM) mode. The quantification of the phenolic compounds was performed using calibration curves with analytical standards with the internal standard method. The internal standard was ethyl gallate (400 $\mathrm{ng} \mathrm{g}^{-1}$ ) (Extrasynthese, Genay, France) and the results were expressed as $\mathrm{mg} \mathrm{kg}^{-1}$ of feed (MartínezHuélamo et al., 20I5).

\section{Statistical Analysis}

All statistical analyses were performed using SAS Studio (SAS Institute, Inc., Cary, NC, USA). Pen was the experimental unit, and individual measurements were averaged per pen. The model included the fixed effects of antioxidant supplementation, display time and the interaction between antioxidant supplementation and display time. The effect of batch was initially included in the statistical model as a fixed effect but it was finally excluded owing as batch never reached statistical significance $(\mathrm{P}>0.05)$. Therefore, the model was:

$$
Y_{i j k}=\mu+A S_{i}+D_{j}+\left(A S_{i} \times D_{j}\right)+e_{i j k}
$$

where $Y_{i j k}$ is the dependent variable; $\mu$ is the population average; $\mathrm{AS}_{\mathrm{i}}$ is the fixed effect of antioxidant supplementation; $\mathrm{D}_{j}$ is the fixed effect of display time; $\left(\mathrm{AS}_{\mathrm{i}} \times \mathrm{D}_{j}\right)$ is the interaction between $\mathrm{AS}_{\mathrm{i}}$ and $\mathrm{D}_{\mathrm{j}}$ and eijk is the random error. Differences were declared significant when $\mathrm{P}<0.05$. Tukey's post hoc test was used to assess differences between mean values when $\mathrm{P}<0.05$.

\section{RESULTS AND DISCUSSION}

\section{Animal Performance}

Data on body weight, average daily weight gain, feed intake and feed efficiency are presented in Table 6.2. There were no effects of either antioxidant source (vitamin $\mathrm{E}$ and rosemary extract) or dosage in the assessed performance parameters. These results are in agreement with previous work in lambs, in which neither vitamin E (Lauzurica et al., 2005, Leal et al., 20I8b) nor rosemary essential oil (Smeti et al., 20I8) supplementation had an effect on growth, feed intake or efficiency.

\section{Polyphenol Content in Feeds and Fat Embedment}

The identification and quantification of the major polyphenols present in the experimental diets are shown in Table 6.3. Overall, we found high concentrations of chlorogenic acid, ferulic acid and ferulic acid-O-hexoside, which are commonly found in cereals (Naczk and Shahidi, 2006), which accounted for $>42 \%$ of the total polyphenol content in the experimental diets. Incorporation of rosemary extracts (either protected or unprotected) 
in the experimental diets, led to a substantial increase in carnosol concentration and to increases in carnosic and rosmarinic acid, recognized as major polyphenols present in rosemary extracts (Cuvelier et al., 1996).

Previous work, pointed at the potential of plant secondary metabolites or polyphenols to interact with rumen bacteria and fermentation (Salem et al., 2006, 20I0). In the current study, we found no differences between the two rosemary supplementation strategies (RE and FRE) on performance (Table 6.2) nor quality parameters of meat stored for $14 \mathrm{~d}$ under retail conditions (Table 6.4-6.7). Due to the lack of response of both rosemary extract sources (RE and FRE) in the aforementioned parameters compared with the control group, it is not possible to draw any conclusions regarding the efficacy of protection intended by fat embedment.

\section{Lipid Oxidation}

Mean TBARS values for each dietary treatment during the $\mathrm{I} 4 \mathrm{~d}$ of display are presented in Table 6.4. Lipid oxidation significantly increased with storage time in all groups $(\mathrm{P}<0.05)$. On the first day of refrigerated storage, apart from the control and SE 250 supplemented lambs, no differences in TBARS values were observed between treatments. However, from $\mathrm{d} 7$ onwards, LTL muscle from vitamin E supplemented lambs (irrespective of dose) presented significantly lower TBARS values than the control, RE and FRE supplemented lambs. Vitamin E supplemented lambs presented TBARS values ranging from o.I6 to 0.3I mg MDA kg-1 meat on $\mathrm{d}$, while the remaining treatments registered TBARS values between I.63 to I.99 mg MDA $\mathrm{kg}^{-1}$ meat. With increasing storage time, the differences between the vitamin E supplemented lambs and the control, RE and FRE lambs became wider. On $\mathrm{d}$ I4 of storage, LTL muscle from control and the rosemary supplemented lambs (RE and FRE) presented TBARS values ranging from 3.25 to $4.00 \mathrm{mg} \mathrm{MDA} \mathrm{kg}{ }^{-1}$ meat, while vitamin E supplemented LTL muscles showed TBARS values from 0.39 to $0.69 \mathrm{mg} \mathrm{MDA} \mathrm{kg}^{-1}$ meat. 


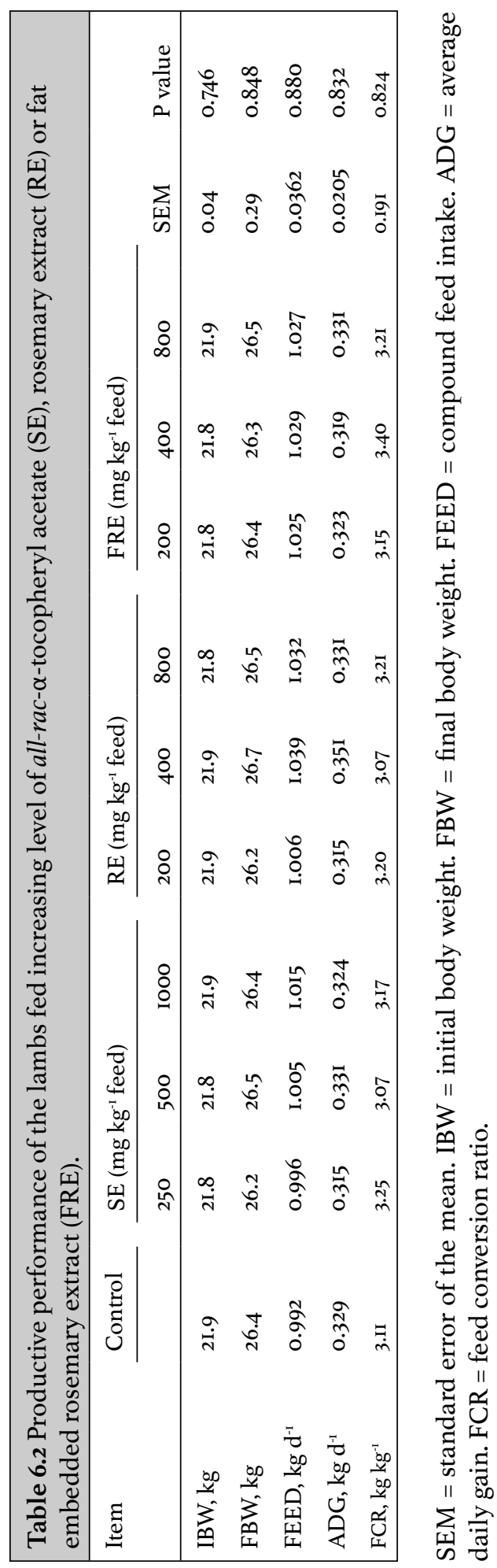


Supplementation of lamb diets with vitamin $E$ and rosemary extracts on meat quality parameters

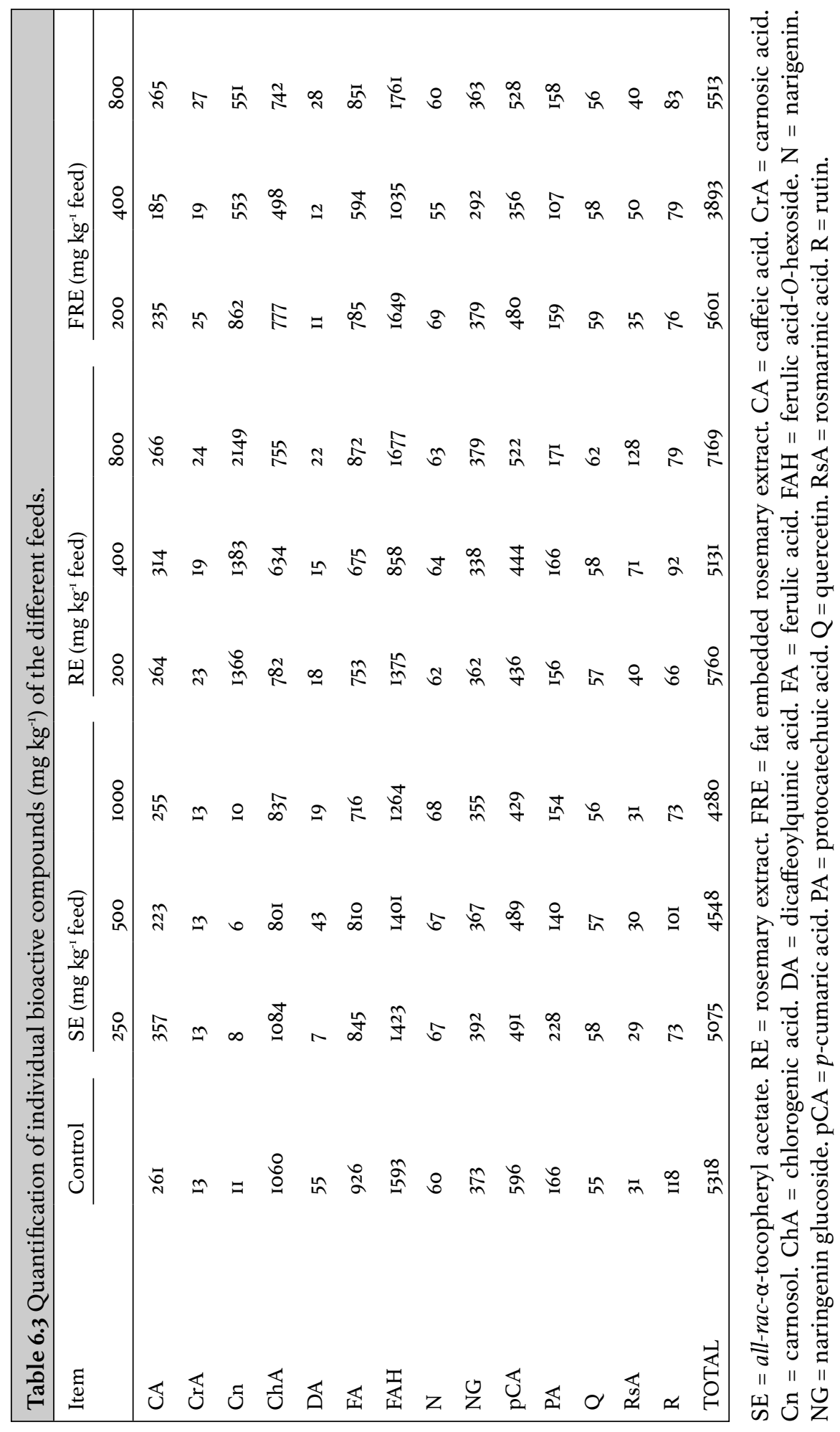

129 
Table 6.4 Effect of dietary supplementation ${ }^{\dagger}$ with all-rac- $\alpha$-tocopheryl acetate (SE), rosemary extract (RE) and fat embedded rosemary extract (FRE) on thiobarbituric acid reactive substances in raw lamb meat stored in modified atmospheric packaging $(70 \%$ $\mathrm{O}_{2}: 30 \% \mathrm{CO}_{2}$ ) kept for I, 7, 9, I2 and $\mathrm{I} 4 \mathrm{~d}$ under retail conditions.

\begin{tabular}{|c|c|c|c|c|c|c|c|}
\hline \multirow[t]{2}{*}{ Item } & \multicolumn{5}{|c|}{ Days of display } & \multirow[b]{2}{*}{ SEM } & \multirow{2}{*}{$\begin{array}{l}\mathrm{P} \text { value } \\
\text { display }\end{array}$} \\
\hline & $\mathrm{I}$ & 7 & 9 & $\mathrm{I} 2$ & 14 & & \\
\hline Control & $0.13^{\mathrm{c}, \mathrm{x}}$ & I. $90^{\text {b,y }}$ & $2.66^{\mathrm{b}, \mathrm{zz}}$ & $3.44^{\mathrm{b}, \mathrm{z}}$ & $3.80^{b, z}$ & 0.25 & $<0.001$ \\
\hline SE 250 & $0.09^{\mathrm{ab}, \mathrm{x}}$ & $0.3 \mathrm{I}^{\mathrm{a}, \mathrm{xy}}$ & $0.32^{a, x y}$ & $0.4 \mathrm{I}^{\mathrm{a,y}}$ & $0.69^{\mathrm{a}, \mathrm{z}}$ & 0.06 & $<0.00 I$ \\
\hline SE 500 & $0.08^{\mathrm{a}, \mathrm{x}}$ & $0.2 \mathrm{I}^{\mathrm{a}, \mathrm{y}}$ & $0.26^{a, y}$ & $0.30^{a, y}$ & $0.56^{\mathrm{a}, \mathrm{z}}$ & 0.03 & 0.00I \\
\hline SE IOOO & $0.09^{\mathrm{ab}, \mathrm{x}}$ & $0.16^{a, x y}$ & $0.18^{a, x y}$ & $0.33^{\mathrm{a}, y z}$ & $0.39^{a, z}$ & 0.04 & 0.017 \\
\hline RE 200 & O.II ${ }^{\mathrm{abc}, \mathrm{w}}$ & I. $99^{\mathrm{b}, \mathrm{x}}$ & $2.85^{\mathrm{b}, x y}$ & $3.53^{\mathrm{byz}}$ & $4.00^{\mathrm{b}, \mathrm{z}}$ & 0.23 & $<0.00 I$ \\
\hline RE 400 & $0 . I^{\mathrm{abc}, \mathrm{w}}$ & $1.9 I^{b, x}$ & $2.75^{\mathrm{b}, \mathrm{xy}}$ & $3.6 \mathrm{I}^{\mathrm{b}, y z}$ & $3.85^{b, z}$ & $0.2 \mathrm{I}$ & $<0.00 I$ \\
\hline RE 800 & O.II $I^{\mathrm{abc}, \mathrm{w}}$ & I. $86^{b, x}$ & $2.55^{\mathrm{b}, \mathrm{xy}}$ & $3.64^{\text {byz }}$ & $3.8 \mathrm{o}^{\mathrm{b}, \mathrm{z}}$ & 0.24 & $<0.00 I$ \\
\hline FRE 200 & O.II ${ }^{\mathrm{abc}, \mathrm{x}}$ & I. $67^{\text {by }}$ & $2.46^{\mathrm{byz}}$ & $2.80^{\text {byz }}$ & $3.25^{\mathrm{b}, \mathrm{z}}$ & 0.30 & $<0.00 I$ \\
\hline FRE 400 & $0 . I^{\mathrm{abc}, \mathrm{w}}$ & $1.63^{b, x}$ & $2.29^{\mathrm{b}, x y}$ & $3.27^{\mathrm{b} y z}$ & $3.5 \mathrm{I}^{\mathrm{b}, \mathrm{z}}$ & 0.23 & $<0.00 I$ \\
\hline FRE 800 & $0 . I^{\mathrm{abc}, \mathrm{x}}$ & $\mathrm{I} .74^{\mathrm{by}}$ & $2.5 \mathrm{O}^{\mathrm{byz}}$ & $3.25^{\mathrm{b}, \mathrm{z}}$ & $3.53^{\mathrm{b}, \mathrm{z}}$ & 0.23 & $<0.00 I$ \\
\hline $\begin{array}{l}\mathrm{P} \text { value } \\
\text { treatment }\end{array}$ & 0.016 & $<0.00 I$ & $<0.00 I$ & $<0.00 I$ & $<0.001$ & & \\
\hline
\end{tabular}

${ }^{\dagger} \mathrm{SE} 250, \mathrm{SE} 500$ and SE IOOO $=250,500$ and $\mathrm{IOOO} \mathrm{mg}$ all-rac- $\alpha$-tocopheryl acetate $\mathrm{kg}^{-1}$ feed; $\mathrm{RE} 200, \mathrm{RE} 400$ and RE $800=200,400$ and $800 \mathrm{mg}$ rosemary extract $\mathrm{kg}^{-1}$ feed; FRE 200 , FRE 400 and FRE $800=200,400$ and $800 \mathrm{mg}$ fat embedded rosemary extract $\mathrm{kg}^{-1}$ feed. a,b,c Values within a column with different superscript are significantly different $(\mathrm{P}<0.05)$. w,x,y,z Values within a row with different superscript are significantly different $(\mathrm{P}<0.05)$. *SEM = standard error of the mean. 


\begin{tabular}{|c|c|c|c|c|c|c|c|}
\hline \multirow[t]{2}{*}{ Item } & \multicolumn{5}{|c|}{ Days of display } & \multirow[b]{2}{*}{ SEM } & \multirow{2}{*}{$\begin{array}{l}\text { P value } \\
\text { display }\end{array}$} \\
\hline & I & 7 & 9 & $\mathrm{I} 2$ & $\mathrm{I} 4$ & & \\
\hline \multicolumn{8}{|l|}{$L^{*}$} \\
\hline Control & $40.94^{x}$ & $39.19^{x}$ & $40.17^{\mathrm{ab}, \mathrm{x}}$ & $45.26^{\mathrm{b}, \mathrm{y}}$ & $47.67^{\mathrm{b}, \mathrm{z}}$ & 0.269 & $<0.001$ \\
\hline SE 250 & $40.22^{y z}$ & $36.74^{\mathrm{w}}$ & $37.98^{a b, w x}$ & $38.78^{a, x y}$ & $40.78^{a, z}$ & 0.173 & $<0.00 I$ \\
\hline SE 500 & $40.32^{y}$ & $37.85^{x}$ & $38.04^{\mathrm{ab}, \mathrm{x}}$ & $39.2 \mathrm{I}^{\mathrm{a}, \mathrm{xy}}$ & $40.55^{\mathrm{ayy}}$ & 0.256 & $<0.001$ \\
\hline SE Iooo & $39.52^{y z}$ & $37.31^{x}$ & $37.68^{a, x y}$ & $38.7 \mathrm{I}^{\mathrm{a}, \mathrm{xyz}}$ & $40.67^{a, z}$ & $0.22 \mathrm{I}$ & $<0.00 I$ \\
\hline RE 200 & $40.1 I^{x}$ & $38.45^{\mathrm{x}}$ & $40.00^{\mathrm{ab}, \mathrm{x}}$ & $44.82^{\mathrm{b}, \mathrm{y}}$ & $47.33^{\mathrm{b}, \mathrm{y}}$ & 0.359 & $<0.00 I$ \\
\hline $\mathrm{RE}_{400}$ & $39.4 \mathrm{I}^{\mathrm{x}}$ & $38.38^{x}$ & $40.24^{\mathrm{ab}, \mathrm{x}}$ & $45.12^{\text {by }}$ & $48.73^{\mathrm{b}, \mathrm{z}}$ & 0.406 & $<0.001$ \\
\hline RE 800 & $39.17^{\mathrm{wx}}$ & $38.15^{\mathrm{w}}$ & $40.67^{\mathrm{b}, \mathrm{x}}$ & $44.92^{\mathrm{b}, \mathrm{y}}$ & $48.42^{\mathrm{b}, \mathrm{z}}$ & 0.252 & $<0.00 I$ \\
\hline FRE 200 & $39.95^{\mathrm{x}}$ & $38.39^{x}$ & $40.09^{\mathrm{ab}, \mathrm{x}}$ & $43.39^{\text {byy }}$ & $46.49^{\mathrm{b}, \mathrm{z}}$ & 0.324 & $<0.00 I$ \\
\hline FRE 400 & $40.85^{x}$ & $38.58^{x}$ & $39.93^{\mathrm{ab}, \mathrm{x}}$ & $44 \cdot 19^{\mathrm{b}, y}$ & $47.09^{b, z}$ & 0.389 & $<0.00 I$ \\
\hline FRE 800 & $40.98^{x}$ & $37.85^{\mathrm{w}}$ & $40.66^{\mathrm{b}, w x}$ & $44.98^{\mathrm{b}, \mathrm{y}}$ & $48.71^{\mathrm{b}, \mathrm{z}}$ & 0.356 & $<0.00 I$ \\
\hline $\begin{array}{l}\text { P value } \\
\text { treatment }\end{array}$ & 0.530 & 0.146 & $0.00 \mathrm{I}$ & $<0.00 I$ & $<0.00 I$ & & \\
\hline \multicolumn{8}{|l|}{$a^{*}$} \\
\hline Control & $8.43^{\mathrm{yz}}$ & $9.95^{\mathrm{ab}, \mathrm{z}}$ & $7.06^{\mathrm{a}, \mathrm{y}}$ & $3.68^{\mathrm{a}, \mathrm{x}}$ & $2.98^{\mathrm{a}, \mathrm{x}}$ & 0.295 & $<0.001$ \\
\hline SE 250 & $9.5 \mathrm{I}^{\mathrm{w}}$ & $\mathrm{I} 2.08^{\mathrm{b}, \mathrm{z}}$ & II. $86^{\mathrm{cyz}}$ & II.IO & IO. $49^{b, x}$ & 0.103 & $<0.00 I$ \\
\hline SE 500 & $8.75^{\mathrm{x}}$ & II. $25^{\text {aby }}$ & $10.93^{b c, y}$ & $10.16^{\text {by }}$ & IO.I. $7^{\mathrm{b}, \mathrm{y}}$ & 0.150 & $<0.001$ \\
\hline SE IOoo & $8.84^{x}$ & II. $5 \mathrm{I}^{\mathrm{ab}, \mathrm{y}}$ & $\mathrm{II} .08^{\mathrm{bc}, y}$ & $10.72^{\text {byy }}$ & I0.74, by & $0.12 \mathrm{I}$ & $<0.00 I$ \\
\hline RE 200 & $8.93^{y z}$ & $9.25^{\mathrm{a}, \mathrm{z}}$ & $6.56^{\mathrm{a}, \mathrm{y}}$ & $3.6 \mathrm{I}^{\mathrm{a}, \mathrm{x}}$ & $3.05^{\mathrm{a}, \mathrm{x}}$ & 0.307 & $<0.00 I$ \\
\hline $\mathrm{RE}_{400}$ & $8.94^{\mathrm{yz}}$ & $9.26^{\mathrm{a}, \mathrm{z}}$ & $6.65^{a, y}$ & $3 . \mathrm{OI}^{\mathrm{a}, \mathrm{x}}$ & $2.52^{a, x}$ & 0.297 & $<0.00 I$ \\
\hline RE 800 & $8.43^{\mathrm{yz}}$ & $10.30^{\mathrm{ab}, \mathrm{z}}$ & 7.II ${ }^{\mathrm{a} y \mathrm{y}}$ & $3.58^{\mathrm{a}, \mathrm{x}}$ & $2.5 \mathrm{I}^{\mathrm{a,x}}$ & 0.245 & $<0.001$ \\
\hline FRE 200 & $9.46^{y}$ & $9 \cdot 49^{\mathrm{a}, \mathrm{y}}$ & $7.76 a^{y}$ & $5.06^{\mathrm{a}, \mathrm{x}}$ & $3.9 \mathrm{I}^{\mathrm{a}, \mathrm{x}}$ & 0.300 & $<0.00 I$ \\
\hline FRE 400 & $8.45^{y}$ & $9.76^{a, y}$ & $8.15 \mathrm{a}^{\mathrm{b}, \mathrm{y}}$ & $4 \cdot \mathrm{IO}^{\mathrm{a}, \mathrm{x}}$ & $3.28^{\mathrm{a}, \mathrm{x}}$ & 0.293 & $<0.001$ \\
\hline FRE 800 & $8.97^{\mathrm{yz}}$ & $9.96^{\mathrm{ab}, \mathrm{z}}$ & $7.26^{\mathrm{a}, \mathrm{y}}$ & $3.55^{\mathrm{a}, \mathrm{x}}$ & $2.6 \mathrm{O}^{\mathrm{a}, \mathrm{x}}$ & 0.274 & $<0.001$ \\
\hline $\begin{array}{l}\text { P value } \\
\text { treatment }\end{array}$ & $0.25 \mathrm{I}$ & $<0.001$ & $<$ O.OOI & $<0.00 I$ & $<0.00 I$ & & \\
\hline \multicolumn{8}{|l|}{$C^{*}$} \\
\hline Control & $13.39^{x}$ & $15.49^{\text {ab,y }}$ & $\mathrm{I} 3.54^{\mathrm{a}, \mathrm{x}}$ & $13.15^{a, x}$ & $\mathrm{I} 3.55^{\mathrm{a}, \mathrm{x}}$ & $0.17 \mathrm{I}$ & $<0.00 I$ \\
\hline SE 250 & $14.84^{x}$ & $16.92^{b, y z}$ & $17.12^{\mathrm{d}, \mathrm{z}}$ & $\mathrm{I} 6.18^{\mathrm{cyz}}$ & $15.94^{\mathrm{b}, \mathrm{y}}$ & 0.122 & $<0.001$ \\
\hline
\end{tabular}




\begin{tabular}{|c|c|c|c|c|c|c|c|}
\hline SE 500 & I3.94 & $\mathrm{I}^{6} . \mathrm{IO}^{\mathrm{ab}}$ & I5.65 & $\mathrm{I} 4.95^{\mathrm{b}}$ & $\mathrm{I} 5.38^{\mathrm{b}}$ & 0.156 & 0.059 \\
\hline SE IOOO & $13.85^{\mathrm{x}}$ & I6.I $2^{\mathrm{ab}, \mathrm{y}}$ & $\mathrm{I} 6.03^{\mathrm{cd}, \mathrm{y}}$ & $\mathrm{I} 5.73^{\mathrm{bc}, \mathrm{y}}$ & I6.08 $8^{\mathrm{b}, \mathrm{y}}$ & $0.13 \mathrm{I}$ & 0.002 \\
\hline RE 200 & I3.93 & $\mathrm{I} 4.8 \mathrm{I}^{\mathrm{a}}$ & $\mathrm{I} 3.37^{\mathrm{a}}$ & $12.95^{\mathrm{a}}$ & $\mathrm{I} 3.77^{\mathrm{a}}$ & 0.179 & 0.189 \\
\hline $\mathrm{RE}_{400}$ & $\mathrm{I} 3.97^{\mathrm{xy}}$ & $\mathrm{I} 4.66^{\mathrm{a}, \mathrm{y}}$ & $\mathrm{I} 3.75^{\mathrm{a}, \mathrm{xy}}$ & $\mathrm{I} 2.98^{\mathrm{a}, \mathrm{x}}$ & $\mathrm{I} 3.74^{\mathrm{a}, \mathrm{xy}}$ & O.I7I & 0.040 \\
\hline RE 800 & $13.20^{\mathrm{x}}$ & $\mathrm{I} 5.42^{\mathrm{a}, \mathrm{y}}$ & $\mathrm{I} 3.99^{\mathrm{ab}, \mathrm{x}}$ & $\mathrm{I} 2.87^{\mathrm{a}, \mathrm{x}}$ & $\mathrm{I} 3.55^{\mathrm{a}, \mathrm{x}}$ & 0.153 & $<0.00 I$ \\
\hline FRE 200 & I 4.84 & $\mathrm{I} 4.89^{\mathrm{ab}}$ & $\mathrm{I} 4.29^{\mathrm{abc}}$ & $\mathrm{I} 3.6 \mathrm{O}^{\mathrm{a}}$ & $13.96^{\mathrm{a}}$ & 0.162 & 0.245 \\
\hline FRE 400 & $\mathrm{I} 3.62^{\mathrm{xy}}$ & I5.I $4^{\mathrm{a}, \mathrm{z}}$ & $\mathrm{I} 4 \cdot 32^{\mathrm{abc}, y z}$ & $\mathrm{I} 2.55^{\mathrm{a}, \mathrm{x}}$ & $\mathrm{I} 3.58^{\mathrm{a}, \mathrm{xy}}$ & O.I54 & 0.006 \\
\hline FRE 800 & $\mathrm{I} 4 \cdot \mathrm{I} 7^{\mathrm{xy}}$ & $\mathrm{I} 5.36^{\mathrm{a}, \mathrm{y}}$ & $\mathrm{I} 3.86^{\mathrm{ab}, \mathrm{x}}$ & $\mathrm{I} 2.9 \mathrm{I}^{\mathrm{a}, \mathrm{x}}$ & $\mathrm{I} 3.56^{\mathrm{a}, \mathrm{x}}$ & 0.156 & $<0.00 I$ \\
\hline $\begin{array}{l}\text { P value } \\
\text { treatment } \\
h\end{array}$ & 0.077 & 0.003 & $<0.001$ & $<0.00 I$ & $<0.00 I$ & & \\
\hline Control & $5 \mathrm{I} .4 \mathrm{I}^{\mathrm{x}}$ & $50.64^{\mathrm{abc}, \mathrm{x}}$ & $58.85^{\mathrm{b}, \mathrm{x}}$ & $74.04^{\text {b,y }}$ & $77 \cdot 15^{\text {by }}$ & I.I2O & $<0.00 I$ \\
\hline SE 250 & $50.15^{2}$ & $44 \cdot 36^{\mathrm{a}, \mathrm{x}}$ & $46.16^{\mathrm{a}, \mathrm{xy}}$ & $46.69^{a, y}$ & $48.96^{\mathrm{a}, \mathrm{z}}$ & 0.238 & $<0.00 I$ \\
\hline SE 500 & $5 \mathrm{I} .15^{\mathrm{z}}$ & $45 \cdot 78^{\mathrm{abc}, \mathrm{x}}$ & $45 \cdot 72^{\mathrm{a}, \mathrm{x}}$ & $47 \cdot 37^{\mathrm{a}, \mathrm{xy}}$ & $48.7 \mathrm{I}^{\mathrm{a}, y z}$ & 0.339 & $<0.00 I$ \\
\hline SE IOOO & $50.68^{z}$ & $44.60^{\mathrm{ab}, \mathrm{x}}$ & $46.25^{\mathrm{a}, \mathrm{xy}}$ & $47 \cdot \mathrm{IO}^{\mathrm{a}, \mathrm{xy}}$ & $48.17^{\mathrm{a}, \mathrm{yz}}$ & 0.288 & $<0.00 I$ \\
\hline RE 200 & $50.24^{x}$ & $52.05^{c, x y}$ & $6 \mathrm{I} . \mathrm{I} 3^{\mathrm{b}, \mathrm{y}}$ & $73.90^{\mathrm{b}, \mathrm{z}}$ & $76.95^{\mathrm{b}, \mathrm{z}}$ & I.I85 & $<0.00 I$ \\
\hline $\mathrm{RE}_{400}$ & $50.38^{x}$ & $5 \mathrm{I} .54^{\mathrm{bc}, \mathrm{x}}$ & $6 \mathrm{I} .73^{\mathrm{b}, \mathrm{y}}$ & $76.42^{\mathrm{b}, \mathrm{z}}$ & $79.26^{\mathrm{b}, \mathrm{z}}$ & I.I45 & $<0.00 I$ \\
\hline RE 800 & $50.74^{x}$ & $48.40^{\mathrm{abc}, \mathrm{x}}$ & $60.00^{\text {by }}$ & $73.98^{\mathrm{b}, \mathrm{z}}$ & $79.29^{\mathrm{b}, \mathrm{z}}$ & 0.936 & $<0.00 I$ \\
\hline FRE 200 & $50.52^{x}$ & $50.74^{\mathrm{abc}, \mathrm{x}}$ & $57 \cdot 74^{\mathrm{b}, \mathrm{x}}$ & $68.23^{\mathrm{by}}$ & $73.35^{\text {b.y }}$ & I.I5I & $<0.001$ \\
\hline FRE 400 & $52.30^{x}$ & $50.35^{\mathrm{abc}, \mathrm{x}}$ & $55 \cdot 32^{\mathrm{ab},} \mathrm{X}$ & $70.54^{\mathrm{by}}$ & $76.03^{\text {by }}$ & I.I56 & $<0.001$ \\
\hline FRE 800 & $51.08^{x y}$ & $49.94^{\mathrm{abc}, \mathrm{x}}$ & $58.96^{\text {by }}$ & $73.93^{\mathrm{b}, \mathrm{z}}$ & $78.78^{\mathrm{b}, \mathrm{z}}$ & I.040 & $<0.001$ \\
\hline$P$ value treatment & 0.883 & $<0.001$ & $<0.001$ & $<0.001$ & $<0.00 I$ & & \\
\hline
\end{tabular}

$\dagger$ SE 250, SE 500 and SE IOOO = 250, 500 and IOoo $\mathrm{mg}$ all-rac- $\alpha$-tocopheryl acetate $\mathrm{kg}^{-1}$ feed; $\mathrm{RE} 200, \mathrm{RE} 400$ and $\mathrm{RE} 800=200,400$ and $800 \mathrm{mg}$ rosemary extract $\mathrm{kg}^{-1}$ feed; FRE 200 , FRE 400 and FRE $800=200,400$ and $800 \mathrm{mg}$ fat embedded rosemary extract $\mathrm{kg}^{-1}$ feed. a,b,c Values within a column with different superscript are significantly different $(\mathrm{P}<0.05)$. $\mathrm{w}, \mathrm{x}, \mathrm{y}, \mathrm{z}$ Values within a row with different superscript are significantly different $(\mathrm{P}<0.05)$.

* SEM = standard error of the mean. 
Table 6.6 Effect of dietary supplementation ${ }^{\dagger}$ with all-rac- $\alpha$-tocopheryl acetate (SE), rosemary extract (RE) and fat embedded rosemary extract (FRE) on myoglobin forms (DeoxyMb, OxyMb and MetMb) in raw lamb meat stored in modified atmospheric packaging $\left(70 \% \mathrm{O}_{2}: 30 \% \mathrm{CO}_{2}\right)$ kept for $\mathrm{I}, 7,9, \mathrm{I} 2$ and $\mathrm{I} 4 \mathrm{~d}$ under retail conditions.

\begin{tabular}{|c|c|c|c|c|c|c|c|}
\hline \multirow[t]{2}{*}{ Item } & \multicolumn{5}{|c|}{ Days of display } & \multirow[b]{2}{*}{ SEM } & \multirow{2}{*}{$\begin{array}{l}\text { Pvalue } \\
\text { display }\end{array}$} \\
\hline & I & 7 & 9 & I2 & I4 & & \\
\hline \multicolumn{8}{|l|}{ DeoxyMb } \\
\hline Control & $49.04^{z}$ & $24 \cdot 37^{x y}$ & $\mathrm{I} 6.4 \mathrm{I}^{\mathrm{a}, \mathrm{x}}$ & $22.53^{\mathrm{abc}, \mathrm{xy}}$ & $24.59^{\mathrm{abc}, y}$ & I.8O & $<0.00 I$ \\
\hline SE 250 & $50.20^{y}$ & $28.70^{\mathrm{x}}$ & $30.3 \mathrm{I}^{\mathrm{c}, \mathrm{x}}$ & $28.93^{\mathrm{cd}, \mathrm{x}}$ & $26.99^{\mathrm{bc}, \mathrm{x}}$ & 0.90 & $<0.001$ \\
\hline SE 500 & $52.86^{\mathrm{y}}$ & $28.9 \mathrm{I}^{\mathrm{x}}$ & $28.86^{\mathrm{c}, \mathrm{x}}$ & $28.65^{\mathrm{cd,x}}$ & $27.76^{b c, x}$ & I.O7 & $<0.001$ \\
\hline SE IOoo & $50.80^{y}$ & $29.47^{x}$ & $30.48^{c, x}$ & $29.7 \mathrm{I}^{\mathrm{d}, \mathrm{x}}$ & $28.36^{c, x}$ & 0.83 & $<0.00 I$ \\
\hline RE 200 & $50.24^{y}$ & $23.23^{\mathrm{x}}$ & $\mathrm{I} 8.23^{\mathrm{ab}, \mathrm{x}}$ & $19.0 \mathrm{I}^{\mathrm{ab}, \mathrm{x}}$ & $23.49^{\mathrm{abc}, \mathrm{x}}$ & 2.22 & $<0.00 I$ \\
\hline RE 400 & $49.58^{y}$ & $23.09^{x}$ & $19.02^{\mathrm{ab}, \mathrm{x}}$ & $20.00^{\mathrm{ab}, \mathrm{x}}$ & $23.02^{\mathrm{ab}, \mathrm{x}}$ & I.73 & $<0.00 I$ \\
\hline RE 800 & $55.29^{\mathrm{y}}$ & $26.40^{\mathrm{x}}$ & $\mathrm{I} 8.35^{\mathrm{ab}, \mathrm{x}}$ & I9.I $4^{\mathrm{ab}, \mathrm{x}}$ & $23.00^{\mathrm{ab}, \mathrm{x}}$ & I.98 & $<0.00 I$ \\
\hline FRE 200 & $48.30^{y}$ & $24.24^{x}$ & $20.50^{\mathrm{ab}, \mathrm{x}}$ & $23.52^{\mathrm{bcd}, \mathrm{x}}$ & $22.88^{\mathrm{ab}, \mathrm{x}}$ & I. 74 & $<0.001$ \\
\hline FRE 400 & $47 \cdot 42^{y}$ & $26.76^{x}$ & $25.55^{\mathrm{bc}, \mathrm{x}}$ & $20.3 \mathrm{I}^{\mathrm{ab}, \mathrm{x}}$ & $2 \mathrm{I} .66^{\mathrm{a}, \mathrm{x}}$ & I.9I & $<0.00 I$ \\
\hline FRE 800 & $53.0 \mathrm{I}^{\mathrm{z}}$ & $25.12^{y}$ & I9.39 $39^{\mathrm{ab}, \mathrm{xy}}$ & $\mathrm{I} 6.4 \mathrm{O}^{\mathrm{a}, \mathrm{x}}$ & $20.59^{a, x y}$ & 2.02 & $<$ O.OOI \\
\hline $\begin{array}{l}\mathrm{P} \text { value } \\
\text { treatment }\end{array}$ & 0.575 & 0.120 & $<0.001$ & $<0.001$ & $<0.001$ & & \\
\hline \multicolumn{8}{|l|}{ OxyMb } \\
\hline Control & $28.24^{y}$ & $4 \mathrm{I} .68^{\mathrm{z}}$ & $37.04^{\mathrm{yz}}$ & $\mathrm{I} 6.4 \mathrm{I}^{\mathrm{a}, \mathrm{x}}$ & II. $85^{\mathrm{a}, \mathrm{x}}$ & 2.90 & $<0.00 I$ \\
\hline SE 250 & $27.02^{x}$ & $42.07^{2}$ & $38.97^{\mathrm{yz}}$ & 38.10 & $37.03^{\text {by }}$ & 0.86 & $<0.00 I$ \\
\hline SE 500 & $22.34^{x}$ & $42.98^{z}$ & $40.59^{y z}$ & $38.60^{c, y z}$ & $36.14^{b, y}$ & I.I5 & $<0.00 I$ \\
\hline SE IOoo & $25.53^{x}$ & $41.57^{2}$ & $38.97^{y z}$ & $37.90^{b c, y}$ & $37.29^{\text {by }}$ & $0.9 \mathrm{I}$ & $<0.00 I$ \\
\hline RE 200 & $26.39^{x y}$ & $40.16^{2}$ & $33.22^{y z}$ & $20.03^{\mathrm{a}, w x}$ & $\mathrm{I} 2.43^{\mathrm{a}, \mathrm{w}}$ & 2.73 & $<0.00 I$ \\
\hline RE 400 & $26.36^{y}$ & $40.98^{z}$ & $31.47^{y}$ & $\mathrm{I} 5.39^{\mathrm{a}, \mathrm{x}}$ & $1 \mathrm{II} .05^{\mathrm{a}, \mathrm{x}}$ & 2.18 & $<0.00 I$ \\
\hline RE 800 & $23.14^{z}$ & $41.73^{z}$ & $34.46^{y}$ & $20.00^{a, x y}$ & $\mathrm{I} 2.39^{\mathrm{a}, \mathrm{x}}$ & 2.32 & $<0.00 I$ \\
\hline FRE 200 & $28.83^{x y}$ & $39.67^{z}$ & $36.16^{\mathrm{yz}}$ & $20.53^{a, w x}$ & $\mathrm{I} 6.23^{\mathrm{a}, \mathrm{w}}$ & 2.40 & $<0.00 I$ \\
\hline FRE 400 & $28.0 I^{x y}$ & $39.86^{z}$ & $33.88^{y z}$ & $22.63^{\mathrm{a}, \mathrm{wx}}$ & $17.04^{a, w}$ & 3.00 & 0.005 \\
\hline FRE 800 & $24 \cdot 52^{x}$ & $40.67^{2}$ & $34.99^{\mathrm{yz}}$ & $25.93^{\mathrm{a}, \mathrm{wx}}$ & $13.72^{\mathrm{a}, \mathrm{w}}$ & 2.30 & $<0.00 I$ \\
\hline $\begin{array}{l}\mathrm{P} \text { value } \\
\text { treatment }\end{array}$ & 0.928 & 0.738 & 0.593 & $<0.00 I$ & $<0.00 I$ & & \\
\hline \multicolumn{8}{|l|}{ MetMb } \\
\hline Control & $22.73^{\mathrm{w}}$ & $33.95^{\mathrm{x}}$ & $46.55^{\text {by }}$ & $6 \mathrm{I} .06^{\mathrm{b}, \mathrm{z}}$ & $63.56^{\mathrm{b}, \mathrm{z}}$ & 2.50 & $<0.00 I$ \\
\hline SE 250 & $22.77^{\mathrm{w}}$ & $29.23^{x}$ & $30.72^{a, x y}$ & $32.97^{\text {a,y }}$ & $35.98^{\mathrm{a}, \mathrm{z}}$ & 0.69 & $<0.001$ \\
\hline
\end{tabular}




\begin{tabular}{|c|c|c|c|c|c|c|c|}
\hline SE 500 & $24.8 \mathrm{O}^{\mathrm{w}}$ & $28 . \mathrm{II}^{\mathrm{wX}}$ & $30.55^{\mathrm{a}, \mathrm{xy}}$ & $32.74^{\mathrm{a}, y z}$ & $36 . \mathrm{IO}^{\mathrm{a}, \mathrm{z}}$ & 0.82 & $<0.001$ \\
\hline SE IOOO & $23.67^{\mathrm{w}}$ & $28.96^{x}$ & $30.55^{\mathrm{a}, \mathrm{xy}}$ & $32.38^{a, y}$ & $34 \cdot 35^{\mathrm{a}, \mathrm{z}}$ & 0.62 & $<0.001$ \\
\hline RE 200 & $23.37^{x}$ & $36.62^{y}$ & $48.54^{\text {ab,y }}$ & $60.96^{\mathrm{b}, \mathrm{z}}$ & $64.08^{\mathrm{b}, \mathrm{z}}$ & 2.78 & $<0.001$ \\
\hline $\mathrm{RE}_{400}$ & $24.07^{\mathrm{w}}$ & $35.93^{\mathrm{x}}$ & $49 \cdot 5 \mathrm{I}^{\mathrm{ab}, \mathrm{y}}$ & $64.6 \mathrm{I}^{\mathrm{b}, \mathrm{z}}$ & $65.93^{\mathrm{b}, \mathrm{z}}$ & 2.26 & $<0.001$ \\
\hline RE 800 & $2 \mathrm{I} .58^{\mathrm{w}}$ & $31.87^{x}$ & $47.19^{\text {b,y }}$ & $60.86^{\mathrm{b}, \mathrm{z}}$ & $65.17^{\mathrm{b}, \mathrm{z}}$ & $2 . \mathrm{OI}$ & $<0.001$ \\
\hline FRE 200 & $22.87^{\mathrm{x}}$ & $36.09^{x}$ & $43 \cdot 34^{\text {b,y }}$ & $55.94^{\mathrm{b}, \mathrm{z}}$ & $60.89^{b, z}$ & 2.70 & $<0.001$ \\
\hline FRE 400 & $24.57^{\mathrm{x}}$ & $33 \cdot 39^{x y}$ & $40.57^{\text {by }}$ & $57.06^{\mathrm{b}, \mathrm{z}}$ & $63.53^{\mathrm{b}, \mathrm{z}}$ & 2.64 & $<0.001$ \\
\hline FRE 800 & $22.47^{\mathrm{w}}$ & $34.2 \mathrm{I}^{\mathrm{x}}$ & $45.62^{\mathrm{by}}$ & $60.23^{b, z}$ & $65.69^{b, z}$ & 2.02 & $<0.001$ \\
\hline $\begin{array}{l}\mathrm{P} \text { value } \\
\text { treatment }\end{array}$ & 0.089 & 0.270 & $<0.00 I$ & $<0.00 I$ & $<0.00 I$ & & \\
\hline
\end{tabular}

${ }^{\dagger} \mathrm{SE} 250, \mathrm{SE} 500$ and SE $1000=250,500$ and $1000 \mathrm{mg}$ all-rac- $\alpha$-tocopheryl acetate $\mathrm{kg}^{-1}$ feed; $\mathrm{RE} 200, \mathrm{RE} 400$ and RE $800=200,400$ and $800 \mathrm{mg}$ rosemary extract $\mathrm{kg}^{-1}$ feed; FRE 200 , FRE 400 and FRE $800=200,400$ and $800 \mathrm{mg}$ fat embedded rosemary extract $\mathrm{kg}^{-1}$ feed. a,b,c Values within a column with different superscript are significantly different $(\mathrm{P}<0.05)$. $w, x, y, z$ Values within a row with different superscript are significantly different $(\mathrm{P}<0.05)$.

* SEM = standard error of the mean. 
Table 6.7 Effect of dietary supplementation ${ }^{\dagger}$ with all-rac- $\alpha$-tocopheryl acetate (SE), rosemary extract (RE) and fat embedded rosemary extract (FRE) on meat discoloration $\left(\mathrm{A}_{580-630}\right.$ and $\left.I_{\mathrm{SO}_{2}}\right)$ in raw lamb meat stored in modified atmospheric packaging $(70 \%$ $\mathrm{O}_{2}: 30 \% \mathrm{CO}_{2}$ ) kept for $\mathrm{I}, 7,9, \mathrm{I} 2$ and $\mathrm{I} 4 \mathrm{~d}$ under retail conditions.

\begin{tabular}{|c|c|c|c|c|c|c|c|}
\hline \multirow[t]{2}{*}{ Item } & \multicolumn{5}{|c|}{ Days of display } & \multirow[b]{2}{*}{ SEM } & \multirow{2}{*}{$\begin{array}{l}\text { P value } \\
\text { display }\end{array}$} \\
\hline & I & 7 & 9 & I2 & I4 & & \\
\hline \multicolumn{8}{|l|}{$\mathrm{A}_{580-630}$} \\
\hline Control & $34.66^{\mathrm{z}}$ & $30.94^{z}$ & $19.29^{\mathrm{a}, \mathrm{y}}$ & $8.88^{\mathrm{a}, \mathrm{x}}$ & $7.60^{a, x}$ & 2.14 & $<0.00 I$ \\
\hline SE 250 & $38.16^{z}$ & $38.52^{z}$ & $36.84^{\mathrm{c}, \mathrm{z}}$ & $33.19^{b, x y}$ & $29 \cdot 48^{\mathrm{b}, \mathrm{x}}$ & 0.99 & $<0.001$ \\
\hline SE 500 & $35.98^{\mathrm{z}}$ & $36.97^{2}$ & $34.54^{\mathrm{bc}, y z}$ & $31.05^{b, x y}$ & $28.93^{\mathrm{b}, \mathrm{x}}$ & I.O7 & $<0.00 I$ \\
\hline SE IOOO & $37.50^{z}$ & $36.96^{z}$ & $35.35^{\mathrm{bc}, y z}$ & $32.94^{b, x y}$ & $31.02^{\mathrm{b}, \mathrm{x}}$ & I.O2 & $<0.001$ \\
\hline RE 200 & $36.84^{z}$ & $28.43^{\mathrm{z}}$ & $\mathrm{I} 7 \cdot 77^{\mathrm{a}, \mathrm{y}}$ & $9.00^{\mathrm{a}, \mathrm{x}}$ & $7.55^{\mathrm{a}, \mathrm{x}}$ & 2.31 & $<0.001$ \\
\hline $\mathrm{RE}_{400}$ & $36.76^{z}$ & $28.47^{\mathrm{z}}$ & $17.60^{a, y}$ & $6.8 \mathrm{o}^{\mathrm{a}, \mathrm{x}}$ & $6.09^{\mathrm{a}, \mathrm{x}}$ & 2.05 & $<0.001$ \\
\hline RE 800 & $36.55^{2}$ & $32.4 \mathrm{I}^{\mathrm{z}}$ & $19.25^{\mathrm{a}, \mathrm{y}}$ & $8.4 \mathrm{I}^{\mathrm{a}, \mathrm{x}}$ & $5.93^{\mathrm{a}, \mathrm{x}}$ & I.7I & $<0.00 I$ \\
\hline FRE 200 & $38.36^{\mathrm{z}}$ & $29.19^{y z}$ & $22.47^{\mathrm{a}, \mathrm{xy}}$ & $\mathrm{I} 3.42^{\mathrm{a}, \mathrm{wx}}$ & $9 \cdot 74^{\mathrm{a}, \mathrm{w}}$ & 2.12 & $<0.001$ \\
\hline FRE 400 & $34.42^{z}$ & 3I.I $8^{\mathrm{yz}}$ & $24.8 \mathrm{I}^{\mathrm{ab}, \mathrm{y}}$ & IO. $86^{\mathrm{a}, \mathrm{x}}$ & $7 \cdot 6 \mathrm{I}^{\mathrm{a}, \mathrm{x}}$ & 2.07 & $<0.001$ \\
\hline FRE 800 & $36.76^{z}$ & $3 \mathrm{I} . \mathrm{II}^{\mathrm{z}}$ & $20.62^{a, y}$ & $8.58^{\mathrm{a}, \mathrm{x}}$ & $5.6 \mathrm{I}^{\mathrm{a}, \mathrm{x}}$ & I.66 & $<0.001$ \\
\hline$P$ value treatment & 0.138 & 0.124 & $<0.00 I$ & $<$ O.ooI & $<0.00 I$ & & \\
\hline \multicolumn{8}{|l|}{$I_{\mathrm{SO}_{2}}$} \\
\hline Control & $19.28^{y z}$ & $21.27^{2}$ & $20.69^{y z}$ & $\mathrm{I} 5.32^{\mathrm{abc}, \mathrm{xy}}$ & $10.62^{\mathrm{a}, \mathrm{x}}$ & I. 38 & $<0.001$ \\
\hline SE 250 & $18.64^{x}$ & $2 \mathrm{I} .54^{\mathrm{y}}$ & $2 \mathrm{I} \cdot 46^{\mathrm{y}}$ & $21.25^{\mathrm{bc}, \mathrm{y}}$ & $21.08^{\text {b.y }}$ & 0.33 & $<0.00 I$ \\
\hline SE 500 & I6. $57^{\mathrm{x}}$ & $22.38^{y}$ & $2 \mathrm{I} .86^{\mathrm{y}}$ & $2 \mathrm{I} .82^{\mathrm{c}, y}$ & $20.76^{\text {by }}$ & 0.53 & $<0.001$ \\
\hline SE IOoo & $\mathrm{I} 7.44^{\mathrm{x}}$ & $2 \mathrm{I} .8 \mathrm{O}^{\mathrm{y}}$ & $2 \mathrm{I} .85^{\mathrm{y}}$ & $2 \mathrm{I} .67^{\mathrm{cyy}}$ & $2 \mathrm{I} .77^{\mathrm{b}, \mathrm{y}}$ & 0.34 & $<0.001$ \\
\hline RE 200 & $17.99^{y z}$ & $20.94^{\mathrm{z}}$ & $\mathrm{I} 8.33^{\mathrm{yz}}$ & $\mathrm{I} 2.5 \mathrm{I}^{\mathrm{a}, \mathrm{xy}}$ & $8.35^{\mathrm{a}, \mathrm{x}}$ & I.45 & $<0.001$ \\
\hline RE 400 & $\mathrm{I} 7.76^{\mathrm{y}}$ & $2 \mathrm{I} .5 \mathrm{I}^{\mathrm{y}}$ & $18.60^{y}$ & IO. $9 I^{\mathrm{a}, \mathrm{x}}$ & $7.2 \mathrm{O}^{\mathrm{a}, \mathrm{x}}$ & $\mathrm{I} .2 \mathrm{I}$ & $<0.00 I$ \\
\hline RE 800 & $17.90^{y z}$ & $21.56^{\mathrm{z}}$ & I8.79 $79^{y z}$ & $\mathrm{I} 4 \cdot 3 \mathrm{I}^{\mathrm{ab}, \mathrm{xy}}$ & $9.04^{\mathrm{a}, \mathrm{x}}$ & I.I8 & $<0.001$ \\
\hline FRE 200 & $19.07^{\mathrm{yz}}$ & $2 I .5 \mathrm{I}^{\mathrm{z}}$ & $20.12^{y z}$ & $\mathrm{I} 5.65^{\mathrm{abc}, \mathrm{xy}}$ & $\mathrm{I} 2 . \mathrm{I} 5^{\mathrm{a}, \mathrm{x}}$ & $\mathrm{I} .28$ & $<0.00 I$ \\
\hline FRE 400 & $17.83^{\mathrm{xy}}$ & $21.03^{y}$ & $19.76^{y}$ & $\mathrm{I} 6.36^{\mathrm{abc}, \mathrm{xy}}$ & $\mathrm{I} 2.26^{\mathrm{a}, \mathrm{x}}$ & I.5I & $<0.001$ \\
\hline FRE 800 & $17.92^{\mathrm{yz}}$ & $21.36^{\mathrm{z}}$ & $20.92^{z}$ & $\mathrm{I} 4.25^{\mathrm{abc}, \mathrm{xy}}$ & IO.II ${ }^{\mathrm{a}, \mathrm{x}}$ & I.06 & $<0.001$ \\
\hline$P$ value treatment & 0.990 & 0.808 & 0.790 & $<0.00 I$ & $<0.001$ & & \\
\hline
\end{tabular}

${ }^{\dagger} \mathrm{SE} 250, \mathrm{SE} 500$ and SE IOOO $=250,500$ and $\mathrm{IOOO} \mathrm{mg}$ all-rac- $\alpha$-tocopheryl acetate $\mathrm{kg}^{-1}$ feed; $\mathrm{RE} 200, \mathrm{RE} 400$ and $\mathrm{RE} 800=200,400$ and $800 \mathrm{mg}$ rosemary extract $\mathrm{kg}^{-1}$ feed; FRE 200 , FRE 400 and FRE $800=200,400$ and $800 \mathrm{mg}$ fat embedded rosemary extract $\mathrm{kg}^{-1}$ feed. a,b,c Values within a column with different superscript are significantly different $(\mathrm{P}<0.05)$. ${ }_{w, x, y, z}$ Values within a row with different superscript are significantly different $(\mathrm{P}<0.05)$. * SEM = standard error of the mean. 
Although dependent on the experience of panellist, thresholds for acceptability of oxidizing lamb meat have been proposed. In concentrate-fed lambs, slaughtered at low body weights (lower than $30 \mathrm{~kg}$ live weight), a threshold of I.o $\mathrm{mg} \mathrm{MDA} \mathrm{kg}{ }^{-1}$ meat has been proposed to be avoided for the development of off flavours in lamb meat (Ripoll et al., 20II). After $7 \mathrm{~d}$ of storage, higher MDA values than $1.0 \mathrm{mg} \mathrm{kg}{ }^{-1}$ meat were found in the LTL muscle from the control, FRE and RE lambs. Interestingly, vitamin E supplementation at 0.25, 0.50 or I.o $\mathrm{g} \mathrm{kg}^{-1}$ feed, led to lower TBARS values (0.69, 0.56 and $0.39 \mathrm{mg}$ MDA kg-1 meat) than the proposed threshold after $\mathrm{I} 4 \mathrm{~d}$ of storage. In a similar study, (Leal et al., 20I8b) found that a supplementation level of $0.16 \mathrm{~g} \mathrm{~kg}^{-1}$ feed with vitamin E (all-rac- $\alpha$-tocopheryl acetate) for I $4 \mathrm{~d}$ before slaughter, was sufficient to maintain TBARS values below the threshold of I.O $\mathrm{mg}$ MDA kg ${ }^{-1}$ meat. Dietary supplementation of lamb diets with vitamin $\mathrm{E}$ is a consistent strategy to increase $\alpha$-tocopherol content in lamb tissues like muscle (Leal et al., 20I8b) and to improve the resistance of lamb meat to oxidative deterioration (Lauzurica et al., 2005, Belles et al., 20I8, Leal et al., 20I8b).

Unlike vitamin E, the effects of rosemary extracts or essential oils on meat oxidative stability are not consistent. Shelf life studies in lambs have demonstrated an improvement in lipid stability of meat when rosemary by-products were included in the diet of lactating ewes (Nieto et al., 20I0) or directly into lamb diets (Bañón et al., 20I2, Ortuño et al., 20I4). In the current study, supplementation of lamb diets with rosemary extracts (RE and FRE) failed to affect the oxidative deterioration of meat. Accordingly, Smeti et al. (2013) and Aouadi et al. (20I4) found that supplementing lambs with rosemary essential oils did not exert any effect on lipid peroxidation in meat. Overall, the mechanisms by which antioxidant compounds present in plant extracts can affect the oxidative deterioration of lamb meat, are still unclear (Guerra-Rivas et al., 2016). Interestingly, several studies found a higher concentration of tocopherol in lamb muscle following dietary supplementation with a plant extracts or by-product (Ortuño et al., 2015, Luciano et al., 2017, Yagoubi et al., 2018). This is of special relevance, because even a slight increase in $\alpha$-tocopherol concentration in muscle (from 0.6 to $0.9 \mathrm{mg} \mathrm{kg}^{-1}$ meat) has shown to substantially decrease lipid oxidation in 5 and $7 \mathrm{~d}$ of display (González-Calvo et al., 2015).

\section{Colour Stability}

Results of the colour measurements are shown in Table 6.5. Overall, storage time significantly affected the evolution of all meat colour parameters. The behaviour of the colour coordinates were similar for all treatments during the first $7 \mathrm{~d}$ of storage.

From $\mathrm{d} 7$ onwards, $L^{*}$ values generally increased with time of storage. Although there were some differences between treatments in $L^{*}$ values at $9 \mathrm{~d}$ of storage, a clear reduction in $L^{*}$ values was found in the meat of vitamin E supplemented lambs (regardless of dose) after I2 $\mathrm{d}$ of storage. When compared with the control, LTL muscle from lambs supplemented with RE or FRE presented no significant improvements in $L^{*}$ values. Our results agree with Guerra-Rivas et al. (2016), who found an improvement in $L^{*}$ when lamb diets were 
supplemented with $0.5 \mathrm{~g} \mathrm{~kg}^{-1}$ vitamin $\mathrm{E}$ but found no effect of dietary supplementation of grape by-products $\left(0.05 \mathrm{~g} \mathrm{~kg}^{-1}\right.$ feed grape seed extract or a $5 \%$ dietary replacement with grape pomace).

Redness ( $a^{*}$ value) is a major determinant of consumer selection in fresh meat (De Oliveira et al., 2013). In the present study, meat of lambs fed vitamin E (0.25, 0.50 or $1.0 \mathrm{~g} \mathrm{~kg}^{-1}$ feed) showed higher overall $a^{*}$ values than meat from the control, RE and FRE lambs from d I2 of display onwards. Rosemary extract supplementation (RE or FRE) or dosage (0.20, 0.40 or $0.8 \mathrm{~g} \mathrm{~kg}^{-1}$ feed) had no effect on $\mathrm{a}^{*}$ values in LTL muscle when compared with the control. The positive effect of synthetic (Guidera et al., 1997, Leal et al., 2018b) and natural (Leal et al., 20I8b) vitamin E supplementation on meat redness has been already described in lambs. However, our findings conflict with earlier studies (Bañón et al., 20I2, Ortuño et al., 20I4) which reported a positive effect of rosemary extract supplementation in $a^{*}$ values in lamb meat.

Effects on meat yellowness $\left(b^{*}\right)$ were very subtle. On d I4 of storage, the meat of vitamin E supplemented lambs presented significantly lower $b^{*}$ values than the RE200, RE40o, RE80o and FRE8oo groups. Previous work in lambs (Atay et al., 2009, Leal et al., 2018b) found no effect of vitamin E supplementation when compared with non-supplemented animals. However, lower $b^{*}$ values during storage in meat from lambs fed different plant extracts have been reported previously (Luciano et al., 2009, Andrés et al., 2013).

Chroma $\left(C^{*}\right)$ in meat like with the $L^{*}$ values, were only affected by the dietary supplementations after $\mathrm{I} 2 \mathrm{~d}$ of storage. Independently from dosage, vitamin $\mathrm{E}$ supplementation led to a significant increase in $\mathrm{C}^{*}$ values compared with the meat of control, RE and FRE lambs. This finding conflict with previous studies that found no effect of vitamin E supplementation in $C^{*}$ values in lamb meat (Muela et al., 20I4, Leal et al., 20I8b) and with an increase in $C^{*}$ values when lambs were supplemented with plant extracts (Ortuño et al., 20I4).

It has been previously proposed (Ripoll et al., 2008) that human evaluators are not able to appreciate individual $L^{*}, a^{*}, b^{*}$ coordinates. Therefore, Hue angle $(h)$ provides a better estimation of meat browning than individual coordinates. Like previously reported for individual coordinates $\left(L^{*}, a^{*}, b^{*}\right)$, vitamin E supplementation significantly affected $h$ development in lamb meat when compared with the control, RE and FRE fed lambs. The effects on $h$ value are clear after $9 \mathrm{~d}$ of display. No effect was found of rosemary extract supplementation in $\mathrm{h}$ values compared with the control. Previous work by Leal et al. (2018a) found that supplementation of lamb diets with natural or synthetic vitamin E had an effect on $h$ values during the I4 $\mathrm{d}$ of display. However, unlike the current study, Moran et al. (20I2) and Ortuño et al. (20I4) found lower $h$ values in meat from lambs supplemented with rosemary extracts when compared with non-supplemented animals. 


\section{Myoglobin Oxidation and Meat Discoloration}

The results of meat myoglobin (metmyoglobin (MetMb), oxymyoglobin (OxyMb) and deoxymyoglobin (DeoxyMb)) oxidation are presented in Table 6.6. Overall, myoglobin oxidation outcomes are consistent with the colorimetric parameters previously discussed. Display time significantly affected all the myoglobin forms analysed $(\mathrm{P}<\mathrm{O} . \mathrm{OI})$. Supplementation of lamb diets with vitamin E (0.25, 0.50 or $1.0 \mathrm{~g} \mathrm{~kg}^{-1}$ feed) was found to consistently affect MetMb, OxyMb and DoexyMb oxidation after I2 $\mathrm{d}$ of storage. Whereas, rosemary extract presentation form (RE or FRE) or dosage $(0.20,0.40$ or $0.8 \mathrm{~g}$ $\mathrm{kg}^{-1}$ feed) had no effect on MetMb, OxyMb and DeoxyMb percentages in the LTL muscle when compared with the control. The effects of vitamin E supplementation on MetMb development are consistent with previous work in lambs (Lauzurica et al., 2005, Leal et al., 2018b), where a clear inhibitory effect of vitamin E supplementation on MetMb formation in lamb meat, especially during longer display periods, was reported. Moreover, in line with the current study, Yagoubi et al. (2018) found no effect of supplementing lamb diets with rosemary leaf residues on MetMb and DeoxyMb percentages in meat displayed for $9 \mathrm{~d}$. High levels of DeoxyMb in meat are associated with the purple colour observed in freshly cut meat (Mancini and Hunt, 2005). The highest DeoxyMb levels in all treatments were found in the first day of display. Moreover, display time was identified as the main factor affecting DeoxyMb values in meat. Although from d 9 onwards, differences among the supplemented lambs were found, there was no effect of antioxidant source nor dose on DeoxyMb levels when compared with the control lambs. The proportion of OxyMb increased significantly in all groups $(\mathrm{P}<\mathrm{O}$.OI $)$ until $7 \mathrm{~d}$ of storage and decreased thereafter until d I4 of storage. Apart from display time, supplementation of lamb diets with vitamin $\mathrm{E}\left(\mathrm{0.25}, 0.50\right.$ or $\left.\mathrm{I} .0 \mathrm{~g} \mathrm{~kg}^{-1} \mathrm{feed}\right)$ significantly reduced OxyMb oxidation when compared with the other treatments after I2 $\mathrm{d}$ of display. These findings contrast with previous work that found no effect of vitamin E supplementation on OxyMb oxidation in lambs (Lauzurica et al., 2005, Leal et al., 2018b). Interestingly, supplementation of lamb diets with rosemary extracts (RE and FRE) had no effect on OxyMb percentages when compared with the control group. However, Yagoubi et al. (2018) found a clear reduction in OxyMb oxidation in the LTL muscle of Barbarine lambs supplemented with rosemary distillation residues for $77 \mathrm{~d}$ before slaughter.

Meat discoloration, as assessed by the decrease in the $\mathrm{A}_{580}-\mathrm{A}_{630}$ parameter, and oxygen saturation on the meat surface $\left(\mathrm{I}_{\mathrm{so2}}\right)$ in LTL muscle are presented in Table 6.7. Meat discoloration and oxygen saturation were significantly affected by storage time in all the groups $(\mathrm{P}<\mathrm{O} .00 \mathrm{I})$. Besides that, an interaction between antioxidant supplementation and storage time was found for the $\mathrm{A}_{580}-\mathrm{A}_{630}$ and Iso2 parameters ( $\mathrm{P}<\mathrm{O}$.0oI). After 9, I2 and I4 $\mathrm{d}$ of storage, the $\mathrm{A}_{580}-\mathrm{A}_{630}$ values were significantly higher in the vitamin $\mathrm{E}$ supplemented lamb meat ( $0.25,0.50$ or $1.0 \mathrm{~g} \mathrm{~kg}^{-1}$ feed) compared with the meat of the control and rosemary supplemented lambs (RE and FRE). Similarly, after I2 and I4 d, supplementation of lamb diets with vitamin $\mathrm{E}$ led to significantly higher Iso2 values compared with the remaining 
treatments. For meat discolouration $\left(\mathrm{A}_{580}-\mathrm{A}_{630}\right)$, Renerre and Mazuel (1985) proposed a value of $\mathrm{I} 2.5$ as the lower limit for colour acceptability. In the current study, apart from the vitamin $E$ supplemented lambs which had $A_{580}-A_{630}$ values higher than 12.5 until $14 \mathrm{~d}$ of display, the other treatments only presented acceptable $A_{580}-A_{630}$ values until d 9 of storage. Similarly, LTL muscle from lambs supplemented with vitamin E presented $\mathrm{I}_{\mathrm{s} 2}$ values higher than 2I.O after I4 d of storage. Whereas, in lamb fed the control or the rosemary supplemented (RE and FRE) diets, higher Iso2 values than 2I.O were only maintained for $7 \mathrm{~d}$ of storage.

\section{CONCLUSIONS}

This study demonstrated that feeding lambs a concentrate diet supplemented with all-rac$\alpha$-tocopheryl acetate for $\mathrm{I} 4 \mathrm{~d}$ before slaughter resulted in a general improvement in meat oxidative and colour stabilities. Moreover, supplementation of lamb diets with lowest level of $\alpha$-tocopheryl acetate ( $0.25 \mathrm{~g} \mathrm{~kg}^{-1}$ compound feed) was sufficient to significantly reduce meat oxidation and colour deterioration. This study demonstrates also that unlike vitamin E, supplementation of lamb diets with a rosemary extract (dosage and fat embedment) had no effect on lipid oxidation or meat colour stability of lambs during the $\mathrm{I} 4 \mathrm{~d}$ of storage under retail conditions.

\section{ACKNOWLEDGEMENTS}

The authors gratefully acknowledge the support of Franco \& Navarro S.A. (Zaragoza, Spain) and Mercazarogoza S.A. (Zaragoza, Spain). The authors also appreciate the technical assistance and support with the polyphenol analysis provided by Prof. Rosa Maria Lamuela-Raventós, José Alvarenga and Paola Quifer (University of Barcelona, Spain). 
Chapter 6 


\section{REFERENCES}

Álvarez, I., J. De la Fuente, M. T. Díaz, S. Lauzurica, C. Pérez, and V. Cañeque. 2008. Estimation of alpha-tocopherol concentration necessary to optimise lamb meat quality stability during storage in high-oxygen modified atmosphere using brokenline regression analysis. Animal 2(9):I405-I4II.

Andrés, S., M. L. Tejido, R. Bodas, L. Morán, N. Prieto, C. Blanco, and F. J. Giráldez. 20I3. Quercetin dietary supplementation of fattening lambs at $0.2 \%$ rate reduces discolouration and microbial growth in meat during refrigerated storage. Meat Science 93(2):207-2I2.

Aouadi, D., G. Luciano, V. Vasta, S. Nasri, D. M. R. Brogna, S. Abidi, A. Priolo, and H. B. Salem. 20I4. The antioxidant status and oxidative stability of muscle from lambs receiving oral administration of Artemisia herba alba and Rosmarinus officinalis essential oils. Meat Science 97(2):237-243.

Atay, O., Ö. Gökdal, V. Eren, Ş. Çetiner, and H. Yikilmaz. 2009. Effects of dietary vitamin E supplementation on fattening performance, carcass characteristics and meat quality traits of Karya male lambs. Archives Animal Breeding 52(6):6I8-626.

Bañón, S., L. Méndez, and E. Almela. 2012. Effects of dietary rosemary extract on lamb spoilage under retail display conditions. Meat Science 90(3):579-583.

Bellés, M., M. Del Mar Campo, P. Roncalés, and J. A. Beltrán. 20I8. Supranutritional doses of vitamin E to improve lamb meat quality. Meat Science I49:I4-23.

Bernués, A., R. Ruiz, A. Olaizola, D. Villalba, and I. Casasús. 20II. Sustainability of pasturebased livestock farming systems in the European Mediterranean context: Synergies and trade-offs. Livestock Science I39(I):44-57.

CIE. 1976. Commission Internationale de l'Eclairage. Vol. I8th session. CIE publication, London, UK.

Cuvelier, M-E., H. Richard, and C. Berset. 1996. Antioxidative activity and phenolic composition of pilot-plant and commercial extracts of sage and rosemary. Journal of the American Oil Chemists' Society 73(5):645.

De la Fuente, J., M. T. Díaz, I. Álvarez, S. Lauzurica, V. Cañeque, and C. Pérez. 2007. Effect of dietary supplementation with vitamin E on characteristics of vacuum-packed lamb. Journal of the Science of Food and Agriculture 87(4):65I-659.

De Oliveira, T. L., A. Soares R. de A., and R. H. Piccoli. 2013. A Weibull model to describe antimicrobial kinetics of oregano and lemongrass essential oils against Salmonella Enteritidis in ground beef during refrigerated storage. Meat Science 93(3):645-65I.

Descalzo, A. M., E. M. Insani, A. Biolatto, A. M. Sancho, P. T. García, N. A. Pensel, and J. A. Josifovich. 2005. Influence of pasture or grain-based diets supplemented with vitamin E on antioxidant/oxidative balance of Argentine beef. Meat Science 70(I):35-44.

González-Calvo, L., G. Ripoll, F. Molino, J. H. Calvo, and M. Joy. 2015. The relationship between muscle alpha-tocopherol concentration and meat oxidation in light lambs 
fed vitamin E supplements prior to slaughter. Journal of the Science of Food and Agriculture 95(I):IO3-IIO.

Guerra-Rivas, C., C. Vieira, B. Rubio, B. Martínez, B. Gallardo, A. R. Mantecón, P. Lavín, and

T. Manso. 2016. Effects of grape pomace in growing lamb diets compared with vitamin E and grape seed extract on meat shelf life. Meat Science II6:22I-229.

Guidera, J., J. P. Kerry, D. J. Buckley, P. B. Lynch, and P. A. Morrissey. 1997. The effect of dietary vitamin E supplementation on the quality of fresh and frozen lamb meat. Meat Science 45(I):33-43.

Jordán, M. J., J. Castillo, S. Bañón, C. Martínez-Conesa, and J. A. Sotomayor. 20I4. Relevance of the carnosic acid/carnosol ratio for the level of rosemary diterpene transfer and for improving lamb meat antioxidant status. Food Chemistry I5I:212-2I8.

Krzywicki, K. 1979. Assessment of relative content of myoglobin, oxymyoglobin and metmyoglobin at the surface of beef. Meat Science 3(I):I-IO.

Lauzurica, S., J. De la Fuente, M. T. Díaz, I. Álvarez, C. Pérez, and V. Cañeque. 2005. Effect of dietary supplementation of vitamin $\mathrm{E}$ on characteristics of lamb meat packed under modified atmosphere. Meat Science 70(4):639-646.

Leal, L. N., S. K. Jensen, J. M. Bello, L. A. Den Hartog, W. H. Hendriks, and J. Martin-Tereso. 20I8a. Bioavailability of alpha-tocopherol stereoisomers in lambs depends on dietary doses of all-rac- or RRR-alpha-tocopheryl acetate. Animal 27:I-9.

Leal, L. N., J. A. Beltrán, V. Alonso, J. M. Bello, L. A. den Hartog, W. H. Hendriks, and J. Martín-Tereso. 20I8b. Dietary vitamin E dosage and source affects meat quality parameters in light weight lambs. Journal of the Science of Food and Agriculture 98(4):I6o6-I6I4.

Liu, Q., M.C. Lanari, and D. M. Schaefer. 1995. A review of dietary vitamin E supplementation for improvement of beef quality. Journal of Animal Science 73(IO):3I3I-3I40.

López-Bote, C. J., A. Daza, M. Soares, and E. Berges. 200I. Dose-response effect of dietary vitamin E concentration on meat quality characteristics in light-weight lambs. Animal Science 73(3):45I-457.

Luciano, G., F. J. Monahan, V. Vasta, L. Biondi, M. Lanza, and A. Priolo. 20o9. Dietary tannins improve lamb meat colour stability. Meat Science 8I(I):I2O-I25.

Luciano, G., V. Roscini, S. Mattioli, S. Ruggeri, R. S. Gravador, A. Natalello, M. Lanza, A. De Angelis, and A. Priolo. 20I7. Vitamin E is the major contributor to the antioxidant capacity in lambs fed whole dried citrus pulp. Animal II(3):4II-4I7.

Mancini, R. A. and M. C. Hunt. 2005. Current research in meat color. Meat Science 7I(I):IOOI2I.

Martínez-Huélamo, M., S. Tulipani, O. Jáuregui, P. Valderas-Martinez, A. VallverdúQueralt, R. Estruch, X. Torrado, and R. M. Lamuela-Raventós. 20I5. Sensitive and rapid UHPLC-MS/MS for the analysis of tomato phenolics in human biological samples. Molecules 2O(II):20409-20425. 
Morán, L., S. Andrés, R. Bodas, N. Prieto, and F. J. Giráldez. 2012. Meat texture and antioxidant status are improved when carnosic acid is included in the diet of fattening lambs. Meat Science 9I(4):430-434.

Morrissey, P. A., P. J. A. Sheehy, K. Galvin, J. P. Kerry, and D. J. Buckley. 1998. Lipid stability in meat and meat products. Meat Science 49:S73-S86.

Muela, E., V. Alonso, M. M. Campo, C. Sañudo, and J. A. Beltrán. 20I4. Antioxidant diet supplementation and lamb quality throughout preservation time. Meat Science 98(2):289-295.

Naczk, M. and F. Shahidi. 2006. Phenolics in cereals, fruits and vegetables: Occurrence, extraction and analysis. Journal of Pharmaceutical and Biomedical Analysis 4I(5):I523I542.

Nieto, G., P. Díaz, S. Bañón, and M. D. Garrido. 2010. Dietary administration of ewe diets with a distillate from rosemary leaves (Rosmarinus officinalis L.): influence on lamb meat quality. Meat Science 84(I):23-29.

Ochoa, L., L. R. McDowell, S. N. Williams, N. Wilkinson, J. Boucher, and E. L. Lentz. 1992. alpha-Tocopherol concentrations in serum and tissues of sheep fed different sources of vitamin E. Journal of Animal Science 70(8):2568-2573.

Ortuño, J., R. Serrano, and S. Bañón. 2015. Antioxidant and antimicrobial effects of dietary supplementation with rosemary diterpenes (carnosic acid and carnosol) vs vitamin $\mathrm{E}$ on lamb meat packed under protective atmosphere. Meat Science IIo:62-69.

Ortuño, J., R. Serrano, and S. Bañón. 2017. Incorporating rosemary diterpenes in lamb diet to improve microbial quality of meat packed in different environments. Animal Science Journal 88(9):I436-I445.

Ortuño, J., R. Serrano, M. J. Jordán, and S. Bañón. 20I4. Shelf life of meat from lambs given essential oil-free rosemary extract containing carnosic acid plus carnosol at 200 or 400 mg kg-1. Meat Science 96(4):I452-I459.

Pfalzgraf, A., M. Frigg, and H. Steinhart. 1995. Alpha-tocopherol contents and lipid oxidation in pork muscle and adipose tissue during storage. Journal of Agricultural and Food Chemistry 43(5):1339-1342.

Renerre, M. and J. P. Mazuel. 1985. Relations entre méthodes de mesures instrumentales et sensorielles de la couleur de la viande. Science des Aliments (5):54I-557.

Ripoll, G., M. Joy, and F. Muñoz. 20II. Use of dietary vitamin E and selenium (Se) to increase the shelf life of modified atmosphere packaged light lamb meat. Meat Science 87(I):8893.

Ripoll, G., M. Joy, F. Muñoz, and P. Albertí. 2008. Meat and fat colour as a tool to trace grassfeeding systems in light lamb production. Meat Science 8o(2):239-248.

Salem, A. Z. M., P. H. Robinson, S. López, Y. M. Gohar, R. Rojo, and J. L. Tinoco. 2010. Sensitivity of sheep intestinal lactic acid bacteria to secondary compounds extracted from Acacia saligna leaves. Animal Feed Science and Technology I6I(3):85-93. 
Salem, A. Z. M., M. Z. M. Salem, M. M. El-Adawy, and P. H. Robinson. 2006. Nutritive evaluations of some browse tree foliages during the dry season: Secondary compounds, feed intake and in vivo digestibility in sheep and goats. Animal Feed Science and Technology I27(3):25I-267.

Serrano, R., M. J. Jordán, and S. Bañón. 20I4. Use of dietary rosemary extract in ewe and lamb to extend the shelf life of raw and cooked meat. Small Ruminant Research II6(2):I44-I52.

Smeti, S., N. Atti, M. Mahouachi, and F. Munoz. 20I3. Use of dietary rosemary (Rosmarinus officinalis L.) essential oils to increase the shelf life of Barbarine light lamb meat. Small Ruminant Research II3(2):340-345.

Smeti, S., H. Hajji, I. Mekki, M. Mahouachi, and N. Atti. 2018. Effects of dose and administration form of rosemary essential oils on meat quality and fatty acid profile of lamb. Small Ruminant Research 158:62-68.

Tsuruga, T., T. Ito, M. Kanda, S. Niwa, T. Kitazaki, T. Okugawa, and S. Hatao. 1994. Analysis of meat pigments with tissue spectrophotometer TS-200. Meat Science 36(3):423-434.

Vallverdú-Queralt, A., J. Regueiro, M. Martínez-Huélamo, J. F. Rinaldi Alvarenga, L. N. Leal, and R. M. Lamuela-Raventos. 20I4. A comprehensive study on the phenolic profile of widely used culinary herbs and spices: Rosemary, thyme, oregano, cinnamon, cumin and bay. Food Chemistry I54:299-307.

van den Oord, A. H. A. and J. J. Wesdorp. I97I. Colour rating and pigment composition of beef: Relation between colour measurement by reflectance spectrophotometry, subjective colour evaluation, and the relative concentration of oxymyoglobin and ferric myoglobin in chilled retail-packed beef. International Journal of Food Science and Technology 6(I):I5-20.

Wulf, D. M., J. B. Morgan, S. K. Sanders, J. D. Tatum, G. C. Smith, and S. Williams. 1995. Effects of dietary supplementation of vitamin E on storage and caselife properties of lamb retail cuts. Journal of Animal Science 73(2):399-405.

Yagoubi, Y., M. Joy, G. Ripoll, M. Mahouachi, J. R. Bertolín, and N. Atti. 20I8. Rosemary distillation residues reduce lipid oxidation, increase alpha-tocopherol content and improve fatty acid profile of lamb meat. Meat Science 136:23-29.

Yang, A., M. C. Lanari, M. Brewster, and R. K. Tume. 2002. Lipid stability and meat colour of beef from pasture- and grain-fed cattle with or without vitamin E supplement. Meat Science $60(\mathrm{I}): 4 \mathrm{I}-50$. 


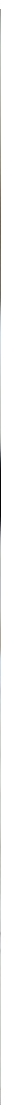




\section{Chapter 7}

\section{General Discussion}




\section{INTRODUCTION}

Meat quality, as defined by its colour and lipid oxidative stability (i.e. shelf-life), is the most important factor that drives consumer preference and purchase decision (Faustman and Cassens, 1990). The "bright red" colour in lamb meat that is appreciated by consumers can be further enhanced with MAP. However, overtime the high concentration of oxygen with MAP also exacerbate lipid oxidation and colour deterioration, which in turn, contributes to the deterioration of flavour, texture and general appearance of the meat or meat product (Gatellier et al., 2005). To delay this oxidative process, retailers and lamb meat producers adopted the use of antioxidants during processing or supplementation to animal diets.

Feed applications of vitamin $\mathrm{E}$, and within the isomers $\left(\alpha-, \beta-, \delta\right.$ - and $\left.\gamma^{-}\right), \alpha$-tocopherol is recognized as the most effective antioxidant in delaying meat discoloration and lipid oxidation. In lambs, the increase in $\alpha$-tocopherol concentration in muscle can be achieved through dietary vitamin $\mathrm{E}$ supplementation above the nutritional recommendations for growth, without any adverse effects on feed intake, performance or carcass characteristics (López-Bote et al., 200I, Lauzurica et al., 2005). When supplementing lamb diets with vitamin $\mathrm{E}$, the synthetic all-rac- $\alpha$-tocopheryl acetate is the most commonly used $\alpha$-tocopherol source. The decision to use all-rac- $\alpha$-tocopheryl acetate instead of RRR- $\alpha$ tocopheryl acetate is mainly driven by the cost difference between both sources, which overshadows the potential benefit of a $36 \%$ increase in biological activity of the RRRsource compared to all-rac- $\alpha$-tocopheryl acetate (USP, 1979). However, there much debate regarding the need to develop new bioequivalence factors for livestock animals, different from the conversion factors used in the International Unit System for vitamins (Jensen and Lauridsen, 2007).

Besides $\alpha$-tocopherol, alternative components such as polyphenols have been consistently reported as exhibiting antioxidant properties (Wojdyło et al., 2007) and have the ability to delay meat oxidation and colour deterioration in lamb meat. Interestingly, there is little information on the effect of dietary administration of polyphenols compared with vitamin E on lipid oxidation and colour stability in lamb meat (Nieto et al., 20Ioa, Bañón et al., 2012). Thus, contrasting both feeding strategies and quantifying their relative value for affecting meat colour and stability, under similar experimental conditions, is a relevant topic for nutritionists, as well as, meat scientists.

The aim of this thesis was to investigate the optimal supplementation level of vitamin $\mathrm{E}$ (natural vs. synthetic) and the use of a standardized polyphenol rich plant extract as an alternative, to extend shelf-life of lamb cuts kept under retail conditions. In the following paragraphs, the work described in this thesis, as well as conclusions and implications for the Mediterranean lamb production system, but not exclusively, are discussed.

\section{Relative Bioavailability of RRR-and All-rac- $\alpha$-Tocopheryl Acetate}

When present in their free form, all-rac- or RRR- $\alpha$-tocopherol can easily interact with other components in the feed during processing, manufacturing and storage. To overcome 
that issue, the phenol group of $\alpha$-tocopherol can be converted to an ester by using acetic acid, so commercial preparations of $\alpha$-tocopherol are normally found as all-rac- or RRR$\alpha$-tocopheryl acetate (Bellés et al., 20I8). Moreover, apart from their high stability in the feeds this acetate forms of $\alpha$-tocopherol are also easily hydrolyzed and absorbed when they reach the gut (Hacquebard and Carpentier, 2005, Rigotti, 2007).

\section{The use of a single ratio to discriminate different $\alpha$-tocopherol sources}

As previously described in this thesis, when formulating lamb diets, nutritionists select the $\alpha$-tocopherol source based on the International Unit System (USP, 1979), which indicates that the biopotency of I.36 mg of all-rac- $\alpha$-tocopheryl acetate equates to the biopotency of I.oo mg of RRR- $\alpha$-tocopheryl acetate. An intense debate about the adequacy of this ratio has occured in the scientific community for the last two decades. In many publications the terms biopotency and bioavailability are frequently used interchangeably, which lead to contradictory conclusions and further fuelled the discussion (Hoppe and Krennrich, 200o, Dersjant-Li and Peisker, 20I0). Bioavailability refers to the absorbed proportion of a substance after its administration, while biopotency is a measure of the biological effects exerted by the substance in a biological system. However, to date there are no biopotency studies comparing all-rac- $\alpha$-tocopheryl acetate and RRR- $\alpha$-tocopheryl acetate in humans or livestock animals, mainly due to the ethical implications associated with this type of studies (e.g. foetal reabsorption in rats) and difficulties to determine relevant clinical endpoints and targets. As an alternative, bioavailability studies have been conducted based on the principle that the magnitude of the effect of a substance (potency) is a function of its concentration at the site of action. Thus, if two different substances have the same bioavailability, it can be inferred that they may also have the same potency (Hoppe and Krennrich, 2000).

\section{Bioavailability of RRR-and all-rac- $\alpha$-tocopheryl acetate in lamb tissues}

To evaluate the bioavailability of two different $\alpha$-tocopherol sources (Chapter 2), lambs were supplemented with increasing amounts of all-rac- $\alpha$-tocopheryl acetate (0.25, 0.5 , I.o and $2.0 \mathrm{~g} \mathrm{~kg}^{-1}$ compound feed) or RRR- $\alpha$-tocopheryl acetate (0.125, 0.25, 0.5 and I.o $\mathrm{g} \mathrm{kg}^{-1}$ compound feed) for a period of $\mathrm{I} 4 \mathrm{~d}$ before slaughter. Under those conditions, the various tissues studied (muscle, heart, liver and spleen) responded differently to increases of dietary supplementation of all-rac- and RRR- $\alpha$-tocopheryl acetate. As summarized in Figure 7.I (same data as presented in Chapter 2), at similar supplementation levels (0.25, 0.50 or I.O $\mathrm{g} \mathrm{kg}^{-1}$ compound feed), the bioavailability ratio between the two $\alpha$-tocopherol sources is different among tissues and increases within tissue with increasing dosages. Interestingly, to attain the same $\alpha$-tocopherol concentrations in muscle and heart as lambs supplemented with $2.0 \mathrm{~g}$ all-rac- $\alpha$-tocopheryl acetate $\mathrm{kg}^{-1}$ feed, lambs supplemented with $\mathrm{RRR}-\alpha$-tocopheryl acetate required approximately half the dosage. In muscle and spleen, a 'plateau' for $\alpha$-tocopherol deposition was reached with all-rac- $\alpha$-tocopheryl acetate 
supplementation. Therefore, as tissue $\alpha$-tocopherol concentrations approach the 'plateau', only a marginal increase in $\alpha$-tocopherol was attained at higher supplementation levels. The non-parallel dose/concentration curves between different $\alpha$-tocopherol sources seems to indicate that their relative bioavailability is associated with the saturation of stereospecific pathways for distribution and elimination (Bramley et al., 2000, Blatt et al., 2004).

\section{Regulation of $\alpha$-tocopherol concentration in tissues}

It is well accepted that hepatic $\alpha$-TTP is the major regulatory mechanism for controlling $\alpha$-tocopherol concentrations in plasma and consequently in tissues (Traber, 2007). From the eight stereoisomers found in all-rac- $\alpha$-tocopheryl acetate, the $2 \mathrm{R}$ configured stereoisomers (RRR-, RRS-, RSR-, and RSS-) are preferentially retained in all tissues except in the liver (Ingold et al., 1987, Burton et al., 1998), where the 2 S stereoisomers (SRR-, SRS-, SSR-, and SSS-) are retained awaiting catabolism (Lauridsen et al., 2002, Traber et al., 2017). On the other hand, the $2 \mathrm{R}$ configured stereoisomers, and to a greater extent the RRR- stereoisomer, are recognized by $\alpha$-TTP and re-secreted from the liver back into plasma (Brigelius-Flohé et al., 2002). Although $\alpha$-TTP is expressed primarily in the liver, it has also been detected in various other tissues such as brain, spleen, lung, kidney, adrenals and uterus (Hosomi et al., 1998, Copp et al., I999, Jishage et al., 200I, Kaempf-Rotzoll et al., 2002, Kaempf-Rotzoll et al., 2003, Gohil et al., 2004). Which could explain the different bioavailability ratios found among tissues. Moreover, it leads to other questions such as tissue specific $\alpha$-tocopherol requirements and other $\alpha$-TTP functions beyond binding and transferring $\alpha$-tocopherol into cells (Lim and Traber, 2007).

Increasing all-rac- $\alpha$-tocopheryl acetate supplementation in lamb diets, was found to affect the $2 \mathrm{R}$ configured stereoisomer profiles in muscle, heart and spleen, where increasing proportions of RRS-, RSR- and RSS- were found at the cost of RRR- $\alpha$-tocopherol. On the other hand, when lambs were supplemented with RRR- $\alpha$-tocopheryl acetate, the relative proportion of all stereoisomers other than RRR- $\alpha$-tocopherol, were reduced in all tissues analysed. Further explaining the change in the bioavailability ratios within tissue. In conclusion, the findings presented here support Blatt et al. (2004) and Jensen et al. (2006), who pointed out that bioavailability of RRR- and all-rac- $\alpha$-tocopheryl acetate varies between tissues and with dosage. As such, the use of a single ratio to discriminate between both $\alpha$-tocopherol sources is inadequate to describe $\alpha$-tocopherol deposition in lamb tissues. 

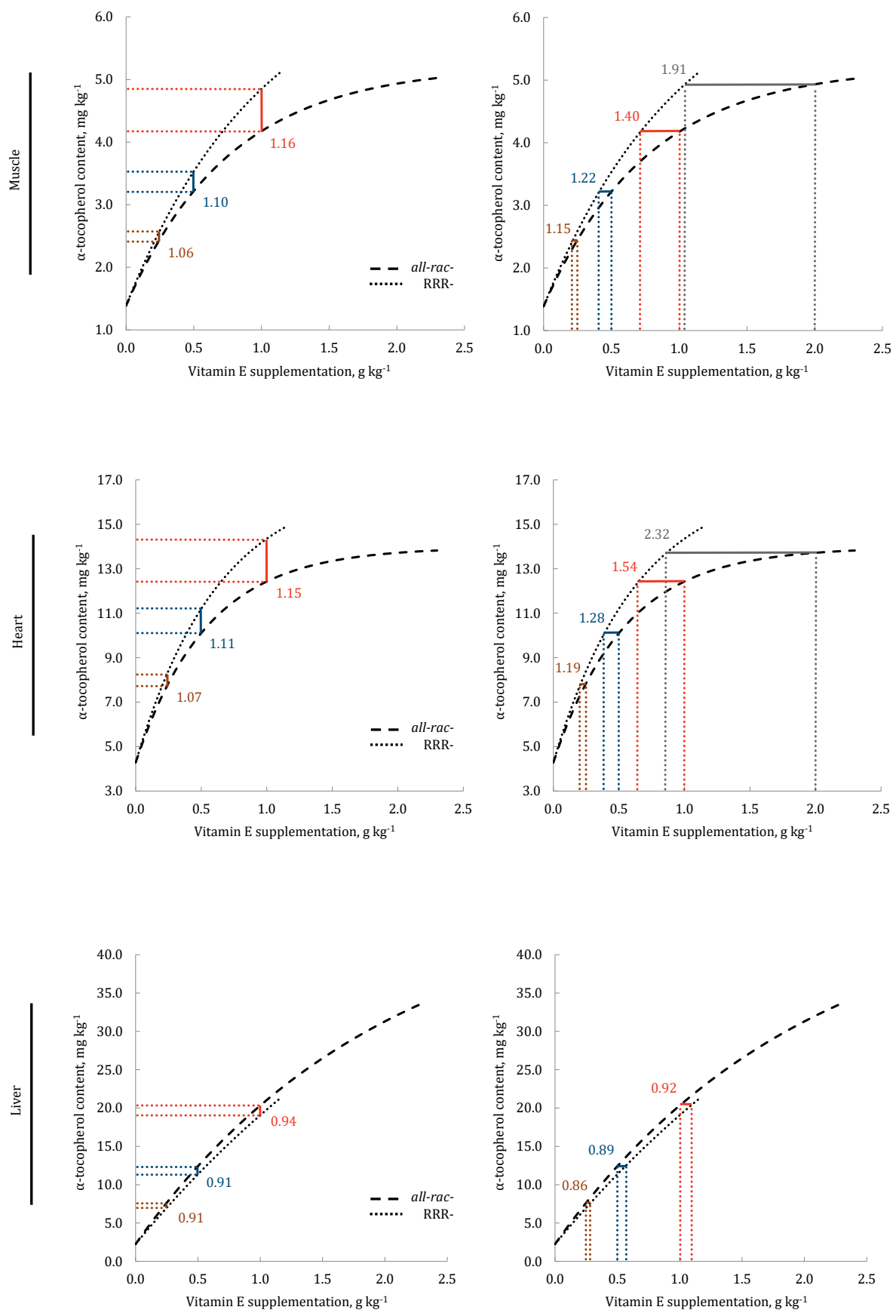

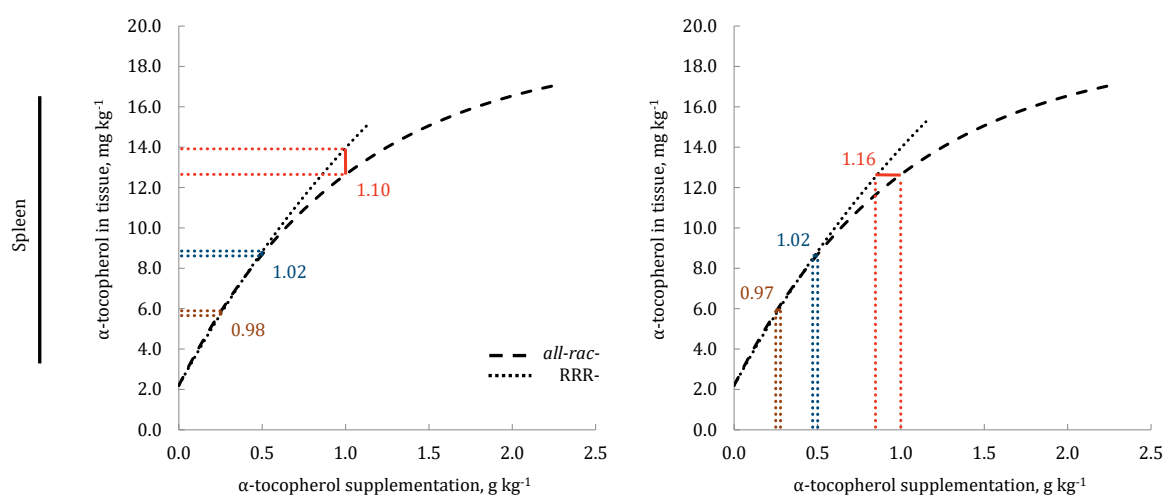

Figure 7.I Bioavailability ratios between RRR- $\alpha$-tocopheryl acetate and all-rac- $\alpha$ tocopheryl acetate in muscle, heart, liver and spleen. Ratios presented on the left side of the figure express the difference between sources at similar dosages $(0.25,0.50$ and I.o $\mathrm{g} \mathrm{kg}^{-1}$ compound feed). Ratios presented on the right side of the figure represent the ratio between the minimum level of RRR- $\alpha$-tocopheryl acetate required to produce the same $\alpha$-tocopherol accumulation in muscle, heart, liver and spleen; as 0.25, 0.50 and I.O $\mathrm{g} \mathrm{kg}^{-1}$ compound feed of all-rac- $\alpha$-tocopheryl acetate.

\section{Dietary Vitamin E Improves Colour and Oxidative Stability of Lamb Meat}

Vitamin E plays a major role in the in vivo antioxidant system by protecting cells and tissues from oxidative damage. In this thesis, however, the focus was primarily on the antioxidant potential of vitamin $\mathrm{E}$ that is carried through to meat after slaughter. Supranutritional doses of $\alpha$-tocopherol before slaughter lead to a significant increase in $\alpha$-tocopherol deposition in lamb muscle (Chapter 2), which in turn, is related with an increased stability of meat against oxidation and colour deterioration (Chapter 3, Chapter 4 and Chapter 6).

\section{$\alpha$-Tocopherol thresholds in meat}

Similar $\alpha$-tocopherol contents in muscle can be achieved with different supplementation strategies. In the work of Kasapidou et al. (2012), a level of $\alpha$-tocopherol of $3.73 \mathrm{mg} \mathrm{kg}^{-1}$ muscle was achieved by supplementing lambs with $0.5 \mathrm{~g}$ all-rac- $\alpha$-tocopheryl acetate $\mathrm{kg}^{-1}$ diet for $63 \mathrm{~d}$. Higher supplementation levels with all-rac- $\alpha$-tocopheryl acetate (I.o g kg-1) led to similar $\alpha$-tocopherol concentrations in lamb muscle $\left(3.57 \mathrm{mg} \mathrm{kg}^{-1}\right)$, but in a considerably shorter supplementation period (37 d) (De la Fuente et al., 2007, Álvarez et al., 2008). In Chapter 2, it was found that higher $\alpha$-tocopherol concentrations than $3.50 \mathrm{mg} \mathrm{kg}^{-1}$ muscle were achieved when supplementing lambs with $0.5 \mathrm{~g} R R R-\alpha$-tocopheryl acetate $\mathrm{kg}^{-1}$ diet or with $0.65 \mathrm{~g}$ all-rac- $\alpha$-tocopheryl acetate $\mathrm{kg}^{-1} \mathrm{diet}$, for $\mathrm{I} 4 \mathrm{~d}$. The effects of $\alpha$-tocopherol on meat oxidation are dose dependent and, therefore, a reflection of its accumulation in the muscle (López-Bote et al., 200I, Lauzurica et al., 2005, Álvarez et al., 2008). Like for $\alpha$-tocopherol 
accumulation in muscle, above a certain threshold only marginal improvements in lipid and colour stability occur. However, a minimum amount of tocopherol in the muscle is required to effectively delay meat oxidation and colour deterioration. In line with this, Ponnampalam et al. (20I4) showed that when muscle $\alpha$-tocopherol concentration is lower than $2.95 \mathrm{mg} \mathrm{kg}^{-1}$ muscle, intrinsic factors such as heme iron or PUFA and extrinsic factors like illumination and packaging conditions during display also affect the lipid oxidation outcomes. Interestingly, as presented in Figure 7.2, which combines data on thiobarbituric acid reactive substances (TBARS) from Chapters 3 and $\mathbf{6}$, the levels of meat oxidation (TBARS values) from non-supplemented lambs in Chapter 6 were approximately 3 fold higher than the TBARS of non-supplemented lambs in Chapter 3, after $\mathrm{I} 4 \mathrm{~d}$ of display. This even though both experiments were conducted under similar conditions accounting for similar genetics, body weight, basal diet, housing, slaughter procedures and display conditions. It appears that the $\alpha$-tocopherol background level of each individual animal plays a major role in meat oxidation and colour stability.

\section{$\alpha$-Tocopherol supplementation on meat oxidation and colour stability}

The effect of vitamin $\mathrm{E}$ on lipid oxidation and colour stability in lamb meat has been previously demonstrated (López-Bote et al., 200I, Lauzurica et al., 2005, Álvarez et al., 2008). In an early titration study, Lauzurica et al. (2005) found that increasing dietary inclusion of vitamin $\mathrm{E}\left(0.25,0.50\right.$ and $\mathrm{I} .0 \mathrm{~g} \mathrm{~kg}^{-1}$ feed) for lambs, led to a significant increase in meat shelf life up to $\mathrm{I} 4 \mathrm{~d}$ of storage.

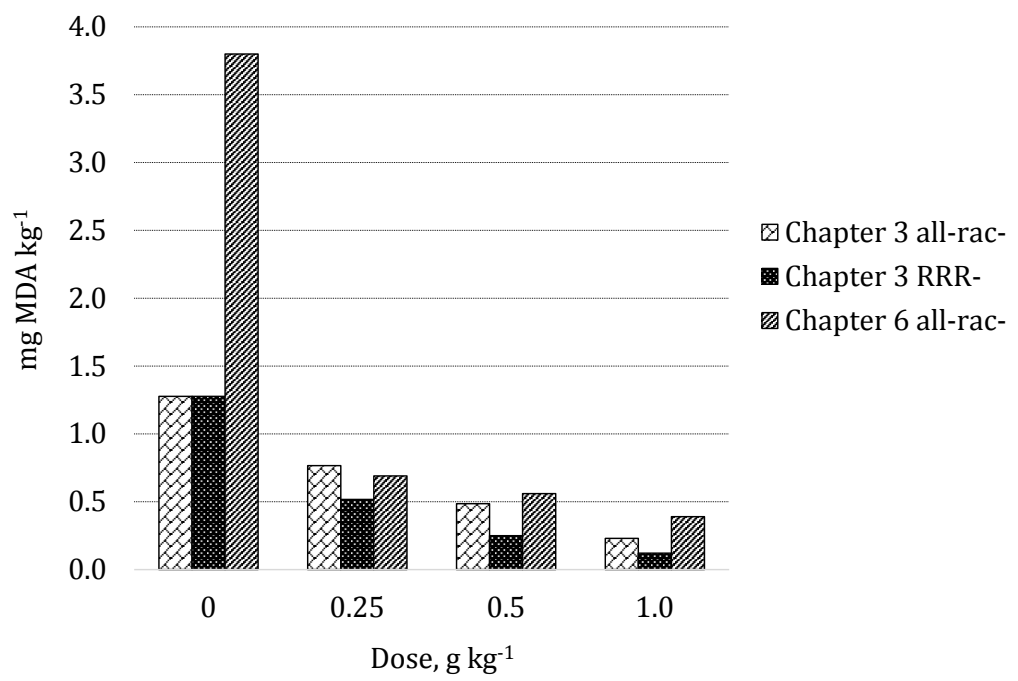

Figure 7.2 Meat oxidation (TBARS, mg malondialdehyde (MDA) $\mathrm{kg}^{-1}$ ) values of longissimus thoracis et lumborum steaks of lambs fed different doses of all-rac- $\alpha$-tocopheryl acetate (all-rac-) or RRR- $\alpha$-tocopheryl acetate (RRR-) for $\mathrm{I} 4 \mathrm{~d}$ before slaughter in Chapter 3 and 6. 
Likewise, in Chapter 3 and 6, the evolution of TBARS values for each dietary intervention with vitamin $\mathrm{E}$ was assessed. Lipid oxidation significantly increased with storage time in both experiments. From d 7 of storage onwards, longissimus thoracis et lumborum (LTL) muscles from vitamin E supplemented lambs (irrespective of dose or source) presented already significantly lower TBARS values than the non-supplemented lambs. As shown in Figure 7.2, vitamin E supplemented lambs registered TBARS values ranging from o.I2 to $0.77 \mathrm{mg}$ malondialdehyde (MDA) $\mathrm{kg}^{-1}$ meat at d I4 of storage. Whereas, non-supplemented lambs presented TBARS values ranging from $\mathrm{I} .28$ to $3.80 \mathrm{mg} \mathrm{MDA} \mathrm{kg}^{-1}$ meat, which were above the threshold of I.O mg MDA kg-1 meat proposed by Ripoll et al. (2OII) as the maximum limit for the development of off-flavours in lamb meat.

Redness ( $a^{*}$ value) is a major determinant of consumer preference in fresh meat (De Oliveira et al., 20I3). Thus, lambs fed with increasing levels of RRR- or all-rac- $\alpha$-tocopheryl acetate in Chapter 3 and 6, presented consistently higher $a^{*}$ values than non-supplemented lambs during the $14 \mathrm{~d}$ of storage. These results are in line with previous work (Guidera et al., 1997), which reported a positive effect of supplementing lamb diets with all-rac- $\alpha$-tocopheryl acetate on meat redness. However, human evaluators are not able to appreciate individual $a^{*}$ values as well as other colour coordinates such as $L^{*}$ and $b^{*}$. Therefore, huge angle $(h)$ is often reported as a better estimate of meat browning that individual colour coordinates (Ripoll et al., 2008). Supplementation of lamb diets with $\alpha$-tocopherol (RRR- or all-rac-) significantly affected $h$ development in meat compared with non-supplemented animals. Moreover, the impact of $\alpha$-tocopherol on $\mathrm{h}$ values are clearer as display time develops.

As previously mentioned, meat colour in lambs is primarily determined by the constant conversion between the heme-containing proteins: deoxymyoglobin (DeoxyMb), oxymyoglobin ( $\mathrm{OxyMb}$ ) and metmyoglobin (MetMb). Display time is known to be the main factor driving myoglobin oxidation in meat. However, dietary supplementation of lamb diets with $\alpha$-tocopherol was found to consistently affect MetMb formation in LTL muscle when compared with non-supplemented lambs (Chapter 3 and 6). Thus, maintaining the 'bright red' colour of lamb meat for at least $\mathrm{I} 4 \mathrm{~d}$ of display. These results are consistent with previous work of Lauzurica et al. (2005), who reported a clear inhibitory effect of all-rac$\alpha$-tocopheryl acetate supplementation on MetMb formation in lamb meat, especially at longer display periods.

Although the benefits of dietary supplementation with $\alpha$-tocopherol in controlling meat oxidation and colour loss in fresh meat are well described, there is a lack of knowledge regarding the effects of $\alpha$-tocopherol supplementation on lamb meat quality after longterm frozen storage. This preservation alternative is highly relevant for distributors and retailers because it provides them with great flexibility in managing meat stocks. However, there are concerns that the primary compounds of lipid oxidation formed during frozen storage cannot be controlled by the $\alpha$-tocopherol present in muscle, after thawing. In Chapter 4, it was demonstrated that supplementation of lamb diets with I.o g all-rac- $\alpha$ tocopheryl acetate $\mathrm{kg}^{-1}$ feed for $\mathrm{I} 4 \mathrm{~d}$ before slaughter effectively delayed meat oxidation 
(TBARS values) and colour deterioration (MetMb formation and hue values) in meat displayed for $9 \mathrm{~d}$ under retail conditions which was previously stored frozen (up to 9 months). Overall, these results highlight the importance of $\alpha$-tocopherol supplementation not only on short-term stored meat (Chapter 3 and 6) but also in preserving meat from oxidation and colour deterioration in long term storage (Chapter 4).

\section{$\alpha$-Tocopherol source on meat oxidation and colour stability}

Both $\alpha$-tocopherol sources (RRR- and all-rac- $\alpha$-tocopheryl acetate) were effective at delaying meat oxidation and colour deterioration. Although the effectiveness of all-rac$\alpha$-tocopheryl acetate has been extensively described before (López-Bote et al., 20oI, Lauzurica et al., 2005, Muela et al., 2014). This thesis (Chapter 3), compares for the first time both $\alpha$-tocopherol sources in their capacity to maintain the quality attributes of lamb meat preserved under retail conditions for $\mathrm{I} 4 \mathrm{~d}$.

Based on the surface response plots for TBARS, it was found that the effectiveness of RRR$\alpha$-tocopheryl acetate at delaying meat oxidation in lamb meat was up to I.8 times higher than with all-rac- $\alpha$-tocopheryl acetate. As a result, supplementation of lamb diets with 0.09 g RRR- $\alpha$-tocopheryl acetate $\mathrm{kg}^{-1}$ compound feed was sufficient to maintain TBARS values below the threshold of I.O mg MDA kg-1 meat after $14 \mathrm{~d}$ of display, compared with the o.I6 $\mathrm{g} \mathrm{kg}^{-1}$ compound feed required in case of all-rac- $\alpha$-tocopheryl acetate. The difference in efficacy between sources was also noticed on colour parameters, where RRR- $\alpha$-tocopheryl acetate was found to be up to I.9, I.5 and I.8 times more effective than all-rac- $\alpha$-tocopheryl acetate at controlling the development of $a^{*}$ values, $h$ values and MetMb \%, respectively during the $\mathrm{I} 4 \mathrm{~d}$ of display.

As previously discussed for $\alpha$-tocopherol deposition in different tissues, a single ratio cannot accurately represent the difference between both sources for any of the meat quality parameters. Moreover, the aforementioned ratios were calculated based on the minimum dose of each $\alpha$-tocopherol source required to achieve a certain threshold or target effect in meat, which can be different from the ratios obtained based on the effect created by both sources when fed at equal dosages. Instead of trying to determine the equivalence ratio between both $\alpha$-tocopherol sources, future research should focus instead, on characterizing the effect of each source (with new surface responses) as two different compounds, on their ability to affect meat oxidation and colour deterioration under different production conditions (basal diet, breed, supplementation time, packaging methods and larger display periods). This information will allow, both producers and retailers to adjust their supplementation strategies based on the desired effect, and the use of either source will depend solely on their capacity to deliver the desired effect at the lowest cost.

\section{Plant Extracts on Antioxidant Capacity of Lamb Tissues}

Since the I990's, scientists and food manufacturers have become increasingly interested in plant-derived antioxidants other than vitamin $\mathrm{E}$. This interest in plant phenolics was 
mainly driven by a recognition of their in vitro antioxidant properties (Zheng and Wang, 200I, Shan et al., 2005) and with epidemiological studies that indicated their probable role in the prevention of various diseases, such as cardiovascular disease, diabetes mellitus, and cancer (Hertog et al., I995, Hirvonen et al., 200I, Arts and Hollman, 2005). This thesis, however, focuses solely on the antioxidant potential of plant phenolics that is carried to meat or organs after slaughter.

\section{Screening results from the use of different polyphenols in lamb diets}

Culinary herbs and spices have been mainly used to enhance or improve the flavour of food, with little attention given to their potential use in animal diets, as a mean to improve meat shelf-life. Culinary herbs and spices belonging to several families, such as Labiatae, Compositae, Umbelliferae, Asteracae, Polygonacae and Myrtacae, have been consistently reported to exhibit strong in vitro antioxidant properties (Wojdyło et al., 2007). However, to effectively act as direct antioxidants in meat systems, phenolic compounds present in these herbs and spices need to be effectively absorbed, transported and have a considerable deposition into the muscle. Therefore, it is not only important to characterize plant extracts for their content in phenolic compounds and potential in vitro antioxidant activity, but it is essential to know the extent to which they exhibit antioxidant activity in the target tissue. Previous to the experimental work described in Chapter 5, plant extracts belonging to the main families of culinary herbs and spices described before, were fully characterized for their phenolic profiles and hydrophilic antioxidant activities (Vallverdú-Queralt et al., 20I4; Vallverdú-Queralt et al., 20I5). As presented in Figure 7.3, the lowest hydrophilic antioxidant capacities based on results from the trolox equivalent antioxidant capacity (TEAC) and 2,2-diphenyl-I-pirylhydrazyl ( $\mathrm{DPPH}^{*}$ ) assays were determined in nutmeg and turmeric followed by dill, bay and marjoram. Whereas, cumin, cinnamon and rosemary presented the highest hydrophilic antioxidant capacity.

Although, this is information is valuable, it does not represent their accumulation and potential antioxidant activity in tissues. The transfer of the antioxidant activity of these extracts to lamb tissues was assessed in vivo, as described in Chapter 5 where lambs were fed a diet consisting of a basal compound feed supplemented with $5.0 \mathrm{~g} \mathrm{~kg}^{-1}$ of each plant extract for a period of $\mathrm{I} 4 \mathrm{~d}$.

Afterwards, muscle (LTL muscle), liver and kidney samples were collected. To access the tissue antioxidant activity, four different assays were performed in parallel (TEAC, ferric reducing antioxidant power (FRAP), oxygen radical absorbing capacity (ORAC) and $\mathrm{DPPH}^{*}$ ), which additionally enable the comparison of these different methods to rank the plant extracts based on their radical-scavenging capacity in the different tissues.

Overall, there was no effect of plant extract supplementation of lamb diets on the tissue antioxidant capacity, as assessed by the FRAP method. Previous work in lambs (Moñino et al., 2008, Jordán et al., 20I0, Luciano et al., 20II), has shown that dietary supplementation of ewes (gestation and lactation) and lambs with plant extracts led to a significant increase 
in antioxidant activity of lamb muscle, which was measured by the use of the FRAP and TEAC methods. However, based on the results obtained by the FRAP method in Chapter 5 none of the plant extract altered significantly the antioxidant potential in lamb tissues. This could indicate a poor bioavailability of these plant extracts in lambs. However, the other 3 assays have revealed significant directional changes in the antioxidant activity of the II plant extracts in the different tissues, as summarized in Table 7.I.

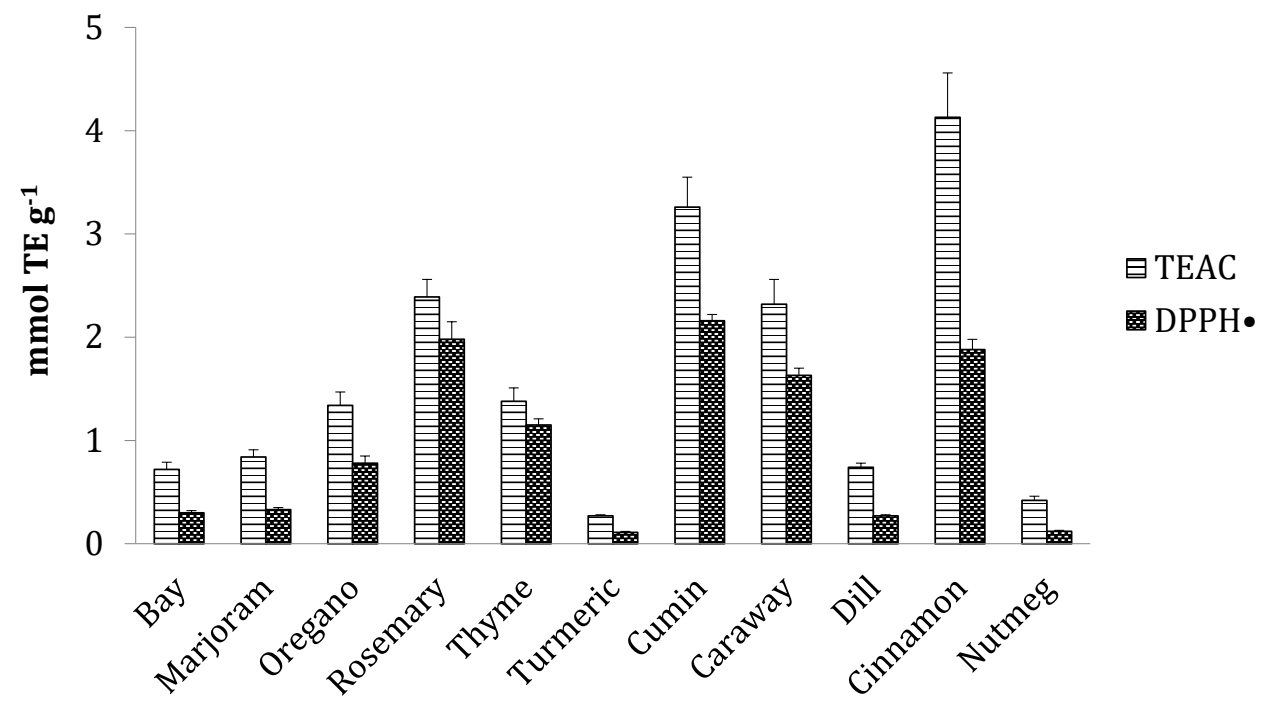

Figure 7.3 Hydrophilic antioxidant capacity of the selected plant extracts evaluated by the Trolox equivalent antioxidant capacity (TEAC) and 2,2-diphenyl-I-pirylhydrazyl (DPPH•) radical-scavenging capacity assays and expressed as mmol Trolox equivalent (TE) $\mathrm{g}^{-1}$. Adapted from Vallverdú-Queralt et al. (2014) and Vallverdú-Queralt et al. (2015). 


\begin{tabular}{|c|c|c|c|c|c|c|c|c|c|}
\hline \multirow[t]{2}{*}{ Item } & \multicolumn{3}{|c|}{ Muscle } & \multicolumn{3}{|c|}{ Liver } & \multicolumn{3}{|c|}{ Kidney } \\
\hline & TEAC & ORAC & $\mathrm{DPPH}^{\bullet}$ & TEAC & ORAC & $\mathrm{DPPH}^{\cdot}$ & TEAC & ORAC & $\mathrm{DPPH}^{\cdot}$ \\
\hline Bay & - & - & - & - & $\downarrow$ & - & - & - & - \\
\hline Marjoram & - & - & - & - & - & - & - & - & - \\
\hline Oregano & - & $\downarrow$ & - & - & - & - & $\downarrow$ & - & $\uparrow$ \\
\hline Rosemary & - & - & - & - & - & - & - & - & - \\
\hline Thyme & - & - & - & - & - & - & - & - & - \\
\hline Turmeric & - & - & - & - & - & $\uparrow$ & - & $\uparrow$ & - \\
\hline Cumin & - & - & - & - & - & - & $\downarrow$ & $\uparrow$ & - \\
\hline Caraway & - & - & - & - & - & - & $\downarrow$ & $\uparrow$ & - \\
\hline Dill & - & $\downarrow$ & - & - & - & - & - & - & - \\
\hline Cinnamon & - & $\downarrow$ & - & - & - & $\uparrow$ & - & $\uparrow$ & - \\
\hline Nutmeg & $\uparrow$ & $\downarrow$ & - & $\uparrow$ & - & $\uparrow$ & - & $\uparrow$ & - \\
\hline
\end{tabular}

${ }^{\text {a }}$ Different signs denote: no differences (-), increase $(\uparrow)$ or reduction $(\downarrow)$ of the antioxidant capacity in the different tissues compared with the non-supplemented lambs $(\mathrm{P}<0.05)$. b TEAC = Trolox equivalent antioxidant capacity; FRAP = ferric reducing antioxidant power; $\mathrm{ORAC}=$ oxygen radical absorbance capacity; $\mathrm{DPPH}^{*}=\mathbf{2 , 2}$-diphenyl-I-picrylhydrazyl radical-scavenging activity.

As presented in Table 7.I and thoroughly discussed in Chapter 5, it is clear that no single plant extract consistently affected the tissue antioxidant activity as measured by the 3 different assays. Noteworthy, nutmeg affected the antioxidant activity in muscle (both increased and decreased), liver and kidney as assessed by different analytical methods. However, as presented in Figure 7.3, nutmeg was the plant extract that exhibited the lowest hydrophilic antioxidant activity of all the selected plant extracts which seems to indicate that the in vitro antioxidant activity of a phenolic compound in an animal diet does not necessarily reflect its in vivo antioxidant activity (D'Archivio et al., 20I0). In general, supplementation of lamb diets with bay, oregano, turmeric, cumin, caraway, dill, cinnamon and nutmeg had an effect on the radical scavenging activity in lamb tissues (either antioxidant or prooxidant). Phenolic compounds are multifunctional and differences among assays can be associated with their antioxidant activity (Frankel and Meyer, 2000) but also with the reaction mechanism of each assay (Karadag et al., 2009). Therefore, it is difficult to draw clear conclusions on the antioxidant capacity of each plant extracts based on the present results, which lead to the conclusion that this approach is not advisable to discriminate or rank plant extracts from different botanical origins. 


\section{Methodological considerations of the TEAC, FRAP, ORAC and DPPH・ assays}

In general, the methods for determining the antioxidant capacity in food components and biological material can be divided into two categories: hydrogen atom transfer (HAT) reaction-based and electron transfer (ET) reaction-based methods (Karadag et al., 2009, Gülçin, 20I2). HAT-based assays (like ORAC) typically measure the capability of an antioxidant to scavenge free radicals (generally peroxyl radicals) by hydrogen donation to form stable compounds (Prior et al., 2005). Whereas, ET-based methods such as TEAC, FRAP and DPPH - detect the ability of a potential antioxidant to transfer one electron to reduce any compound (metals, carbonyls, and radicals) (Karadag et al., 2009). Due to similarities in the mechanism of action, ET-based assays are generally assumed to correlate well among themselves, which has led some researcher to consider the application of a series of ET-based assays redundant (Apak et al., 20I6). Notwithstanding, as shown in Table 7.I, conflicting results between TEAC and DPPH • (both ET-based assays) were obtained in the kidney of oregano supplemented lambs.

HAT- and ET-based assays are known to correlate poorly among each other, as found by (Cao and Prior, 1998) when comparing different methods for assessing total antioxidant capacity of serum in humans. Thus, a better evaluation of the overall antioxidant capacity of complex samples (like biological fluids and tissues) can be attained by the use of multiple assays. That is recommend to generate an "antioxidant profile" that contemplates both the reactivity towards lipid/organic radicals and aqueous radicals (Prior et al., 2005). However, as pointed out by Apak et al. (20I6), both methods (HAR and ET-based) are known to correlate poorly with assays based on the inhibition of lipid peroxidation, which means that an antioxidant or plant extract with high antioxidant activity as measured by one of this methods may not perform well in preventing or retarding lipid peroxidation. Future work should focus on analytical methods and "endpoints" that better reflect the target antioxidant effect of plant extracts both in vivo as well as post-morten, which in the current thesis is to delay lipid oxidation and prevent colour deterioration in lamb meat stored under retail conditions for $\mathrm{I} 4 \mathrm{~d}$.

\section{Plant Extracts as Vitamin E Alternatives at Improving the Shelf-Life Stability of Lamb Meat}

Supplementation of lamb diets with phenolic rich plant by-products such as leaves, distillation residues, essential oils and extracts has been proposed as an alternative to replace the supranutritional applications of $\alpha$-tocopherol to reduce meat oxidation, colour loss and increase the shelf-life of meat.

\section{Effects of phenolic rich plant materials on meat oxidative stability}

In early studies, (Nieto et al., 2010 a,b) found that the administration of thyme leaves or distilled rosemary leaves to ewes during pregnancy and lactation significantly reduced lipid oxidation (TBARS) in fresh lamb meat, stored for $\mathrm{I} 4 \mathrm{~d}$ in modified atmosphere 
packaging. These results were later corroborated by the same group (Nieto et al., 20I2), who found lower lipid oxidation and increased surface redness ( $a^{*}$ values) in lamb meat from ewes supplemented with 5 or $10 \%$ of their diet with thyme distillation by-products. Interestingly, Serrano et al. (20I4) when supplementing sheep diets $\left(0.6 \mathrm{~g} \mathrm{~kg}^{-1}\right.$ per $\mathrm{kg}$ feed) with a rosemary extract during pregnancy and lactation (ewe) and/or during the fattening phase (lambs), found that supplementing the ewe's diet did not offer any benefit compared to supplementing only the lambs during the fattening phase. Despite that, both supplementation strategies were found to extend the shelf-life of lamb meat by $2 \mathrm{~d}$.

Nevertheless, most studies in this field focused on the supplementation of lamb diets with phenolic rich plant materials during the fattening phase. Bañón et al. (2012), reported a reduction of $73 \%$ in TBARS values after $\mathrm{I} 4 \mathrm{~d}$ of display under retail conditions, following a supplementation of lamb diets with a rosemary extract at $0.6 \mathrm{~g} \mathrm{~kg}^{-1}$ feed for a period of 2I d before slaughter. Moreover, these authors reported also a significant improvement in $\mathrm{h}$ values during the same storage period. In line with that, supplementation of lamb diets with a rosemary extracts at $0.4 \mathrm{~g} \mathrm{~kg}^{-1}$ feed (for $80 \mathrm{~d}$ before slaughter) or $0.6 \mathrm{~g} \mathrm{~kg}^{-1}$ feed (for $50 \mathrm{~d}$ before slaughter), have been shown to reduce TBARS values after $\mathrm{I} 4 \mathrm{~d}$ of display by 74 and $48 \%$, respectively (Ortuño et al., 20I4, Ortuño et al., 20I5). Moreover, supplementation of lamb diets with carnosic acid, a major phenolic compound found in rosemary extracts at I.2 $\mathrm{g} \mathrm{kg}^{-1}$ diet, was found to reduce TBARS values after I4 $\mathrm{d}$ of display by $39 \%$ in longissimus lumborum and by $93 \%$ in gluteus medius muscles compared with non-supplemented lambs (Moran et al., 20I2). Apart from thyme and rosemary, other phenolic rich plant materials were reported to have a positive effect on meat shelf-life stability of lambs. Andrés et al. (20I4), found that quercetin supplementation (2.0 $\mathrm{g} \mathrm{kg}^{-1} \mathrm{diet}$ ) was an effective tool to control meat oxidation (TBARS values) even when lambs are fed diets rich in polyunsaturated fatty acids. Figure 7.4 summarizes the results on meat oxidation (TBARS values) results from studies that reported a positive effect of phenolic rich plant materials on meat oxidative stability in lambs, after $\mathrm{I} 4 \mathrm{~d}$ of display under retail conditions. 


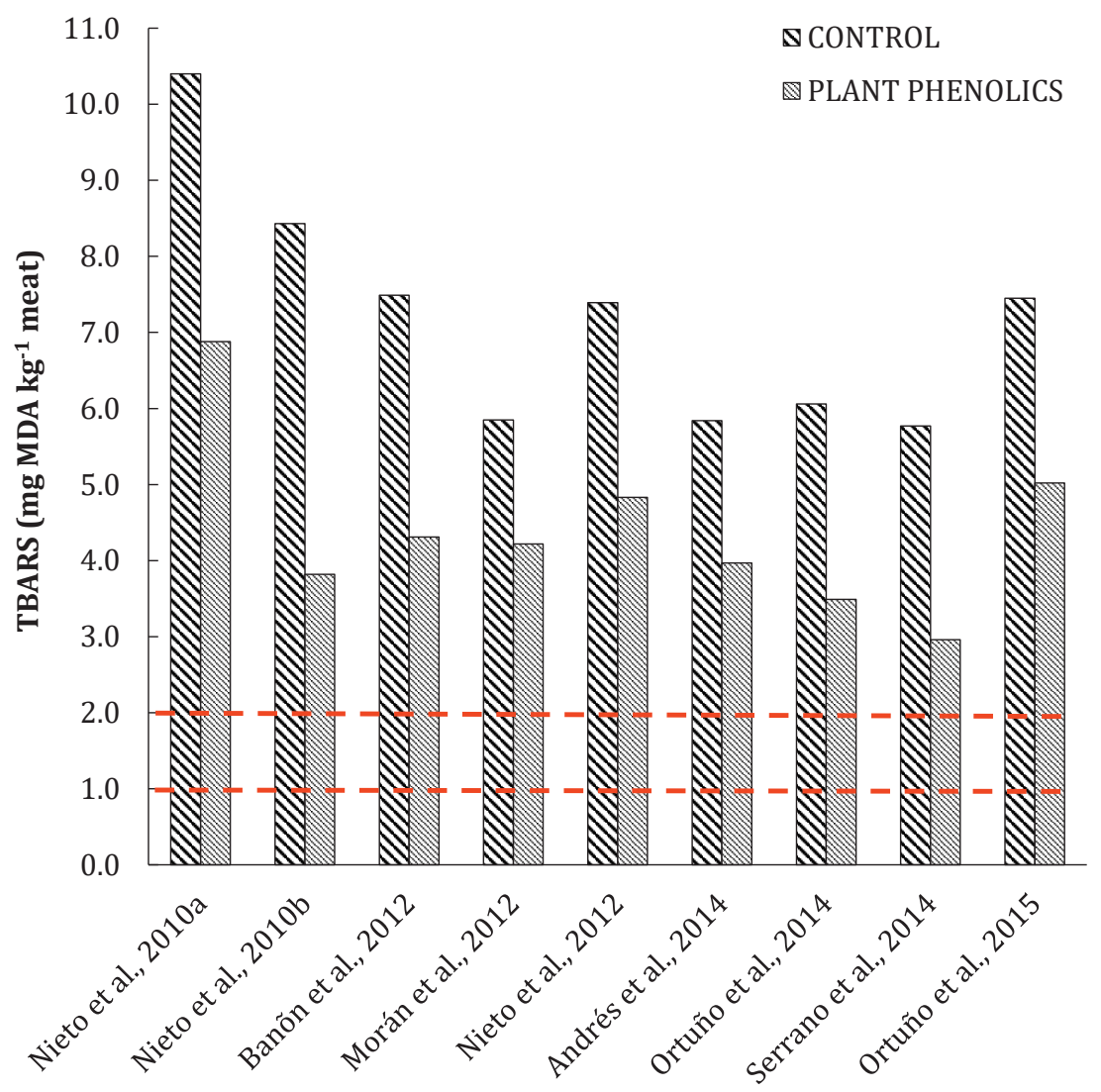

Figure 7.4 Thiobarbituric acid reactive substances (TBARS) (mg malondialdehyde (MDA) $\mathrm{kg}^{-1}$ meat) values of longissimus thoracis et lumborum muscle of lambs fed different phenolic rich plant materials (Plant Phenolics) in different studies. The dashed red lines represent the thresholds for meat oxidation (TBARS values) in lambs, proposed by (Ripoll et al., 20II) and Muíño et al. (20I4).

Several studies, however, found no effect of dietary supplementation with phenolic rich plant materials of lamb diets on meat oxidation and colour stability of lambs. Aouadi et al. (20I4) when feeding lambs with $0.4 \mathrm{~g} \mathrm{~kg}^{-1}$ diet of rosemary or with artemisia essential oils found that both supplementation strategies increased the reducing capacity of the muscle compared with non-supplemented lambs (FRAP and TEAC assay), but had no effect on oxidative stability (TBARS values) nor colour ( $L^{*}, a^{*}, b^{*}, C^{*}$ and $\mathrm{h}$ values) of meat over $7 \mathrm{~d}$ of aerobic display. In line with that, Smeti et al. (2013) found that supplementation of Barberine lambs with a rosemary extract ( $0.6 \mathrm{~g} \mathrm{~kg}^{-1}$ compound feed) for $60 \mathrm{~d}$ before slaughter, had no effect on TBARS values and meat discoloration across the storage time. Moreover, supplementation of lamb diets with red wine extract (0.9 $\mathrm{g} \mathrm{kg}^{-1} \mathrm{diet}$ ), Quillaja saponaria bark extract (0.06 or $0.09 \mathrm{~g} \mathrm{~kg}^{-1}$ compound feed), sage distillation by-products 
(IOo $\mathrm{g} \mathrm{kg}^{-1}$ compound feed), grape seed extract (0.05 $\mathrm{g} \mathrm{kg}^{-1}$ diet) or dried red grape pomace ( $50 \mathrm{~g} \mathrm{~kg}^{-1} \mathrm{diet}$ ), were also found to have no effect on meat oxidative stability of lambs (Nasri et al., 20I2, Muíño et al., 20I4, Guerra-Rivas et al., 20I6, Leticia et al., 20I7).

Unlike vitamin $\mathrm{E}$, the protective role of phenolic rich plant by-products and their extracts against lipid oxidation and colour deterioration in lamb meat, is not well established. When applying the thresholds of I.O mg MDA kg-1 lamb meat as the maximum limit for meat oxidation in lambs (Ripoll et al., 20II), or a less conservative threshold of $2.0 \mathrm{mg}$ MDA kg-1 lamb meat (Muíño et al., 20I4), it is clear that none of the phenolic rich plant extracts was able to maintain the TBARS values below these thresholds, after $\mathrm{I} 4 \mathrm{~d}$ of display under retail conditions (Figure 7.4). Therefore, the value of supplementing lamb diets with phenolic rich plant by-products, as a mean to delay meat oxidation and colour deterioration, seems limited when compared with $\alpha$-tocopherol.

\section{Comparison between phenolic rich plant materials and all-rac- $\alpha$-tocopheryl acetate}

There are only few studies that compared the use of supranutritional doses of $\alpha$-tocopherol with phenolic rich plant by-products on their capability to protect lamb meat from oxidative deterioration. Chapter 6 of this thesis describes a dose-titration study where lamb diets were supplemented with increasing levels of all-rac- $\alpha$-tocopheryl acetate $\left(0.25,0.5,1.0 \mathrm{~g} \mathrm{~kg}^{-1}\right.$ compound feed) or a standardized rosemary extract $\left(0.20,0.40\right.$ or $0.80 \mathrm{~g} \mathrm{~kg}^{-1}$ compound feed) with or without fat embedment.

Administration of phenolic rich plant by-products to high concentrate fed lambs has been shown to affect ruminal fermentation (Jiménez-Peralta et al., 20II). Phenolic compounds present in these plants and their by-products have been shown to possess high antimicrobial (Panizzi et al., 1993) and antiprotozoal (Calsamiglia et al., 2007) activities. The lipophilic nature of some phenolic compounds allows for their accumulation in membranes which seem associated with the disruption of membrane associated events that are required for cell metabolism such as energy (Sikkema et al., 1995) and metal ion depletion (Calsamiglia et al., 2007). Therefore, to reduce the interactions between rumen microorganisms and the phenolic compounds present in the plant extract tested in Chapter 6, a rosemary extract embedded in a hydrogenated fat matrix was also studied. Due the lack of differences on meat oxidation and colour stability parameters between the two rosemary supplementation strategies (with or without fat embedment) and the non-supplemented lambs, it is not possible to withdraw any conclusion regarding the efficacy of the protection intended by fat embedment. 


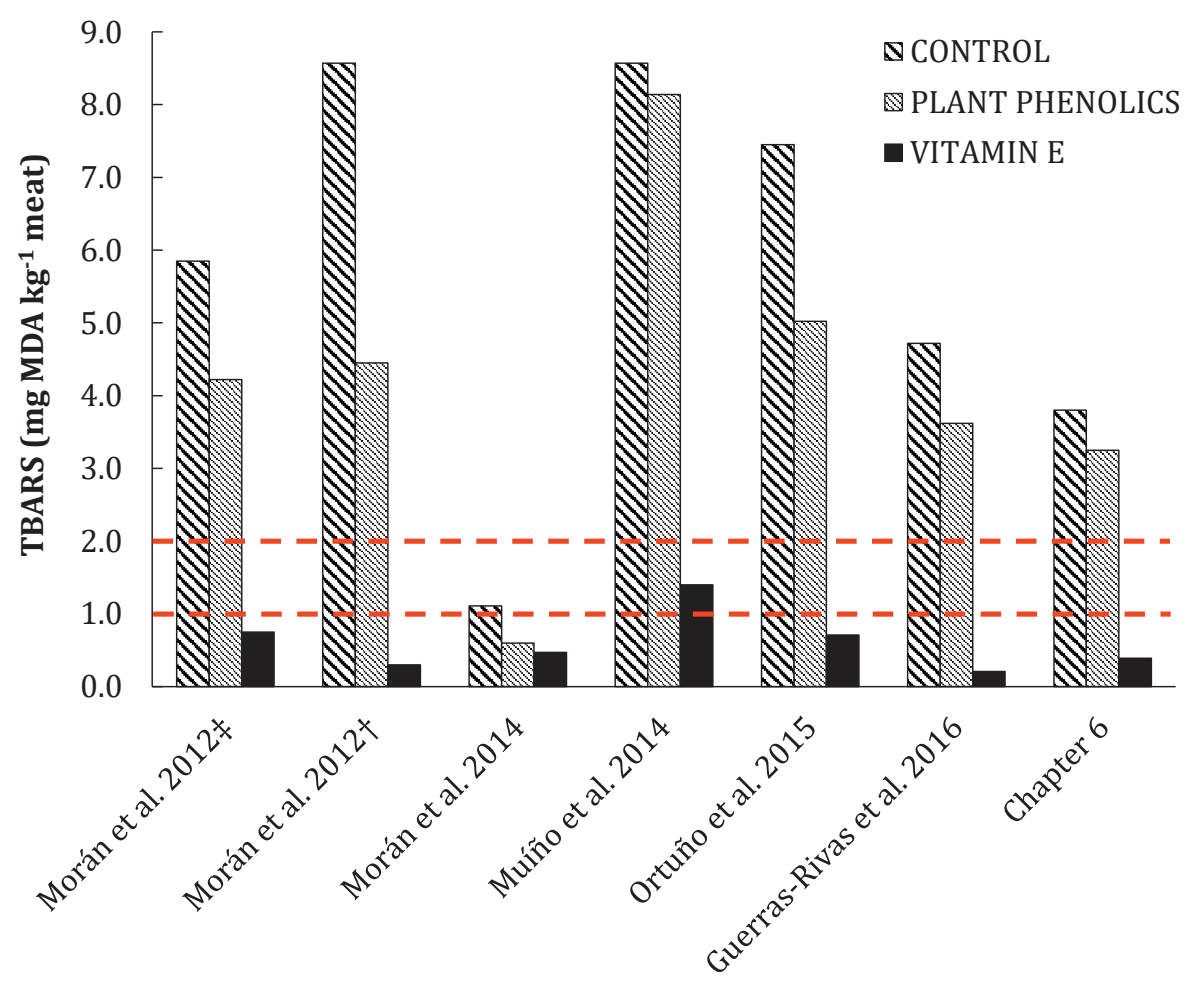

Figure 7.5 Thiobarbituric acid reactive substances (TBARS) (mg malondialdehyde (MDA) $\mathrm{kg}^{-1}$ meat) values obtained in lamb meat, following a dietary supplementation with different phenolic rich plant materials (Plant phenolics) or with all-rac- $\alpha$-tocopheryl acetate (Vitamin E). The dashed red lines represent the thresholds for meat oxidation (TBARS values) in lambs, proposed by Ripoll et al. (2OII) and Muíño et al.(2014). ${ }^{\ddagger}$ longissimus thoracis et lumborum muscle. ${ }^{\dagger}$ gluteus medius muscle.

Overall, supplementation of lamb diets with a standardized rosemary extract for I $4 \mathrm{~d}$ before slaughterhad noeffectonlipid oxidationand colourstability parametersinlambs (Chapter6). However, as previously highlighted, $\alpha$-tocopherol supplementation significantly reduced lipid oxidation (TBARS values), improved colour stability ( $L^{*}, a^{*}, C^{*}$ and $h$ values), reduced MetMb formation and meat discolouration $\left(\mathrm{A}_{580-630}\right.$ and $\left.\mathrm{I}_{\mathrm{SO}_{2}}\right)$. In Figure 7.5, TBARS results from studies that compared the supplementation of lamb diets with phenolic rich plant byproducts with all-rac- $\alpha$-tocopheryl acetate, on meat oxidation (TBARS values) after I4 $\mathrm{d}$ of display under retail conditions, are presented. Supplementation of lamb diets with all-rac$\alpha$-tocopheryl acetate consistently maintained the levels of TBARS within the thresholds of acceptability (I.o to $2.0 \mathrm{mg}$ MDA kg${ }^{-1}$ meat). Whereas, with the exception of the study of 
Morán et al. (2014), all other studies in which lambs were supplemented with phenolic rich plant by-products, reported TBARS values higher than $2.0 \mathrm{mg} \mathrm{MDA} \mathrm{kg}^{-1}$ meat (Figure 7.5). Morán et al. (2014), supplemented milk fed lambs with carnosic acid (0.096 $\mathrm{g} \mathrm{kg}^{-1}$ live weight) or all-rac- $\alpha$-tocopheryl acetate $\left(0.024 \mathrm{~g} \mathrm{~kg}^{-1}\right)$, until they were slaughtered at II-I2 $\mathrm{kg}$ live weight. Although MDA levels were generally low for all groups after $\mathrm{I} 4 \mathrm{~d}$ of display (below 2.0 mg MDA kg-1), significantly lower TBARS values were obtained when lambs were supplemented with both antioxidant sources. In line with that, Moran et al. (2012) found that supplementation of lamb diets with carnosic acid ( $1.2 \mathrm{~g} \mathrm{~kg}^{-1}$ dry matter) or with all-rac- $\alpha$-tocopheryl acetate ( $0.6 \mathrm{~g} \mathrm{~kg}^{-1} \mathrm{dry}$ matter) significantly reduced the development of TBARS in LTL and gluteus medius muscles when compared with non-supplemented lambs. However, supplementation of lamb diets with all-rac- $\alpha$-tocopheryl acetate was 5.6 and I4.8 times more effective than carnosic acid at delaying meat oxidation in the LTL and gluteus medius muscles, respectively. Ortuño et al. (2015), also found that supplementation of lamb diets with rosemary diterpenes ( $0.6 \mathrm{~g} \mathrm{~kg}^{-1}$ compound feed) significantly reduced TBARS development in meat by $33 \%$. However, in the same study, supplementation of lamb diets with all-rac- $\alpha$-tocopheryl acetate (at $0.6 \mathrm{~g} \mathrm{~kg}^{-1}$ compound feed) was found to be 7.0 times more effective at delaying TBARS development in lamb meat than rosemary diterpenes. Likewise, supplementation of lamb diets with all-rac- $\alpha$-tocopheryl acetate was found to be 5.8 (Muíño et al., 20I4), 8.3 (Chapter 6) and 20.0 (Guerra-Rivas et al., 20I6) times more effective than phenolic rich plant byproducts at delaying TBARS development in lamb meat stored for $\mathrm{I} 4 \mathrm{~d}$ under retail conditions (Figure 7.5).

Under similar experimental conditions, the effects of phenolic rich plant by-products on oxidative stability of lamb meat are negligible, when compared with dietary applications with all-rac- $\alpha$-tocopheryl acetate. However, the significant reductions in meat oxidation and colour deterioration parameters that have been reported following dietary supplementation of lamb diets with phenolic rich plant materials cannot be ignored.

\section{Final considerations on the effects of phenolic rich plant materials on lamb meat}

The mechanisms by which the phenolic compounds present in plant by-product affect the oxidative deterioration in lamb meat whether direct (Moñino et al., 2008), indirect/ synergistic (Halliwell et al., 2005, Kerem et al., 2006, Yamamoto et al., 2006) or through antimicrobial activity (Ortuño et al., 20I4, Ortuño et al., 2015, Ortuño et al., 20I7), remains unclear.

A major drawback when studying the effect of phenolic rich plant materials on the antioxidant status of lambs is the lack of product standardization. A wide range of plants and plant presentations have been tested in lambs, these include whole plants, plant parts (like leaves), essential oils, distillation residues and extracts, which vary greatly in their level of purity (Chapter 4). Interestingly, Yagoubi et al. (2018) when supplementing lambs with rosemary distillation residues found that supplemented lambs had a fourfold increase in $\alpha$-tocopherol concentration in muscle, when compared with the non-supplemented lambs. 
It is not clear, however, if the increased $\alpha$-tocopherol concentrations in muscle, were due to high concentrations of $\alpha$-tocopherol in the rosemary distillation residues, or due to a sparing effect of the phenolic compounds on $\alpha$-tocopherol. This is an important point that has to be clarified, because even the slight increase in $\alpha$-tocopherol concentration in muscle (from 0.6 to $0.9 \mathrm{mg} \mathrm{kg}^{-1}$ meat) has been shown to exponentially decrease lipid oxidation (González-Calvo et al., 2015). Therefore, future research should consider if phenolic rich plant materials might contain substantial amounts of other bioactive molecules, such as $\alpha$-tocopherol, which can affect the interpretation of the results and its reproducibility.

\section{CONCLUSIONS}

The objective of this thesis was to investigate the effects of dietary supplementation of lightweight lambs with different antioxidants sources to extend the shelf life of meat under retail conditions. The studies reported in these chapters have contributed to improve our understanding on $\alpha$-tocopherol physiology and tissue deposition in lambs, particularly the differences between RRR- and all-rac- $\alpha$-tocopheryl acetate, supplemented at increasing levels, and ultimately their effect on the oxidative and colour stability of meat stored for short- or long-periods under retail conditions. Phenolic rich plant materials were also investigated as an alternative supplementation strategy for supranutritional applications of $\alpha$-tocopherol, phenolic rich plant materials from different botanical origins were screened and evaluated for their tissue antioxidant capacity. In addition, a standardized phenolic rich plant extract was contrasted with all-rac- $\alpha$-tocopheryl acetate in its effectiveness to delay meat oxidation and colour deterioration, in lamb meat stored for a short-period under retail conditions. Briefly, the studies described in this thesis have led to the following conclusions:

- Different tissues respond differently to incremental dietary supplementation of RRR- and all-rac- $\alpha$-tocopheryl acetate indicating that a single ratio cannot accurately describe the difference between RRR- and all-rac- $\alpha$-tocopheryl acetate.

- Supplementation of lamb diets with $\alpha$-tocopherol has a clear inhibitory effect on meat oxidation and colour deterioration in lamb meat stored under retail conditions. This effect is related to the increase in $\alpha$-tocopherol content in muscle, which delays the initiation and propagation of oxidative reactions in meat.

- $\quad$ RRR- $\alpha$-tocopheryl acetate is substantially more effective than all-rac- $\alpha$-tocopheryl acetate at improving the shelf life of lamb meat.

- Dietary all-rac- $\alpha$-tocopheryl acetate is an effective strategy not only at extending the self-life of meat stored for short-term but also, in preserving meat from oxidation and colour deterioration in long-term storage periods.

- Supplementation of lamb diets with selected plant extracts can affect the radical scavenging activity in muscle, liver and kidney. However, the relevance of these results is debatable due to contrasting outcomes between assays in the same tissue. 
- It is not advisable to discriminate or rank plant extracts in their post-morten antioxidant capacity in tissues with DPPH•, TEAC, FRAP and ORAC assays.

- Under similar experimental conditions, the effects of phenolic rich plant by-products on oxidative stability of lamb meat are negligible, when compared with dietary applications with all-rac- $\alpha$-tocopheryl acetate. 


\section{REFERENCES}

Álvarez, I., J. De la Fuente, M. T. Díaz, S. Lauzurica, C. Pérez, and V. Cañeque. 2008. Estimation of alpha-tocopherol concentration necessary to optimise lamb meat quality stability during storage in high-oxygen modified atmosphere using brokenline regression analysis. Animal 2(9):I4O5-I4II.

Andrés, S., L. Morán, N. Aldai, M. L. Tejido, N. Prieto, R. Bodas, and F. J. Giraldez. 2014. Effects of linseed and quercetin added to the diet of fattening lambs on the fatty acid profile and lipid antioxidant status of meat samples. Meat Science 97(2):I56-I63.

Aouadi, D., G. Luciano, V. Vasta, S. Nasri, D. M. R. Brogna, S. Abidi, A. Priolo, and H. B. Salem. 20I4. The antioxidant status and oxidative stability of muscle from lambs receiving oral administration of Artemisia herba alba and Rosmarinus officinalis essential oils. Meat Science 97(2):237-243.

Apak, R., M. Özyürek, K. Güçlü, and E. Çapanoğlu. 20I6. Antioxidant activity/capacity measurement: I. Classification, physicochemical principles, mechanisms, and electron transfer (ET)-based assays. Journal of Agricultural and Food Chemistry 64(5):997-IO27.

Arts, I. C. and P. C. Hollman. 2005. Polyphenols and disease risk in epidemiologic studies. The American Journal of Clinical Nutrition 8I(I Suppl):3I7s-325s.

Bañón, S., L. Méndez, and E. Almela. 2012. Effects of dietary rosemary extract on lamb spoilage under retail display conditions. Meat Science 90(3):579-583.

Bellés, M., M. del Mar Campo, P. Roncalés, and J. A. Beltrán. 20I8. Supranutritional doses of vitamin E to improve lamb meat quality. Meat Science I49:I4-23.

Blatt, D. H., W. A. Pryor, J. E. Mata, and R. Rodriguez-Proteau. 2004. Re-evaluation of the relative potency of synthetic and natural alpha-tocopherol: experimental and clinical observations. The Journal of Nutritional Biochemistry I5(7):380-395.

Bramley, P. M., I. Elmadfa, A. Kafatos, F. J. Kelly, Y. Manios, H. E. Roxborough, W. Schuch, P. J. A. Sheehy, and K. H. Wagner. 200o. Vitamin E. Journal of the Science of Food and Agriculture 80(7):913-938.

Brigelius-Flohé, R., F. J. Kelly, J. T. Salonen, J. Neuzil, J. M. Zingg, and A. Azzi. 2002. The European perspective on vitamin E: current knowledge and future research. The American Journal of Clinical Nutrition 76(4):703-716.

Burton, G. W., M. G. Trabet, R. V. Acuff, D. N. Walters, H. Kayden, L. Hughes, and K. U. Ingold. I998. Human plasma and tissue $\alpha$-tocopherol concentrations in response to supplementation with deuterated natural and synthetic vitamin E. American Journal of Clinical Nutrition 67(4):669-684.

Calsamiglia, S., M. Busquet, P. W. Cardozo, L. Castillejos, and A. Ferret. 2007. Invited review: Essential oils as modifiers of rumen microbial fermentation. Journal of Dairy Science 90(6):2580-2595.

Cao, G. and R. L. Prior. 1998. Comparison of different analytical methods for assessing total antioxidant capacity of human serum. Clinical Chemistry 44(6):I309-I3I5. 
Copp, R. P., T. Wisniewski, F. Hentati, A. Larnaout, M. Ben Hamida, and H. J. Kayden. 1999. Localization of alpha-tocopherol transfer protein in the brains of patients with ataxia with vitamin E deficiency and other oxidative stress related neurodegenerative disorders. Brain Research 822(I-2):80-87.

D'Archivio, M., C. Filesi, R. Vari, B. Scazzocchio, and R. Masella. 20Io. Bioavailability of the polyphenols: status and controversies. International Journal of Molecular Sciences II(4):I32I-I342.

De la Fuente, J., M. T. Díaz, I. Álvarez, S. Lauzurica, V. Cañeque, and C. Pérez. 2007. Effect of dietary supplementation with vitamin $E$ on characteristics of vacuum-packed lamb. Journal of the Science of Food and Agriculture 87(4):65I-659.

De Oliveira, T. L., A. Soares R. de A., and R. H. Piccoli. 20I3. A Weibull model to describe antimicrobial kinetics of oregano and lemongrass essential oils against Salmonella Enteritidis in ground beef during refrigerated storage. Meat Science 93(3):645-65I.

Dersjant-Li, Y. and M. Peisker. 20Io. A critical review of methodologies used in determination of relative bio-availability ratio of RRR-alpha-tocopheryl acetate and all-rac-alphatocopheryl acetate. Journal of the Science of Food and Agriculture 90(IO):I57I-I577.

Faustman, C. and R. G. Cassens. 1990. The biochemical basis for discoloration in fresh meat: a review. Journal of Muscle Foods I(3):217-243.

Frankel, E. N. and A. S. Meyer. 200o. The problems of using one-dimensional methods to evaluate multifunctional food and biological antioxidants. Journal of the Science of Food and Agriculture 80(13):I925-I94I.

Gatellier, P., Y. Mercier, H. Juin, and M. Renerre. 2005. Effect of finishing mode (pasture- or mixed-diet) on lipid composition, colour stability and lipid oxidation in meat from Charolais cattle. Meat Science 69(I):I75-I86.

Gohil, K., R. Godzdanker, E. O’Roark, B. C. Schock, R. R. Kaini, L. Packer, C. E. Cross, and M. G. Traber. 2004. Alpha-tocopherol transfer protein deficiency in mice causes multiorgan deregulation of gene networks and behavioral deficits with age. Annals of the New York Academy of Sciences I03I:I09-I26.

González-Calvo, L., G. Ripoll, F. Molino, J. H. Calvo, and M. Joy. 20I5. The relationship between muscle alpha-tocopherol concentration and meat oxidation in light lambs fed vitamin E supplements prior to slaughter. Journal of the Science of Food and Agriculture 95(I):IO3-IIO.

Guerra-Rivas, C., C. Vieira, B. Rubio, B. Martínez, B. Gallardo, A. R. Mantecón, P. Lavín, and T. Manso. 20I6. Effects of grape pomace in growing lamb diets compared with vitamin E and grape seed extract on meat shelf life. Meat Science II6:22I-229.

Guidera, J., J. P. Kerry, D. J. Buckley, P. B. Lynch, and P. A. Morrissey. 1997. The effect of dietary vitamin $\mathrm{E}$ supplementation on the quality of fresh and frozen lamb meat. Meat Science 45(I):33-43.

Gülçin, İ. 20I2. Antioxidant activity of food constituents: an overview. Archives of Toxicology 86(3):345-39I. 
Hacquebard, M. and Y. A. Carpentier. 2005. Vitamin E: absorption, plasma transport and cell uptake. Current Opinion in Clinical Nutrition and Metabolic Care 8(2):I33-I38.

Halliwell, B., J. Rafter, and A. Jenner. 2005. Health promotion by flavonoids, tocopherols, tocotrienols, and other phenols: direct or indirect effects? Antioxidant or not? The American Journal of Clinical Nutrition 8I(I Suppl):268s-276s.

Hertog, M. G., D. Kromhout, C. Aravanis, H. Blackburn, R. Buzina, F. Fidanza, S. Giampaoli, A. Jansen, A. Menotti, S. Nedeljkovic, M. Pekkarinen, B. S. Simic, H. Toshima, E. J. M. Feskens, P. C. H. Hollman and M. B. Katan. 1995. Flavonoid intake and long-term risk of coronary heart disease and cancer in the seven countries study. Archives of Internal Medicine I55(4):38I-386.

Hirvonen, T., J. Virtamo, P. Korhonen, D. Albanes, and P. Pietinen. 20oI. Flavonol and flavone intake and the risk of cancer in male smokers (Finland). Cancer Causes and Control I2(9):789-796.

Hoppe, P. P. and G. Krennrich. 2000. Bioavailability and potency of natural-source and all-racemic alpha-tocopherol in the human: a dispute. European Journal of Nutrition 39(5):I83-I93.

Hosomi, A., K. Goto, H. Kondo, T. Iwatsubo, T. Yokota, M. Ogawa, M. Arita, J. Aoki, H. Arai, and K. Inoue. 1998. Localization of alpha-tocopherol transfer protein in rat brain. Neuroscience Letters 256(3):I59-I62.

Ingold, K. U., G. W. Burton, D. O. Foster, L. Hughes, D. A. Lindsay, and A. Webb. 1987. Biokinetics of and discrimination between dietary RRR- and SRR- $\alpha$-tocopherols in the male rat. Lipids 22(3):I63-I72.

Jensen, S. K. and C. Lauridsen. 2007. Alpha-tocopherol stereoisomers. Vitamins and Hormones 76:28I-308.

Jensen, S. K., J. V. Norgaard, and C. Lauridsen. 2006. Bioavailability of alpha-tocopherol stereoisomers in rats depends on dietary doses of all-rac- or RRR-alpha-tocopheryl acetate. The British Journal of Nutrition 95(3):477-487.

Jiménez-Peralta, F. S., A. Z. M. Salem, P. Mejia-Hernández, M. González-Ronquillo, B. Albarrán-Portillo, R. Rojo-Rubio, and J. L. Tinoco-Jaramillo. 20II. Influence of individual and mixed extracts of two tree species on in vitro gas production kinetics of a high concentrate diet fed to growing lambs. Livestock Science I36(2):I92-200.

Jishage, K., M. Arita, K. Igarashi, T. Iwata, M. Watanabe, M. Ogawa, O. Ueda, N. Kamada, K. Inoue, H. Arai, and H. Suzuki. 20oI. Alpha-tocopherol transfer protein is important for the normal development of placental labyrinthine trophoblasts in mice. The Journal of Biological Chemistry 276(3):I669-I672.

Jordán, M. J., M. I. Moñino, C. Martínez, A. Lafuente, and J. A. Sotomayor. 20Io. Introduction of distillate rosemary leaves into the diet of the Murciano-Granadina goat: transfer of polyphenolic compounds to goats' milk and the plasma of suckling goat kids. Journal of Agricultural and Food Chemistry 58(I4):8265-8270. 
Kaempf-Rotzoll, D. E., M. Horiguchi, K. Hashiguchi, J. Aoki, H. Tamai, O. Linderkamp, and H. Arai. 2003. Human placental trophoblast cells express alpha-tocopherol transfer protein. Placenta 24(5):439-444.

Kaempf-Rotzoll, D. E., K. Igarashi, J. Aoki, K. Jishage, H. Suzuki, H. Tamai, O. Linderkamp, and H. Arai. 2002. Alpha-tocopherol transfer protein is specifically localized at the implantation site of pregnant mouse uterus. Biology of Reproduction 67(2):599-604.

Karadag, A., B. Ozcelik, and S. Saner. 2009. Review of Methods to Determine Antioxidant Capacities. Food Analytical Methods 2(I):4I-60.

Kasapidou, E., J. D. Wood, R. I. Richardson, L. A. Sinclair, R. G. Wilkinson, and M. Enser. 2012. Effect of vitamin E supplementation and diet on fatty acid composition and on meat colour and lipid oxidation of lamb leg steaks displayed in modified atmosphere packs. Meat Science 90(4):908-916.

Kerem, Z., D. Chetrit, O. Shoseyov, and G. Regev-Shoshani. 2006. Protection of lipids from oxidation by epicatechin, trans-resveratrol, and gallic and caffeic acids in intestinal model systems. Journal of Agricultural and Food Chemistry 54(26):IO288-IO293.

Lauridsen, C., H. Engel, A. M. Craig, and M. G. Traber. 2002. Relative bioactivity of dietary RRR- and all-rac-alpha-tocopheryl acetates in swine assessed with deuterium-labeled vitamin E. Journal of Animal Science 80(3):702-707.

Lauzurica, S., J. De la Fuente, M. T. Díaz, I. Álvarez, C. Pérez, and V. Cañeque. 2005. Effect of dietary supplementation of vitamin $\mathrm{E}$ on characteristics of lamb meat packed under modified atmosphere. Meat Science 70(4):639-646.

Leticia, M., P. Delgado, J. Ortuño, Julio Otal, and S. Bañón. 20I7. Effects of sage distillation by-product (Salvia lavandulifolia Vahl.) dietary supplementation in light lambs fed on concentrates on meat shelf life and fatty acid composition. Meat Science 134:44-53.

Lim, Y. and M. G. Traber. 2007. Alpha-tocopherol transfer protein (alpha-TTP): Insights from alpha-tocopherol transfer protein knockout mice. Nutrition Research and Practice I(4):247-253.

López-Bote, C. J., A. Daza, M. Soares, and E. Berges. 200I. Dose-response effect of dietary vitamin E concentration on meat quality characteristics in light-weight lambs. Animal Science 73(3):45I-457.

Luciano, G., V. Vasta, F. J. Monahan, P. López-Andrés, L. Biondi, M. Lanza, and A. Priolo. 20II. Antioxidant status, colour stability and myoglobin resistance to oxidation of longissimus dorsi muscle from lambs fed a tannin-containing diet. Food Chemistry I24(3):IO36-IO42.

Moñino, I., C. Martínez, J. A. Sotomayor, A. Lafuente, and M. J. Jordán. 2008. Polyphenolic transmission to segureño lamb meat from ewes' diet supplemented with the distillate from rosemary (Rosmarinus officinalis) leaves. Journal of Agricultural and Food Chemistry 56(9):3363-3367. 
Morán, L., S. Andrés, R. Bodas, N. Prieto, and F. J. Giráldez. 2012. Meat texture and antioxidant status are improved when carnosic acid is included in the diet of fattening lambs. Meat Science 9I(4):430-434.

Morán, L., S. Andrés, J. Mateo, C. Blanco, S. Soto, and F. J. Giráldez. 20I4. Effect of dietary carnosic acid on meat quality from suckling lambs. Small Ruminant Research I2I(2):3I4-3I9.

Muela, E., V. Alonso, M. M. Campo, C. Sañudo, and J. A. Beltrán. 20I4. Antioxidant diet supplementation and lamb quality throughout preservation time. Meat Science 98(2):289-295.

Muíño, I., E. Apeleo, J. De la Fuente, C. Pérez-Santaescolástica, A. Rivas-Cañedo, C. Pérez, M. T. Díaz, V. Cañeque, and S. Lauzurica. 20I4. Effect of dietary supplementation with red wine extract or vitamin $\mathrm{E}$, in combination with linseed and fish oil, on lamb meat quality. Meat Science 98(2):II6-I23.

Nasri, S., G. Luciano, V. Vasta, D. Aouadi, A. Priolo, H. P. Makkar, and H. Ben Salem. 2012. Effect of Quillaja saponaria dietary administration on colour, oxidative stability and volatile profile of muscle longissimus dorsi of Barbarine lamb. Meat Science 92(4):582586.

Nieto, G., S. Bañón, and M. D. Garrido. 2012. Administration of distillate thyme leaves into the diet of Segurena ewes: effect on lamb meat quality. Animal 6(I2):2048-2056.

Nieto, G., P. Díaz, S. Bañón, and M. D. Garrido. 20I0a. Effect on lamb meat quality of including thyme (Thymus zygis ssp. gracilis) leaves in ewes' diet. Meat Science 85(I):8288.

Nieto, G., P. Díaz, S. Bañón, and M. D. Garrido. 20ıob. Dietary administration of ewe diets with a distillate from rosemary leaves (Rosmarinus officinalis L.): influence on lamb meat quality. Meat Science 84(I):23-29.

Ortuño, J., R. Serrano, and S. Bañón. 2015. Antioxidant and antimicrobial effects of dietary supplementation with rosemary diterpenes (carnosic acid and carnosol) vs vitamin $\mathrm{E}$ on lamb meat packed under protective atmosphere. Meat Science IIo:62-69.

Ortuño, J., R. Serrano, and S. Bañón. 2017. Incorporating rosemary diterpenes in lamb diet to improve microbial quality of meat packed in different environments. Animal Science Journal 88(9):I436-I445.

Ortuño, J., R. Serrano, M. J. Jordán, and S. Bañón. 20I4. Shelf life of meat from lambs given essential oil-free rosemary extract containing carnosic acid plus carnosol at 200 or 400 mg kg-1. Meat Science 96(4):I452-I459.

Panizzi, L., G. Flamini, P. L. Cioni, and I. Morelli. 1993. Composition and antimicrobial properties of essential oils of four Mediterranean Lamiaceae. Journal of Ethnopharmacology 39(3):I67-I70.

Ponnampalam, E. N., S. Norng, V. F. Burnett, F. R. Dunshea, J. L. Jacobs, and D. L. Hopkins. 20I4. The synergism of biochemical components controlling lipid oxidation in lamb muscle. Lipids 49(8):757-766. 
Prior, R. L., X. Wu, and K. Schaich. 2005. Standardized methods for the determination of antioxidant capacity and phenolics in foods and dietary supplements. Journal of Agricultural and Food Chemistry 53(I0):4290-4302.

Rigotti, A. 2007. Absorption, transport, and tissue delivery of vitamin E. Molecular Aspects of Medicine 28(5-6):423-436.

Ripoll, G., M. Joy, and F. Muñoz. 20II. Use of dietary vitamin E and selenium (Se) to increase the shelf life of modified atmosphere packaged light lamb meat. Meat Science 87(I):8893.

Ripoll, G., M. Joy, F. Muñoz, and P. Albertí. 2008. Meat and fat colour as a tool to trace grassfeeding systems in light lamb production. Meat Science 8o(2):239-248.

Serrano, R., M. J. Jordán, and S. Bañón. 20I4. Use of dietary rosemary extract in ewe and lamb to extend the shelf life of raw and cooked meat. Small Ruminant Research II6(2):I44-I52.

Shan, B., Y. Z. Cai, M. Sun, and H. Corke. 2005. Antioxidant capacity of 26 spice extracts and characterization of their phenolic constituents. Journal of agricultural and food chemistry 53(20):7749-7759.

Sikkema, J., J. A. de Bont, and B. Poolman. 1995. Mechanisms of membrane toxicity of hydrocarbons. Microbiological Reviews 59(2):20I-222.

Smeti, S., N. Atti, M. Mahouachi, and F. Muñoz. 20I3. Use of dietary rosemary (Rosmarinus officinalis L.) essential oils to increase the shelf life of Barbarine light lamb meat. Small Ruminant Research II3(2):340-345.

Traber, M. G. 2007. Vitamin E regulatory mechanisms. Annual Review of Nutrition 27:347362.

Traber, M. G., E. Mah, S. W. Leonard, G. Bobe, and R. S. Bruno. 20I7. Metabolic syndrome increases dietary alpha-tocopherol requirements as assessed using urinary and plasma vitamin E catabolites: a double-blind, crossover clinical trial. The American Journal of Clinical Nutrition I05(3):57I-579.

USP. 1979. The United States Pharmacopeia. National Formulary. United States Pharmacopeial Convention, Rockville, MD.

Vallverdú-Queralt, A., J. Regueiro, M. Martínez-Huélamo, J. F. Rinaldi Alvarenga, L. N. Leal, and R. M. Lamuela-Raventos. 20I4. A comprehensive study on the phenolic profile of widely used culinary herbs and spices: Rosemary, thyme, oregano, cinnamon, cumin and bay. Food Chemistry I54(Suppl C):299-307.

Vallverdú-Queralt, A., J. Regueiro, J. F. Rinaldi Alvarenga, M. Martinez-Huelamo, L. N. Leal, and R. M. Lamuela-Raventos. 20I5. Characterization of the phenolic and antioxidant profiles of selected culinary herbs and spices: caraway, turmeric, dill, marjoram and nutmeg. Food Science and Technology 35:189-I95.

Wojdyło, A., J. Oszmiański, and R. Czemerys. 2007. Antioxidant activity and phenolic compounds in 32 selected herbs. Food Chemistry I05(3):940-949. 
Yagoubi, Y., M. Joy, G. Ripoll, M. Mahouachi, J. R. Bertolín, and N. Atti. 20I8. Rosemary distillation residues reduce lipid oxidation, increase alpha-tocopherol content and improve fatty acid profile of lamb meat. Meat Science 136:23-29.

Yamamoto, M., S. Miyamoto, J. H. Moon, K. Murota, Y. Hara, and J. Terao. 2006. Effect of dietary green tea catechin preparation on oxidative stress parameters in large intestinal mucosa of rats. Bioscience, Biotechnology, and Biochemistry 7O(I):286-289.

Zheng, W. and S. Y. Wang. 20oI. Antioxidant activity and phenolic compounds in selected herbs. Journal of Agricultural and Food Chemistry 49(II):5I65-5I70. 


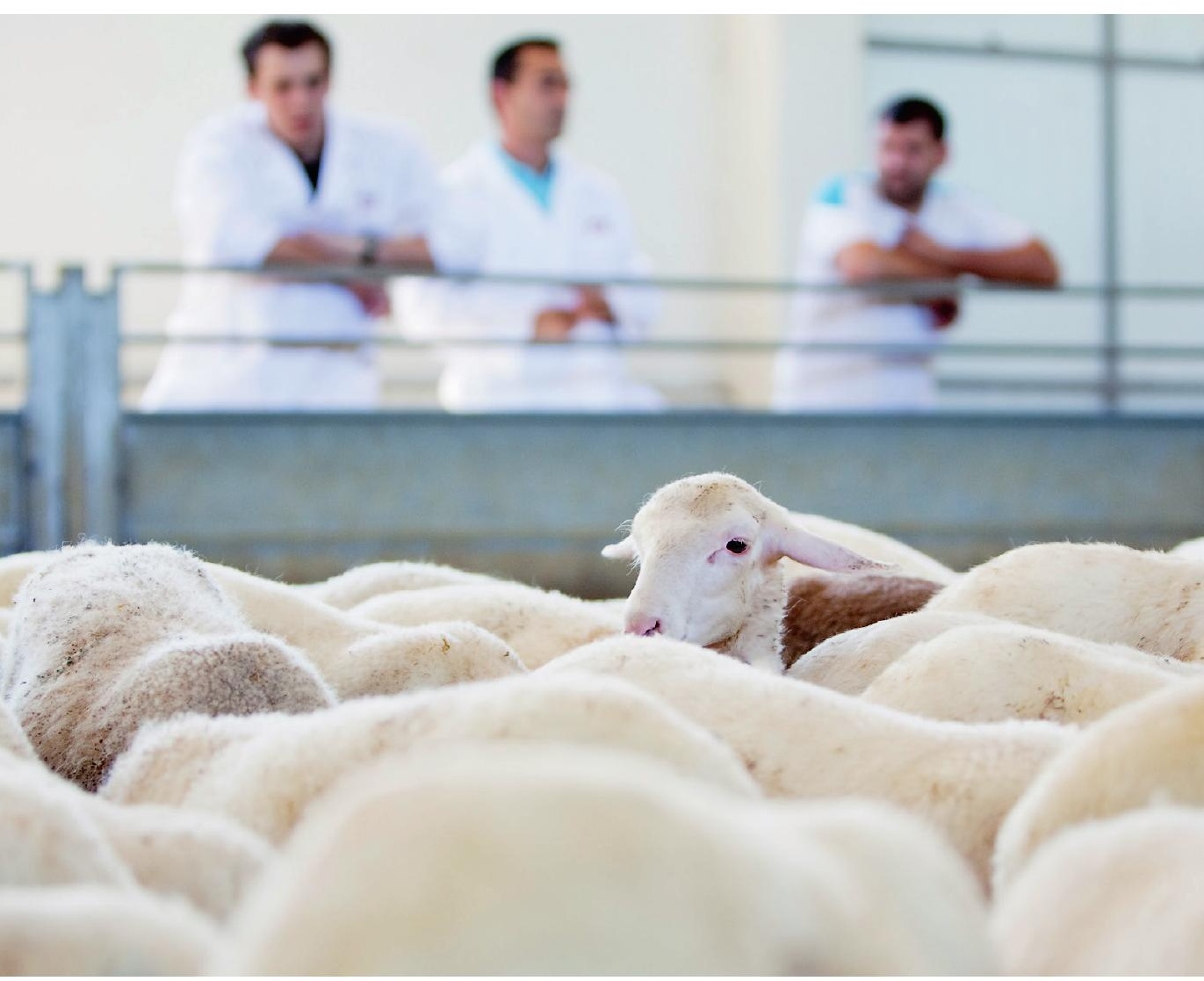


Appendices 


\section{SUMMARY}

Meat quality, as defined by its colour stability is the main sensory attribute of lamb meat that drives consumer preference and purchase decision. The 'bright red' colour in meat, perceived by consumers as an indicator of freshness and superior product quality, can be further enhanced by highly oxidizing packaging methods. Overtime, these packaging methods also accelerate the deterioration of colour, flavour and texture. To delay that, meat processors and retailers have adopted the use of antioxidants into animal diets. As a result, the use of supra-nutritional doses of $\alpha$-tocopherol (all-rac- $\alpha$-tocopheryl acetate) has become a common practice in South European lamb production systems. Alternatively, phenolic rich plant by-products are capturing the interest of nutritionists and meat scientists, which are continuously looking for alternatives to the $\alpha$-tocopherol usage. The aim of this thesis was to provide a scientific basis for the determination of the optimal supplementation level of $\alpha$-tocopherol (RRR-vs. all-rac- $\alpha$-tocopheryl acetate) and the use of phenolic rich plant by-products as an alternative to extend shelf life of lamb meat kept under typical retail conditions.

The experiment described in Chapter 2, aimed to investigate the effect of different dietary levels of two $\alpha$-tocopherol sources (RRR- and all-rac- $\alpha$-tocopheryl acetate) on total $\alpha$-tocopherol concentration and stereoisomer distribution in muscle, heart, liver and spleen of lambs. Moreover, it was hypothesized, that the single ratio of 1.36 used to discriminate both $\alpha$-tocopherol was inadequate to predict differences in $\alpha$-tocopherol deposition in the different tissues. A total of 360 Rasa Aragonesa breed lambs, were fed increasing amounts of all-rac- $\alpha$-tocopheryl acetate (0.25, 0.5, I.o and $2.0 \mathrm{~g} \mathrm{~kg}^{-1}$ compound feed) or RRR- $\alpha$-tocopheryl acetate (0.I25, 0.25, 0.5 and I.O $\mathrm{g} \mathrm{kg}^{-1}$ compound feed) for I4 $\mathrm{d}$ before slaughter. Alpha-tocopherol supplementation had no effect on average daily gain, feed intake and feed efficiency. The tissue with the highest $\alpha$-tocopherol concentration was the liver, followed by spleen, heart and muscle. At similar supplementation levels, the ratios between RRR- and all-rac- $\alpha$-tocopheryl acetate increased with the increasing $\alpha$-tocopherol supplementation (at 0.25 and I.O $\mathrm{g} \mathrm{kg}^{-1}$ compound feed), from I.06 to I.I6 in muscle, I.07 to I.I5 in heart, 0.9I to 0.94 in liver and 0.98 to I.IO in spleen. Increasing all-rac- $\alpha$-tocopheryl acetate supplementation increased the proportions of RRS-, RSR-, and RSS- stereoisomers at the cost of RRR- $\alpha$-tocopherol, which indicates that relative bioavailability of RRR- and all-rac- $\alpha$-tocopheryl acetate, depends on stereospecific pathways for tissue distribution. Therefore, the relative bioavailability of RRR- and all-rac- $\alpha$-tocopheryl acetate is dose- and tissue-dependent and a single ratio to discriminate the two sources cannot be used.

In Chapter 3, the effect of both $\alpha$-tocopherol sources (RRR- and all-rac- $\alpha$-tocoheryl acetate) on meat colour and lipid stability of lamb meat, stored for I4 $\mathrm{d}$ under retail conditions was quantified. The LTL muscle from the lambs described in Chapter 2, were sliced into small steaks, packed under modified atmosphere packaging (with $70 \% \mathrm{O}_{2}+30 \% \mathrm{CO}_{2}$ ) and displayed under retail conditions $\left(4 \pm \mathrm{I}^{\circ} \mathrm{C}\right.$, with a daily light exposure to $\mathrm{I} 4 \mathrm{~h}$ of light at $\mathrm{I} 2 \mathrm{OO}$ lux) for I4 d. Display time had a larger effect on lipid oxidation, colour stability, myoglobin 
forms and meat discolouration parameters than $\alpha$-tocopherol supplementation. However, $\alpha$-tocopherol dosage substantially extended meat shelf-life as indicated by lipid oxidation (TBARS values), redness, hue angle, metmyoglobin formation, $\mathrm{A}_{580-630}$ and $\mathrm{I}_{\text {s02 }}$. Based on the surface response plots comparing the effects of RRR- and all-rac- $\alpha$-tocopheryl acetate, was found that RRR- $\alpha$-tocopheryl acetate was I.8, I.9, I.5 and I.8 times more effective than all-rac- $\alpha$-tocopheryl acetate at controlling the development of TBARS, $a^{*}$ values, $h$ values and MetMb\% respectively, during the $\mathrm{I} 4 \mathrm{~d}$ of display. Thus, illustrating that the use of a single ratio to discriminate both $\alpha$-tocopherol sources is not appropriate to describe their effectiveness in enhancing different meat quality properties in meat.

From literature and results presented in Chapter 3, the positive effect of $\alpha$-tocopherol supplementation of lamb diets, on meat oxidative and colour stability during short-term refrigerated conditions is undisputed. However, there were concerns that the $\alpha$-tocopherol present in muscle following a dietary supplementation with vitamin $\mathrm{E}$ was not effective at delaying meat oxidation and colour loss in thawed lamb meat maintained under retail conditions, after frozen stored up to 9 months. Therefore, Chapter 4 describes an experiment that aimed to investigate the effect of single, high dose of all-rac- $\alpha$-tocopheryl acetate (I.o g $\mathrm{kg}^{-1}$ compound feed) on physicochemical and fatty acid stability of fresh and thawed lamb leg chops, frozen stored for 3, 6 and 9 months. Ninety-six male Rasa Aragonesa breed lambs were fed either a basal diet or the basal diet plus I.o $\mathrm{g} \mathrm{kg}{ }^{-1}$ compound feed of all-rac- $\alpha$ tocopheryl acetate, for $\mathrm{I} 4 \mathrm{~d}$ before slaughter. The right leg of each carcass was removed and assigned to one of four different frozen storage durations: o d, 3, 6 and 9 months. Following the frozen storage, legs were sliced and packed under modified atmosphere packaging, and displayed under retail conditions during $9 \mathrm{~d}$. Supplementation of lamb diets with I.o $\mathrm{g} \mathrm{kg}^{-1}$ compound feed of all-rac- $\alpha$-tocopheryl acetate, effectively reduced lipid oxidation, protected polyunsaturated fatty acids from oxidation, delayed MetMb formation and improved the overall colour stability in meat, during the $9 \mathrm{~d}$ of display. Overall, these results highlighted the importance of $\alpha$-tocopherol supplementation not only on shortterm stored meat (Chapter 3 and 6 ) but also in preserving meat from oxidation and colour deterioration in long term storage (Chapter 4).

Because of their high in vitro antioxidant potential, culinary herbs and spices have been proposed as a replacement for supranutritional applications of $\alpha$-tocopherol in lambs. Like $\alpha$-tocopherol, the direct antioxidant capacity of a dietary phenolic rich plant material is affected by its absorption and deposition in the tissue. Chapter $\mathbf{5}$ describes a study that aimed to investigate whether the supplementation of lamb diets with plant extracts from II culinary herbs and spices effects the antioxidant capacity of selected lamb tissues. Two hundred and eighty-eight Rasa Aragonesa male lambs (23.5 $\pm \mathrm{I} .38 \mathrm{~kg}$ ) were assigned to one of I2 diets consisting of a basal compound feed or the basal compound feed supplemented with $5.0 \mathrm{~g} \mathrm{~kg}^{-1}$ with II different plant extracts (bay, marjoram, oregano, rosemary, thyme, turmeric, cumin, caraway, dill, cinnamon and nutmeg). To access the antioxidant capacity in muscle, liver and kidney, four antioxidant assays were performed in parallel (TEAC, 
FRAP, ORAC and DPPH•). Dietary supplementation with plant extracts had no effect on feed intake, growth performance or antioxidant activity in blood. No single plant extract affected consistently the tissue antioxidant activity as assessed by the four different assays. Supplementation of lamb diets with bay, oregano, turmeric, cumin, caraway, dill, cinnamon and nutmeg revealed that although not consistent, these plant extracts led to significant directional changes in the antioxidant capacity in the different tissues. However, due to the divergent results of the different assay for the same tissue, it would be misleading to evaluate plant extracts using this approach. Instead, future work should focus on analytical methods that reflect better the target "endpoint", which in this thesis was to delay lipid oxidation and colour deterioration in lamb meat. With that in mind, Chapter 6 of this thesis, describes a study were a standardized plant extract (rosemary extract) was compared with $\alpha$-tocopherol in their ability to improve meat colour and oxidative stability parameters in fresh lamb meat stored for $\mathrm{I} 4 \mathrm{~d}$ under retail conditions. Indoor concentrate fed lambs were supplemented with increasing levels of all-rac- $\alpha$-tocopheryl acetate (0.25, 0.5 , I.o $\mathrm{g} \mathrm{kg}^{-1}$ compound feed) or a rosemary extract (0.2, $0.4,0.8 \mathrm{~g} \mathrm{~kg}^{-1}$ compound feed), for I4 $\mathrm{d}$ before slaughter. Supplementation of either antioxidant source had no effects on average daily weight gain, feed intake or feed efficiency. Like in Chapter 3 and 4, supplementation of lamb diets with all-rac- $\alpha$-tocopheryl acetate significantly reduced lipid oxidation, improved colour stability, affected the development of the myoglobin forms and delayed meat discoloration. However, supplementation of lamb diets with rosemary extracts had no effect, in the aforementioned meat quality parameters. Overall, based on the work described in this thesis and literature studies, under similar experimental conditions, the effect of dietary supplementation of lamb diets with phenolic rich plant materials on the oxidative stability of lamb meat is negligible, when compared with $\alpha$-tocopherol. 


\section{Peer-Reviewed Scientific Publications}

Vallverdú-Queralt, A., J. Regueiro, M. Martínez-Huélamo, J. F. Rinaldi Alvarenga, L. N. Leal, and R. M. Lamuela-Raventos. 20I4. A comprehensive study on the phenolic profile of widely used culinary herbs and spices: Rosemary, thyme, oregano, cinnamon, cumin and bay. Food Chemistry I54:299-307.

Vallverdú-Queralt, A., J. Regueiro, J. F. Rinaldi Alvarenga, M. Martinez-Huelamo, L. N. Leal, and R. M. Lamuela-Raventos. 2015. Characterization of the phenolic and antioxidant profiles of selected culinary herbs and spices: caraway, turmeric, dill, marjoram and nutmeg. Food Science and Technology 35:189-I95.

Meale, S. J., L. N. Leal, J. Martín-Tereso, and M. A. Steele. 20I5. Delayed weaning of Holstein bull calves fed an elevated plane of nutrition impacts feed intake, growth and potential markers of gastrointestinal development. Animal Feed Science and Technology 209:268-273.

MacPherson, J. A. R., H. Berends, L. N. Leal, J. P. Cant, J. Martín-Tereso and M. A. Steele. 20I6. Effect of plane of milk replacer intake and age on glucose and insulin kinetics and abomasal emptying in female Holstein Friesian dairy calves fed twice daily. Journal of Dairy Science 99:8007-8017.

Steele, M. A., J. H. Doelman, L. N. Leal, F. Soberon, M. Carson and J. A. Metcalf. 20I7. Abrupt weaning reduces postweaning growth and is associated with alterations in gastrointestinal markers of development in dairy calves fed an elevated plane of nutrition during the preweaning period. Journal of Dairy Science IO0:5390-5399.

Bellés, M., L. N. Leal, V. Díaz, V. Alonso, P. Roncalés and J. A. Beltrán. 2018. Effect of dietary vitamin $\mathrm{E}$ on physicochemical and fatty acid stability of fresh and thawed lamb. Food Chemistry 239:I-8.

Leal, L. N., J. A. Beltrán, V. Alonso, J. M. Bello, L. A. den Hartog, W. H. Hendriks and J. MartínTereso. 20I8. Dietary vitamin E dosage and source affects meat quality parameters in light weight lambs. Journal of the Science of Food and Agriculture 98:I606-I6I4.

Leal, L. N., J. M. Romao, G. J. Hooiveld, F. Soberon, H. Berends, M. V. Boekshoten, M. E. Van Amburgh, J. Martín-Tereso and M. A. Steele. 20I8. Nutrient supply alters transcriptome regulation in adipose tissue of pre-weaning Holstein calves. PLOS ONE I3:e020I929.

Berends, H., M. Vidal, M. Terré, L. N. Leal, J. Martín-Tereso and A. Bach. 2018. Effects of fat inclusion in starter feeds for dairy calves by mixing increasing levels of a highfat extruded pellet with a conventional highly fermentable pellet. Journal of Dairy Science IOI:I0962-I0972.

Leal, L. N., S. K. Jensen, J. M. Bello, L. A. Den Hartog, W. H. Hendriks and J. Martín-Tereso. 20I9. Bioavailability of alpha-tocopherol stereoisomers in lambs depends on dietary doses of all-rac- or RRR-alpha-tocopheryl acetate. Animal I3:I874-I882.

Hare, K. S., L. N. Leal, J. M. Romao, G. J. Hooiveld, F. Soberon, H. Berends, M. E. Van Amburgh, J. Martín-Tereso and M. A. Steele. 20I9. Preweaning nutrient supply alters mammary gland transcriptome expression relating to morphology, lipid accumulation, 
DNA synthesis, and RNA expression in Holstein heifer calves. Journal of Dairy Science I02:26I8-2630.

Amado, L., H. Berends, L. N. Leal, J. Wilms, H. Van Laar, W. J. J. Gerrits and J. MartínTereso. 20I9. Effect of energy source in calf milk replacer on performance, digestibility, and gut permeability in rearing calves. Journal of Dairy Science I02:3994-400I.

Leal, L. N., M. J. Jordán, J. M. Bello, J. Otal, L. A. Den Hartog, W. H. Hendriks and J. MartínTereso. 20I9. Dietary supplementation of II different plant extracts on the antioxidant capacity of blood and selected tissues in lightweight lambs. Journal of the Science of Food and Agriculture 99:4296-4303.

Welboren, A. C., L. N. Leal, M. A. Steele, M. A. Khan and J. Martín-Tereso. 20I9. Performance of ad libitum fed dairy calves weaned using fixed and individual methods. Animal 2I:I8 [Epub ahead of print].

\section{Contributions to Conferences, Symposia, and Other Scientific Output}

Carvalho, I. P. C., L. N. Leal, H. Berends and J. Martín-Tereso. 20I5. Effects of preweaning nutrient supply on growth and pre and post-weaning glucose tolerance test in male Holstein calves. In: Journal of Animal Science, Vol. 93 (Suppl. 3): 3IO-3IO. 2015 Joint Annual Meeting of ADSA-ASAS. Orlando, Florida, USA.

MacPherson, J. A. R., H. Berends, L. N. Leal, J. Martín-Tereso and M. A. Steele. 2015. Effects of plane of nutrition on glucose tolerance test kinetics pre- and postweaning in Holstein calves fed twice daily. In: Journal of Animal Science, Vol. 93 (Suppl. 3): 56-56. 2015 Joint Annual Meeting of ADSA-ASAS. Orlando, Florida, USA.

Steele, M. A., L. N. Leal, M. Carson, J. H. Doelman and J. A. Metcalf. 20I5. Gradual weaning affects pre- and postweaning feed intake, growth, and gastrointestinal development in Holstein calves fed an elevated plane of nutrition during the pre-weaning stage. In: Journal of Animal Science, Vol. 93 (Suppl. 3): 242-242. 2015 Joint Annual Meeting of ADSA-ASAS. Orlando, Florida, USA.

Leal, L. N., V. Alonso, J. A. Beltrán, L. A. Den Hartog, W. H. Hendriks and J. Martín-Tereso. 20I5. The effect of dietary vitamin $\mathrm{E}$ source and dose on lamb meat colour stability under retail conditions. In: Proceedings of the 6Ist International Congress of Meat Science and Technology. 2015 6 ${ }^{\text {st }}$ ICOMST. Clermont Ferrand, France.

Leal, L. N., G. J. Hooiveld, M. A. Steele, M. V. Boekschoten, F. Soberon, M. E. Van Amburgh and J. Martín-Tereso. 20I6. Effect of nutrient supply on mammary gland development and gene expression in pre-weaned calves. In: Book of abstracts of the $67^{\text {th }}$ Annual Meeting of the European Federation of Animal Science. EAAP publication No. 22: 279279. Belfast, United Kingdom.

Leal, L. N., S. K. Jensen, J. M. Bello, L. A. Den Hartog, W. H. Hendriks and J. MartínTereso. 2017. Supplementation of natural and synthetic vitamin E on alpha tocopherol concentration in lamb tissues. In: Book of abstracts of the 68th Annual Meeting of 
the European Federation of Animal Science. EAAP publication No. 23: 355-355. Tallin, Estonia.

Leal, L. N., G. J. Hooiveld, F. Soberon, H. Berends, M. V. Boekschoten, M. A. Steele, M. E. Van Amburgh and J. Martín-Tereso. 20I7. Neonatal nutrient supply affects pancreatic development in Holstein calves. In: Book of abstracts of the $68^{\text {th }}$ Annual Meeting of the European Federation of Animal Science. EAAP publication No. 23: 387-387. Tallin, Estonia.

Leal, L. N., G. J. Hooiveld, F. Soberon, H. Berends, M. V. Boekschoten, M. A. Steele, M. E. Van Amburgh and J. Martín-Tereso. 20I7. Pre-weaning nutrient supply affects gene expression profiles in bone marrow and muscle in calves. In: Book of abstracts of the $68^{\text {th }}$ Annual Meeting of the European Federation of Animal Science. EAAP publication No. 23: 447-447. Tallin, Estonia.

Hare, K., J. Romao, L. Leal, G. Hooiveld, F. Soberon, H. Berends, M. Boekschoten, M. Van Amburgh, J. Martín-Tereso and M. Steele. Increased pre-weaning metabolizable energy supply affects the expression of genes related to adipogenesis and lipid metabolism in the skeletal muscle of prepubertal Holstein heifers. In: Journal of Animal Science, Vol. 96 (Suppl. 3): 348-349. 2018 ASAS-CSAS Annual Meeting and Trade Show. Vancouver, Canada.

Romao, J., L. Leal, G. Hooiveld, F. Soberon, H. Berends, M. Boekschoten, M. Van Amburgh, J. Martín-Tereso and M. Steele. 20I8. Nutrient supply alters adipose tissue physiology in pre-weaned calves. In: Journal of Animal Science, Vol. 96 (Suppl. 3): 4I7-4I7. 2018 ASAS-CSAS Annual Meeting and Trade Show. Vancouver, Canada.

Welboren, A., B. Hatew-Chuko, H. Berends, L. Leal, J. Martín-Tereso and M. Steele. 2018. Energy sources of milk replacer affects glucose homeostasis in neonatal calves. In: Journal of Animal Science, Vol. 96 (Suppl. 3): I72-I72. 2018 ASAS-CSAS Annual Meeting and Trade Show. Vancouver, Canada.

Welboren, A., L. Leal, M. Steele, A. Khan and J. Martín-Tereso. 2018. Weaning of ad libitum fed dairy calves with automated feeders using fixed and individual methods. In: Journal of Animal Science, Vol. 96 (Suppl. 3): 449-450. 20I8 ASAS-CSAS Annual Meeting and Trade Show. Vancouver, Canada. 


\section{Curriculum Vitae}

Leonel Neto Leal was born on April I8, 1986 and grew up in Paços de Ferreira, Portugal. He obtained his high school diploma from Escola Secundária D. Dinis of Santo Tirso in 2005, after which he started his BSc in Zootechnical Engineering at the University of Trás-osMontes e Alto Douro (UTAD), Vila Real, Portugal. After his graduation in 2008, he started his MSc in Zootechnical Engineering at the same University. His major specialization was animal production and nutrition, and for his major thesis, he investigated the effect of high planes of milk replacer feeding on growth performance and general health status of rearing calves at the Ruminant Research Centre of Nutreco in Boxmeer, the Netherlands. In January 20II, after obtaining his MSc, Leonel joined Nutreco as a ruminant researcher. At the beginning of his professional career, his focus was devoted to small ruminant nutrition, health and productivity. In 20I3, he was given the opportunity to start a $\mathrm{PhD}$ at the Animal Nutrition group of Wageningen University (Wageningen, the Netherlands), focusing on improving meat colour and oxidative stability of lamb meat by dietary antioxidant supplementation, resulting in this thesis. Apart from his $\mathrm{PhD}$ appointment, for the past 6 years, Leonel has been focusing as well on functional nutrition of calves, were he has been leading the LifeStart science platform within Trouw Nutrition R\&D. After completing his $\mathrm{PhD}$, Leonel aims to continue to expand his knowledge on functional nutrition of dairy and beef calves. 


\section{Training and Supervision Plan}

Completed in fulfilment of the requirements for the education certificate of the Wageningen Institute of Animal Sciences (WIAS)

The Basic Package (3 ECTSI)

WIAS Introduction Course 2014

Philosophy of Science and/or Ethics 2018

\section{Scientific Exposure (12 ECTS)}

ADSA Discovery Conference - Immunity, nutrition, and management of calves 2013

$7^{\text {th }}$ ISANH World Congress on Polyphenols

WIAS Science Day

ICOMST - International Conference on Meat Science and Technology

(I poster presentation)

EAAP $-67^{\text {th }}$ Annual Meeting of the European Federation of Animal Science

2016

(I oral presentation)

EAAP $-68^{\text {th }}$ Annual Meeting of the European Federation of Animal Science $\quad 2017$

(3 oral presentations)

XXII Congresso Internacional ANEMBE de Medicina Bovina

(I oral presentation)

\section{Disciplinary and interdisciplinary courses (5.5 ECTS)}

WIAS course: Advanced Statistics Course on Design of Experiments

VLAG course: 3rd International Advanced Course on Epigenesis and Epigenetics 2014

$\begin{array}{ll}\text { WIAS course: Statistics for the Life Sciences } & 2017\end{array}$

VLAG course: Applied Biocatalysis 2019

VLAG course: Healthy and Sustainable Diets: synergies and trade-offs $\quad 2019$

\section{Statutory Courses (4.4 ECTS)}

Use of Laboratory Animals: basic course and species specific ruminants $\quad 2018$

\section{Professional Skills and Support Courses (3.I ECTS)}

WIAS course: High Impact writing in Science

WIAS course: Survival Guide to Peer-Review $\quad 2017$

$\begin{array}{ll}\text { Project and Time Management } & 2018\end{array}$

\section{Research and Didactic Skills Training (13.5 ECTS)}

Preparing Own PhD Proposal

\section{Total 4I.5 ECTS}

'One ECTS credit equals a study load of 28 hours. 


\section{Acknowledgements}

All the support and dedication from everyone involved, directly or indirectly, in the work described in this thesis is gratefully acknowledged.

My outmost gratitude is extended to my promotors Wouter Hendriks and Leo den Hartog and co-promotor, Javier Martín-Tereso. Wouter and Leo, thank you for believing that I was capable to undertake this project and for creating a great environment for me to learn and develop as an independent scientist. Javier, I cannot thank you enough for the unending support during the past 6 years. It has been a pleasure to work with you, Sir!

I would like to thank Nutreco B.V. for financial support in making my project come to life. To all my current and past colleagues at the Ruminant Research and Marketing departments of Nutreco, a special thank you, for the support, patience and encouragement during all these years. I am especially indebted to Harmen, for the possibility to join the ruminant research team; to Jeroen, for the support in the early years of my career, from whom I have learned a lot; and to Harma, for the great times we had setting up the calf research program.

I would like to give credit to all the collaborators and their institutions for their input in this thesis. I am particularly grateful to Prof. José Antonio Beltrán, Dr. Verónica Alonso and Dr. Marc Bellés from University of Zaragoza; Prof. Soren Krogh Jensen from Aarhus University; Dr. Maria Jordán from IMIDA; and Prof. Rosa Lamuela-Raventos and Dr. Anna Vallverdú-Queralt from University of Barcelona.

The work described in this thesis might have never happened without the support of Nanta S.A., Franco Y Navarro and Mercazaragoza. During these years, I was fortunate enough to work with some of the most able and hardworking people I have ever met. Chema, thank you for your hard work, friendship and positive thinking, you are a true friend and one of the persons I admire the most.

Quiero manifestar mi agradecimiento a Franco Y Navarro y a todo su equipo, por su implicación y su desinteresada colaboración. La calidad humana y profesional de José María Navarro hacen de él un referente en el sector ovino español. Su inquebrantable voluntad por aprender e innovar han hecho posible estos trabajos. Asimismo, quiero dar las gracias a Mercazaragoza y a su responsable de producción Mateo Izquierdo, por su predisposición para la toma de muestras en el matadero. Deseo también reconocer la labor de mis compañeros de Nanta S.A. por su apoyo en la organización de los ensayos y por haber compartido momentos de trabajo y de ocio, en la misma granja o incluso en una cancha deportiva.

To my foreign "Crew", Gustavo, Justyna, JB, Inês, Isabela, Radek, Laura, Helena, Eva, Martin, Abel, Raquel and Tiago, thank you for being there for me.

Como não poderia deixar de ser, quero também agradecer a todos os meus amigos "Pacenses" e da "UTAD". Muito obrigado por todo o apoio, independentemente da distância que nos separa. 
Aos meus pais, Joaquim e Emília, que muitas vezes renunciaram aos seus sonhos, para que eu pudesse realizar os meus. Não foi fácil deixar-vos para trás, mas este foi o rumo que a vida quis que eu tomasse. Onde quer que esteja trago-os sempre comigo, e cada conquista minha também é vossa. Fred, tu és a melhor prenda de Natal que eu alguma vez tive! É para mim um orgulho ter-te como irmão. Mariana, obrigado pela tua amizade e alegria contagiante. Quero também dar um agradecimento especial à tia Zeza, à Tânia (a irmã que eu nunca tive) e ao Rui por estarem sempre presentes nos momentos mais importantes da minha vida.

Quero agradecer à minha família Manteiguense pela forma como me acolheram, e espero poder partilhar convosco muitos momentos de felicidade!

Por fim, as últimas palavras de agradecimento vão para a Alcina que dia após dia, me faz ter a certeza que sem ela nada disto faz sentido. À minha melhor amiga, namorada e esposa muito obrigado por tudo!

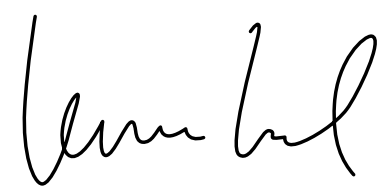




\section{COLOPHON}

The research described in this thesis was financially supported by Nutreco B.V.

Cover Artwork

Dennis Hendriks / ProefschriftMaken

Cover Layout \& Thesis Printing

ProefschriftMaken.nl

Support Printing

Nutreco B.V. 

